\title{
Pulmonary immune responses to respirable elongate mineral particles of asbestiform and non-asbestiform morphologies
}

Timur Khaliullin

West Virginia University, tokhaliullin@mix.wvu.edu

Follow this and additional works at: https://researchrepository.wvu.edu/etd

Part of the Circulatory and Respiratory Physiology Commons, Environmental Health Commons, and the Immunity Commons

\section{Recommended Citation}

Khaliullin, Timur, "Pulmonary immune responses to respirable elongate mineral particles of asbestiform and non-asbestiform morphologies" (2020). Graduate Theses, Dissertations, and Problem Reports. 7820. https://researchrepository.wvu.edu/etd/7820

This Dissertation is protected by copyright and/or related rights. It has been brought to you by the The Research Repository @ WVU with permission from the rights-holder(s). You are free to use this Dissertation in any way that is permitted by the copyright and related rights legislation that applies to your use. For other uses you must obtain permission from the rights-holder(s) directly, unless additional rights are indicated by a Creative Commons license in the record and/ or on the work itself. This Dissertation has been accepted for inclusion in WVU Graduate Theses, Dissertations, and Problem Reports collection by an authorized administrator of The Research Repository @ WVU.

For more information, please contact researchrepository@mail.wvu.edu. 


\title{
Pulmonary immune responses to respirable elongate mineral particles of asbestiform and non-asbestiform morphologies
}

\author{
Timur Oskarovich Khaliullin
}

\begin{abstract}
Dissertation submitted to the School of Medicine at West Virginia University in partial fulfillment of the requirements for the degree of
\end{abstract}

\author{
Robert Brock, Ph.D., Chair \\ Anna Shvedova, Ph.D., D.Sc. \\ Vincent Castranova, Ph.D. \\ Valery Khramtsov, Ph.D., D.Sc. \\ Max Sokolov, Ph.D.
}

Department of Physiology and Pharmacology

\author{
Morgantown, West Virginia \\ 2020
}

Keywords: Asbestos, Alveolar Macrophages, Elongate Mineral Particles, Lungs, Immune Response

Copyright 2020 Timur Khaliullin 


\title{
ABSTRACT \\ Pulmonary immune responses to respirable elongate mineral particles of asbestiform and non-asbestiform morphologies
}

\author{
Timur Oskarovich Khaliullin
}

Inhalation exposure to asbestiform elongate mineral particles (EMPs) may cause pulmonary fibrosis, lung and pleural cancer. At the same time, epidemiological evidence for nonasbestiform EMP pathogenicity is scarce, with little if any risk of cancer, but consistent findings of pneumoconiosis and increased mortality. Globally, conditions caused by asbestos exposures contribute most to the occupational cancer burden and are responsible for the increasing mortality for occupational respiratory diseases. Immunological components of the fiber-induced lesions are extremely understudied, partly due to the lack of comparable test articles. In this study I utilized respirable preparations of asbestiform and non-asbestiform riebeckite and tremolite to assess pulmonary immune responses, following exposures to studied EMPs in the alveolar macrophage (AM) cell culture model and a A/J mice. First, respirable samples of asbestiform fibers and respective non-asbestiform cleavage fragments (CF) were harvested, and detailed information on the length-width ratios, variability in metal ion concentrations and chemical composition of the studied EMPs were obtained. In the in vitro study alveolar macrophage-like cells were treated with mass-, surface area- (s.a.), and particle number- (p.n.) equivalent concentrations of the test articles for 24 hours. Equal mass-based dosing resulted in markedly different responses between asbestiform and non-asbestiform EMPs; at equal "critical fiber" surface area-based doses asbestos and corresponding CF had similar cytotoxic effects, but distinct transcriptional reprogramming patterns and DNA damage response, also specific for the mineral type. For the in vivo study I used A/J mouse strain that is prone to lung tumors, originating from atypical hyperplastic lesions in the periphery of the lung, similar to humans. Mice were exposed via repeated pharyngeal aspiration to the mass- and s.a.-based doses of the studied EMPs. Neoplastic manifestations at 1 year were much more frequent in asbestos-treated animals. Histopathology also revealed hyperplasia, mild fibrosis and immune cell infiltration, but no extensive lung fibrosis in asbestiform EMP groups. CF provoked very little histological changes. DNA damage response was evoked by asbestiform EMPs with the foci of $\mathrm{YH} 2 \mathrm{AX}$ staining found in the vicinity of deposited fibers, but not CF. Overall, the immune response to asbestos particles was characterized as leaning towards $T_{H} 2-$ or $T_{H} 17$ type. There was relative depletion of resident AMs by asbestiform EMPs and increase in the mean fluorescence intensity of inflammatory CD11b surface marker on AM surface in all treatment groups compared to controls at 12 months. Exposure to asbestiform and non-asbestiform EMPs led to discrete pulmonary immune responses at 3- and 12-months post-exposure, leading to specific long-term fibroproliferative and carcinogenic outcomes. The principal findings from this work confirm that alveolar macrophages play a major role in responding to EMPs; the preservation of resident "homeostatic" pool of AMs in the lungs might led to the lack of fibrotic and neoplastic outcomes in CF-treated animals. In conclusion, this work supplements the notion that in addition to habit and biodurability, chemical composition, unique for different minerals, plays major role in the immunological responses and respective long-term pulmonary outcomes. The work presented here calls for further investigations of the pulmonary and systemic immune cell population dynamics in the development of long-term carcinogenic and non-carcinogenic outcomes following exposures to well-characterized reference materials. 


\section{ACKNOWLEDGEMENTS}

This PhD degree was a substantial chunk of my Earthly experience so far and I immensely appreciate all other human beings who directly shared and helped me to shape some of that experience.

It is with great pleasure that I would like to acknowledge first my Scientific Advisor, Mentor, Boss, Trustee, and Confidante - Dr. Anna Shvedova. The completion of this work would simply not have been possible without your guidance, unquivering support and nurturing throughout all those years. You took the responsibility of inviting me over for a research fellowship almost 10 years ago and were instrumental in all my successes since then. Thank you for your faith in me, for expert advising within the field of science and, most importantly, outside of it. Whether I am going to run my own lab someday, or serve the humanity in any other role, I hope I could employ at least a subset of the skills I learned from your mentorship.

I am extremely grateful to the members of my Advisory Committee. My Committee Chair, Dr. Brock, cannot thank you enough for guiding me into the CIP Program, for your teaching, for all those letters of support that helped me to acquire memberships and fellowships. I cannot begin to express my thanks to Dr. Castranova for numerous expert suggestions that helped shape my dissertation study, and for being there for me when I needed strong recommendations. Dr. Sokolov, I was so lucky to have a rotation with you in my first year, and even more lucky to have you on my Committee to provide oh so necessary guidance. Dr. Khramtsov, many thanks for your "radical biological" approach; your class opened my eyes to the complexity of redox environments. You and your family made me truly feel like home on more than one occasion.

My PhD was fostered at the Department of Physiology and Pharmacology, for what I am truly grateful to its current Chair - Dr. Nurkiewicz, and previous - Dr. Siderovski. Many thanks to all faculty members, who taught us the advanced physiology, and especially to our Journal Club facilitator - Dr. Stauber.

I am hugely proud to have worked at National Institute of Occupational Safety and Health (NIOSH). I absolutely cannot leave NIOSH without mentioning my supervisors, colleagues and administrative personnel, who made me feel wanted and appreciated, some of them directly contributing to my research - Dr. Beezhold, Dr. Wells, Dr. Lanciotti, Dr. Stueckle, Dr. Coyle, Dr. Probst, Lori, Ray, Ava, Joyce and Yvette.

I also had great pleasure of working with my lab-mates: Supraja, Naveena, Mariana, and Autumn. Dear Elena - not only you were the one who taught me a vast majority of all my lab skills, but also played the decisive role in my overall performance. Dr. Kagan, Drs. Galina and Michael Shurin, and Dr. Gutkin from University of Pittsburgh, Dr. Harper from University of Gainesville, thank you for fruitful discussions, provoking questions, and for always being ready to help with your expert advice.

To my Russian friends, sending the waves of support across the ocean - I will be back to hug you all soon enough. They say it is harder to make friends after 30 - exactly when I moved to the US - which makes my new friends so much dear to me. Mackey, Drew, Hutch, Tiffany, Daniel, Anton, Jenni, Evan, Shae, Erika, Ashley - your encouragement and assistance in all kinds of matters was especially helpful during this time. Know that I will be there for you long after school ends, just as you were there for me.

Finally, to my Mom, sister Ksenia, grandparents, and all big family... You have been a constant source of inspiration, love, and encouragement. I love you so much. To my nephews, Pyotr and Pavel, if you ever read this, I am sorry for having been so far away for so long during one of the most exciting periods of your lives - early school years. We will catch up. 


\section{TABLE OF CONTENTS}

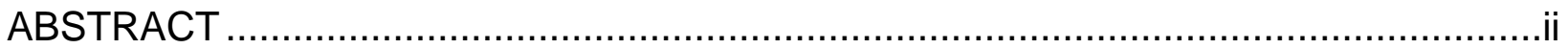

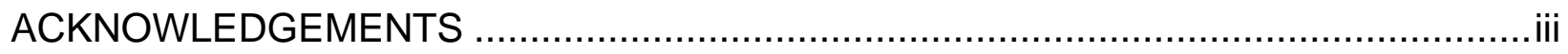

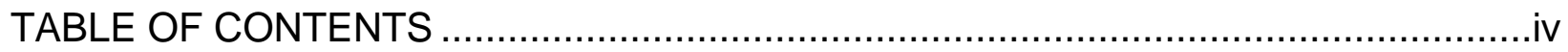

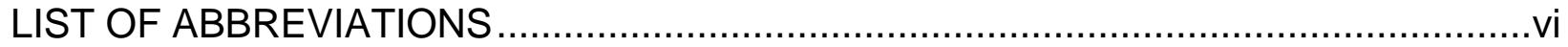

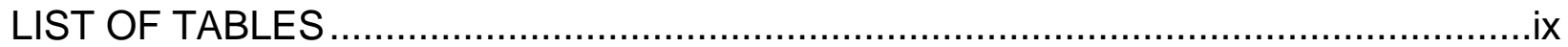

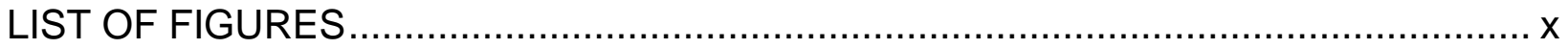

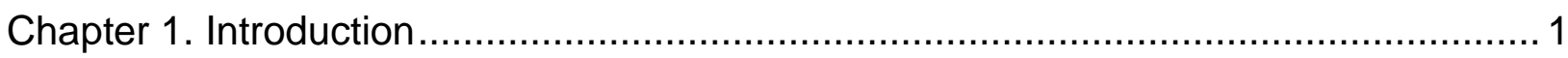

1.1. Definitions and a little bit of mineralogy .................................................... 1

1.2. Exposure to asbestiform and non-asbestiform EMPs .................................. 4

1.3. Health burden of asbestos and non-asbestiform EMPs ............................... 6

1.4. Pathological outcomes of exposures to asbestiform and non-asbestiform......... 8

1.5. The role of EMP dimensions and chemistry ............................................. 9

1.6. Immune component of the biological response to EMPs .............................. 12

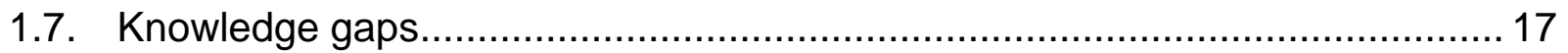

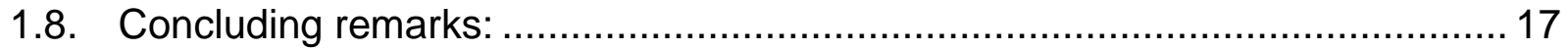

1.9. Objective and Aims of this dissertation study .............................................. 19

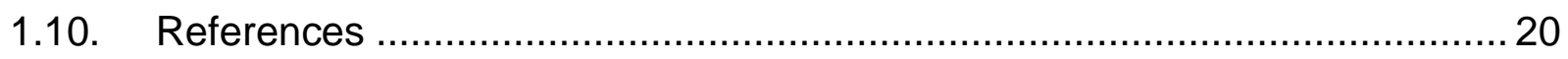

Chapter 2. Characterization and harvesting of the Riebeckite and Tremolite Elongate Mineral Particles for Toxicological Studies .......................................................... 30

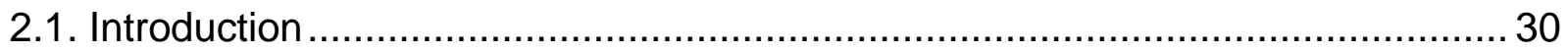

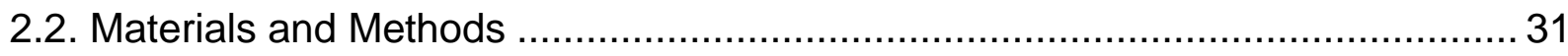

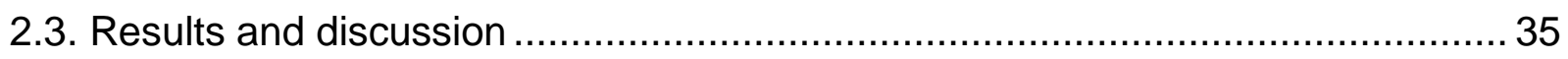

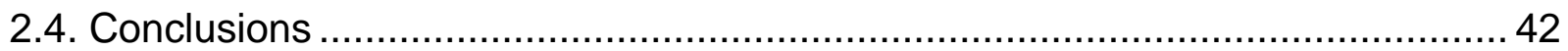

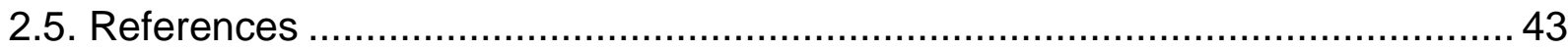

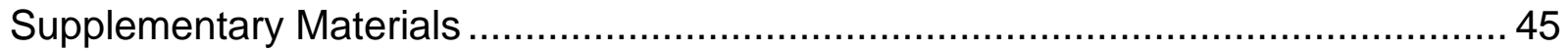

Chapter 3. Differential responses of murine alveolar macrophages to elongate mineral particles of asbestiform and non-asbestiform varieties: cytotoxicity, cytokine secretion

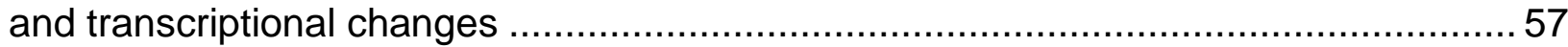

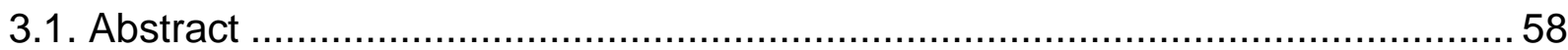

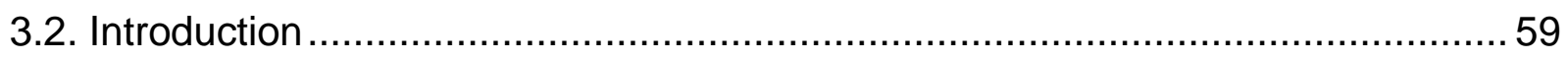

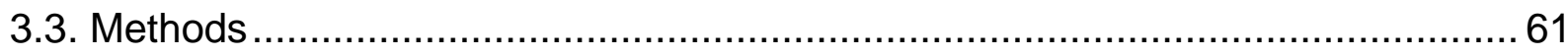




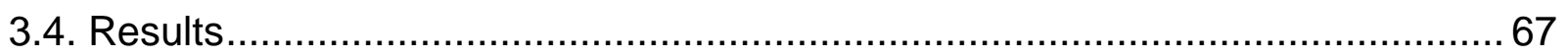

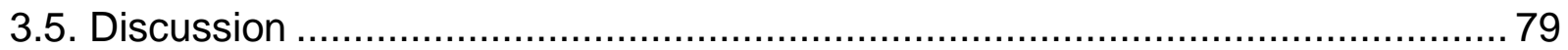

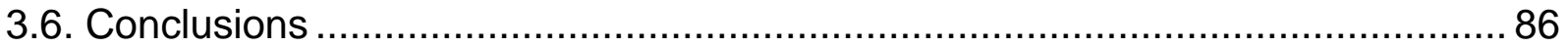

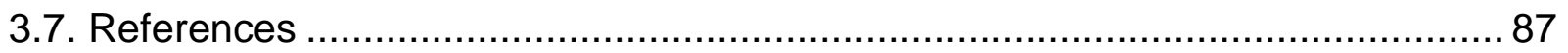

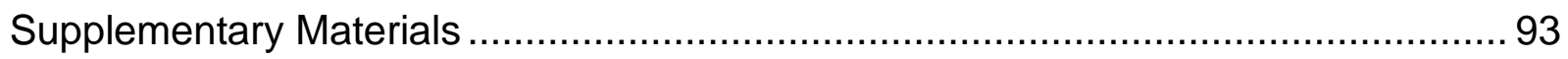

Chapter 4. Elongate mineral particles of different growth habit elicit differential

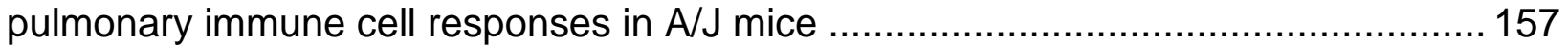

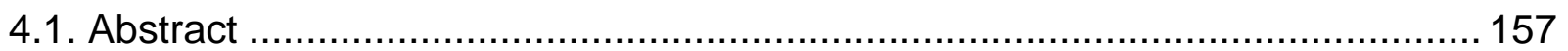

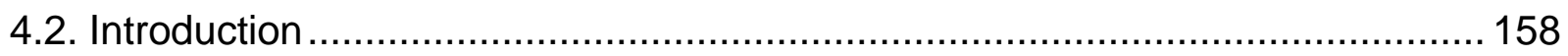

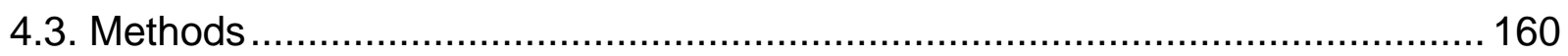

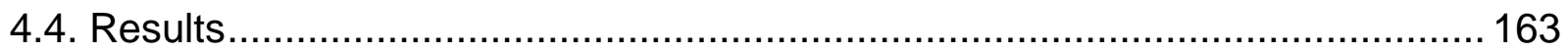

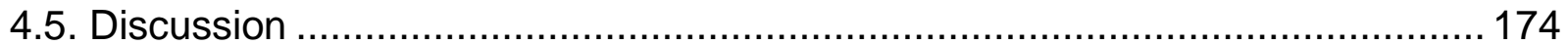

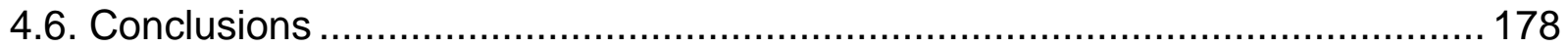

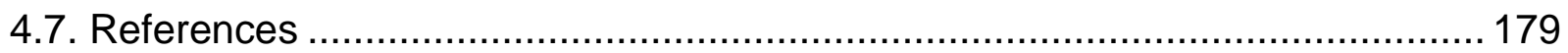

Chapter 5. Conclusions and Future Directions .................................................... 183

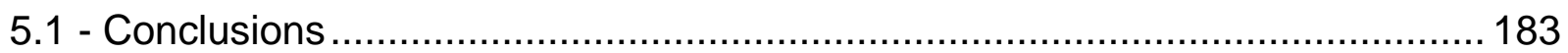

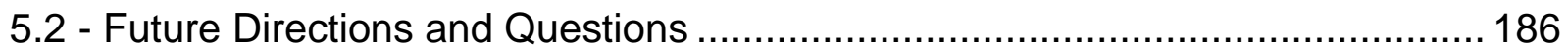

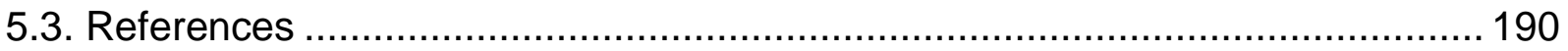




\section{LIST OF ABBREVIATIONS}

\begin{tabular}{ll} 
EMP & Elongate Mineral Particles \\
AM & Alveolar Macrophage \\
BAL & Bronchoalveolar Lavage \\
CCL2 & C-C Chemokine Ligand 2 \\
CD & Cluster of Differentiation \\
CF & Cleavage Fragment \\
DEG & Differentially Expressed Gene \\
DSB & Double Strand DNA Breaks \\
ECM & Extracellular Matrix \\
EDS & Energy-Dispersive Spectroscopy \\
EPA & Environmental Protection Agency \\
FESEM & Field Emission Scanning Electron Microcopy \\
FPKM & Fragments Per Kilobase of transcript per Million mapped reads \\
GO & Gene Ontology \\
H2O2 & Hydrogen Peroxide \\
IFN-Y & Interferon-gamma \\
IL-17 & Interleukin-17 \\
IL-1 $\alpha$ & Interleukin-1-alpha \\
IL-1 & Interleukin-1-beta \\
IL-6 & Interleukin-6 \\
\hline
\end{tabular}




\begin{tabular}{|c|c|}
\hline IL-9 & Interleukin-9 \\
\hline IPF & Idiopathic Pulmonary Fibrosis \\
\hline KEGG & Kyoto Encyclopedia of Genes and Genomes \\
\hline LDH & Lactate Dehydrogenase \\
\hline LDH & Lactate Dehydrogenase \\
\hline LMP & Lysosomal Membrane Permeabilization \\
\hline MARCO & Macrophage Receptor with Collagenous Structure \\
\hline MCE & Mixed Cellulose Ester \\
\hline MDSC & Myeloid-Derived Suppressor Cell \\
\hline MNP & Minimal Number of Particles \\
\hline MPI & Max Plank Institute \\
\hline MSHA & Mining Safety and Health Administration \\
\hline NIEHS & National Institute of Environmental Health Sciences \\
\hline $\mathrm{NIOSH}$ & Nation Institutes for Occupation Safety and Health \\
\hline NLRP3 & Nod-like Receptor Family, Pryin Domain Containing-3 \\
\hline OSHA & Occupations Safety and Health Administration \\
\hline PBS & Phosphate Buffered Saline \\
\hline PCM & Phase Contrast Microscopy \\
\hline PDGF & Platelet-derived Growth Factor \\
\hline PLM & Polarized Light Microscopy \\
\hline PMN & Polymorphonuclear leukocytes \\
\hline ROS & Reactive Oxygen Species \\
\hline SR-A & Scavenger Receptor A \\
\hline
\end{tabular}




$\begin{array}{ll}\text { TEM } & \text { Transmission Electron Microscopy } \\ \text { TGF } \beta & \text { Transforming Growth Factor-beta } \\ \text { TNF- } \alpha & \text { Tumor Necrosis Factor-alpha } \\ \text { UICC } & \text { Union Internationale Centre le Cancer } \\ \text { VEGFA } & \text { Vascular Endothelial Growth Factor-A } \\ \text { WHO } & \text { World Health Organization }\end{array}$




\section{LIST OF TABLES}

Table 2.1. Summary Statistics for Riebeckite Asbestos Particle Size Data TEM $(2,000 X$ to $10,000 X$ Magnification)

Table 2.2. Summary Statistics for Riebeckite CF Particle Size Data TEM (2,000X to $10,000 X$ Magnification)

Table 2.3. Summary Statistics for Tremolite Asbestos Particle Size Data TEM (2,000X to 10,000X Magnification)

Table 2.4. Summary Statistics for Tremolite CF Particle Size Data TEM (2,000X to $10,000 X$ Magnification)

Table 2.5. The total number and surface areas of particles in the test articles, including "critical" fibers, having length $>5 \mu \mathrm{m}$ and aspect ratio of $\geq 3: 1$, per $120 \mu \mathrm{g}$ of dry bulk preparations. CF - Cleavage Fragments.

Table 3.1. Morphological characteristics of the studied EMPs, calculated from the detailed TEM analysis of at least 700 particles per sample. A.R. - aspect ratio

Table 3.2. Pooled cytokine values for MPI cells, following treatment with various elongate mineral particles (EMPs) in $p g / 10^{\wedge} 6$ viable cells. RCF - Riebeckite Cleavage Fragmetns, RAsb - Riebeckite Asbestos, TCF - Tremolite Cleavage Fragments, TAsb Tremolite Asbestos. OOR = Out of Range; OOR $>=$ Out of Range Above; OOR $<=$ Out of Range Below. The cytokines/chemokines values, showing significant difference $(p<0.05)$ compared to respective controls have a red font color. Cytokines with at least 3 different EMP samples, significantly different, compared to respective controls, are highlighted in yellow.

Table 3.3 The top 10 most significantly up- and down-regulated genes. Bold font indicates dysregulated genes common for all treatments.

Table 4.1. Detailed cytokine concentrations in the mouse lungs at 3- and 12-months post exposure, pg/mg protein. RCF - Riebeckite cleavage fragments, RAsb - Riebeckite Asbestos, TCF - Tremolite cleavage fragments, TAsb - Tremolite Asbestos. Values, showing significant difference $(p<0.05)$ compared to respective controls have a red font color

Table 4.2. Lymphohistiocytic aggregates findings in the mouse lungs at 1-year postexposure time point. CF- cleavage fragments, LD - low dose.

Table 4.3. Neoplastic lesions in the mouse lungs at 1-year post-exposure time point. CF- cleavage fragments. LD - low dose. 


\section{LIST OF FIGURES}

Figure 1. Representation of the different mineral particles as a function of their morphology/dimensions. WHO - World Health Organization. From: Opinion of the French Agency for Food, Environmental and Occupational Health \& Safety on "Health Effects and the identification of cleavage fragments of amphiboles from quarried minerals" (https://www.anses.fr/en/system/files/AIR2014sa0196RaEN.pdf).

Figure 1.2. Asbestiform and non-asbestiform varieties of riebeckite and tremolite minerals.

Figure 1.3. Comparison of proposed size ranges of asbestos fibers causing specific diseases compared with the fiber sizes detected using TEM and PCM techniques.

Figure 2.1. Schema for preparation and harvesting of the cleavage fragments.

Figure 2.2. Measuring the lengths and widths of tremolite EMPs harvested during the study using TEM microphotographs.

Figure 2.3. A - Riebeckite asbestos. B - Riebeckite CF. C - Tremolite asbestos, 4,000x Magnification. D - Tremolite CF, 10,000x Magnification.

Figure 2.4. Representative EDS spectra of the studied EMPs. The highest peaks have the associated element identifications. $\mathrm{RF}$ - riebeckite asbestos, $\mathrm{RC}$ - riebeckite cleavage fragments, TF - tremolite asbestos, TC - tremolite cleavage fragments

Figure 3.1. Gating strategy for the flow cytometric analysis. Individual cells were gated out from debris using Area vs. Aspect ratio chart. Signal Gate was based on the cell population having $\mathrm{pH} 2 \mathrm{AX}$ signal intensity $>98.5 \%$ of control cells. $\mathrm{Y}$ axis $-\mathrm{yH} 2 \mathrm{AX}$ fuorescence signal intensity, $\mathrm{X}$ axis - nuclear dye (Hoechst 33342) signal intensity. CF - cleavage fragments

Figure 3.2. Normalized viable/dead cells ratios, $24 \mathrm{~h}$ exposure to riebeckite $(A)$ or tremolite (B) EMPs. Values are expressed as mean \pm SEM from 3 independent experiments. Stauro $-1 \mu \mathrm{M}$ of staurosporine. Equal mass: $9 \mu \mathrm{g} / \mathrm{cm}^{2}$ for both riebeckite asbestos and cleavage fragments (CF); $5 \mu \mathrm{g} / \mathrm{cm}^{2}$ for both tremolite asbestos and CF; Equal surface area of critical fibers: 9 and $40 \mu \mathrm{g} / \mathrm{cm}^{2}$ for riebeckite asbestos and CF, 5 and $60 \mu \mathrm{g} / \mathrm{cm}^{2}$ for tremolite asbestos and CF; Equal number: 6 and $40 \mu \mathrm{g} / \mathrm{cm}^{2}$ for riebeckite asbestos and CF, 1.2 and $60 \mu \mathrm{g} / \mathrm{cm}^{2}$ for tremolite asbestos and CF. ${ }^{\alpha} p<0.05$ vs. control; ${ }^{*} p<0.05$ vs. cleavage fragments equivalent.

Figure 3.3. LDH activity in the supernatant, as percentage of untreated cell values. $24 \mathrm{~h}$ exposure to riebeckite (A) or tremolite (B) EMPs. Values are expressed as mean \pm SEM from 3 independent experiments. Stauro $-1 \mu \mathrm{M}$ of staurosporine. Equal mass: $9 \mu \mathrm{g} / \mathrm{cm}^{2}$ for both riebeckite asbestos and cleavage fragments (CF); $5 \mu \mathrm{g} / \mathrm{cm}^{2}$ for both tremolite asbestos and CF; Equal surface area of critical fibers: 9 and $40 \mu \mathrm{g} / \mathrm{cm}^{2}$ for riebeckite

Figure 3.4. Median Max Pixel intensity (arbitrary units) of the $\mathrm{yH} 2 \mathrm{AX}$ fluorescence staining in the signal gate, $24 \mathrm{~h}$ exposure to riebeckite $(\mathrm{A})$ or tremolite $(\mathrm{B})$. Values are expressed as mean of three biological replicates \pm SEM. Equal mass: $9 \mu \mathrm{g} / \mathrm{cm}^{2}$ for both riebeckite asbestos and cleavage fragments $(\mathrm{CF}) ; 5 \mu \mathrm{g} / \mathrm{cm}^{2}$ for both tremolite asbestos 
and CF; Equal surface area of critical fibers: 9 and $40 \mu \mathrm{g} / \mathrm{cm}^{2}$ for riebeckite asbestos and CF, 5 and $60 \mu \mathrm{g} / \mathrm{cm}^{2}$ for tremolite asbestos and CF; Equal number: 6 and 40

Figure 3.5. \% of cells in the sub-G1 gate, relative to total cells, $24 \mathrm{~h}$ exposure to riebeckite $(A)$ or tremolite $(B)$. Values are expressed as mean of three biological replicates \pm SEM. Equal mass: $9 \mu \mathrm{g} / \mathrm{cm}^{2}$ for both riebeckite asbestos and cleavage fragments (CF); $5 \mu \mathrm{g} / \mathrm{cm}^{2}$ for both tremolite asbestos and CF; Equal surface area of critical fibers: 9 and $40 \mu \mathrm{g} / \mathrm{cm}^{2}$ for riebeckite asbestos and CF, 5 and $60 \mu \mathrm{g} / \mathrm{cm}^{2}$ for tremolite asbestos and CF; Equal number: 6 and $40 \mu \mathrm{g} / \mathrm{cm}^{2}$ for riebeckite asbestos and $\mathrm{CF}, 1.2$ and $60 \mu \mathrm{g} / \mathrm{cm}^{2}$ for tremolite asbestos and CF. ${ }^{\alpha} p<0.05$ vs. control; ${ }^{*} p<0.05$ vs. cleavage fragments equivalent.

Figure 3.6. Hierarachical clustering of the secreted cytokine profiles for the MPI cells exposeed to riebeckite $(\mathrm{A})$ or tremolite (B) EMPs. RF - riebeckite asbestos, $\mathrm{RC}$ riebeckite cleavage fragments, TF - tremolite asbestos, TC - tremolite cleavage fragments. Rows are centered; unit variance scaling is applied to rows. Both rows and columns are clustered using Euclidean distance and Ward linkage. Heatmap reflects unit variance.

Figure 3.7. Principal component analysis of the gene expression profiles in MPI cells, treated with critical fibers' surface area-equivalent doses of riebeckite and tremolite asbestiform and non-asbetiform EMPs. CF - cleavage fragments.

Figure 3.8. Heatmap of Pearson R2 correlation of gene expression between biological replicates. Blue colors indicate high Pearson correlation, and white colors indicate low correlation. Per ENCODE Consortium guidelines RNA sequencing experiments should be performed with two or more biological replicates, unless there is a compelling reason why this is impractical or wasteful. Typically, the Pearson R2 correlation of gene expression between two biological replicates should be over 0.92. CF - Cleavage Fragments

Figure 3.9. Venn Diagrams for upregulated $(A)$ and downregulated genes (B) of MIP cells, treated with critical fibers' surface area-equivalent doses of riebeckite and tremolite asbestiform and non-asbetiform EMPs, compared to untreated cells.

Figure 3.10. Summary of the alveolar macrophages' responses to asbestiform and nonasbestiform EMPS if compared at the critical fibers' surface area-equivalent doses.

Figure 4.1. Experimental design of the animal study

Figure 4.2. A - Adenomatous hyperplasia. B - Adenoma. C and D - Adenocarcinoma. All slides have $\mathrm{H} \& \mathrm{E}$ staining.

Figure 4.3. A -Multifocal adenomatous hyperplasia with mild fibrosis (blue staining). Tremolite asbestos-treated animal. B -Focal type II pneumocyte hyperplasia and mild alveolar septal fibrosis (blue staining). Riebeckite asbestos-treated animal. Both slides stained with Masson trichrome.

Figure 4.4. Tremolite CF-treated animal. Arrow points at the singular cleavage fragment with no fibrosis. Masson trichrome staining.

Figure 4.5. Macrophages containing riebeckite and tremolite asbestos fibers were stained positive for ARG1 (A); CF-treated animals did not exhibit much staining (B). 
Figure 4.6. A - Riebeckite asbestos-treated animal. Arrows point at $\mathrm{\gamma H} 2 \mathrm{AX}$ staining. B Tremolite asbestos-treated animal. Arrows point at $\mathrm{yH} 2 \mathrm{AX}$ staining. $\mathbf{C}-$ Riebeckite CFtreated animal. Arrow points at a singular CF. No yH2AX staining to be found. D Tremolite CF-treated animal. Arrow points at a singular CF. No yH2AX staining to be found.

Figure 4.7. A - Alveolar Macrophage population in the mouse lungs, as a $\%$ of nonlymphocytic cell, at 3- and 12-months' time points. B - Mean Fluorescence Intensity of CD11b surface marker in gated Alveolar Macrophages at 3- and 12-months' time points. RA - Riebeckite asbestos, RALD - Riebeckite asbestos low dose, RC - Riebeckite cleavage fragments, TA - Tremolite asbestos, TALD - Tremolite asbestos low dose, TC - Tremolite cleavage fragments.

Figure 4.8 Eosinophil populations in the mouse lungs, as a \% of non-lymphocytic cell, at 3- and 12-months' time points. RA - Riebeckite asbestos, RALD - Riebeckite asbestos low dose, RC - Riebeckite cleavage fragments, TA - Tremolite asbestos, TALD - Tremolite asbestos low dose, TC - Tremolite cleavage fragments.

Figure 4.9. Neutrophils populations in the mouse lungs, as a \% of non-lymphocytic cell, at 3- and 12-months' time points. RA - Riebeckite asbestos, RALD - Riebeckite asbestos low dose, RC - Riebeckite cleavage fragments, TA - Tremolite asbestos, TALD - Tremolite asbestos low dose, TC - Tremolite cleavage fragments.

Figure 4.10. Inflammatory (iMono) and regulatory (rMono) monocyte populations in the mouse lungs, as a \% of non-lymphocytic cell, at 3- and 12-months' time points. RA Riebeckite asbestos, RALD - Riebeckite asbestos low dose, RC - Riebeckite cleavage fragments, TA - Tremolite asbestos, TALD - Tremolite asbestos low dose, TC Tremolite cleavage fragments.

Figure 4.11. B- and T-Cell populations in the mouse lungs, as a \% of lymphocytes in the appropriate gate, at 3- and 12-months' time points. RA - Riebeckite asbestos, RALD - Riebeckite asbestos low dose, RC - Riebeckite cleavage fragments, TA Tremolite asbestos, TALD - Tremolite asbestos low dose, TC - Tremolite cleavage fragments.

Figure 5.1. Images of the alveolar macrophages from exposed mice 1 year after exposure with phagocytized riebeckite asbestos fibers, obtained by imaging flow cytometry.

Figure 5.2. Images of the alveolar macrophage with tremolite cleavage fragment inside and free floating EMPs from exposed mouse 1 year after exposure, obtained by imaging flow cytometry. 


\section{Chapter 1. Introduction}

Since ancient times, people have noticed that working in a particularly dusty environment leads to morbidity and early death [1]. Throughout the history of human civilization, natural scientists and physicians registered and described the symptoms occurring in workers, proposed treatments, and prevention methods. Several thousand years ago humans discovered minerals that looked like fabric and could be woven into sheets. Since this material was essentially a rock, it was fireproof, and thus came the name - "asbestos" from "indistinguishable" in Greek. In early XX century asbestos was proclaimed a "miracle mineral" [2], the material of the future for its properties; too late came the recognition of potential adverse health outcomes and calls for a worldwide ban [3]. In modern times nanotechnology could share that fate, but thankfully, research community recognized early the need to investigate the potential toxicity of nanomaterials [4]. Despite the findings, asbestos is still relevant in modern society: human exposures occur frequently, coupled to the long latency of the associated diseases. Issues with asbestos definitions, exposure scenarios, persisting regulatory arguments, still-understudied mechanisms of toxicity and their relation to the properties of fibers, have no end in sight as of today. Some of these issues have been at least partially addressed: we know that the health burden can be prevented [5] and there are newer substitute materials [6] even if the safety of the substitutes may be disputed [7]. This dissertation addresses the immune responses to not only asbestos, but also similar long and thin particles that are not designated as asbestiform (looking like asbestos).

\subsection{Definitions and a little bit of mineralogy}

"Asbestos" is the commercial term applied to the asbestiform varieties of six minerals: chrysotile, belonging to the serpentine group and five amphiboles - amosite, crocidolite, anthophyllite, tremolite, and actinolite. The term intentionally specifies asbestiform nature (or habit) of the minerals in question, meaning that they are comprised of very thin fibers with high lengths (longer than five $\mu \mathrm{m}$ ) and aspect ratios (ratio of length to width); in addition, particles must have at least two of the following: parallel fibers occurring in bundles, fiber bundles displaying splayed ends, matted masses of individual fibers and/or 
fibers showing curvature. To encompass the full range of fiber-like mineral particles that have an aspect ratio of more than $3: 1$, the term "elongate mineral particles" (EMP) is now widely used in professional literature [8].

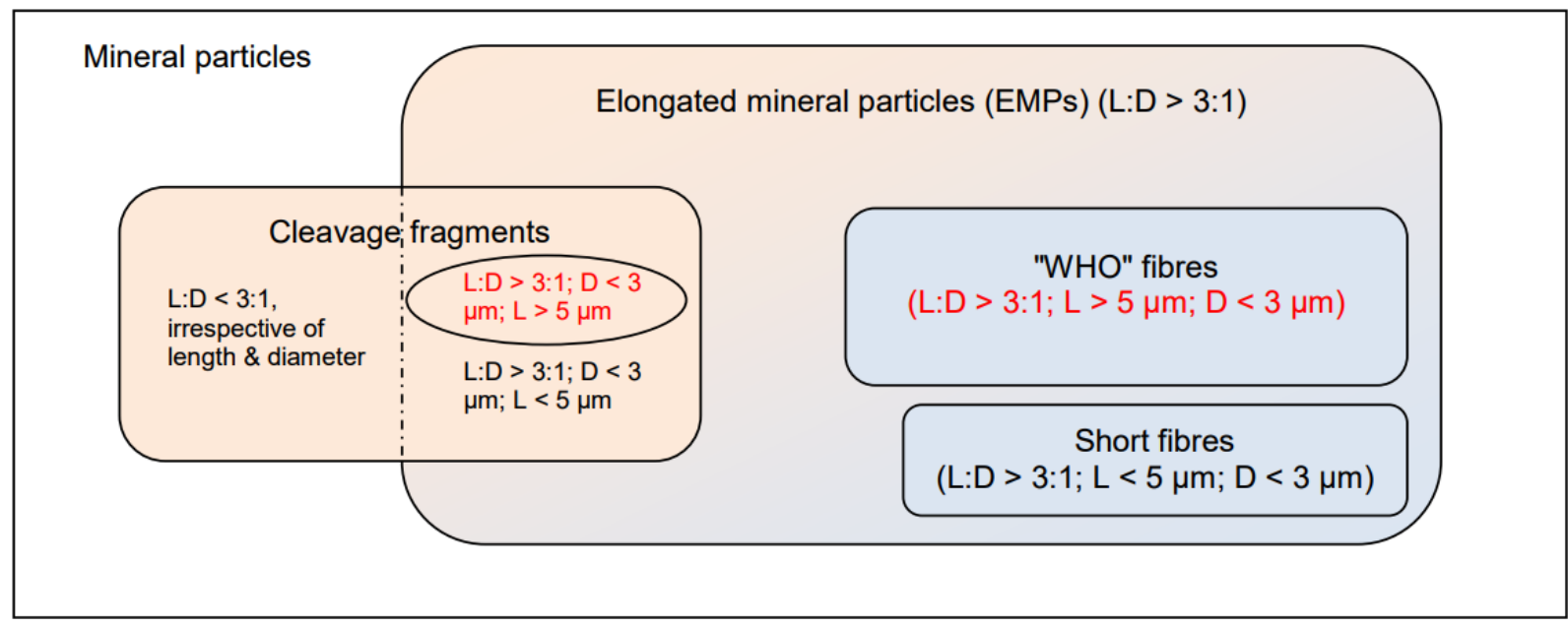

Legend (in red, dimensions of a "WHO" fibre)

Non-asbestiform morphology

Asbestiform morphology

Figure 1.1. Representation of the different mineral particles as a function of their morphology/dimensions. WHO - World Health Organization. From: Opinion of the French Agency for Food, Environmental and Occupational Health \& Safety on "Health Effects and the identification of cleavage fragments of amphiboles from quarried minerals" (https://www.anses.fr/en/system/files/AIR2014sa0196RaEN.pdf).

Crystal habit is another widely used term, that helps to understand how the mineral particle assumed the elongated shape. In short, habit is how singular mineral crystal, or an aggregate of crystals, look and behave if subjected to physical stress, both micro- and macroscopically. During the crystal forming phase, asbestiform minerals naturally grow into the long and thin (meaning high aspect ratio) fibrils with parallel sides, that can stick together, forming a fibrous aggregate. In comparison, non-asbestiform minerals grow in several spatial directions, and can only produce high aspect ratio particles when broken into such, along the so-called cleavage planes; hence the term "cleavage fragments" (Figures 1.1. and 1.2.). The topic of habit is covered in much greater detail by Belluso, Cavallo and Halterman [9]. 

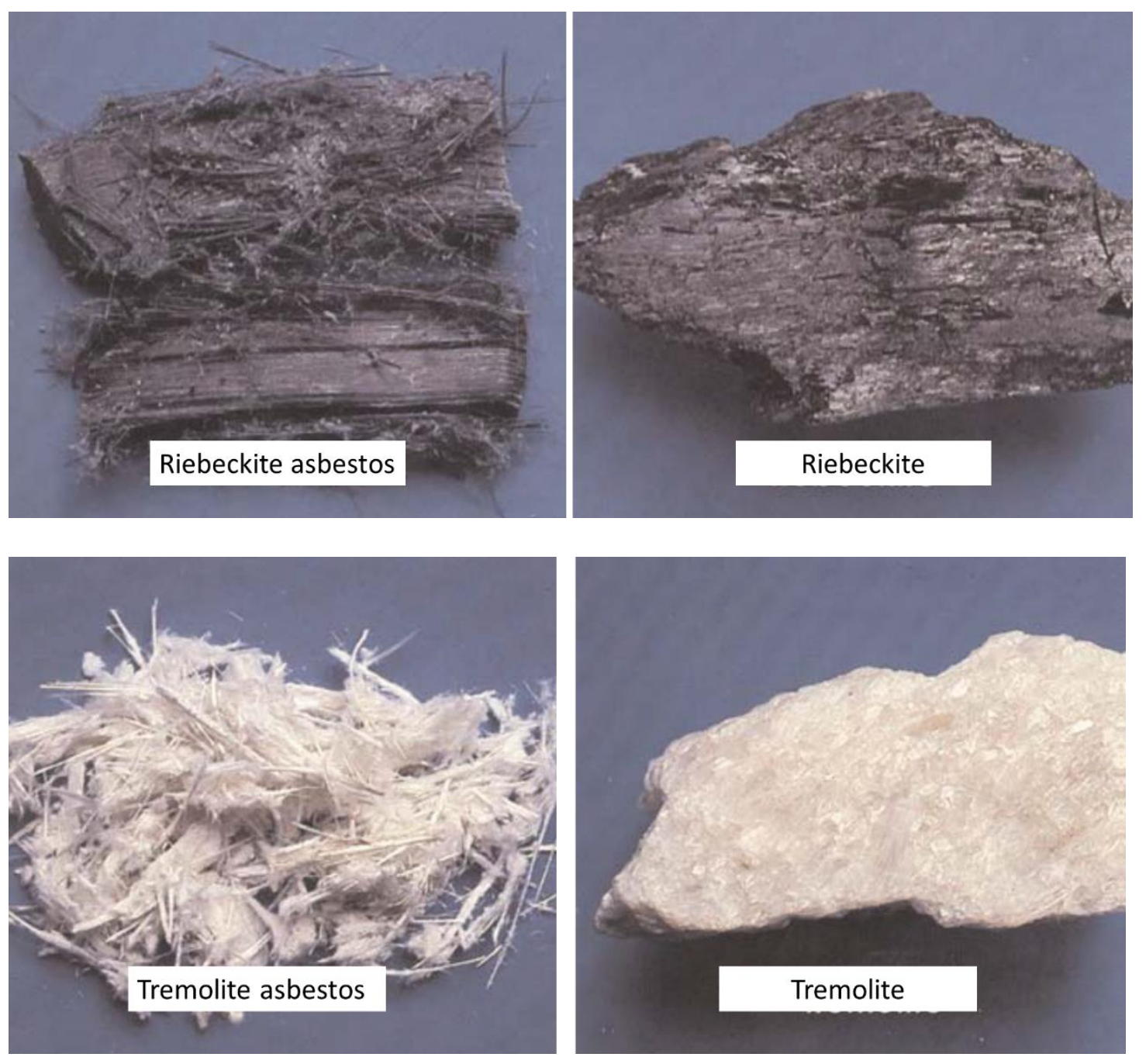

Figure 1.2. Asbestiform and non-asbestiform varieties of riebeckite and tremolite minerals.

Chemical composition of EMPs can be very diverse. For instance, natural minerals that are considered asbestos, are all silicates, built from silicate tetrahedral unit cells, but also incorporating various metals and other atoms into the lattice. Artificial fibers can be made of glass, clay, silicon carbide or just carbon, with a substantial variety of other elements. This diversity means that the particles can have unique or common chemical reactivities, with downstream biological consequences [10].

Chrysotile is a serpentine mineral that always occurs as fibers with nanometer width dimensions (henceforth nanofibers) or in bundles of larger overall size. Most asbestos products were made with this material. Fibrous silicate minerals that can be associated with chrysotile and antigorite include rare carlosturanite and balangeroite, and 
the much more common amphiboles tremolite and anthophyllite. Amphibole-group minerals can crystallize as large crystals, fine prismatic or acicular crystals, or truly nanofibrous asbestos. The main amphiboles which crystallize in nanofibers are the commonly exploited crocidolite (fibrous riebeckite), amosite, anthophyllite and tremoliteactinolite. However, other amphibole minerals have been found to crystallize in the nanofibrous habit. For instance, winchite and richterite, which contaminate vermiculite from Libby, MT, and have health effects identical to asbestos, were formerly included within the definition of tremolite but are not specifically named in Occupational Health and Safety Administration (OSHA) and Mine Safety and Health Administration (MSHA) regulations [11, 12]. Other examples include sodic amphiboles in Nevada and Arizona $[13,14]$, and a new nanofibrillar amphibole, glaucophane, found in the Franciscan mélange of CA [15].

\subsection{Exposure to asbestiform and non-asbestiform EMPs}

Exposure to asbestiform and non-asbestiform mineral varieties occurs both at workplaces and in the natural environment [16]. While asbestos is no longer mined in the U.S. as a primary commodity, it can be encountered along with additional EMPs as an accessory mineral in deposits that are routinely mined [17]. EMP's are not confined to exploitable deposits and are geologically widely spread. This can lead to potentially hazardous exposures in mining almost any commodity mineral. In 2015, 1.32 billion metric tons of crushed stone valued at more than $\$ 13.8$ billion was produced by 1,430 companies operating 3,700 quarries, 82 underground mines, and 187 sales/distribution yards in 50 states [18]. The National Occupational Health Survey of Mining recorded detectable asbestos fibers in settled dust collected from mines involved in the extraction of 21 different non-asbestos commodities [19]. In samples collected during 2000-2007, the Mining Safety and Health Administration (MSHA) found that $3 \%$ of personal samples had asbestos fiber concentrations in excess of the OSHA-regulated concentration of 0.1 fibers/cc. $12 \%$ of those same samples had non-asbestos EMP concentrations above 0.1 fibers/cc. A range of $0.004-16.0$ asbestos fibers/cc in the air has been reported during maintenance and replacement of vehicle brakes [20]. In 2011, NIOSH estimated that 44,000 mine workers may have been exposed to EMPs, in addition to 568,000 and 
114,000 workers in the service and construction industries, respectively. Nearly 1.3 million employees in general industry could face significant asbestos exposure in occupational settings [8]. A number of studies reported that disturbance of gravel and soils may be a source of exposure [21, 22], which carry risks even at low concentrations of EMPs released by construction, road building, or dust storms. Non-asbestiform tremolite when mixed with talc enhances its usefulness for the production of ceramic appliances. Most of the naturally occurring asbestiform EMPs are amphiboles, which require lower dosages to cause asbestosis than chrysotile [23]. A recent review found that off-road vehicles can generate quantifiable airborne concentrations of mineral fibers in areas where they are naturally occurring [24]. Exposure to asbestos and asbestiform fibers is also occurring naturally, since rock types containing asbestos are common across the US, i.e. Coastal Ranges of the Rocky Mountains i.e. CA, OR, WA and AK and in the Appalachians from VT all the way down to AL, but can be found in almost every State, including, for example, TX, CO and MN, and several other countries [25, 26]. As Americans more and more prefer to build homes in forests, mountains and arid areas, an increasing part of general population is being affected. Aside from the more obvious consumer exposures through the brake pads and construction materials, the extreme cases also include asbestos fibers in cosmetic talc [27], and even toys [28]. Transplacental transfer was described for several asbestos species [29].

As of today, researchers in the field have not reached a consensus as to whether distinctions between "regulated" and "unregulated" amphibole EMPs should exist [30]. Bearing in mind the importance of EMP dimensions, most of the exposure assessment methods for regulated EMPs are based on "counts". Thus, it becomes extremely important to know exactly what must be counted and what should be "censored" during the counting process. This was emphasized in the NIOSH Roadmap and brought up in a recent extensive review by Egilman et al. [31]. US OSHA believes that the epidemiological studies provide insufficient evidence to inform as to the carcinogenicity of non-asbestiform asbestos-group minerals and was unable to conclude that non-asbestiform minerals present a significant risk of non-malignant respiratory diseases. The American Thoracic Society (ATS) reviewing the same studies concluded that "although the role of chrysotile versus tremolite in producing disease in these patients could not be clearly sorted out, 
the (...) data appear to indicate that fairly low aspect ratio fibers of tremolite are capable of causing disease, probably in fairly low concentrations in the case of pleural plaques, but certainly only in very high concentrations in regard to mesothelioma and asbestosis" (Ex. 525, p. 10). Stating that for most mineral deposit asbestos and non-asbestiform habit are distinguishable (populations of cleavage fragments and asbestos can be distinguished), OSHA treats cleavage fibers as physical irritants (occupational exposure limit of $5 \mathrm{mg} / \mathrm{m}^{3}$ for respirable dust). NIOSH acknowledges different risk of nonasbestiform amphiboles might compared to asbestos, but at the same time insists that recommended exposure level (REL) for airborne asbestos fibers also encompass EMPs from the non-asbestiform analogs of the asbestos minerals due to the inconclusive epidemiological evidence for cancer risk associated with exposure to cleavage fragments. $\mathrm{NIOSH}$ deems that as a precautionary approach. The NIOSH REL for airborne asbestos fibers and related EMPs is " 0.1 countable EMP from one or more covered minerals per cubic centimeter, averaged over 100 minutes, where a countable elongate mineral particle is any fiber or fragment of a mineral longer than $5 \mu \mathrm{m}$ with a minimum aspect ratio of 3:1 when viewed microscopically with use of NIOSH Analytical Method 7400 ('A' rules) or its equivalent." Some other agencies worldwide also adhere to this principle. French Agency for Food, Environmental and Occupational Health and Safety deemed that "...in the current state of knowledge concerning their health effects, cleavage fragments (...) meeting the WHO's dimensional criteria for fibres $(L>5 \mu \mathrm{m} ; \mathrm{D}<3 \mu \mathrm{m}$ and $L: D>3: 1)$ should not be distinguished from their asbestiform counterparts; there is no reason to make a distinction between the cleavage fragments meeting the "WHO" dimensional criteria for fibres $(L>5 \mu \mathrm{m} ; \mathrm{D}<3 \mu \mathrm{m}$ and $\mathrm{L}: \mathrm{D}>3: 1)$ and asbestiform fibres of calcic and sodic-calcic EMPs."

\subsection{Health burden of asbestos and non-asbestiform EMPs}

It is well known that inhalation exposure to respirable asbestiform EMPs leads to chronic fibrotic lung disorders, cancer, including malignant mesothelioma and other noncarcinogenic outcomes [4]. This signifies a substantial healthcare and economic burden worldwide. NIOSH, OSHA, and MSHA all agree on exposure limits of less than 0.1 countable fiber/cc. Nevertheless, substantial risk for adverse health effects remains even 
at this exposure limit, which was established based on limitations of the phase contrast microscopy analytical method for counting asbestos fibers. At the current Permissible Exposure Limit (PEL) applied to airborne fibers of the asbestos minerals, OSHA predicts an excess risk of 2.3 cancers per thousand over a 20 -year period, increasing to 3.4 per thousand over a 40-year working life [32]. This PEL is also implemented by MSHA. The acceptable cancer risk for workplaces is 1 per thousand, but the PEL must be based on technological feasibility factors in addition to risk. The risk at the PEL is very much higher than that tolerated in the ambient environment; for example, the Environmental Protection Agency (EPA) typically considers 1 in 10,000 to be the point at which intervention is warranted no matter the local opinion. NIOSH recommends that cleavage fragments, crystallized in massive form, be counted as asbestos fibers, if they meet dimensional criteria. However, these EMPs are not currently included as asbestos under MSHA and OSHA regulations. For instance, winchite and richterite, which contaminate vermiculite from Libby, MT, and have health effects identical to asbestos, were formerly included within the definition of tremolite but are not specifically named in OSHA and MSHA regulations [11, 12]. Other examples include sodic amphiboles in Nevada and Arizona $[13,14]$, non-asbestiform EMPs in taconite, and talc and gold mining [33]. NIOSH estimated that 44,000 mine workers may be exposed to EMPs, in addition to 568,000 and 114,000 workers in the service and construction industries, respectively.

Experimental and epidemiologic data indicates an increased risk for mesothelioma, lung fibrosis, interstitial and pleural abnormalities as well as lung cancer in humans exposed to asbestiform fibers. Peak of asbestos consumption in the USA was in 1951, but the long latency period means that the disease in populations persists for decades. The disease was predicted to claim the lives in excess of 29,000 individuals, between the years 2005 and 2027 [34]. There were 25,413 asbestosis deaths in the USA between 1970 and 2004, with 6.9 per million population maximum age-adjusted death rate, 35-fold greater for men than for women [35]. The areas of the country with the highest death rates were the coastal regions, with the shipbuilding industry sustaining an expected proportionate mortality ratio. Some estimates range between 55,100 [36] and 76,700 [37] EMP-caused lung cancer deaths between the years of 1980 and 2009. Another source lists a total of 13,024 deaths due to asbestosis in the US in 2005-2014, 
accounting for 120,905 years of potential life lost to life expectancy [38]. Globally, conditions caused by asbestos exposures contribute most to the occupational cancer burden and are responsible for the increasing mortality for occupational respiratory diseases [39], with 243000 deaths were attributable to asbestos in 2017 worldwide [40]. A total of 13,024 deaths might be attributed to asbestosis in the US in 2005-2014, accounting for 120,905 years of potential life lost to life expectancy [38]. Recent papers showed that mortality rates of nasopharyngeal and laryngeal cancer, lung cancer, intestinal cancer, and mesothelioma can be significantly influenced by naturally occurring asbestos [22, 41]. One should also take into account the observed reappearance of progressive pneumoconiosis cases in the United States, with silcates, including silicate EMPs being implicated [42]. Productivity losses due to asbestos-related diseases in the US amount to approximately $0.36 \%$ of GDP, or 86,100 million USD [43]. It was found the total cost of asbestos damage payments in the US will eventually reach $\$ 200$ billion [44]. In Canada economic burden of asbestos-related lung cancer in 2011 was estimated to be almost 2 billion Canadian dollars (1,99 billion USD)[45]. In Australia estimated hospital and primary care costs were found to be 130,5 million USD per year, and indirect costs arising from time out of the workforce to be 321 million USD per year. Globally the diseases caused by asbestos are estimated to cost 300 billion USD in compensations over the coming years [5].

\subsection{Pathological outcomes of exposures to asbestiform and non-asbestiform EMPs}

Both carcinogenic and non-carcinogenic health outcomes such as pulmonary fibrosis (asbestosis), pleural fibrosis and plaques, have been extensively described in asbestosexposed populations [16, 46]. Verified studies established a structure-activity relationship paradigm for long and thin particles with high aspect ratio and demonstrated that exposure to asbestos fibers causes many lung diseases including pleural and lung fibrosis (asbestosis), lung cancer, and pleural and peritoneal malignant mesothelioma (MM) [47-50]. Although not technically classified as asbestos, erionite [51] - a fibrous zeolite having analogous physical, chemical and morphological properties as asbestos fibers - causes a spectrum of asbestos-associated lung diseases, including pleural fibrosis, plaques and MM [52-54]. A recent study also described erionite evoking $\mathrm{TH}_{\mathrm{H}} 17$ 
responses and inducing autoimmune responses in mice $[55,56]$. Exposure to silicon carbide ( $\mathrm{SiC}$ ) has not been indicted of causing the lung cancer [57].

Epidemiological evidence for the pathogenicity of non-asbestiform mineral varieties is scarce, but it seems that there is little if any risk of lung cancer or mesothelioma [58-60]. This is in part due to the lack of reliable exposure assessment methods for non-asbestiform EMPs, however, there is evidence for exposures during taconite, talc and gold mining associated with an increased risk for non-malignant respiratory diseases, such as as pneumoconiosis, and the excess of cardiovascular and respiratory mortality $[33,61]$. There is some epidemiological evidence for non-asbestiform nephrite to be the cause of pulmonary fibrosis and lung cancer [62, 63]. A case of lung cancer was described following exposure to tremolite cleavage fragments in gravel quarry [64]. At the same time, in rat carcinogenicity study asbestiform tremolite had much higher carcinogenic potential compared to non-fibrous tremolite after intrapleural injections [65]. Practically all outcomes are tightly dependent on the immunological responses, both innate and adaptive, local and systemic [66-68].

\subsection{The role of EMP dimensions and chemistry}

Substantial evidence suggests that fiber dose, number, dimensions, durability, surface reactivity, surface area, and their propensity to split into thin fibers in vivo are important mediators of asbestos-related diseases [69, 70]. Relatively few EMPs with diameters larger than $\sim 3 \mu \mathrm{m}$ will penetrate into the lungs [71], but those with diameters less than $0.1 \mu \mathrm{m}$ are also less retained in the lungs compared to larger diameters [72]. Longer fibers deposit more readily in the airways compared to alveolar region due to the interception mechanism [73]. The World Health Organization (WHO) considers EMPs longer than 5 $\mu \mathrm{m}$ "critical" for lung pathology development [74]; however, there are propositions to only consider fibers longer than $10 \mu \mathrm{m}[75,76]$ as dangerous for human health. In a comprehensive review Lippmann (2014) states that thin fibers up to $5 \mu \mathrm{m}$ cause pleural fibrosis and MM, while those $20 \mu \mathrm{m}$ and longer - lung cancer. [77]. The diseasepromoting potential of the various fiber morphologies is summarized on Figure 1.3., taken from the NIOSH Manual of Analytical Methods [78]. 


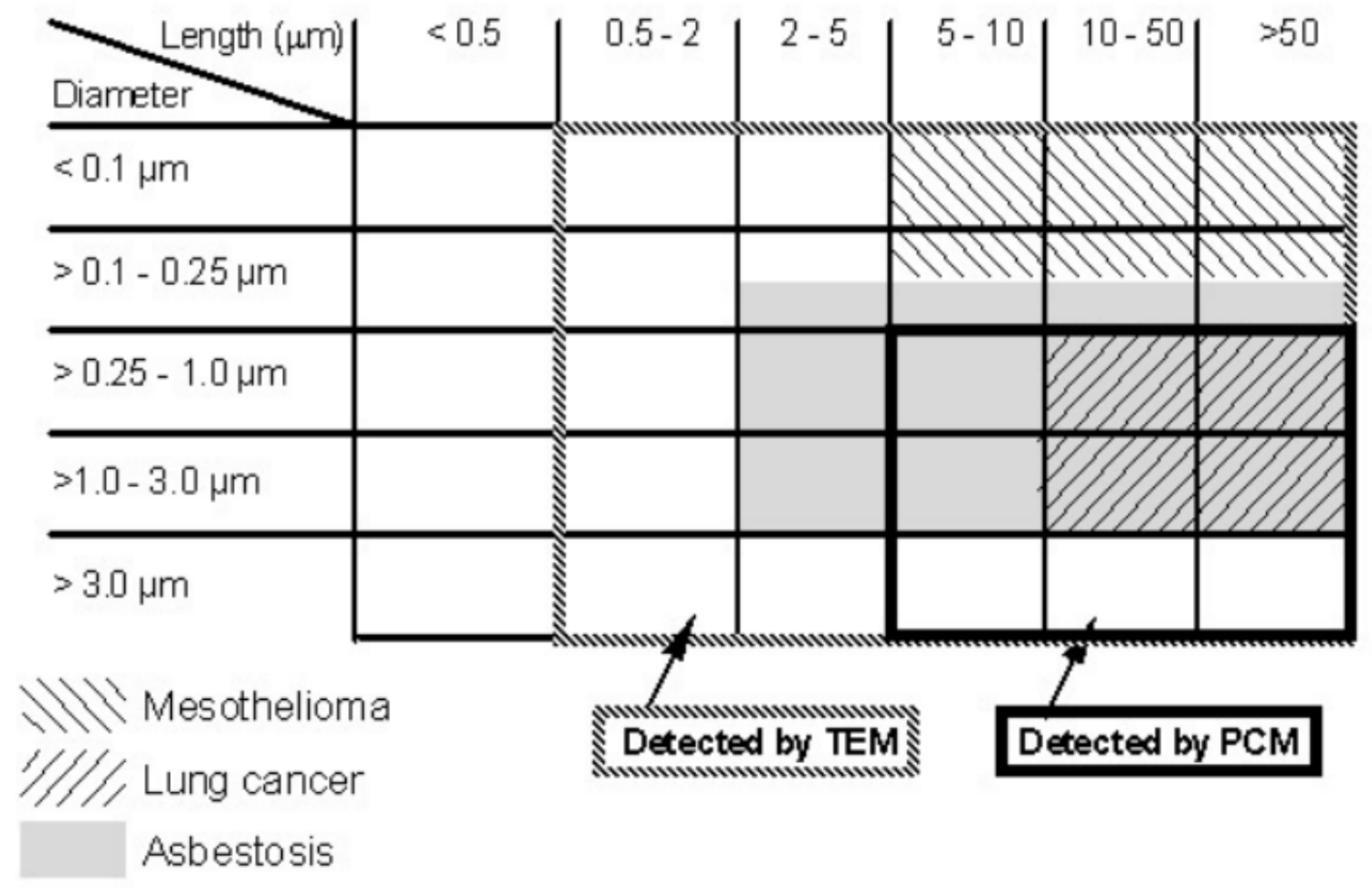

Figure 1.3. Comparison of proposed size ranges of asbestos fibers causing specific diseases compared with the fiber sizes detected using TEM and PCM techniques.

Bearing in mind the inferred importance of fiber dimensions, most of the exposure assessment methods for regulated EMPs are based on "counts". Thus, it is crucial to know exactly what must be counted and what should be "censored" during the counting process. This was emphasized in the NIOSH roadmap on EMP research [8] and brought up in a recent extensive review by Egilman et al. [31]. There was a limited batch of in vitro studies on non-asbestiform EMP varieties [79, 80], whereas significant number of research projects focused on the shorter vs. longer asbestos fibers rather than asbestiform vs. non-asbestiform EMP comparisons. The earliest evidence led to a prevailing opinion that long asbestos fibers are the most dangerous, i.e. shown to be more cytotoxic to macrophages in vitro than short ones [81]. For non-fibrogenic fibers Castranova et al. found that short and thin glass fibers are more cytotoxic than thick and long [82] while Padmore et al. discovered that shorter fibers are less potent in inducing the inflammatory responses [83]. However, both short and long riebeckite asbestos fibers were able to induce $\mathrm{H}_{2} \mathrm{O}_{2}$ production by macrophages and cause cell death [81]. The 
situation can be quite different in vivo, since EMPs longer than $20 \mu \mathrm{m}$ rarely penetrates deep into the alveolar region. In the critical review Dodson et al. (2003) emphasizes the need to account for shorter fibers when assessing the potential hazard of asbestiform EMPs [84]. It is confirmed that short fibers still remain in significant proportions in the lungs of workers with occupational asbestos exposure [85]. And apparently, short fibers may be quite cytotoxic in vivo when the clearance of these fibers is prevented $[81,86]$.

The early evidence of surface area importance was highlighted by Lippmann (1988), who stated that "....asbestosis is most closely related to the surface area of retained fibers" [87]. In the study by Davis et al. (1991) total surface area of tremolite samples were highly correlated to the incidence of mesothelioma in rats [65]. Mossman et al.(Mossman, Lippmann et al. 2011) concluded that the surface area of retained fibers rather than the phagocytized particle numbers, mass or volume correlated best with inflammatory responses in vivo [88]. In vitro studies, such as the one done by Dunkan et al. (2014) show good association between the asbestiform fibers surface area and inflammatory responses [89]. The reason surface area must be accounted for is the presence of certain reactive sites on the exterior of individual EMPs. Those could be dangling bonds, silanol groups or transition metals, all capable of participating in redox reactions with the biological molecules. Iron is considered one of the major players in the EMP toxicity. Change from ferric iron to ferrous increases activity and vice versa. Even outside of the direct cytotoxic events, iron status influences macrophage polarization overload leads to M2 responses, whereas deficiency - to M1 [90]. Heme Oxygenase -1 (HO-1) expression in the lungs of rats exposed to crocidolite [91]. However, redox potential of the fibers is not completely related to the iron content. For instance, in A549 lung adenocarcinoma cells both tremolite and crocidolite had comparable toxic effects despite 10-20 times difference in iron content between samples [92]. Later the same authors have evaluated the surface reactivity of the same amphibole samples and concluded that the reactivity of studied fibers was due to specific iron sites, and the radical activity persists throughout the long dissolution process [93]. The importance of fiber surface area in fiber toxicity mechanisms, i.e. active sites, surface redox-active iron, milling effect etc. is explored in detail by Aust et al. (2011) [10]. A good example of the intersection between chemical reactivity and distant pathological outcome is the 
production of peroxynitrite, one of the most powerful oxidants, and a product of chemical reaction between $\cdot \mathrm{NO}$ and superoxide anion $\left(\mathrm{O}_{2}^{-}\right)$, during asbestos lung injury (Figure 4.). Increased levels of peroxynitrite are associated with tumour progression in many types of cancer [94, 95], which has been linked with T-cell unresponsiveness.

Further, fibers that dissolved in lung fluid in a matter of weeks or months appear to be somewhat less toxic than more insoluble fibers. Studies performed in rats produced the evidence of high biodurability of crocidolite and tremolite fibers [96]. Conversely, lowtoxicity wollastonite (a calcium inosilicate mineral $\mathrm{CaSiO}$ ) fibers are much less biopersistent with very short half-time of 15 to 21 days [97]. If the fiber is durable and biopersistent, there is a chance it penetrates the epithelium translocates to the interstitium/pleura. [98]. Another evidence for the importance of mineral type rather than the EMPs size was provided by Wylie et al. (1997), who compared the toxicity of fibrous talc, chrysotile, and asbestiform riebeckite, each sample having significant proportion of long and thin durable fibers, but causing toxic responses of different magnitude [99].

The evolution of knowledge about toxic properties of various mineral fibers naturally led to an idea that dimensions alone should not be considered the primary metric critical for the hazard assessment.

\subsection{Immune component of the biological response to EMPs}

\subsubsection{Overview of the immune system involvement}

It is clear now that alterations of the immune system functions play important role in the development of asbestos pathology. For instance, lung cancer and mesothelioma following pulmonary exposure to all types of asbestos, are directly associated with immunosuppression [100]. The evidence for development of autoimmunity after asbestos exposure starts building up [14], akin to chemically similar silica, which is already recognized as a provoker of systemic autoimmune disease [101]. The impairment of phagocytic function, constant recruitment of neutrophils and cellular damage can lead to an increased secretion of host-derived antigens, that drive the autoantibodies production upon exposure to asbestos [102]. Exposure to EMP leads to changes in the population of AMs, which have a long turnover rate in mice [103], and recruitment of phagocytes that actively participate in clearance mechanisms, proinflammatory and pro/antifibrotic 
signaling, contributing to the polarization of immune response. AM depletion can also enhance antigen-presenting function of resident phagocytes (parenchymal dendritic cells) and their migration, leading to re-activation of the T-cells [104]. There is also indication that asbestos-initiated chronic oxidative stress contributes to carcinogenesis and fibrosis by promoting oxidative DNA damage and regulating redox signaling pathways [105-109]. Increased biopersistence and low clearance, leading to bioaccumulation of asbestiform fibers in the lungs can not only elicit proliferative and immune response, but also directly or indirectly affect the function of the immune system. The hyperplastic outcomes thus may be anticipated based on the immune cell functionality as well as on physicochemical properties of particles. There is also a strong role of immune system in the development of pulmonary fibrosis following asbestos exposures.

Quantification of cellular and humoral immune responses as a function of physical/chemical/structural properties of asbestos fibers and their cleavage fragments is an essential step to determine factors and mechanisms by which these fibers exert toxicity and carcinogenesis. The early phase of lung innate immune response to foreign agents is characterized by the onset of inflammation mediated by resident phagocytic cells. The inflammatory milieu in the lung following exposure to the mineral fibers provides a range of signals required for activation and potential polarization of macrophages, which shape the subsequent $T$ cell response and the whole local immune microenvironment. These signals are presented in the context of cytokines and chemokines, damaged cells/cell fragments, and, perhaps, specific features of the asbestos/asbestiform fibers themselves. However, little data exist on the transcriptional reprogramming that takes place upon the contact with asbestiform or non-asbestiform EMPs. Understanding of the macrophage function and lymphocytes involvement in EMP-induced lung injury will significantly contribute to the EMP immunotoxicity paradigms.

\subsubsection{Alveolar macrophages responses and role in pathogenesis}

Numerous cell populations are involved in asbestos-related pathology, with resident alveolar macrophages being one of the primary mediators of the host immune response. Their depletion during asbestos-induced lung disease exacerbates fibrosis and worsens overall prognosis [110]. Accordingly, macrophage responses, including patterns of cell damage, cytokines, chemokines, and changes in gene expression could be related to the 
specific features of the fibers, meaning toxicological studies must go hand in hand with detailed EMP characterization. Macrophage receptor with collagenous structure (MARCO) and scavenger receptor A (SR-A) are implicated in asbestos recognition [111], through sensing polyanionic ligands. AMs mostly express SR-A, but MARCO also is heavily involved in the disease progression and immune polarization [112]. Complement activation also plays role in chemotaxis of AMs towards deposited EMPs [113]. The uptake of cylindrical microparticles particles in murine macrophages usually happens within the first 1.5-3 hours [114] and requires a proper orientation - so that the macrophage could approach from one of the ends [115]. The efficiency and speed of phagocytosis depends heavily on particle shape [116]. A paradigm is proposed that "SR$A$ and MARCO amplify responses of both intracellular Toll-like receptors (TLRs) and nucleotide-binding oligomerization domain (NOD)-like receptors (NLRs), possibly increasing ligand availability in intracellular compartments." [117]. After the recognition and (un)successful phagocytosis, asbestos fibers with different morphology and chemistry have been shown to activate NLRP-3 inflammasome through different mechanisms [118-121]. This inflammasome participates in initial inflammatory response and the chronic inflammatory conditions arising in fiber exposure settings, including driving the IL-17 responses [122], implicated in amphibole asbestos pathogenicity [56] and specifically in the associated reduction in antitumor immunity [123]. Successful internalization is actually not always necessary, since crystalline structures can activate NLRP3 through the surface contact [124]. The example of inert glass fibers is very characteristic - longer ones cannot be phagocytized, and cause inflammatory mediators production, but little toxicity per se [83]. In this case another mechanism may kick in foreign body giant cells (FBGC) arise when dealing with poorly soluble large foreign materials [125]. Foreign bodies reaction may lead to the influx of monocytes from the bloodstream (mostly $\mathrm{Ly}_{6} \mathrm{C}^{+}$), more prominent in severe inflammation. At the site monocytes mature into macrophages [126].

The same mechanisms of NLRP3 activation were proposed for both asbestos and nanoscale fibers, such as carbon nanotubes (CNT) [127]. Probably one of the most important downstream consequence of EMP internalization by AMs is lysosome membrane permeabilization (LMP), leading to the leakage of lysosomal enzymes, 
potassium influx, and activation of apoptotic cascades. As an alternative mechanisms, if mitochondrial damage occurred foremost, release of mitochondrial ROS into the cytosol may also act as a mediator for LMP induction [128]. Ultimately, it sems that AM death through necrosis/necrosis/apoptosis is what drives the disease further. Asbestos materials have been proven to be potent proapoptotic agents in alveolar macrophages [129].

Another important function of AMs is secretion of biologically active molecules, including cytokines, chemokines, growth factors etc. Normally the "tolerant" nature of the majority of AMs prevents overreaction and excessive activation. However, AM population is not homogenous and includes genotypically and functionally different varieties. [130132]. Not all of them are strictly immunosuppressive and as early as in 1996 researchers hypothesized that the disbalance of suppressive vs. reactive subtypes (i.e. caused by the excessive apoptosis of the former subtype) is what constitutes the development of lung disease [133]. Polarization of Immune response heavily impacts the resulting outcomes by shaping the immune responses to EMPs. It is established that, in humans with asbestosis, alveolar macrophages secrete pro-inflammatory cytokines and are overresponsive to the other stimuli $[134,135]$. Driscoll et al. reported considerable IL-1 and TNF- $\alpha$ secretion by alveolar macrophages obtained from exposed rats at day 3 post exposure to crocidolite, which decreased substantially on days 7,14 , and 28 [136]. The increased cytokine secretion observed in humans and animals, however, has not been reproduced in vitro [134]. There is huge amount of data on the role of TGF- $\beta 1$ in AM homeostasis [137, 138] and AM-related lung pathology [139], including upregulation of TGF- $\beta 1$ production in asbestosis [140]. AMs themselves may act as a source of PDGF (IFN- $\gamma$, IL-1 $\beta$ and IL-13 implicated). Additionally, proinflammatory cytokines (IL-1b, TGFb.) upregulate PDGFR-alpha [141]. PDGF along with TGF- $\beta 1$ are the cornerstones of fibrotic lung diseases.

\subsubsection{Role of lymphocytes: immunosuppression and autoimmunity}

Role of lymphocytes in asbestos-related pathology can vary greatly depending on whether we look at carcinogenic or non-carcinogenic outcomes. Pulmonary fibrosis in general is accompanied by the influx of T-lymphocytes, engaging in pro- or antifibrotic 
activities [142]. For example, CD4+ and esp. CD8+ are capable of producing CCL3 (MIP1a), involved in fibrocytes recruitment. Activated T-lymphocytes express CD40L that binds to CD40R on fibroblasts, stimulating their proliferation. Several important predictive/prognostic parameters have been suggested, such as CD4+/CD8+ relative proportion, and accumulation of quiescent versus activated T-cells. In idiopathic pulmonary fibrosis patients CD4/CD8 ratios in BAL are variable, and higher CD4/CD8 ration means better response to the therapy, while elevated CD8+ is unfavorable [143]. If fibers are translocated to lymph nodes, which happens in exposed humans [144], there is a potential for CD8 differentiation into CTL suppression by asbestos (chrysotile and crocidolite), compared with glass wool fibers, leading to decreased IFN- $\gamma$ and TNF- $\alpha$ production [145]. Disbalance of Th17 and Treg lymphocytes can also be a major event in the development of asbestos-driven lung pathology [123].

Autoimmunity caused by EMP exposure is a pressing issue. A comprehensive set of studies have been performed by Dr. Pfau and colleagues, following the news of Libby amphibole (6-mix) exposure-related surge in autoimmune conditions in workers and general population: rheumatoid arthritis, systemic lupus erythematoides, systemic scleroderma, and lamellar pleural thickening were diagnosed at higher prevalence in LAexposed populations [146-148]. At the same time, negative correlation of asbestos exposure and autoantibody titers have also been described [149].

\subsubsection{Role of other immune cell types}

Polymorphonuclear leukocytes (PMN), including neutrophils, myeloid-derived suppressor cells (MDSCs), mast cells and dendritic cells Our previous in vivo study comparing pulmonary effects of tremolite, crocidolite, and wollastonite EMPs revealed differential innate inflammatory responses. In particular, it was found that tremolite elicited inflammatory responses with polymorphonuclear leukocytes (PMN) influx peaking at day 1 and eosinophil response at day 7 post-exposure. In contrast, exposure to crocidolite fibers induced a "delayed" inflammatory response with maximal influx of PMNs and eosinophils occurring on day 7 post exposure [150]. MDSCs are emerging as potent immunosuppressive agents, participating in the pathogenesis of many lung diseases [151], including mesothelioma induced by asbestos exposures [152]. Higher eosinophils 
count was previously observed in animal models and humans exposed to asbestos [153, 154], and eosinophils are known to facilitate lymphocytes-driven $\mathrm{TH}_{\mathrm{H}}$-type response. Steady increase in mast cells (including submesothelial) was observed in rats, inhaling both chrysotile and amphibole fibers $[155,156]$, which can facilitate ECM deposition, $\mathrm{TH}_{\text {H }}$ and autoimmune responses. Suppression of the dendritic and other cells contributes to asbestos-induced tumorigenesis [157].

\subsection{Knowledge gaps}

Although it is not easy to recapitulate human asbestos-induced lung disease in rodents, first murine asbestosis models were proposed in 1980s [158, 159]. They utilized BALB/C mice and chrysotile asbestos administered via inhalation or instillation. However, despite the knowledge of major outcomes, it is still unclear from existing literature what characteristics of fibers are the major determinants of toxicity and how does it contribute to the (non-) carcinogenic outcomes associated with their exposure. The evidence of knowledge gap lies in the fact that Immunological components of the fiber-induced lesions are extremely understudied; especially important is determining whether similar long-term health outcomes are reached through disparate immunological mechanisms in the case of different types of EMP. If the lung immune responses play decisive role in pulmonary and extrapulmonary long-term outcomes following various EMP exposures; what is the role of antigen-presenting cells and $\mathrm{T}_{\mathrm{H}}$ polarization in asbestos exposures; how significant is the immune suppression from EMP of different chemical composition and growth habit; what is the significance of alterations in the alveolar macrophage populations following exposures to various EMPs? Recent discoveries of new occupational and incidental exposures to EMPs, emergence of new technologies and new engineered materials, continuous use of old-fashioned methods for EMP quantification and characterization makes studies aimed at elucidating precise immune mechanisms of EMP-related pathology extremely timely.

\subsection{Concluding remarks:}

There is a strong need for research on fundamental mineralogical properties of EMPs in their relevance to inhalation toxicity, which can be used as a basis for exposure assessment and workers' protection. Ultimately, the knowledge of what EMP 
characteristics are major determinants of health outcomes will improve our understanding of dose-response relationships and help us to better determine how much of a reduction in exposure is needed to prevent adverse health effects. Data on immunotoxicity of various EMP is critical for the occupational health specialists, including clinical doctors, who deal with the adverse health effects in overexposed workers. There are still many questions remaining on exposure assessment, measurements and health effects for asbestos fibers and other EMPs, and these questions are a large source of confusion for many stakeholders in the mining, construction (building and road), and manufacturing industries. Unambiguous identification and characterization of accurate and reliable biomarkers of lung diseases associated with EMP exposures in animals or humans has not been achieved. This is due, at least in part, to the lack of comprehensive comparative studies that evaluate the adverse effects of asbestiform and non-asbestiform fibers in relation to their physical, chemical, morphological and surface characteristics, as well as their bioavailability and biopersistence. It is currently impossible to present comprehensive model of the immune responses to elongate mineral fibers due to the sheer diversity of the latter. In his letter to editor Dr. Gualtieri, a renowned asbestos researcher, states (talking about carcinogenesis, as an example outcome) that creating such models requires "...the intersection of different perspectives, ..., comparison of experimental evidence from other research fields (e.g. biochemistry, mineralogy, physics, and toxicology) to take into account the complex synergy of all the factors at play in defining the toxicity and pathogenicity of mineral fibers (e.g. fiber morphometry, frustrated phagocytosis, production of reactive oxygen species/nitric oxide synthase, inflammasome models, genetic factors, and many more)" [160]. Occasionally, complex schemas are provided, such as the one by Otsuki et al. [161], but they usually include limited test articles (i.e. only "asbestos"), as well as specific humoral (certain cytokines/chemokines) and cellular components (for instance, lymphocytic origin cells only). Studying the dosimetry and mode of action of multiple types of asbestiform minerals and respective cleavage fragments is essential to understanding the specific exposure responses. Consequently, quantification of cellular and humoral immune responses as a function of physical/chemical/structural properties of asbestos fibers and their cleavage fragments is an essential step to determine factors and mechanisms by which these fibers exert 
toxicity and carcinogenesis. The early phase of lung innate immune response to foreign agents is characterized by the onset of inflammation mediated by resident phagocytic cells. The inflammatory milieu in the lung following exposure to the mineral fibers provides a range of signals required for activation and potential polarization of macrophages, which shape the subsequent $\mathrm{T}$ cell response and the whole local immune microenvironment. These signals are presented in the context of cytokines and chemokines, damaged cells/cell fragments, and, perhaps, specific features of the asbestos/asbestiform fibers themselves. However, little data exist on the transcriptional reprogramming that takes place upon the contact with asbestiform or non-asbestiform EMPs. Understanding of the function of antigen-presenting cells and lymphocytes activation patterns will significantly contribute to the EMP immunotoxicity paradigms.

\subsection{Objective and Aims of this dissertation study}

The broad, long-term objective of this project focuses on the assessment of local and systemic immune responses to two distinct types of elongate mineral fibers (EMPs): asbestiform fibers and their non-asbestiform mineral analogue cleavage fragments in order to identify the critical cellular and humoral mediators. The central research question of the dissertation was: how do the asbestiform and non-asbestiform respirable EMP preparations influence the immune landscape in the mouse lungs, in regard to pulmonary fibrotic/neoplastic outcomes after repeated pharyngeal aspiration exposure?

To answer the central research question, three specific aims were proposed:

Aim 1: To prepare respirable test samples of two amphiboles - riebeckite and tremolite, and their respective cleavage fragments, with comparable dimensions, and assess their size distribution, morphology, composition and structural make-up, using polarized light microscopy, transmission electron microscopy, and X-ray spectroscopy.

Aim 2: To determine the contribution of innate tissue resident macrophages to the development of specific responses to asbestiform and non-asbestiform EMPs, alveolar macrophage-like cells will be incubated with studied EMPs to determine cytotoxic responses, and transcriptional reprogramming.

Aim 3: To evaluate the myeloid lineage cellular composition and humoral component of the immune response in the mouse lungs upon exposure to the tested 
EMPs, in relation to the histopathological changes, mouse animal model of repeated pharyngeal aspiration will be utilized, where animals are sacrificed at 3 and 12 months post final exposure day, and cytokine production/release will be assessed in the lungs. Lungs will be also enzymatically digested to produce a single cell suspension that will be stained for respective immune cells surface markers and analyzed on Flow Cytometer. Histopathology and immunohistochemistry analysis to be performed by board-certified pathologist.

\subsection{References}

1. Ramazzini, B., De morbis artificum diatriba [diseases of workers]. 1713. American journal of public health, 2001. 91(9): p. 1380-1382.

2. Nelson, E.W., Asbestos, the miracle mineral. Earth Sci. Digest, 1947. 1(11): p. 38.

3. Ramazzini, C., Asbestos Is Still With Us: Repeat Call for a Universal Ban. Archives of Environmental \& Occupational Health, 2010. 65(3): p. 121-126.

4. Oberdorster, G. and U. Graham, Predicting EMP hazard: Lessons from studies with inhaled fibrous and non-fibrous nano- and micro-particles. Toxicol Appl Pharmacol, 2018. 361: p. 50-61.

5. Asbestos-related disease--a preventable burden. Lancet, 2008. 372(9654): p. 1927.

6. Ramazzini, C., The global health dimensions of asbestos and asbestos-related diseases. Journal of occupational health, 2016. 58(2): p. 220-223.

7. Endes, C., et al., A critical review of the current knowledge regarding the biological impact of nanocellulose. Journal of Nanobiotechnology, 2016. 14(1): p. 78.

8. Middendorf, P., et al., Current intelligence bulletin 62: asbestos fibers and other elongate mineral particles: state of the science and roadmap for research. 2011, U.S. Department of Health and Human Services, Public Health Service, Centers for Disease Control and Prevention, National Institute for Occupational Safety and Health, DHHS (NIOSH) Cincinnati, OH. p. 173.

9. Belluso, E., et al., Crystal habit of mineral fibres, in Mineral Fibres: Crystal Chemistry, Chemical-Physical Properties, Biological Interaction and Toxicity. 2017, Mineralogical Society of Great Britain and Ireland. p. 0.

10. Aust, A.E., P.M. Cook, and R.F. Dodson, Morphological and chemical mechanisms of elongated mineral particle toxicities. J Toxicol Environ Health B Crit Rev, 2011. 14(1-4): p. 40-75.

11. Dunning, K.K., et al., Mesothelioma associated with commercial use of vermiculite containing Libby amphibole. J Occup Environ Med, 2012. 54(11): p. 1359-63.

12. Miller, A., "Not your grandfather's pleural disease": rapid progression, ventilatory impairment, and chronic pleuritic pain from Libby vermiculite/amphibole. Am J Ind Med, 2014. 57(11): p. 1195-6. 
13. Metcalf, R.V. and B.J. Buck, Genesis and health risk implications of an unusual occurrence of fibrous NaFe3+-amphibole. Geology, 2015. 43(1): p. 63-66.

14. Pfau, J.C., et al., Comparative health effects in mice of Libby amphibole asbestos and a fibrous amphibole from Arizona. Toxicol Appl Pharmacol, 2017. 334: p. 2434.

15. Di Giuseppe, D., et al., Characterization and assessment of the potential toxicity/pathogenicity of fibrous glaucophane. Environ Res, 2019. 178: p. 108723.

16. Cancer, I.A.f.R.o., A Review of Human Carcinogens: Arsenic, metals, fibres, and dusts. 2012: International Agency for Research on Cancer.

17. VanGosen, B.S., The geologic relationships of industrial mineral deposits and asbestos in the western united states.

18. USGS, Mineral commodity summaries. United States Department of Interior, United States Geological Survey. 2016.

19. NIOSH, National Occupational Health Survey of Mining. DHHS (NIOSH) Publication No. 2011-159 1996, U.S. Department of Health and Human Services, Centers for Disease Control and Prevention, National Institute for Occupational Safety and Health: Cincinnati, $\mathrm{OH}$.

20. Organization, W.H., WHO International Programme on Chemical Safety, Chrysotile asbestos, Environmental health criteria. 1998: Geneva, Switzerland.

21. Van Orden, D.R., Identification and analysis of ambient EMPs. Toxicol Appl Pharmacol, 2018. 361: p. 21-26.

22. Wei, B., et al., Impacts of land use on spatial distribution of mortality rates of cancers caused by naturally occurring asbestos. J Expo Sci Environ Epidemiol, 2012. 22(5): p. 516-21.

23. Churg AM, G.F., Occupational lung disease, Ch 24 inThurlbeck's Pathology of the Lung. 2005, New York: Thieme.

24. Wolfe, C., et al., Exposure to naturally occurring mineral fibers due to off-road vehicle use: A review. Int J Hyg Environ Health, 2017. 220(8): p. 1230-1241.

25. Carbone, M., et al., Erionite exposure in North Dakota and Turkish villages with mesothelioma. Proc Natl Acad Sci U S A, 2011. 108(33): p. 13618-23.

26. Lahondère, D., et al., TEM and FESEM characterization of asbestiform and nonasbestiform actinolite fibers in hydrothermally altered dolerites (France). Environmental Earth Sciences, 2018. 77(10): p. 385.

27. Steffen, J.E., et al., Serous Ovarian Cancer Caused by Exposure to Asbestos and Fibrous Talc in Cosmetic Talc Powders-A Case Series. Journal of Occupational and Environmental Medicine, 2020. 62(2).

28. Silvestri, S., et al., Asbestos in toys: an exemplary case. Scand J Work Environ Health, 2016. 42(1): p. 80-5.

29. Haque, A.K., et al., Asbestos in organs and placenta of five stillborn infants suggests transplacental transfer. Environ Res, 1992. 58(2): p. 163-75.

30. Berman, D.W., P. Hibbs, and M. Lippmann, Proceedings of the the Monticello Conference on Elongated Mineral Particles. Session III: Human exposure, effects \& risk. Toxicology and Applied Pharmacology, 2018. 361: p. 145-148.

31. Egilman, D., et al., Health Effects of Censored Elongated Mineral Particles: A Critical Review. Detection Limits in Air Quality and Environmental Measurements. 2019, West Conshohocken, PA: ASTM International. 239-2019. 
32. Occupational Exposure to Asbestos. Final Rule. 08/10/1994. Federal Register \# 59:40964-41162., O.S.a.H.A. Department of Labor, Editor. 1994.

33. Mandel, J.H., B.H. Alexander, and G. Ramachandran, A review of mortality associated with elongate mineral particle (EMP) exposure in occupational epidemiology studies of gold, talc, and taconite mining. Am J Ind Med, 2016. 59(12): p. 1047-1060.

34. Antao, V.C., G.A. Pinheiro, and J.T. Wassell, Asbestosis mortality in the USA: facts and predictions. Occup Environ Med, 2009. 66(5): p. 335-8.

35. Bang, K.M., et al., Asbestosis mortality surveillance in the United States, 19702004. Int J Occup Environ Health, 2008. 14(3): p. 161-9.

36. Walker, A.M., et al., Projections of Asbestos-Related Disease 1980-2009. 1983. 25(5): p. 409-425.

37. Lilienfeld, D.E., et al., Projection of asbestos related diseases in the United States, 1985-2009. I. Cancer. British journal of industrial medicine, 1988. 45(5): p. 283-291.

38. NIOSH, Work-Related Lung Disease Surveillance System (eWoRLD). 2017, U.S. Department of Health and Human Services, Centers for Disease Control and Prevention, National Institute for Occupational Safety and Health, Respiratory Health Division: Morgantown, WV.

39. De Matteis, S., et al., Current and new challenges in occupational lung diseases. Eur Respir Rev, 2017. 26(146).

40. Collaborators, G.B.D.R.F., Global, regional, and national comparative risk assessment of 84 behavioural, environmental and occupational, and metabolic risks or clusters of risks for 195 countries and territories, 1990-2017: a systematic analysis for the Global Burden of Disease Study 2017. Lancet, 2018.

392(10159): p. 1923-1994.

41. Baumann, F., et al., The Presence of Asbestos in the Natural Environment is Likely Related to Mesothelioma in Young Individuals and Women from Southern Nevada. J Thorac Oncol, 2015. 10(5): p. 731-737.

42. Cohen, R.A., et al., Lung Pathology in U.S. Coal Workers with Rapidly Progressive Pneumoconiosis Implicates Silica and Silicates. Am J Respir Crit Care Med, 2016. 193(6): p. 673-80.

43. WHO Mortality Database. 2017, World Health Organization. Health Statistics and Health Information Systems.

44. White, M.J., Asbestos and the future of mass torts. J Econ Perspect, 2004. 18(2): p. 183-204.

45. Tompa, E., et al., The economic burden of lung cancer and mesothelioma due to occupational and para-occupational asbestos exposure. Occupational and Environmental Medicine, 2017. 74(11): p. 816-822.

46. Cancer, I.A.f.R.o., Some Nanomaterials and Some Fibres. 2017: World Health Organization.

47. Mossman, B.T., et al., Asbestos: scientific developments and implications for public policy. Science, 1990. 247(4940): p. 294-301.

48. Mossman, B.T. and A. Churg, Mechanisms in the pathogenesis of asbestosis and silicosis. Am J Respir Crit Care Med, 1998. 157(5 Pt 1): p. 1666-80. 
49. Robinson, B.W. and R.A. Lake, Advances in malignant mesothelioma. N Engl J Med, 2005. 353(15): p. 1591-603.

50. Sterman, D.H. and S.M. Albelda, Advances in the diagnosis, evaluation, and management of malignant pleural mesothelioma. Respirology, 2005. 10(3): $p$. 266-83.

51. Artvinli, M. and Y.I. Baris, Malignant mesotheliomas in a small village in the Anatolian region of Turkey: an epidemiologic study. J Natl Cancer Inst, 1979. 63(1): p. 17-22.

52. Emri, S., et al., Lung diseases due to environmental exposures to erionite and asbestos in Turkey. Toxicology Letters, 2002. 127(1-3): p. 251-257.

53. Ross, M., et al., Health-Effects of Mineral Dusts Other Than Asbestos. Reviews in Mineralogy, 1993. 28: p. 361-407.

54. Dikensoy, O., Mesothelioma due to environmental exposure to erionite in Turkey. Curr Opin Pulm Med, 2008. 14(4): p. 322-5.

55. Zebedeo, C.N., et al., Erionite induces production of autoantibodies and IL-17 in C57BL/6 mice. Toxicol Appl Pharmacol, 2014. 275(3): p. 257-64.

56. Ferro, A., et al., Amphibole, but not chrysotile, asbestos induces anti-nuclear autoantibodies and IL-17 in C57BL/6 mice. J Immunotoxicol, 2014. 11(3): p. 28390.

57. Bugge, M.D., et al., Lung cancer incidence among Norwegian silicon carbide industry workers: associations with particulate exposure factors. Occup Environ Med, 2012. 69(8): p. 527-33.

58. Garabrant, D.H. and S.T. Pastula, A comparison of asbestos fiber potency and elongate mineral particle (EMP) potency for mesothelioma in humans. Toxicol Appl Pharmacol, 2018. 361: p. 127-136.

59. Wild, P., Lung cancer risk and talc not containing asbestiform fibres: a review of the epidemiological evidence. Occupational and environmental medicine, 2006. 63(1): p. 4-9.

60. Allen, E.M., et al., Occupational exposures and lung cancer risk among Minnesota taconite mining workers. Occupational and environmental medicine, 2015. 72(9): p. 633-639.

61. Coggiola, M., et al., An update of a mortality study of talc miners and millers in Italy. Am J Ind Med, 2003. 44(1): p. 63-9.

62. Yang, H.Y., R.H. Shie, and P.C. Chen, Pulmonary fibrosis in workers exposed to non-asbestiform tremolite asbestos minerals. Epidemiology, 2013. 24(1): p. 1439.

63. Yang, H.Y., R.H. Shie, and P.C. Chen, Carving of non-asbestiform tremolite and the risk of lung cancer: a follow-up mortality study in a historical nephrite processing cohort. Occup Environ Med, 2013. 70(12): p. 852-7.

64. Kohyama, N., et al., Lung cancer in a patient with predominantly short tremolite fibers in his lung. Am J Ind Med, 2017. 60(9): p. 831-838.

65. Davis, J.M., et al., Variations in the carcinogenicity of tremolite dust samples of differing morphology. Ann N Y Acad Sci, 1991. 643: p. 473-90.

66. Wick, G., et al., The immunology of fibrosis. Annu Rev Immunol, 2013. 31: p. 107-35. 
67. Stankovic, B., et al., Immune Cell Composition in Human Non-small Cell Lung Cancer. Front Immunol, 2018. 9: p. 3101.

68. Corthay, A., Does the Immune System Naturally Protect Against Cancer? 2014. 5(197).

69. Lippmann, M., Effects of Fiber Characteristics on Lung Deposition, Retention, and Disease. Environmental Health Perspectives, 1990. 88: p. 311-317.

70. Baron, P.A., Measurement of airborne fibers: A review. Industrial Health, 2001. 39(2): p. 39-50.

71. Lippmann, M., Man-made mineral fibers (MMMF): human exposures and health risk assessment. Toxicol Ind Health, 1990. 6(2): p. 225-46.

72. Lippmann, M. and V. Timbrell, Particle Loading in the Human Lung-Human Experience and Implications for Exposure Limits. Journal of Aerosol Medicine, 1990. 3(s1): p. S-155-S-168.

73. Sussman, R.G., B.S. Cohen, and M. Lippmann, Asbestos Fiber Deposition in a Human Tracheobronchial Cast. li. Empirical Model. Inhalation Toxicology, 1991. 3(2): p. 161-179.

74. World Health, O., Air quality guidelines for Europe. WHO Reg Publ Eur Ser, 2000(91): p. V-X, 1-273.

75. Berman, D.W. and K.S. Crump, A meta-analysis of asbestos-related cancer risk that addresses fiber size and mineral type. Crit Rev Toxicol, 2008. 38 Suppl 1: $p$. 49-73.

76. Roggli, V.L., Measuring EMPs in the lung what can be measured in the lung: Asbestiform minerals and cleavage fragments. Toxicol Appl Pharmacol, 2018. 361: p. 14-17.

77. Lippmann, M., Toxicological and epidemiological studies on effects of airborne fibers: coherence and public [corrected] health implications. Crit Rev Toxicol, 2014. 44(8): p. 643-95.

78. Ashley, K., NIOSH Manual of Analytical Methods 5(th) Edition and Harmonization of Occupational Exposure Monitoring. Gefahrst Reinhalt Luft, 2015. 2015(1-2): p. 7-16.

79. Palekar, L.D., C.M. Spooner, and D.L. Coffin, Influence of crystallization habit of minerals on in vitro cytotoxicity. Ann N Y Acad Sci, 1979. 330: p. 673-86.

80. Castranova, V., et al., Comparative Cytotoxic Effects of Crocidolite and its NonAsbestiform Polymorph on Rat Alveolar Macrophages. The Annals of Occupational Hygiene, 1994. 38(inhaled_particles_VII): p. 665-673.

81. Goodglick, L.A. and A.B. Kane, Cytotoxicity of long and short crocidolite asbestos fibers in vitro and in vivo. Cancer Res, 1990. 50(16): p. 5153-63.

82. Castranova, V., et al., In vitro effects of large and small glass fibers on rat alveolar macrophages. J Toxicol Environ Health, 1996. 49(4): p. 357-69.

83. Padmore, T., et al., Quantitative analysis of the role of fiber length on phagocytosis and inflammatory response by alveolar macrophages. Biochim Biophys Acta Gen Subj, 2017. 1861(2): p. 58-67.

84. Dodson, R.F., M.A.L. Atkinson, and J.L. Levin, Asbestos fiber length as related to potential pathogenicity: A critical review. 2003. 44(3): p. 291-297. 
85. Adib, G., et al., Short, fine and WHO asbestos fibers in the lungs of quebec workers with an asbestos-related disease. Am J Ind Med, 2013. 56(9): p. 100114.

86. MacCorkle, R.A., et al., Intracellular protein binding to asbestos induces aneuploidy in human lung fibroblasts. Cell Motil Cytoskeleton, 2006. 63(10): p. 646-57.

87. Lippmann, M., Asbestos exposure indices. Environ Res, 1988. 46(1): p. 86-106.

88. Mossman, B.T., et al., Pulmonary endpoints (lung carcinomas and asbestosis) following inhalation exposure to asbestos. J Toxicol Environ Health B Crit Rev, 2011. 14(1-4): p. 76-121.

89. Duncan, K.E., et al., In vitro determinants of asbestos fiber toxicity: effect on the relative toxicity of Libby amphibole in primary human airway epithelial cells. Part Fibre Toxicol, 2014. 11: p. 2.

90. Agoro, R., et al., Cell iron status influences macrophage polarization. PLoS One, 2018. 13(5): p. e0196921.

91. Nagatomo, H., et al., Expression of Heme Oxygenase-1 in the Lungs of Rats Exposed to Crocidolite Asbestos. Inhalation Toxicology, 2005. 17(6): p. 293-296.

92. Pacella, A., et al., Iron topochemistry and surface reactivity of amphibole asbestos: relations with in vitro toxicity. Anal Bioanal Chem, 2012. 402(2): p. 87181.

93. Andreozzi, G.B., et al., Surface reactivity of amphibole asbestos: a comparison between crocidolite and tremolite. Sci Rep, 2017. 7(1): p. 14696.

94. Vickers, S.M., et al., Association of increased immunostaining for inducible nitric oxide synthase and nitrotyrosine with fibroblast growth factor transformation in pancreatic cancer. Arch Surg, 1999. 134(3): p. 245-51.

95. Cobbs, C.S., et al., Inactivation of wild-type p53 protein function by reactive oxygen and nitrogen species in malignant glioma cells. Cancer Res, 2003. 63(24): p. 8670-3.

96. Muhle, H., B. Bellmann, and F. Pott, Comparative investigations of the biodurability of mineral fibers in the rat lung. Environ Health Perspect, 1994. 102 Suppl 5: p. 163-8.

97. Bellmann, B. and H. Muhle, Investigation of the biodurability of wollastonite and xonotlite. Environ Health Perspect, 1994. 102 Suppl 5: p. 191-5.

98. Murphy, F.A., et al., Length-dependent pleural inflammation and parietal pleural responses after deposition of carbon nanotubes in the pulmonary airspaces of mice. Nanotoxicology, 2013. 7(6): p. 1157-67.

99. Wylie, A.G., et al., Mineralogical features associated with cytotoxic and proliferative effects of fibrous talc and asbestos on rodent tracheal epithelial and pleural mesothelial cells. Toxicol Appl Pharmacol, 1997. 147(1): p. 143-50.

100. Muhle, H. and F. Pott, Asbestos as reference material for fibre-induced cancer. Int Arch Occup Environ Health, 2000. 73 Suppl: p. S53-9.

101. Lee, S., et al., Silica exposure and altered regulation of autoimmunity. Environ Health Prev Med, 2014. 19(5): p. 322-9.

102. Pfau, J.C., K.M. Serve, and C.W. Noonan, Autoimmunity and asbestos exposure. Autoimmune Dis, 2014. 2014: p. 782045. 
103. Maus, U.A., et al., Resident alveolar macrophages are replaced by recruited monocytes in response to endotoxin-induced lung inflammation. Am J Respir Cell Mol Biol, 2006. 35(2): p. 227-35.

104. Jakubzick, C., et al., Modulation of dendritic cell trafficking to and from the airways. J Immunol, 2006. 176(6): p. 3578-84.

105. Huang, S.X.L., et al., Role of Mutagenicity in Asbestos Fiber-Induced Carcinogenicity and Other Diseases. Journal of Toxicology and Environmental Health-Part B-Critical Reviews, 2011. 14(1-4): p. 179-245.

106. Kamp, D.W. and S.A. Weitzman, The molecular basis of asbestos induced lung injury. Thorax, 1999. 54(7): p. 638-52.

107. Shukla, A., et al., Multiple roles of oxidants in the pathogenesis of asbestosinduced diseases. Free Radical Biology and Medicine, 2003. 34(9): p. 11171129.

108. Xu, A., et al., Mechanisms of the genotoxicity of crocidolite asbestos in mammalian cells: Implication from mutation patterns induced by reactive oxygen species. Environmental Health Perspectives, 2002. 110(10): p. 1003-1008.

109. Huang, S.X.L., et al., Mitochondria-Derived Reactive Intermediate Species Mediate Asbestos-Induced Genotoxicity and Oxidative Stress-Responsive Signaling Pathways. Environmental Health Perspectives, 2012. 120(6): p. 840847.

110. Joshi, N., et al., A spatially restricted fibrotic niche in pulmonary fibrosis is sustained by M-CSF/M-CSFR signalling in monocyte-derived alveolar macrophages. Eur Respir J, 2020. 55(1).

111. Peiser, L. and S. Gordon, The function of scavenger receptors expressed by macrophages and their role in the regulation of inflammation. Microbes Infect, 2001. 3(2): p. 149-59.

112. Murthy, S., et al., Alternative activation of macrophages and pulmonary fibrosis are modulated by scavenger receptor, macrophage receptor with collagenous structure. FASEB journal : official publication of the Federation of American Societies for Experimental Biology, 2015. 29(8): p. 3527-3536.

113. Warheit, D.B., et al., Pulmonary Macrophages Are Attracted to Inhaled Particles through Complement Activation. Experimental Lung Research, 1988. 14(1): p. 51-66.

114. Blake, D.J., et al., Internalization of Libby amphibole asbestos and induction of oxidative stress in murine macrophages. Toxicol Sci, 2007. 99(1): p. 277-88.

115. Tscheka, C., et al., Macrophage uptake of cylindrical microparticles investigated with correlative microscopy. Eur J Pharm Biopharm, 2015. 95(Pt A): p. 151-5.

116. Champion, J.A. and S. Mitragotri, Shape induced inhibition of phagocytosis of polymer particles. Pharm Res, 2009. 26(1): p. 244-9.

117. Mukhopadhyay, S., et al., SR-A/MARCO-mediated ligand delivery enhances intracellular TLR and NLR function, but ligand scavenging from cell surface limits TLR4 response to pathogens. Blood, 2011. 117(4): p. 1319-28.

118. Li, M., M.E. Gunter, and N.K. Fukagawa, Differential activation of the inflammasome in THP-1 cells exposed to chrysotile asbestos and Libby "six-mix" amphiboles and subsequent activation of BEAS-2B cells. Cytokine, 2012. 60(3): p. 718-30. 
119. Hillegass, J.M., et al., Asbestos and erionite prime and activate the NLRP3 inflammasome that stimulates autocrine cytokine release in human mesothelial cells. Part Fibre Toxicol, 2013. 10: p. 39.

120. Dostert, C., et al., Innate immune activation through Nalp3 inflammasome sensing of asbestos and silica. Science, 2008. 320(5876): p. 674-7.

121. Sayan, M. and B.T. Mossman, The NLRP3 inflammasome in pathogenic particle and fibre-associated lung inflammation and diseases. Part Fibre Toxicol, 2016. 13(1): p. 51.

122. Mills, K.H., et al., The role of inflammasome-derived IL-1 in driving IL-17 responses. J Leukoc Biol, 2013. 93(4): p. 489-97.

123. Maeda, M., et al., Induction of IL-17 production from human peripheral blood CD4+ cells by asbestos exposure. Int J Oncol, 2017. 50(6): p. 2024-2032.

124. Hari, A., et al., Activation of NLRP3 inflammasome by crystalline structures via cell surface contact. Sci Rep, 2014. 4: p. 7281.

125. McNally, A.K. and J.M. Anderson, Macrophage fusion and multinucleated giant cells of inflammation. Adv Exp Med Biol, 2011. 713: p. 97-111.

126. Klopfleisch, R., Macrophage reaction against biomaterials in the mouse model Phenotypes, functions and markers. Acta Biomater, 2016. 43: p. 3-13.

127. Palomaki, J., et al., Long, needle-like carbon nanotubes and asbestos activate the NLRP3 inflammasome through a similar mechanism. ACS Nano, 2011. 5(9): p. 6861-70.

128. Heid, M.E., et al., Mitochondrial reactive oxygen species induces NLRP3dependent lysosomal damage and inflammasome activation. J Immunol, 2013. 191(10): p. 5230-8.

129. Kovacikova, Z., et al., The effect of fibrous dusts on lung cells. In vitro study. Cent Eur J Public Health, 2004. 12 Suppl: p. S44-8.

130. Joshi, N., J.M. Walter, and A.V. Misharin, Alveolar Macrophages. Cell Immunol, 2018. 330: p. 86-90.

131. Holt, P.G., Down-regulation of immune responses in the lower respiratory tract: the role of alveolar macrophages. Clin Exp Immunol, 1986. 63(2): p. 261-70.

132. Alber, A., et al., The role of macrophages in healing the wounded lung. Int $\mathrm{J}$ Exp Pathol, 2012. 93(4): p. 243-51.

133. Hamilton, R.F., L.L. lyer, and A. Holian, Asbestos induces apoptosis in human alveolar macrophages. Am J Physiol, 1996. 271(5 Pt 1): p. L813-9.

134. Perkins, R.C., et al., Human alveolar macrophage cytokine release in response to in vitro and in vivo asbestos exposure. Exp Lung Res, 1993. 19(1): p. 55-65.

135. Holian, A., et al., Asbestos and silica-induced changes in human alveolar macrophage phenotype. Environ Health Perspect, 1997. 105 Suppl 5: p. 113942.

136. Driscoll, K.E., et al., Alveolar macrophage cytokine and growth factor production in a rat model of crocidolite-induced pulmonary inflammation and fibrosis. $\mathrm{J}$ Toxicol Environ Health, 1995. 46(2): p. 155-69.

137. Yu, X., et al., The Cytokine TGF- $\beta$ Promotes the Development and Homeostasis of Alveolar Macrophages. Immunity, 2017. 47(5): p. 903-912.e4.

138. Aluwihare, P. and J.S. Munger, What the Lung Has Taught Us about Latent TGF$\beta$ Activation. 2008. 39(5): p. 499-502. 
139. Grunwell, J.R., et al., TGF- $\beta 1$ Suppresses the Type I IFN Response and Induces Mitochondrial Dysfunction in Alveolar Macrophages. 2018. 200(6): p. 2115-2128.

140. Nishimura, Y., et al., Altered functions of alveolar macrophages and NK cells involved in asbestos-related diseases. Environmental Health and Preventive Medicine, 2013. 18(3): p. 198-204.

141. Andrae, J., R. Gallini, and C. Betsholtz, Role of platelet-derived growth factors in physiology and medicine. Genes Dev, 2008. 22(10): p. 1276-312.

142. Luzina, I.G., et al., Roles of $T$ lymphocytes in pulmonary fibrosis. J Leukoc Biol, 2008. 83(2): p. 237-44.

143. Fireman, E., et al., Predictive value of response to treatment of T-lymphocyte subpopulations in idiopathic pulmonary fibrosis. Eur Respir J, 1998. 11(3): p. 706-11.

144. Dodson, R.F., et al., A comparison of asbestos burden in lung parenchyma, lymph nodes, and plaques. Ann N Y Acad Sci, 1991. 643: p. 53-60.

145. Kumagai-Takei, N., et al., Effect of Asbestos Exposure on Differentiation of Cytotoxic T Lymphocytes in Mixed Lymphocyte Reaction of Human Peripheral Blood Mononuclear Cells. 2013. 49(1): p. 28-36.

146. Pfau, J.C., K.M. Serve, and C.W. Noonan, Autoimmunity and asbestos exposure. Autoimmune diseases, 2014. 2014: p. 782045-782045.

147. Pfau, J.C., et al., Autoimmune markers for progression of Libby amphibole lamellar pleural thickening. Inhalation toxicology, 2019. 31(11-12): p. 409-419.

148. Pfau, J.C., et al., Analysis of autoantibody profiles in two asbestiform fiber exposure cohorts. Journal of toxicology and environmental health. Part A, 2018. 81(19): p. 1015-1027.

149. Lee, E., et al., Asbestos exposure and autoantibody titers. Annals of Occupational and Environmental Medicine, 2020. 32: p. e32.

150. Yanamala, N., et al., Characterization of pulmonary responses in mice to asbestos/asbestiform fibers using gene expression profiles. J Toxicol Environ Health A, 2018. 81(4): p. 60-79.

151. Kolahian, S., et al., The emerging role of myeloid-derived suppressor cells in lung diseases. 2016. 47(3): p. 967-977.

152. Huaux, F., et al., Mesothelioma response to carbon nanotubes is associated with an early and selective accumulation of immunosuppressive monocytic cells. Particle and fibre toxicology, 2016. 13(1): p. 46-46.

153. Gellert, A.R., et al., Asbestosis: assessment by bronchoalveolar lavage and measurement of pulmonary epithelial permeability. Thorax, 1985. 40(7): p. 50814.

154. Robinson, B.W., et al., Alveolitis of pulmonary asbestosis. Bronchoalveolar lavage studies in crocidolite- and chrysotile-exposed individuals. Chest, 1986. 90(3): p. 396-402.

155. Wagner, M.M., et al., Mast cells and inhalation of asbestos in rats. Thorax, 1984. 39(7): p. 539-544.

156. Keith, I., et al., Asbestos-Induced Fibrosis in Rats: Increase in Lung Mast Cells and Autacoid Contents. Experimental Lung Research, 1987. 13(3): p. 311-327. 


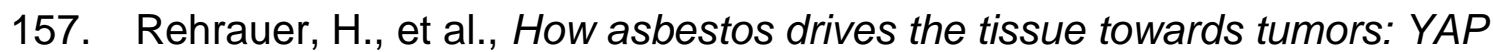
activation, macrophage and mesothelial precursor recruitment, RNA editing, and somatic mutations. Oncogene, 2018. 37(20): p. 2645-2659.

158. Bissonnette, E. and M. Rola-Pleszczynski, Pulmonary inflammation and fibrosis in a murine model of asbestosis and silicosis. Possible role of tumor necrosis factor. Inflammation, 1989. 13(3): p. 329-39.

159. Bozelka, B.A., et al., A murine model of asbestosis. Chest, 1983. 83(5 Suppl): p. 9S-10S.

160. Gualtieri, A.F., Sharing different perspectives to understand asbestos-induced carcinogenesis: A comment to Jiang et al. (2016). 2017. 108(1): p. 156-157.

161. Otsuki, T., et al., Environmental factors and human health: fibrous and particulate substance-induced immunological disorders and construction of a healthpromoting living environment. Environmental health and preventive medicine, 2016. 21(2): p. 71-81. 


\section{Chapter 2. Characterization and harvesting of the Riebeckite and Tremolite Elongate Mineral Particles for Toxicological Studies}

\subsection{Introduction}

Currently it is not exactly clear from existing literature what characteristics of fibers are the major determinants of toxicity and how do they contribute to pathological outcomes associated with EMP exposures. Accumulated data suggests that fiber dose, number, dimensions, durability, surface reactivity, surface area, and their propensity to split into thin fibers in vivo are important mediators of asbestos-related diseases [1, 2]. The World Health Organization (WHO) considers EMPs longer than $5 \mu \mathrm{m}$ "critical" for lung pathology development [3]; however, there are propositions to only consider fibers longer than $10 \mu \mathrm{m}[4,5]$ as dangerous for human health. Bearing in mind the inferred importance of fiber dimensions, most of the exposure assessment methods for regulated EMPs are based on "counts". Thus, it is crucial to know exactly what must be counted and what should be "censored" during the counting process. This was brought up in a recent extensive review by Egilman et al. [6]. In 2011 the National Institute for Occupational Safety and Health (NIOSH) published its Current Intelligence Bulletin 62 Asbestos Fibers and Other Elongate Mineral Particles: State of the Science and Roadmap for Research. In the concluding part, this document has indicated two major research needs that have to be addressed: “...(1) for the asbestos minerals, development of a clearer understanding of the important dimensional and physicochemical determinants of pathogenicity; (2) for other EMPs, such as those from non-asbestiform habits of the asbestos minerals and erionite, development of a deeper understanding of the determinants of toxicity..."[7].

Accordingly, particle preparation is a crucial part of any studies aimed at investigating the toxicological properties, be it cell culture or animal models. In this chapter I would like to address the preparation and characterization of the asbestiform and non-asbestiform varieties of riebeckite and tremolite minerals, with an ultimate goal of obtaining respirable fiber size ranges similar to those encountered in workplace air and potentially respirable by the exposed human populations. Two amphiboles have been chosen for the study - riebeckite and tremolite. Both exist in asbestiform and non- 
asbestiform varieties, both have been implicated in the most severe health outcomes in humans, such as asbestosis, lung cancer, and mesothelioma. However, while riebeckite asbestos (also known as crocidolite) mostly causes lung cancer, tremolite is a much more potent inducer of mesothelioma. The two minerals are dissimilar in their chemical structure, specifically, iron content. Utilizing test articles of distinct crystal growth habits allowed us to investigate another important issue: only a handful of studies previously addressed the biological effects of EMPs with similar chemistry, but different geometry.

Since "counted" fibers are by protocol supposed to be greater than $5 \mu \mathrm{m}$ in length and have an aspect ratio (length to width) of 3:1 or greater. We have deemed necessary to achieve less than $3.0 \mu \mathrm{m}$ in diameter for all fibers, since this is a cutoff for reliable deep lung penetration. The procedure involved crushing massive mineral samples using a hydraulic press, sieving crushed minerals to harvest fine fractions, and hand-grinding using a mortar and pestle to obtain/produce fibers similar to those found in the workplace. Following the generation of fibers, parameters concerning fiber length, width, and aspect ratio (length:width) was determined by Phase Contrast Microscopy (PCM) and Transmission Electron Microscopy (TEM). Altogether, a combination of light microscopy, electron microscopy, and X-ray methods was used to characterize physical parameters of particles and chemical composition.

\subsection{Materials and Methods}

\subsubsection{Raw materials description and sources}

Obtaining relevant test articles relies heavily on the relevant initial bulk samples source. For this study we have chosen four reliable sources of representative asbestiform and non-asbestiform EMPs. In 1990 U.S. Bureau of Mines prepared non-asbestiform tremolite samples for the National Institute of Environmental Health Sciences (NIEHS). they were used in rat oral ingestion studies to investigate the oral toxicity [8]. Union Internationale Centre le Cancer (UICC) riebeckite asbestos (crocidolite) was supplied by Research Triangle Institute (RTI International). Non-asbestiform riebeckite was originally obtained by NIOSH from Pikes Peak in Colorado Springs, Colorado. Tremolite asbestos was sourced from Lone Pine, California, also by NIOSH.

\subsubsection{Preparation of the test articles}


Cleavage fragments were prepared from the bulk material as follows: each bulk specimen was crushed to centimeter-sized fragments using a hydraulic press. The material was sieved progressively through $1 \mathrm{~mm}$ (No. 18), $364 \mu \mathrm{m}$ (No. 45), and $250 \mu \mathrm{m}$ (No. 60) sieve pans. The material passing through the finest sieve was then weighed and divided into aliquots approximately 2 grams each. These were then ground by mortar and pestle with minimal hand pressure. Periodically mineral grains were mounted on a glass slide in a refractive index oil and examined by polarized light microscopy (PLM) to observe the range of particle sizes present. When a minimum of $5 \mu \mathrm{m}$ long and a maximum of $3 \mu \mathrm{m}$ wide particles were observed, the grinding was stopped. The resultant material was weighed and reserved for suspension and filtration. Suspensions was poured into a $2 \mathrm{~L}$ graduated cylinder with a magnetic stir plate, made to a volume of $2 \mathrm{~L}$ of deionized water (with two drops of Liquinox detergent), and stirred for 5 minutes. A $10 \mathrm{~mL}$ aliquot of the suspension was drawn from the $1200 \mathrm{~mL}$ level of the graduated cylinder at increments of 5, 7, 10, 20, and 30 minutes, and 1, 2, 5, and 21 hours. Each aliquot was placed in a clean $50 \mathrm{ml}$ beaker, and then $1 \mathrm{ml}$ aliquots of each drawn suspension were immediately pipetted on to the filtration system. Aliquots were deposited on $25-\mathrm{mm}$ diameter $0.45 \mu \mathrm{m}$ mixed cellulose ester (MCE) filters using a 6-station filtration manifold. Filters were allowed to dry on a slide warmer. A quarter of each filter was placed on a labeled slide and collapsed using an acetone vaporizer. Slides were examined to note the characteristics of the particle population, the presence of elongate particles and cleavage fragments, and the density of the particle population. Following the exploratory phase of the work, the sample was re-stirred for 5 minutes, and the clock was restarted. The sample was allowed to settle for 30 minutes, at which time ten 20 -ml aliquots were placed in the vacuum filtration funnel and filtered for harvest and for analysis by TEM. This process was repeated five times to harvest at least 100 milligrams. Schematic representation of the process is presented on Figure 2.1.

Riebeckite asbestos particles were already supplied in respirable range and thus did not require mechanical preparation, but only characterization. Tremolite asbestos bulk material was crushed by a hydraulic press, sieved, and ground using a ball mill until sufficient amount of EMPs with the desired dimensions were observed under polarized 
light microscopy. Samples were then suspended in a mixture of deionized water and isopropanol and filtered through $0.45 \mu \mathrm{m}$ mixed cellulose ester (MCE) filters.

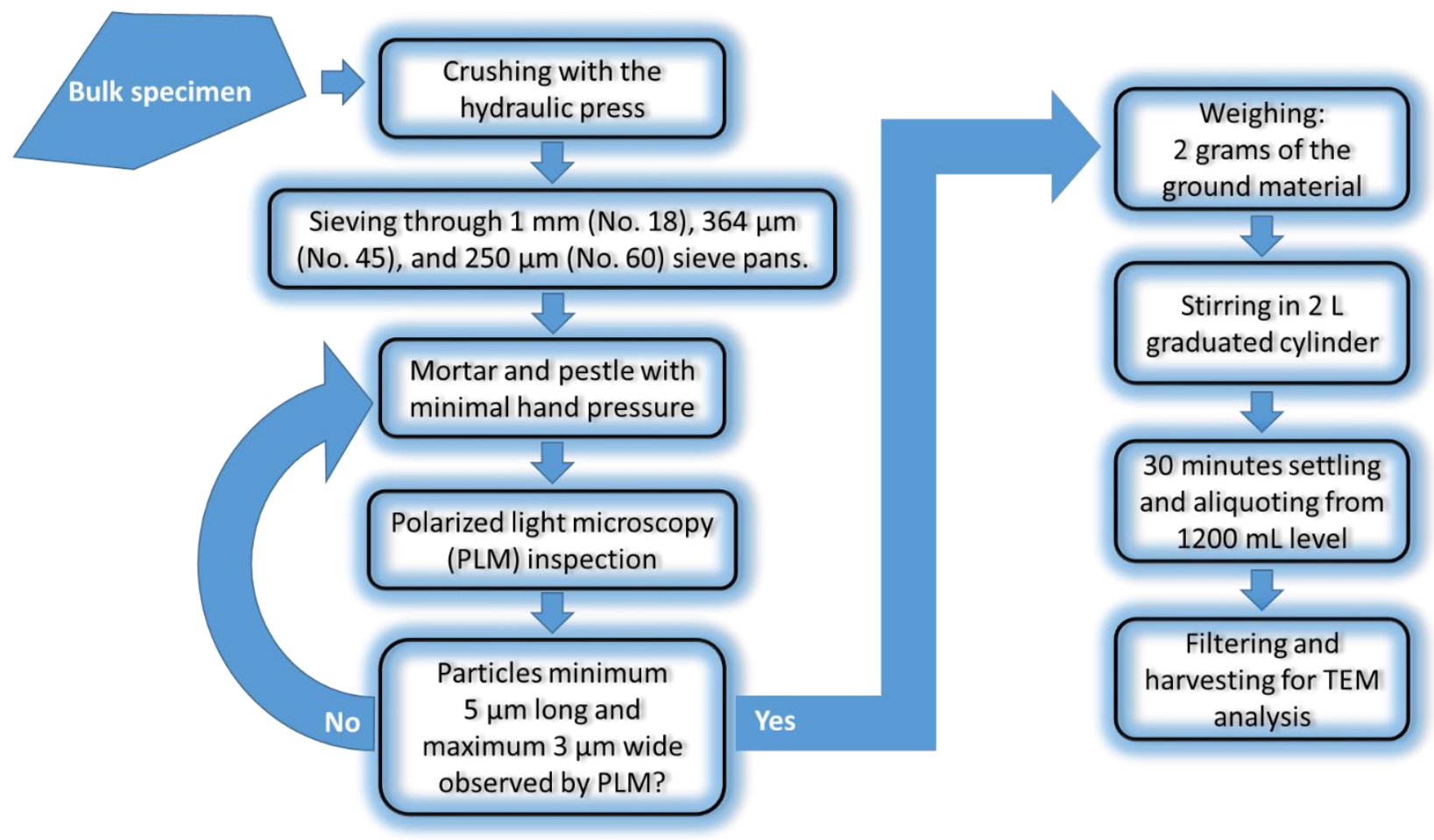

Figure 2.1. Schema for preparation and harvesting of the cleavage fragments.

\subsubsection{Polarized Light Microscope Alignment}

PCM analysis (400x) - to estimate the length and diameter during the harvesting step was performed using a standard Walton-Beckett graticule (as described in $\mathrm{NIOSH}$ 740024). The Olympus BX50 polarized light microscope used for the analysis of the mineral samples for the NIOSH project was aligned prior to use per Analytical Sciences SOP No. 1609-001, "Aligning the Polarized Light Microscope," to obtain the most accurate measurements possible. The alignment included centering the objectives, aligning the substage condenser, aligning the polarizer and analyzer, and aligning the ocular crosshairs. Photomicrographs acquired using an Olympus BX50 polarized light microscopes (Olympus America, Center Valley, PA), were used to estimate optical properties of the fibers such as extinction angle and refractive indices of several fibers $(n=\sim 10-20)$. Further, spindle stage analysis under PLM was used to determine and 
confirm whether individual fibers from the samples contain polycrystalline bundles or single fibrils, or cleavage fragments from larger crystals.

\subsubsection{TEM measurements:}

TEM particle characterization was performed using a Hitachi 7000 analytical electron microscope with AMT XR280 digital camera. Particles were measured at an on-screen magnification ranging from $4570 \mathrm{X}$ to $21,900 \mathrm{X}$. Three TEM grids were prepared from each of the mineral samples. Each grid square analyzed was traversed from left to right. At least 700 particles were measured in each sample. Length and width measurements in microns and aspect ratio for each particle were registered. From that data approximate surface areas of individual particles were calculated using the formula $4 *$ (length* width $)+2 *($ width $*$ width $)$. The length and width of each fiber were measured using a calibrated image from the AMT XR280 digital camera. We were basing our calculations on the established numbers. 550 would be the Minimal number of particles (MNP) necessary for determination of the percentage distributions. 100 would be the MNP required for determination of the shape descriptors [9]. Figure 2.2. contains the example of microphotograph used for measurements. Elemental makeup of the studied EMPs was determined by energy-dispersive spectroscopy (EDS) detector Such analysis allowed determining the similarities and differences in the cleavage planes of these fibers, which are critical for obtaining parameters concerning their cleavage fragments. 


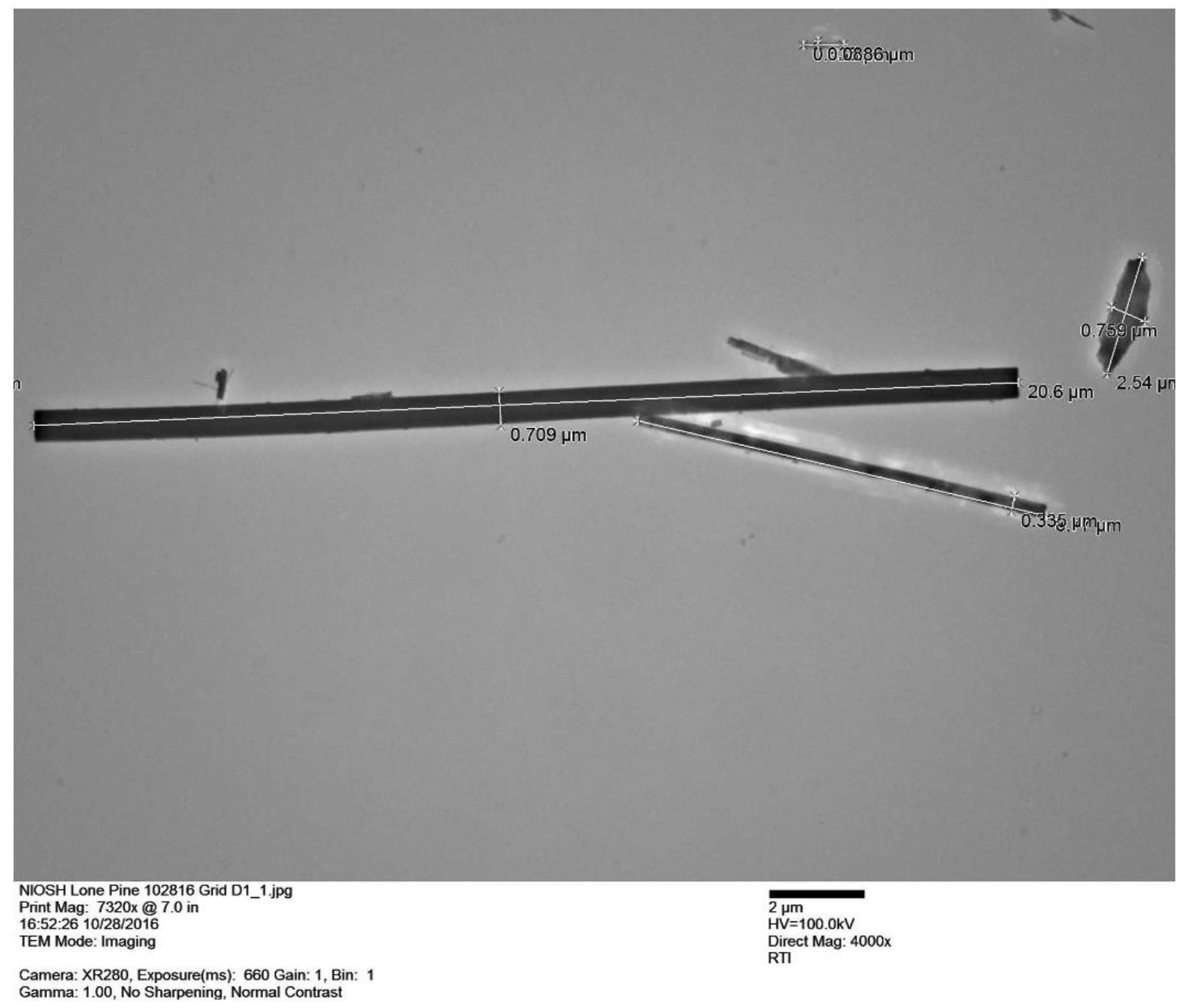

Figure 2.2. Measuring the lengths and widths of tremolite EMPs harvested during the study using TEM microphotographs.

\subsubsection{Gravimetric Analysis}

The Mettler PG503 balance was used to weigh the subsamples before and after each step of sample reduction. It was calibrated before each use as prescribed by SOP No. 0100-001 "Calibration and Operation of Mettler PG503 Balance." The balance is calibrated using a pair of NIST-traceable 0.020-gram and 200-gram reference weights that are recertified annually by Troemner.

\subsection{Results and discussion}




\subsubsection{Morphology of the acquired samples}

TEM analysis offers the highest resolution and the most accurate identification capabilities in the case of EMPs. It allows detection of particle shape and structure down to the individual fibrils. Hence, we used it to calculate the approximate surface areas and masses of individual particles, based on known density values. Representative microphotographs of the harvested EMPs can be seen on Figure 2.3.
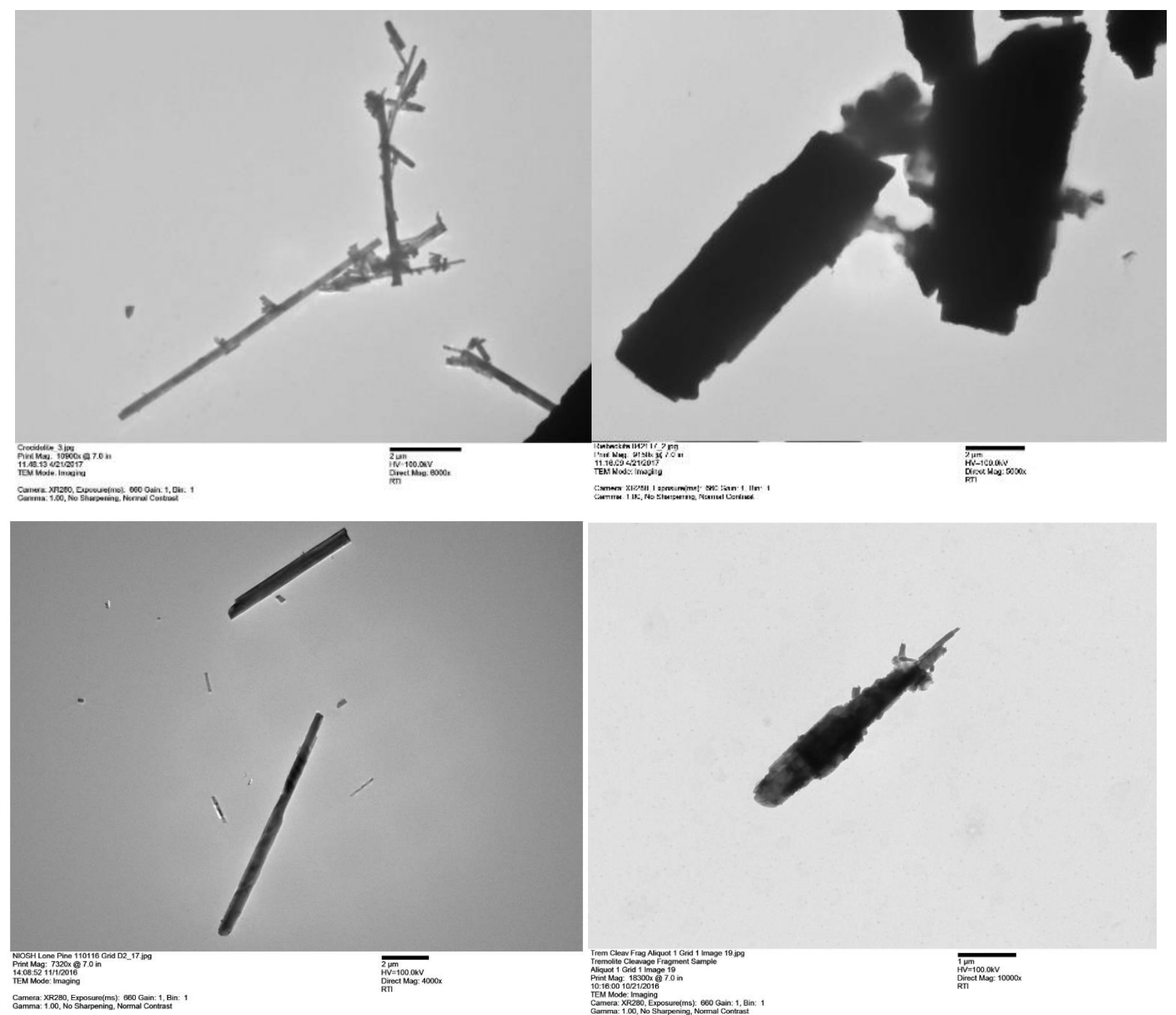

Figure 2.3. A - Riebeckite asbestos. B - Riebeckite CF. C - Tremolite asbestos, 4,000x Magnification. D - Tremolite CF, 10,000x Magnification.

Detailed particle characteristics summaries and size distribution charts were prepared after measuring at least 700 individual particles on TEM photographs. The summaries are listed in Tables 2.1-2.4. 
Table 2.1. Summary Statistics for Riebeckite Asbestos Particle Size Data TEM (2,000X to $10,000 X$ Magnification)

\begin{tabular}{llllll}
\hline \multicolumn{2}{l}{ Length (microns) } & \multicolumn{2}{l}{ Width (microns) } & \multicolumn{2}{l}{ Aspect Ratio } \\
\hline Mean & 6.36 & Mean & 0.34 & Mean & 23.72 \\
Standard & & Standard & & Standard & \\
Error & 0.24 & Error & 0.01 & Error & 1.18 \\
Median & 4.43 & Median & 0.26 & Median & 15.68 \\
Mode & 15.60 & Mode & 0.15 & Mode & 14.14 \\
Standard & & Standard & & Standard & \\
Deviation & 6.61 & Deviation & 0.29 & Deviation & 32.71 \\
Sample & & Sample & & Sample & \\
Variance & 43.74 & Variance & 0.08 & Variance & 1070.01 \\
Kurtosis & 19.66 & Kurtosis & 27.56 & Kurtosis & 166.18 \\
Skewness & 3.57 & Skewness & 4.06 & Skewness & 10.12 \\
Range & 62.53 & Range & 3.23 & Range & 633.66 \\
Minimum & 0.67 & Minimum & 0.03 & Minimum & 2.70 \\
Maximum & 63.20 & Maximum & 3.26 & Maximum & 636.36 \\
Sum & 4885.58 & Sum & 258.77 & Sum & 18215.96 \\
Count & 768 & Count & 768 & Count & 768 \\
\hline
\end{tabular}

Table 2.2. Summary Statistics for Riebeckite CF Particle Size Data $\operatorname{TEM}(2,000 \mathrm{X}$ to $10,000 \mathrm{X}$ Magnification)

\begin{tabular}{llllll}
\hline \multicolumn{2}{l}{ Length (microns) } & \multicolumn{2}{l}{ Width (microns) } & \multicolumn{2}{l}{ Aspect Ratio } \\
\hline Mean & 6.09 & Mean & 1.88 & Mean & 3.69 \\
Standard & & Standard & & Standard & 0.07 \\
Error & 0.11 & Error & 0.04 & Error & 3.20 \\
Median & 5.45 & Median & 1.74 & Median & 3.07 \\
Mode & 10.20 & Mode & 1.18 & Mode & \\
Standard & & Standard & & Standard & 1.89 \\
Deviation & 3.28 & Deviation & 1.02 & Deviation & \\
Sample & & Sample & & Sample & 3.58 \\
Variance & 10.75 & Variance & 1.03 & Variance & 7.84 \\
Kurtosis & 2.88 & Kurtosis & 0.55 & Kurtosis & 2.13 \\
Skewness & 1.32 & Skewness & 0.78 & Skewness & 17.38 \\
Range & 22.74 & Range & 6.44 & Range & 1.12 \\
Minimum & 0.96 & Minimum & 0.14 & Minimum \\
Maximum & 23.70 & Maximum & 6.58 & Maximum & 18.50 \\
Sum & 5052.01 & Sum & 1556.76 & Sum & 3063.01 \\
Count & 829 & Count & 829 & Count & 829 \\
\hline
\end{tabular}


Table 2.3. Summary Statistics for Tremolite Asbestos Particle Size Data $\operatorname{TEM}(2,000 \mathrm{X}$ to $10,000 \mathrm{X}$ Magnification)

\begin{tabular}{llllll}
\hline \multicolumn{2}{l}{ Length (microns) } & \multicolumn{3}{l}{ Width (microns) } & \multicolumn{2}{l}{ Aspect Ratio } \\
\hline Mean & 6.56 & Mean & 0.31 & Mean & 25.73 \\
Standard Error & 0.21 & Standard Error & 0.01 & Standard Error & 0.92 \\
Median & 4.65 & Median & 0.25 & Median & 17.20 \\
Mode & 1.75 & Mode & 0.17 & Mode & 10.30 \\
Standard & & Standard & & Standard & \\
Deviation & 6.13 & Deviation & 0.22 & Deviation & 26.29 \\
Sample & & Sample & & Sample & \\
Variance & 37.53 & Variance & 0.05 & Variance & 691.38 \\
Kurtosis & 11.67 & Kurtosis & 12.11 & Kurtosis & 40.12 \\
Skewness & 2.69 & Skewness & 2.63 & Skewness & 4.47 \\
Range & 54.40 & Range & 2.12 & Range & 360.00 \\
Minimum & 0.61 & Minimum & 0.02 & Minimum & 2.00 \\
Maximum & 55.00 & Maximum & 2.14 & Maximum & 362.00 \\
Sum & 5362.24 & Sum & 253.29 & Sum & 21024.96 \\
Count & 817 & Count & 817 & Count & 817 \\
\hline
\end{tabular}

Table 2.4. Summary Statistics for Tremolite CF Particle Size Data $\operatorname{TEM}(2,000 X$ to $10,000 X$ Magnification)

\begin{tabular}{llllll}
\hline \multicolumn{2}{l}{ Length (microns) } & \multicolumn{2}{l}{ Width (microns) } & \multicolumn{2}{l}{ Aspect Ratio } \\
\hline Mean & 7.71 & Mean & 1.83 & Mean & 6.51 \\
Standard & & Standard & & Standard & \\
Error & 0.24 & Error & 0.07 & Error & 0.29 \\
Median & 5.59 & Median & 1.11 & Median & 4.93 \\
Mode & 10.50 & Mode & 1.19 & Mode & 3.33 \\
Standard & & Standard & & Standard & \\
Deviation & 6.38 & Deviation & 1.95 & Deviation & 7.57 \\
Sample & & Sample & & Sample & \\
Variance & 40.71 & Variance & 3.81 & Variance & 57.35 \\
Kurtosis & 2.99 & Kurtosis & 4.73 & Kurtosis & 116.48 \\
Skewness & 1.71 & Skewness & 2.04 & Skewness & 8.99 \\
Range & 33.00 & Range & 13.39 & Range & 125.07 \\
Minimum & 0.70 & Minimum & 0.01 & Minimum & 1.00 \\
Maximum & 33.70 & Maximum & 13.40 & Maximum & 126.07 \\
Sum & 5429.00 & Sum & 1289.09 & Sum & 4580.69 \\
Count & 704 & Count & 704 & Count & 704 \\
\hline
\end{tabular}


Size distribution charts for all 4 tested materials are available in the Appendix A. The output data included frequency distribution of lengths, widths, and aspect ratios of the studied test articles.

Relatively few EMPs with diameters larger than $\sim 3 \mu \mathrm{m}$ will penetrate into the lungs [10], but those with diameters less than $0.1 \mu \mathrm{m}$ are also less retained in the lungs compared to larger diameters [11]. All EMPs had widths less than $3 \mu \mathrm{m}$, with much smaller median numbers for asbestiform varieties, which was unsurprising. However, if applied to the macrophage functions, diameter of the fiber does not affect phagocytosis or internalization [12]. It was obvious that the surface areas of individual EMPs will be quite dissimilar between respective habits. TEM measurements data allowed us to find approximate volumes, masses and surface areas of individual EMPs, using the respective formulas:

Volume $=$ length $*$ width $*$ width

Mass $=$ Volume $*$ density

Surface Area $=4 *($ length $*$ width $)+2 *($ width $*$ width $)$.

The comparative surface areas for "critical" fibers and non-fibers are listed in Table 2.5. Again, unsurprisingly, asbestiform varieties had much higher surface areas per unit of weight.

Table 2.5. The total number and surface areas of particles in the test articles, including "critical" fibers, having length $>5 \mu \mathrm{m}$ and aspect ratio of $\geq 3: 1$, per $120 \mu \mathrm{g}$ of dry bulk preparations. CF - Cleavage Fragments.

\begin{tabular}{|l|l|r|r|r|}
\hline & \multicolumn{2}{|c|}{ Total number } & \multicolumn{1}{c|}{$\begin{array}{c}\text { Total surface area of } \\
\text { all particles, } \mathbf{~ c m} \mathbf{2} / \mathbf{g}\end{array}$} & $\begin{array}{r}\text { Total surface area of } \\
\text { critical fibers, } \mathbf{~ c m}^{\mathbf{2}} \mathbf{g}\end{array}$ \\
\cline { 1 - 2 } Per $\mathbf{1 2 0} \boldsymbol{\mu g}$ & Fibers & Non-fibers & $2.43 \mathrm{E}+04$ & $2.02 \mathrm{E}+04$ \\
\hline Tremolite & $1.48 \mathrm{E}+07$ & $4.68 \mathrm{E}+08$ & $1.15 \mathrm{E}+04$ & $9.91 \mathrm{E}+03$ \\
\hline Riebeckite & $4.88 \mathrm{E}+06$ & $4.21 \mathrm{E}+08$ & $2.94 \mathrm{E}+03$ & $1.68 \mathrm{E}+03$ \\
\hline Tremolite CF & $2.83 \mathrm{E}+05$ & $1.10 \mathrm{E}+06$ & $5.11 \mathrm{E}+03$ & $2.47 \mathrm{E}+03$ \\
\hline Riebeckite CF & $7.77 \mathrm{E}+05$ & $3.88 \mathrm{E}+06$ & &
\end{tabular}

The importance of surface area calculation stems from the nature of mineral-cell interactions, that depend on active sites present on that surface, microscopic topography 
and surface charge of the mineral particles [13]. Dangling bonds, silanol groups, and unoccupied cation coordination sites can all lead to drastic changes in redox environment around EMPs. Previously it was found that both riebeckite and tremolite fibers exhibit sustained surface reactivity, and in both studied minerals free radical production does not depend on total iron content, but rather on specific $\mathrm{Fe}^{2+}$ and $\mathrm{Fe}^{3+}$ sites on the surface [14]. Upon incubation with $\mathrm{H}_{2} \mathrm{O}_{2}$ - simulating the lysosomal conditions - hydroxyl radical yield from tremolite significantly dropped by 24 hours, as opposed to significant increase in riebeckite fibers, but sustained radical reactivity of tremolite continued for quite a long time (especially the COO-• production) [14].

\subsubsection{Chemical composition.}

The EDS analysis showed elemental signatures to be predominantly $\mathrm{Si}, \mathrm{Fe}, \mathrm{Mg}$, $\mathrm{Na}$, and $\mathrm{O}$ for riebeckite EMPs, and $\mathrm{Si}, \mathrm{Ca}, \mathrm{Mg}$, and $\mathrm{O}$ with only trace $\mathrm{Fe}$ for tremolite particles (Figure 2.4.). Cu signal comes from the copper grids utilized in the process. Previous studies on crocidolite toxicity suggested that the chemistry, presumably the high iron content, is important not only for cytotoxicity per se, but also for a set of biological effects, such as transcriptional activation of iNOS. 


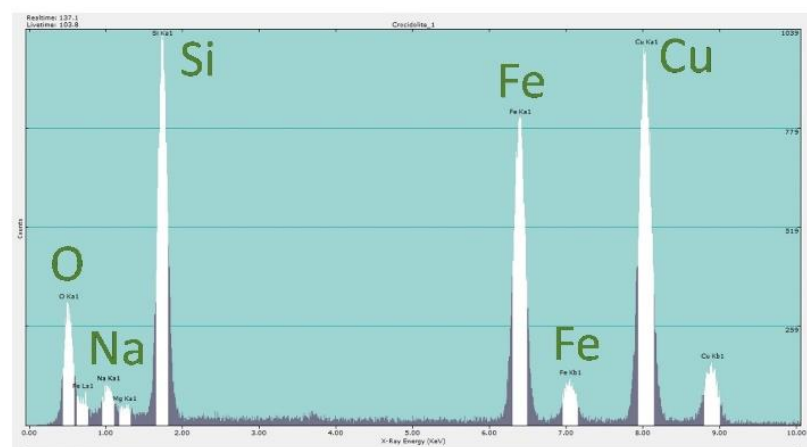

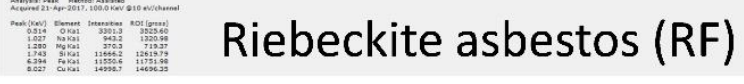

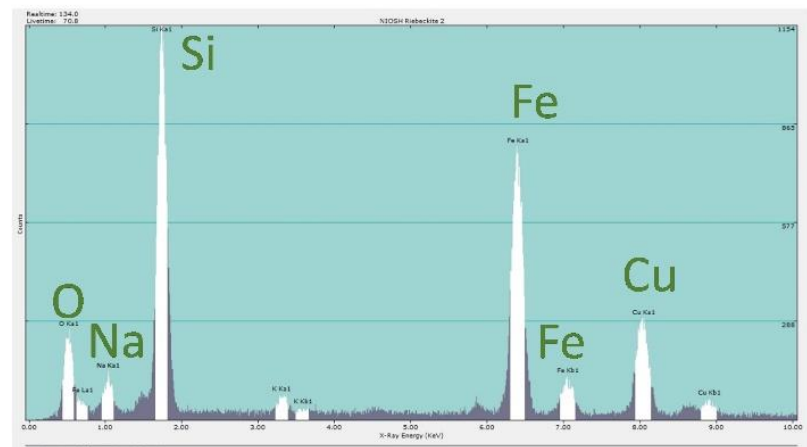

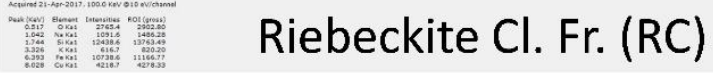

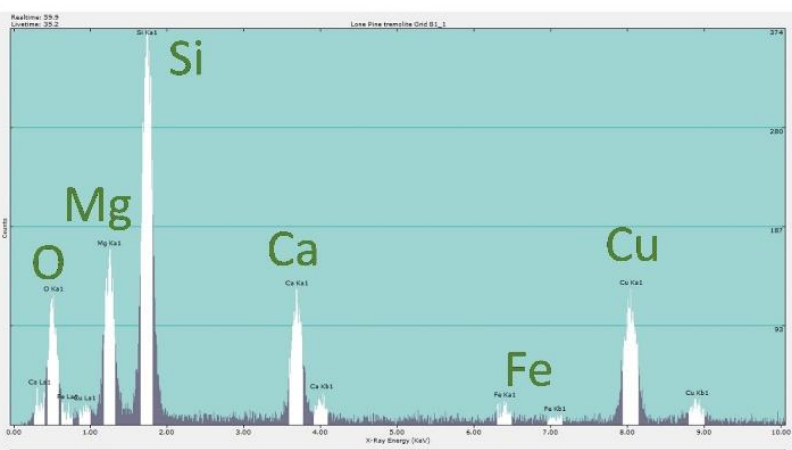

Tremolite asbestos (TF)

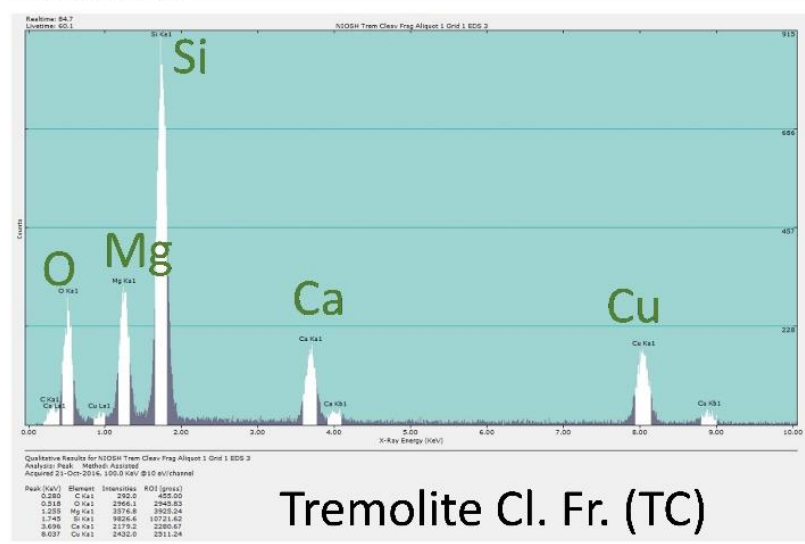

Figure 2.4. Representative EDS spectra of the studied EMPs. The highest peaks have the associated element identifications. $\mathrm{RF}$ - riebeckite asbestos, $\mathrm{RC}$ - riebeckite cleavage fragments, TF - tremolite asbestos, TC - tremolite cleavage fragments

\subsubsection{Dose calculations for toxicological studies}

For the in vitro experiments with murine alveolar macrophages (MPI cells): Based on the TEM calculations, we recalculated the amount of "critical" fibers ( $>5 \mu \mathrm{m}$ in length, aspect ratio of $>3: 1)$ in the used EMP preparations per macrophage in the plates. $1 \mu \mathrm{g}$ of riebeckite asbestos contained $4.07 \times 10^{4}$ fibers, $1 \mu \mathrm{g}$ of tremolite asbestos contains 1.23 $x 10^{5}$. For the surface areas of individual wells of $9.6 \mathrm{~cm}^{2}$ and $0.32 \mathrm{~cm}^{2}$ and seeding densities of $1 \times 10^{6}$ and $3 \times 10^{4}$ per well for 6 -well plate and 96-well plate respectively, riebeckite asbestos dose $9 \mu \mathrm{g} / \mathrm{cm}^{2}$ had 3.5 fibers per cell. $6 \mu \mathrm{g} / \mathrm{cm}^{2}-2.5$ fibers per cell; tremolite asbestos dose $5 \mu \mathrm{g} / \mathrm{cm}^{2}$ had 6 fibers per cell. $1.2 \mu \mathrm{g} / \mathrm{cm}^{2}-1.5$ fibers per cell. From Stone et al. [15] - $6 \times 10^{9} \mathrm{AMs}$ per lungs in humans. 9-36 $\times 10^{9}$ total fibers - within the lifetime of significant population of workers as listed in Chapter 6.2 of the WHO 
guidelines on air quality [3]. For in vitro studies usually higher fiber doses are needed to observe the cytotoxic effects, but for mechanistic studies and gene expression profiling lower doses are more suitable [16].

For in vivo study we based off our dosing calculations on the suggested cancer risks at specific numbers of critical fibers per gram dry wight of the lung tissue - a threshold for cancer causation in humans. While there are no established limits in the US, Japan uses the following number of fibers for establishing the asbestos exposure and cancer risks: more than $2 \times 10^{6}$ per gram of dry weight for fibers longer than $5 \mu \mathrm{m}$ [17]. In the Finnish study researchers deemed that the highest odds ratio (9) for lung cancer in asbestos-exposed workers was achieved at fiber concentrations of more than $3 \times 10^{6}$ per gram of dry weight [18]. Assuming the human lungs weight of $\sim 840 \mathrm{~g}$ [19] and dry weight of $26 \% \sim 218.4 \mathrm{~g}$ [20], it is more than $4.37 \times 10^{8}$ fibers $>5 \mu \mathrm{m}$ in length per pair of lungs if using Japanese threshold value and $6.55 \times 10^{8}$ fibers $>5 \mu \mathrm{m}$ if using the Finnish study value. Again, it fits the workers' accumulated lifetime concentration. We used mouse wet lung weight of $0.13 \mathrm{~g}$ and dry weight of $0.0325 \mathrm{~g}$ [21]. Assuming the $20 \%$ loss of the microparticles administered via pharyngeal aspiration [22], and the riebeckite asbestos retention data [23] as $35 \%$ for fibers longer than $5 \mu \mathrm{m}$, at 1 year post-exposure, the mice receiving $120 \mu \mathrm{g}$ of riebeckite asbestos test article will have $4.2 \times 10^{7}$ critical fibers per gram of dry lung weight left. There was no data on what cleavage fragments retention would be, but if using the same approach as used for riebeckite fibers, tremolite cleavage fragment (having the least number of critical fibers per unit of mass) will have $8.72 \times 10^{6}$ $\times 0.8 \times 0.35=2.44 \times 10^{6}$ critical fibers per gram of dry lung weight, meaning that we can use $120 \mu \mathrm{g}$ as an equal mass-based dose. Considering the importance of surface area parameter in fiber toxicity paradigm, we also added to critical fiber surface-area equivalent

doses for riebeckite and tremolite asbestos and respective cleavage fragments (10 $\mu \mathrm{g} /$ mouse and 120 for tremolite asbestos and CF, $30 \mu \mathrm{g} /$ mouse and 120 for riebeckite asbestos and CF).

\subsection{Conclusions}

A detailed characterization of physical, chemical and structural characteristics of asbestiform fibers and corresponding mineral analog cleavage fragments is an essential 
step in determining the factors and mechanisms by which these fibers exert toxicity. Our approach allowed to: 1) harvest the required amount of the material for the testing, 2) obtain detailed information on the length-width ratios, variability in metal ion concentrations and chemical composition of the studied riebeckite and tremolite EMPs. Prepared EMP samples were characterized by the uniform median lengths and the sufficient amount of EMPs longer that $5 \mu \mathrm{m}$, which is a requirement for the "critical" fibers. Using the TEM measurements of particles, surface areas of the critical fibers were calculated to provide additional reference doses for the toxicological studies. Test articles were deemed appropriate for use in toxicological experiments in cell culture models and in vivo repeated pharyngeal aspiration exposure in mice.

\subsection{References}

1. Lippmann, M., Effects of Fiber Characteristics on Lung Deposition, Retention, and Disease. Environmental Health Perspectives, 1990. 88: p. 311-317.

2. Baron, P.A., Measurement of airborne fibers: A review. Industrial Health, 2001. 39(2): p. 39-50.

3. World Health, O., Air quality guidelines for Europe. WHO Reg Publ Eur Ser, 2000(91): p. V-X, 1-273.

4. Berman, D.W. and K.S. Crump, A meta-analysis of asbestos-related cancer risk that addresses fiber size and mineral type. Crit Rev Toxicol, 2008. 38 Suppl 1: $p$. 49-73.

5. Roggli, V.L., Measuring EMPs in the lung what can be measured in the lung: Asbestiform minerals and cleavage fragments. Toxicol Appl Pharmacol, 2018. 361: p. 14-17.

6. Egilman, D., et al., Health Effects of Censored Elongated Mineral Particles: A Critical Review. Detection Limits in Air Quality and Environmental Measurements. 2019, West Conshohocken, PA: ASTM International. 239-2019.

7. Middendorf, P., et al., Current intelligence bulletin 62: asbestos fibers and other elongate mineral particles: state of the science and roadmap for research. 2011, U.S. Department of Health and Human Services, Public Health Service, Centers for Disease Control and Prevention, National Institute for Occupational Safety and Health, DHHS (NIOSH) Cincinnati, OH. p. 173.

8. National Toxicology, P., NTP Toxicology and Carcinogenesis Studies of Tremolite (CAS No. 14567-73-8) in F344/N Rats (Feed Studies). Natl Toxicol Program Tech Rep Ser, 1990. 277: p. 1-183.

9. Souza, D.O.C. and F.C. Menegalli, Image analysis: Statistical study of particle size distribution and shape characterization. Powder Technology, 2011. 214(1): p. 57-63.

10. Lippmann, M., Man-made mineral fibers (MMMF): human exposures and health risk assessment. Toxicol Ind Health, 1990. 6(2): p. 225-46. 
11. Lippmann, M. and V. Timbrell, Particle Loading in the Human Lung-Human Experience and Implications for Exposure Limits. Journal of Aerosol Medicine, 1990. 3(s1): p. S-155-S-168.

12. Ishida, T., et al., Live-cell imaging of macrophage phagocytosis of asbestos fibers under fluorescence microscopy. Genes Environ, 2019. 41: p. 14.

13. Hochella, M. CHAPTER 8. SURFACE CHEMISTRY, STRUCTURE, AND REACTIVITY OF HAZARDOUS MINERAL DUST. 1993.

14. Andreozzi, G.B., et al., Surface reactivity of amphibole asbestos: a comparison between crocidolite and tremolite. Sci Rep, 2017. 7(1): p. 14696.

15. Stone, K.C., et al., Allometric relationships of cell numbers and size in the mammalian lung. Am J Respir Cell Mol Biol, 1992. 6(2): p. 235-43.

16. Nguea, H.D., et al., Macrophage culture as a suitable paradigm for evaluation of synthetic vitreous fibers. Crit Rev Toxicol, 2008. 38(8): p. 675-95.

17. Kohyama, N., et al., Lung cancer in a patient with predominantly short tremolite fibers in his lung. Am J Ind Med, 2017. 60(9): p. 831-838.

18. Karjalainen, A., et al., Asbestos exposure among Finnish lung cancer patients: occupational history and fiber concentration in lung tissue. Am J Ind Med, 1993. 23(3): p. 461-71.

19. Molina, D.K. and V.J.M. DiMaio, Normal Organ Weights in Men: Part II-The Brain, Lungs, Liver, Spleen, and Kidneys. The American Journal of Forensic Medicine and Pathology, 2012. 33(4).

20. Blaszczyk, M., et al., The relationships between dry and wet weight of lung and tumor tissues influenced by the drying procedure. Fresenius Environmental Bulletin 2016. 25(6): p. 1755-1759.

21. Wang, Y., et al., Transgenic Mice Overexpressing Peroxiredoxin 6 Show Increased Resistance to Lung Injury in Hyperoxia. 2006. 34(4): p. 481-486.

22. Rao, G.V., et al., Efficacy of a technique for exposing the mouse lung to particles aspirated from the pharynx. J Toxicol Environ Health A, 2003. 66(15): p. 144152.

23. Musselman, R.P., et al., Biopersistences of man-made vitreous fibers and crocidolite fibers in rat lungs following short-term exposures. Environmental health perspectives, 1994. 102 Suppl 5(Suppl 5): p. 139-143. 


\section{Supplementary Materials}

\section{Size distribution charts for the studied EMP preparations}

Frequency distribution of aspect ratios, lengths and widths for riebeckite asbestos particles. Measured by TEM $(2,000$ to 10,000X Magnification), $n=768$

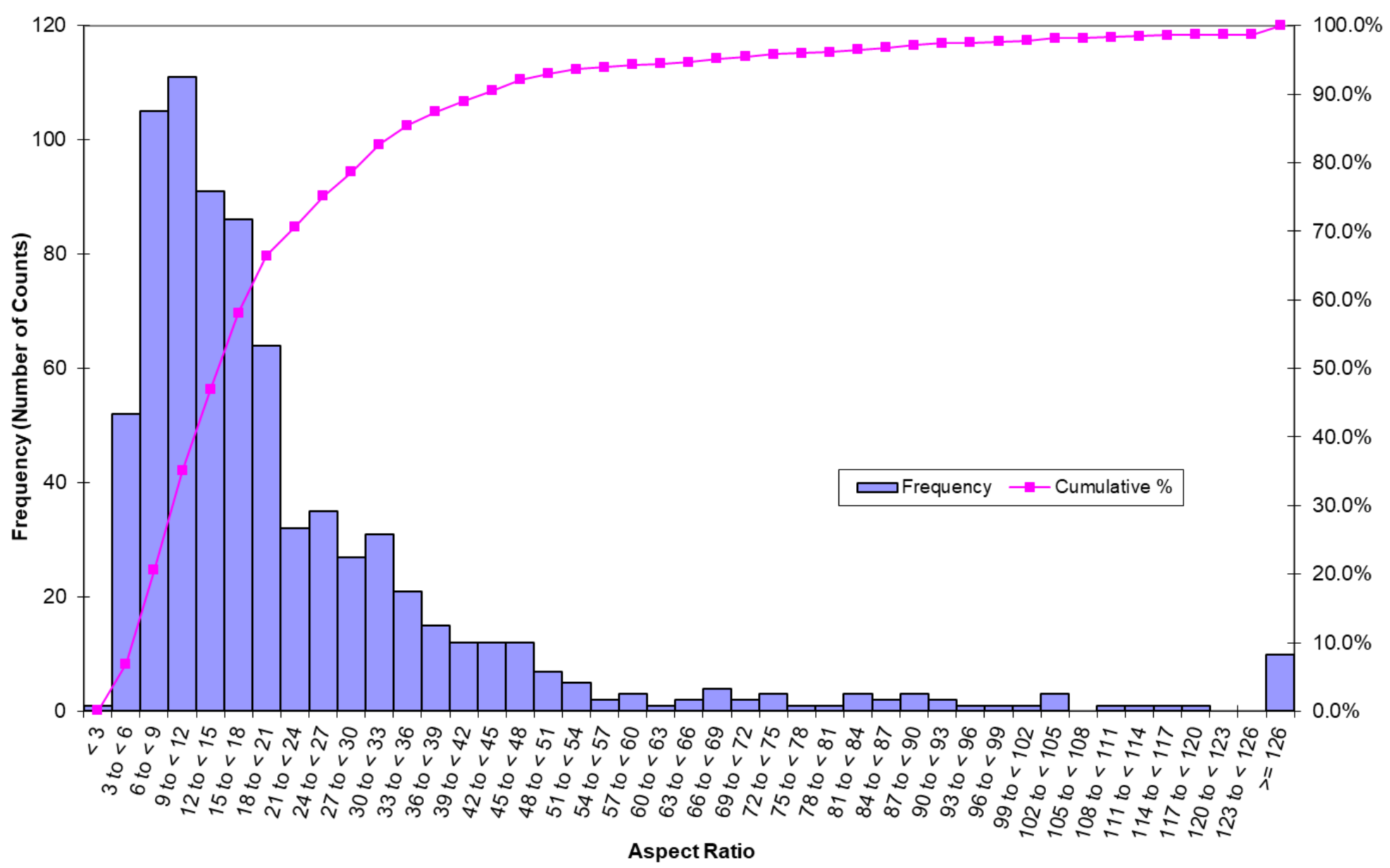




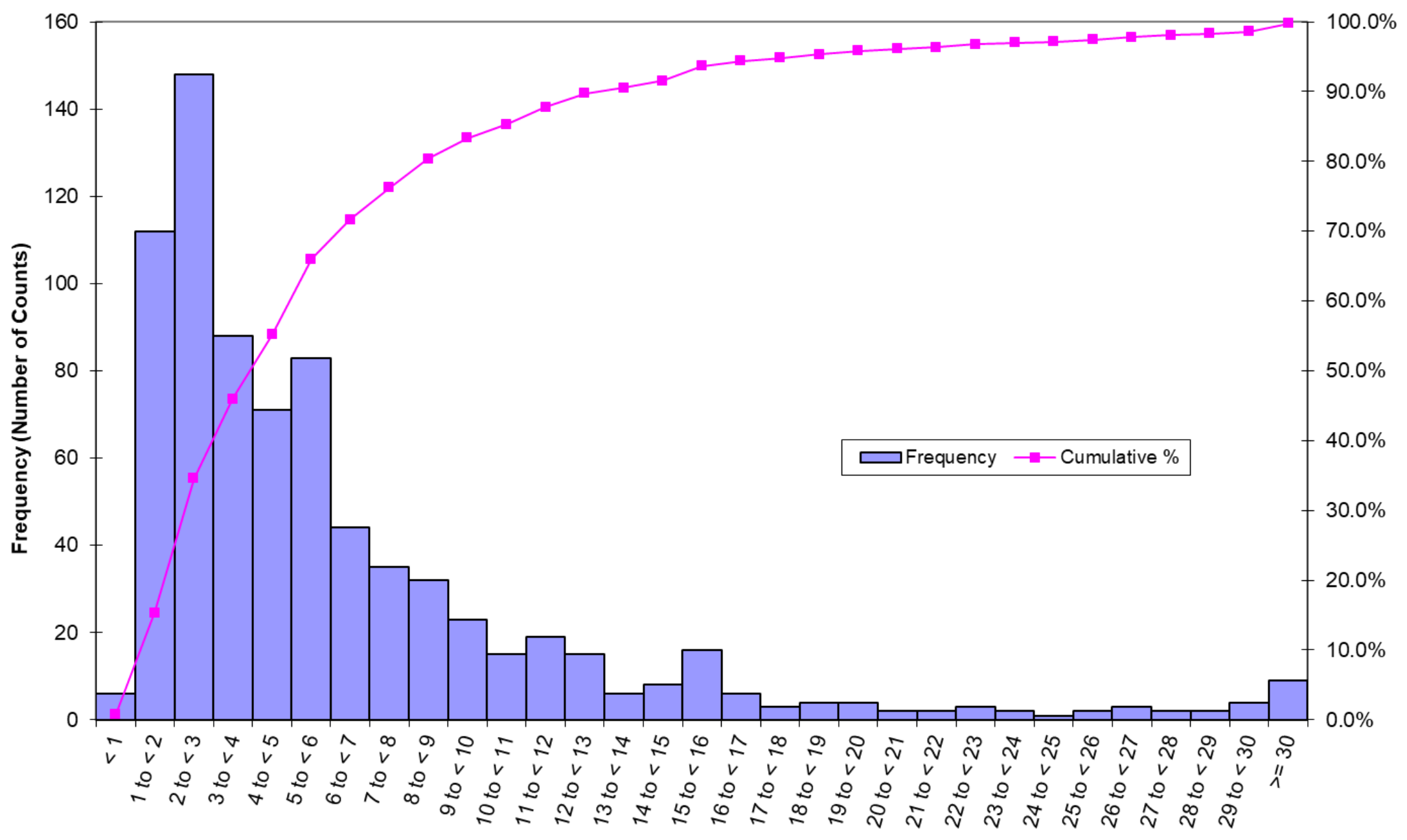

Length (microns) 


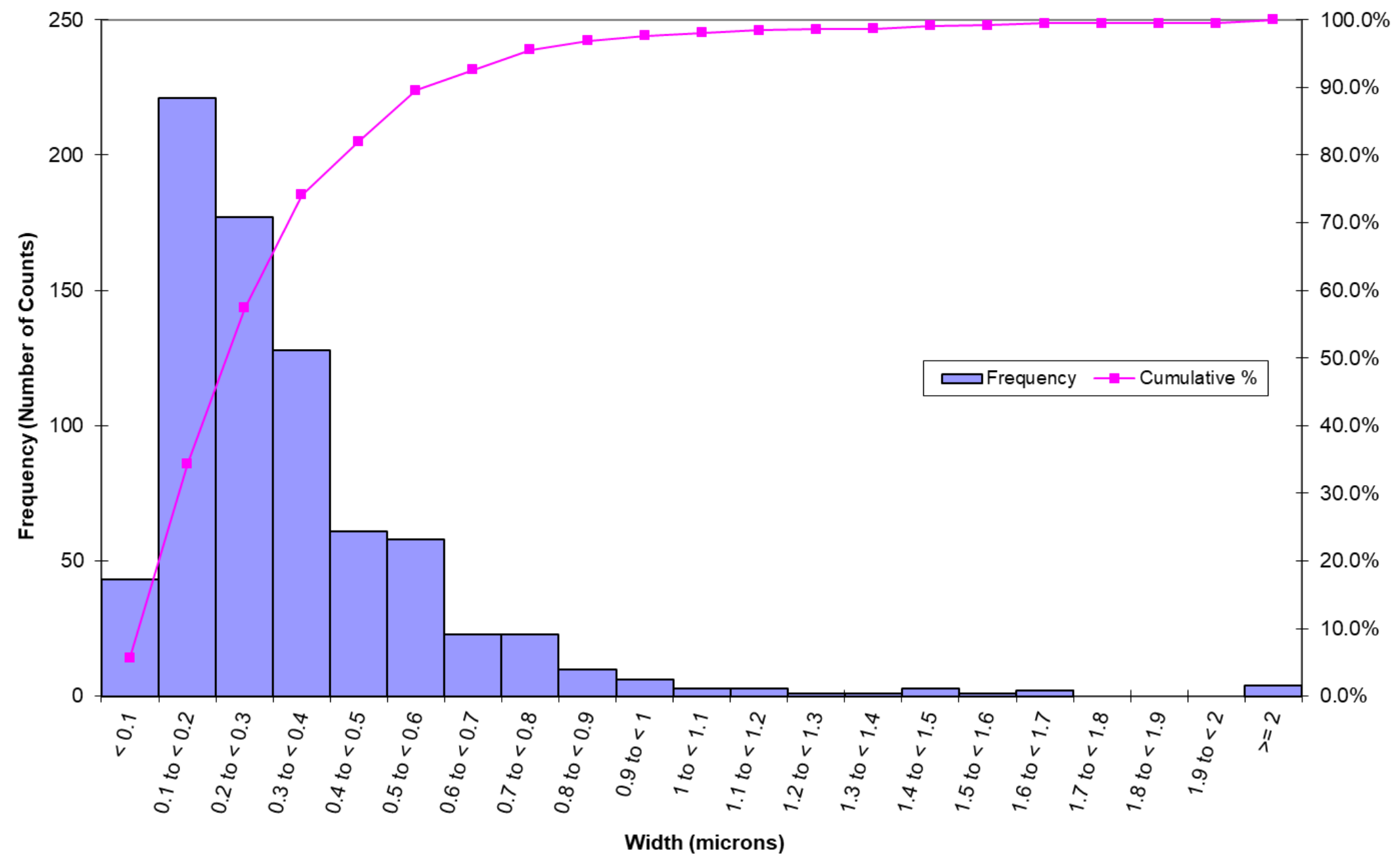


Frequency distribution of aspect ratios, lengths and widths for riebeckite cleavage fragments. Measured by TEM $(2,000$ to $10,000 X$ Magnification), $\mathrm{n}=829$

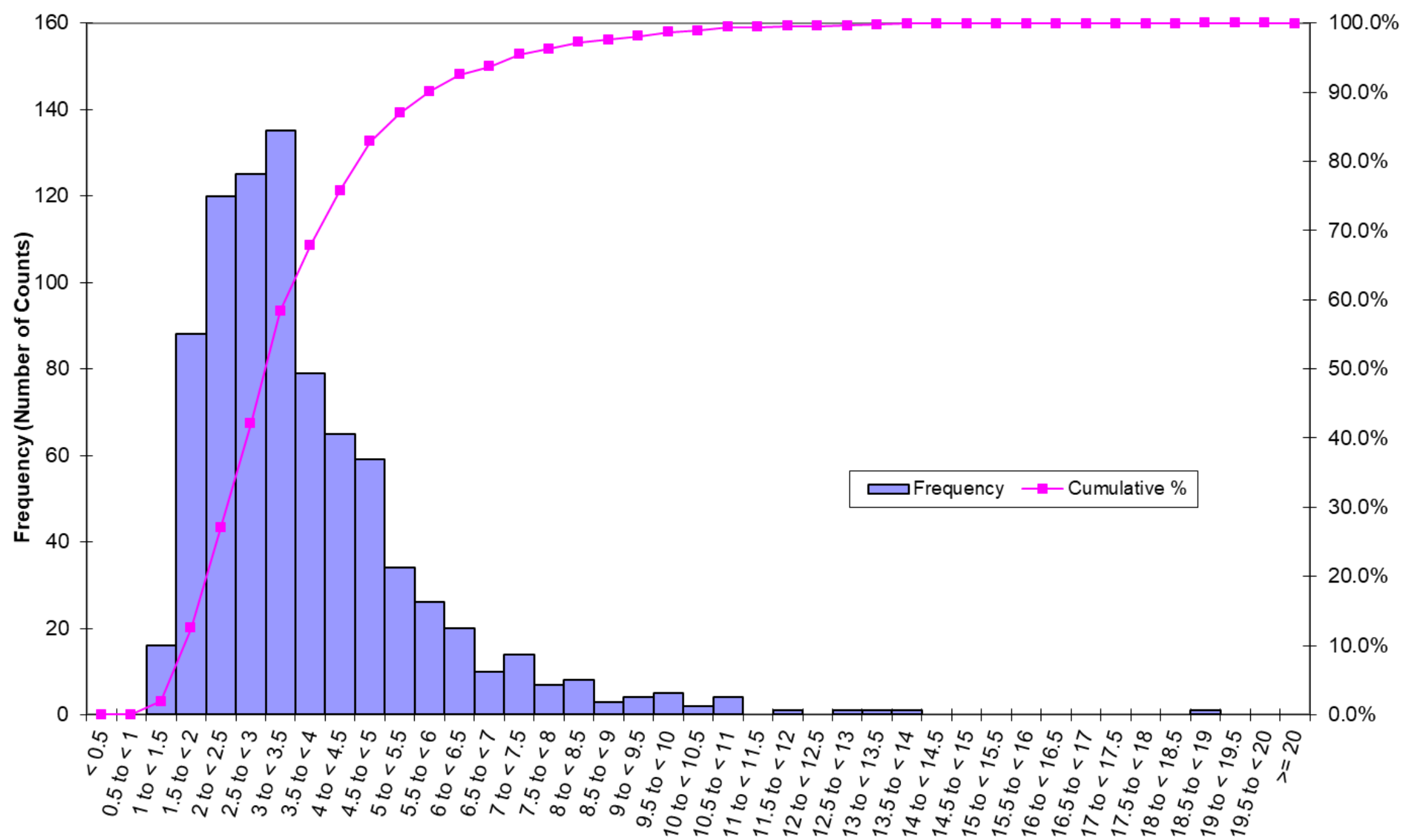

Aspect Ratio 


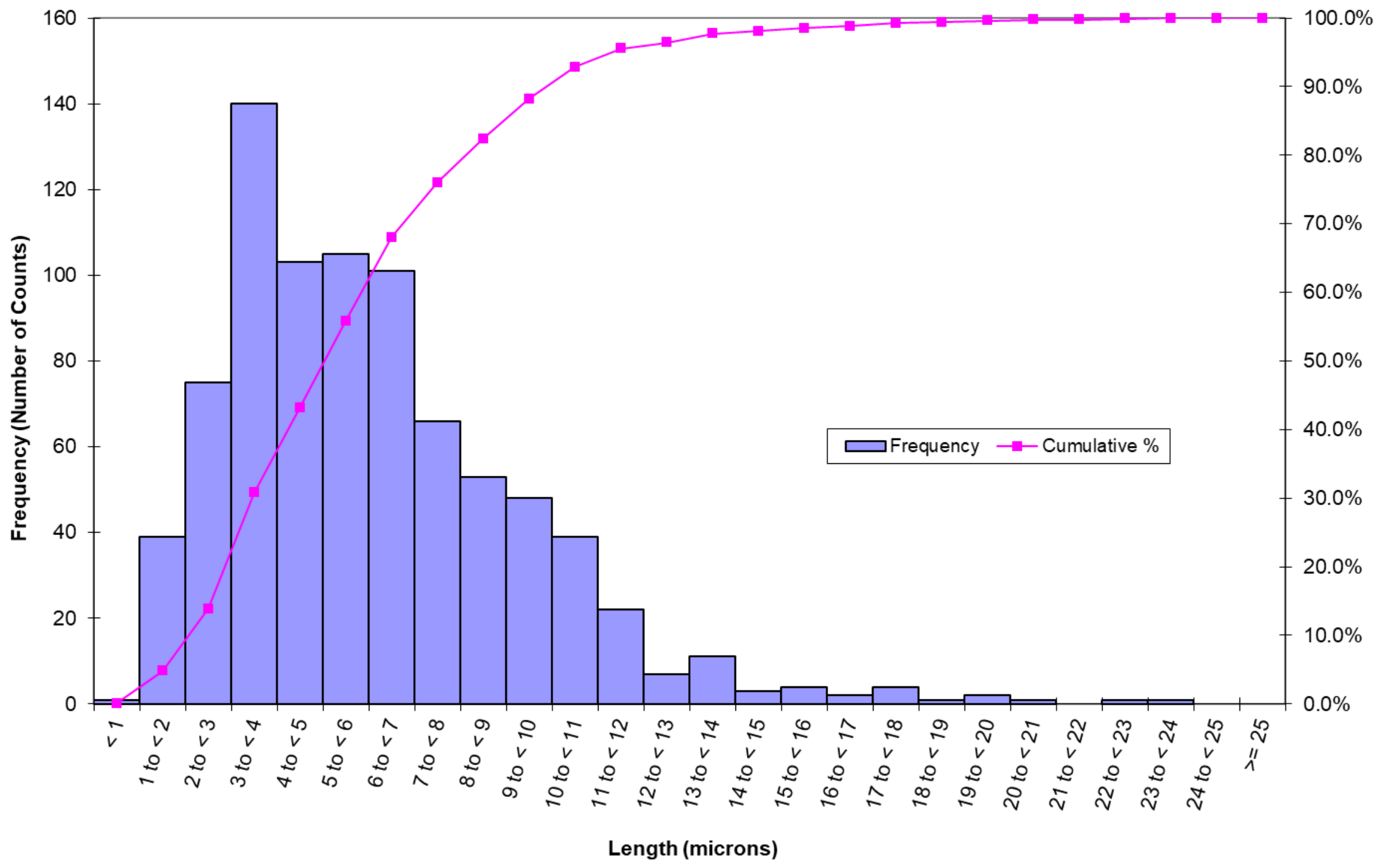




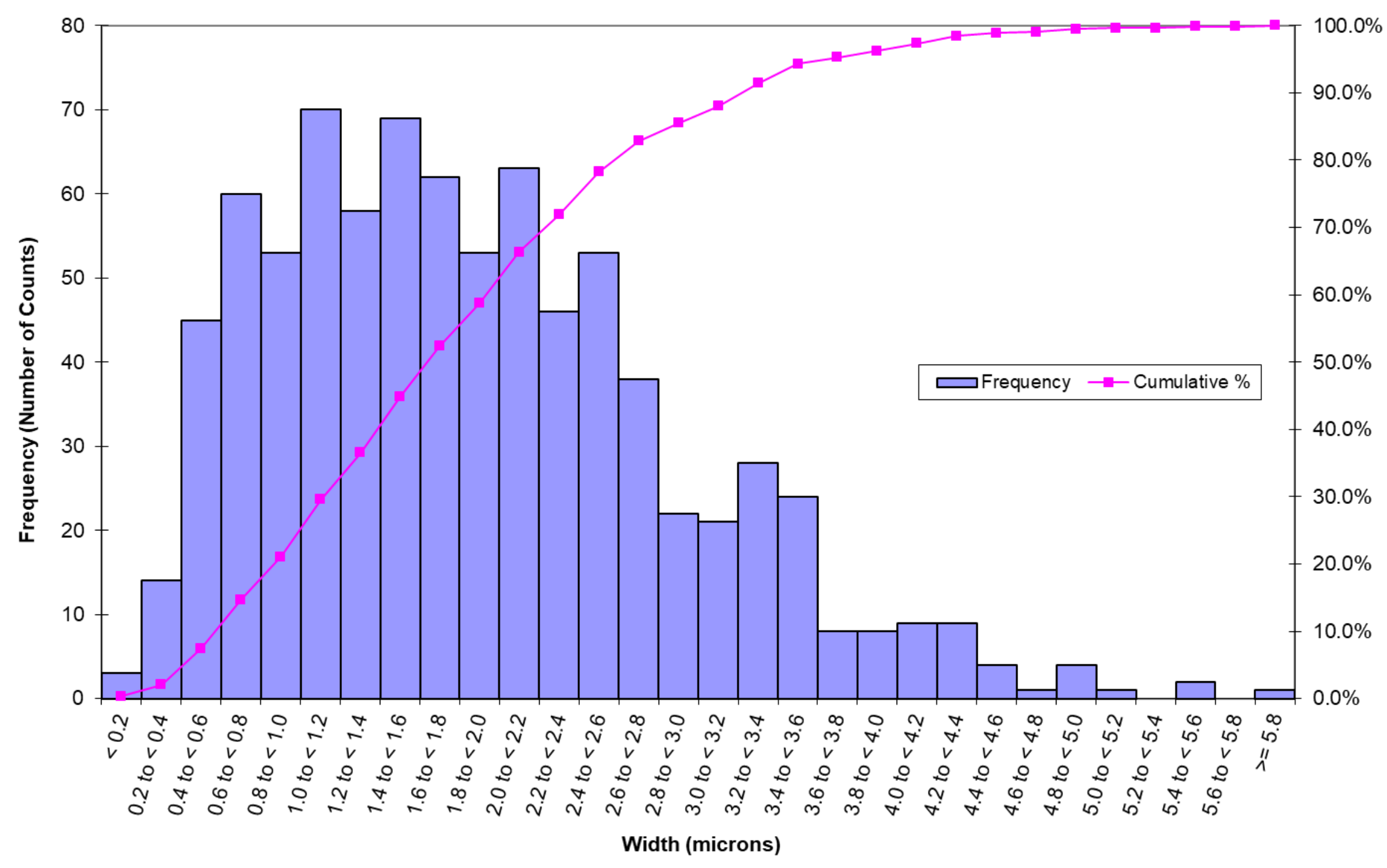


Frequency distribution of aspect ratios, lengths and widths for tremolite asbestos particles. Measured by TEM $(2,000$ to 10,000X Magnification), $\mathrm{n}=817$

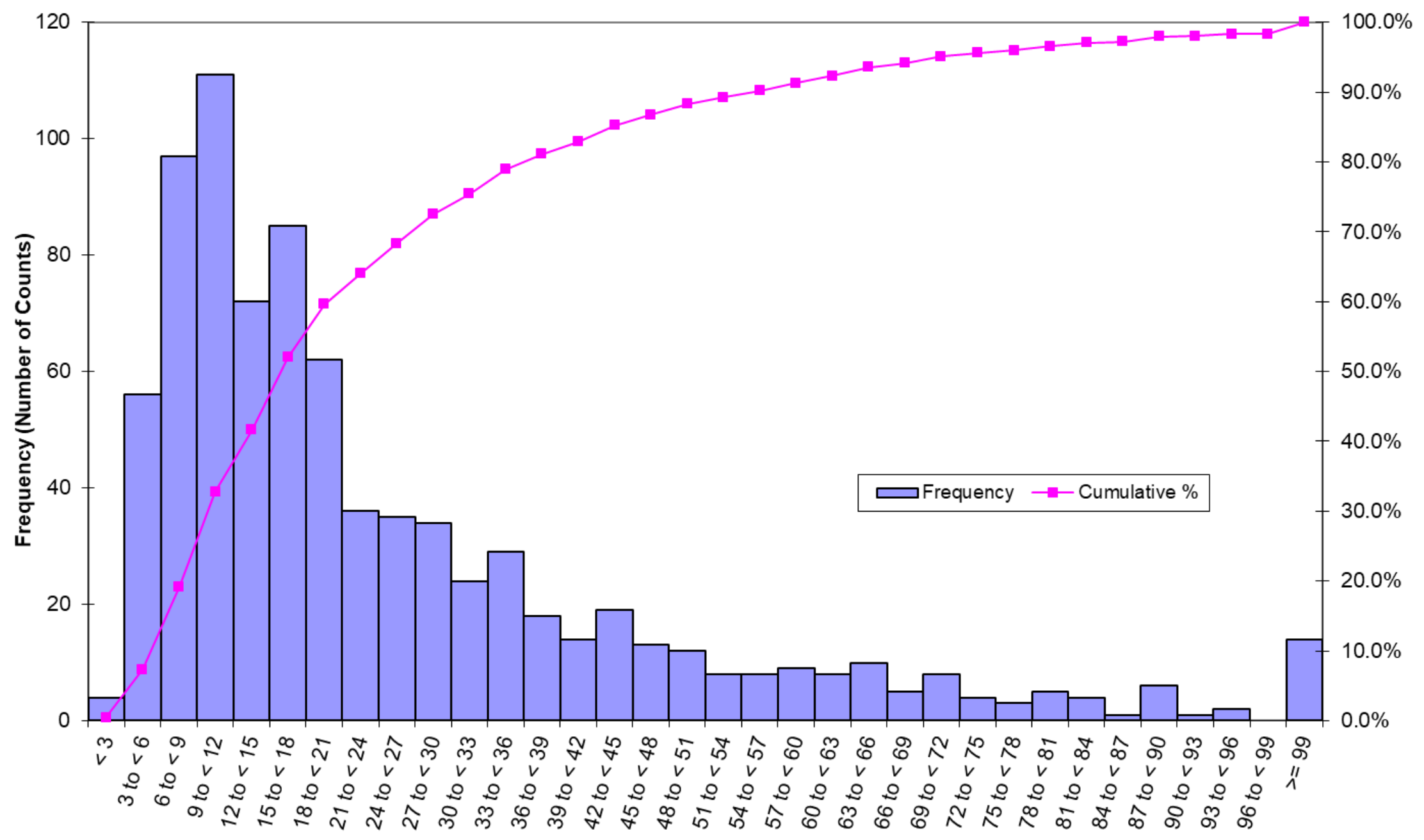

Aspect Ratio 


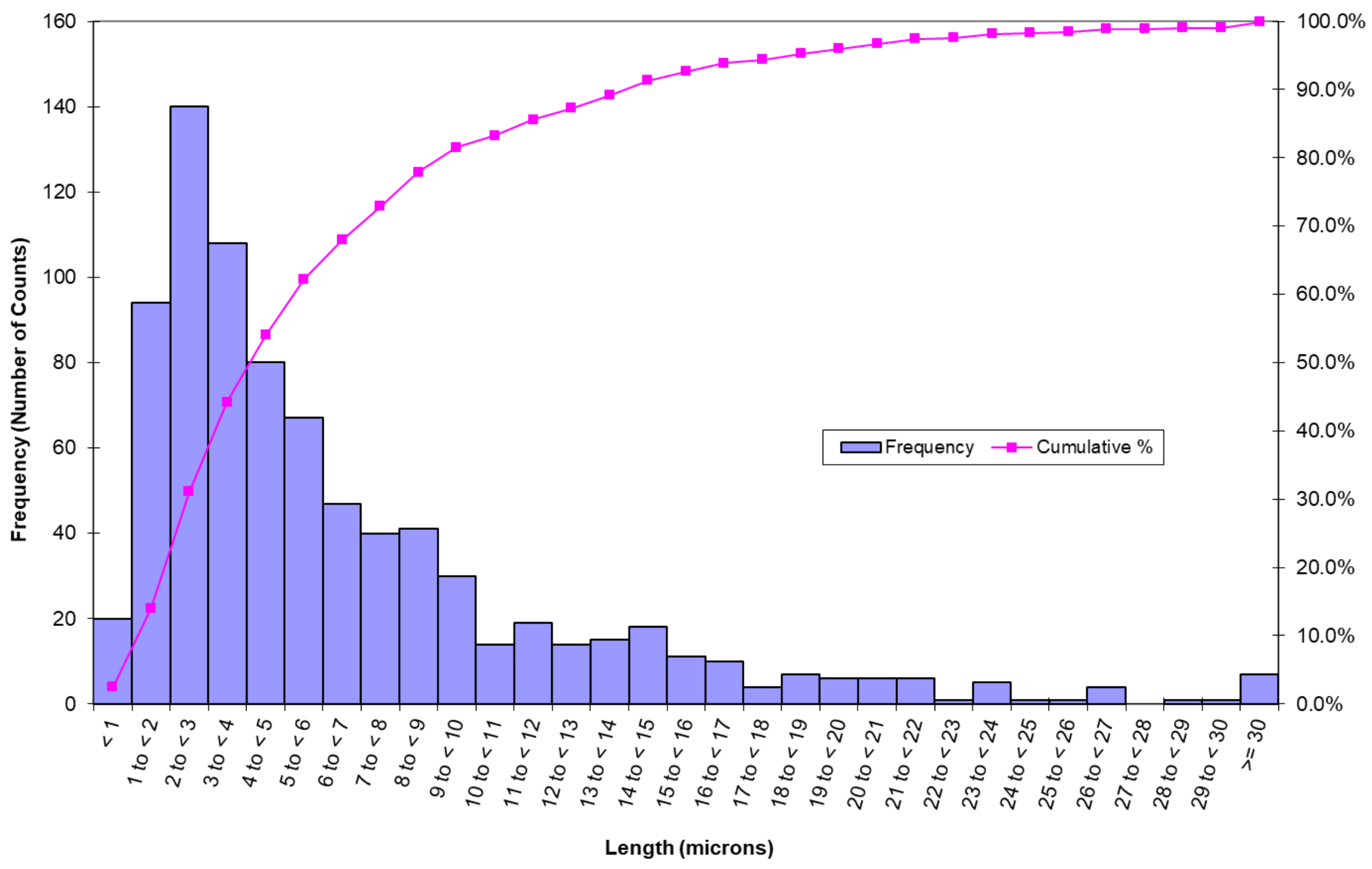




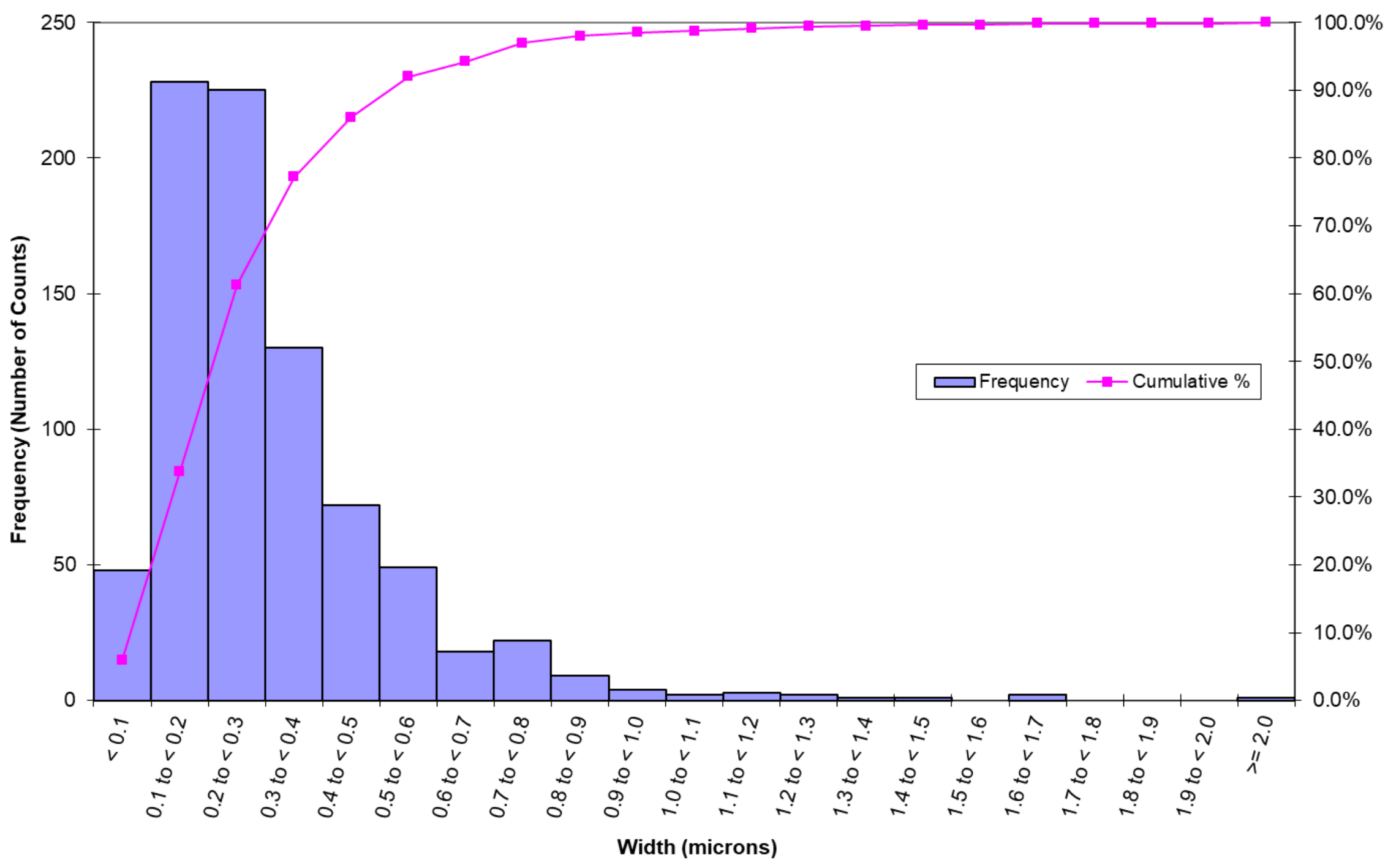


Frequency distribution of aspect ratios, lengths and widths for tremolite cleavage fragments. Measured by TEM $(2,000$ to 10,000X Magnification), $\mathrm{n}=704$

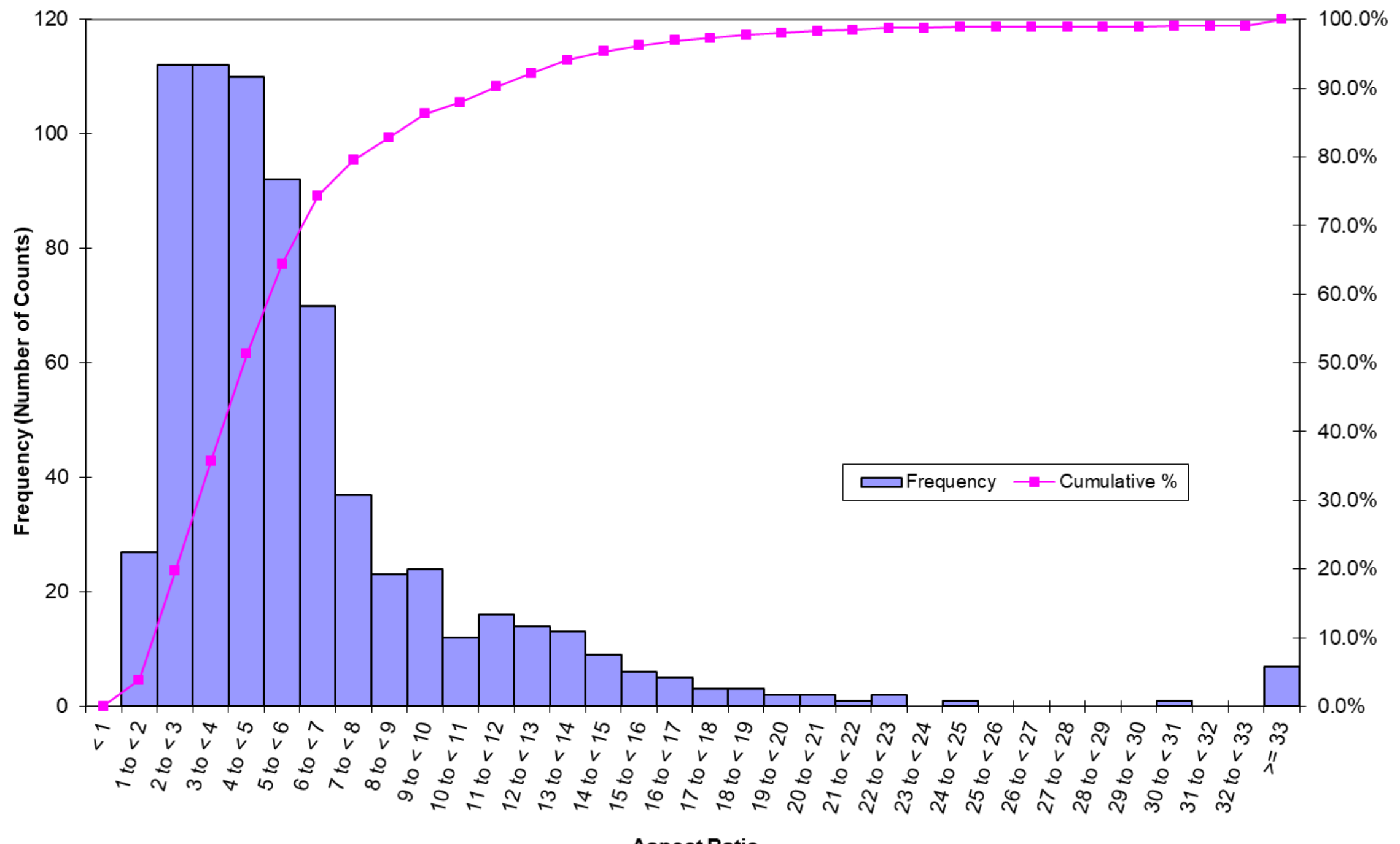

Aspect Ratio 


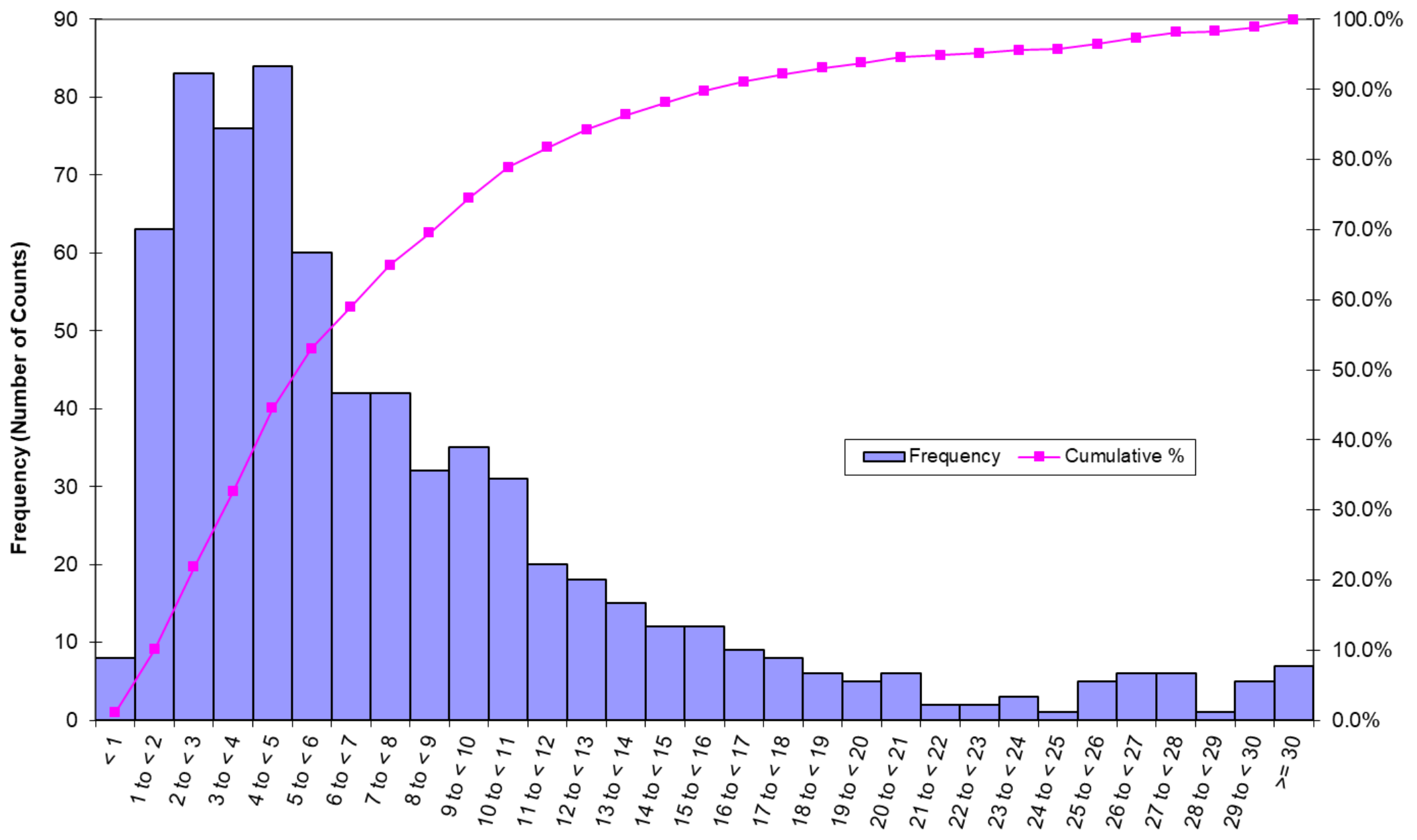

Length (microns) 


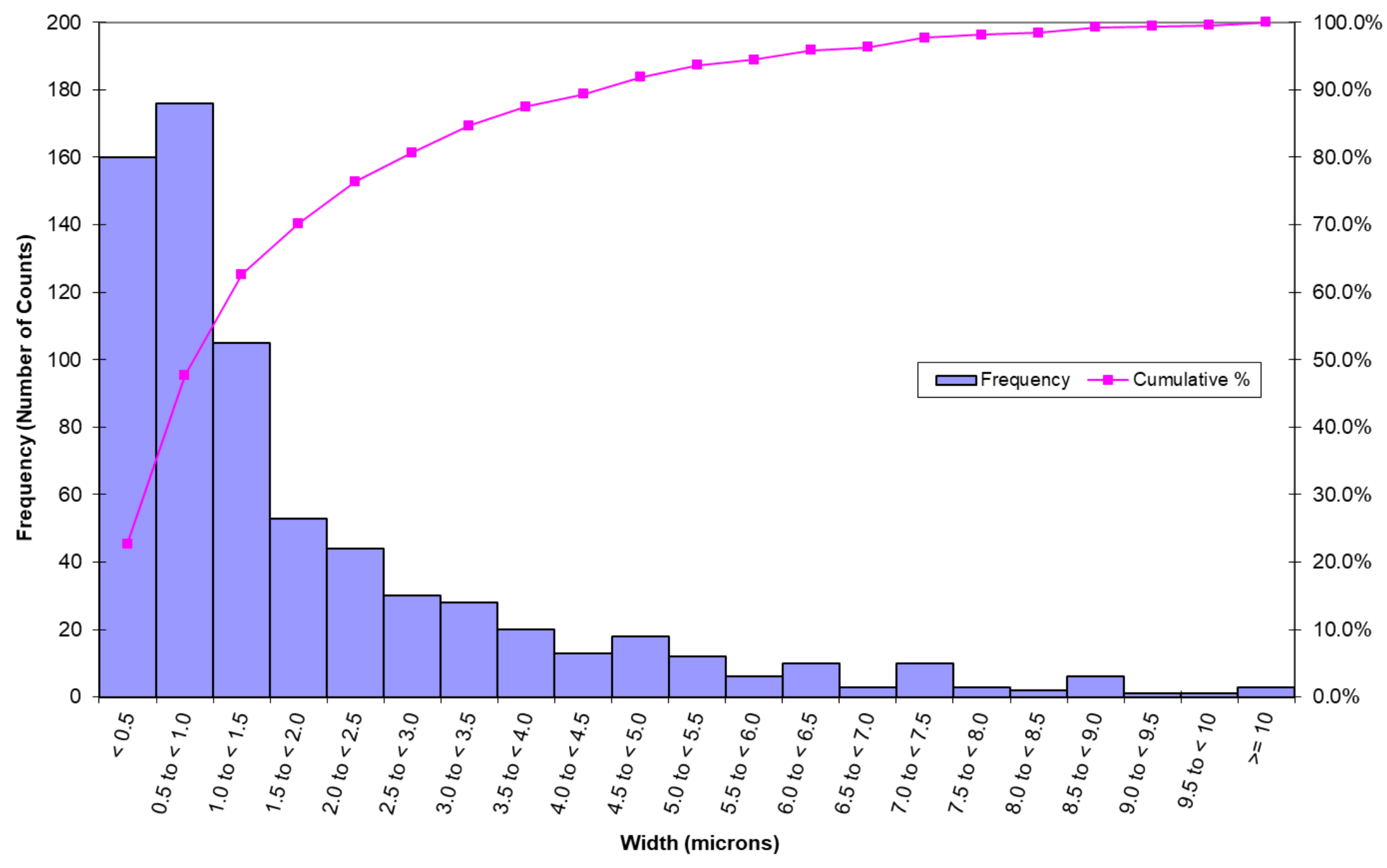




\section{Chapter 3. Differential responses of murine alveolar macrophages to elongate mineral particles of asbestiform and non-asbestiform varieties: cytotoxicity, cytokine secretion and transcriptional changes}

T.O. Khaliullin 1, 2, E.R. Kisin², S. Guppi², N. Yanamala1, 3, V. Zhernovkov ${ }^{4}$, A.A.

Shvedova ${ }^{1,2}$

${ }^{1}$ West Virginia University, Morgantown, WV, ${ }^{2} \mathrm{HELD}, \mathrm{NIOSH}, \mathrm{CDC}$, Morgantown, WV, ${ }^{3}$ Carnegie Mellon University, Pittsburgh, PA, and ${ }^{4}$ University College Dublin, Dublin, Ireland

Adapted from: Khaliullin, T. O., et al. (2020). "Differential responses of murine alveolar macrophages to elongate mineral particles of asbestiform and non-asbestiform varieties: Cytotoxicity, cytokine secretion and transcriptional changes." Toxicology and Applied Pharmacology: 115302. https://doi.org/10.1016/j.taap.2020.115302 


\subsection{Abstract}

Human exposures to asbestiform elongate mineral particles (EMP) may lead to diffuse fibrosis, lung cancer, malignant mesothelioma and autoimmune diseases. Cleavage fragments (CF) are chemically identical to asbestiform varieties (or habits) of the parent mineral, but no consensus exists on whether to treat them as asbestos from toxicological and regulatory standpoints. Alveolar macrophages (AM) are the first responders to inhaled particulates, participating in clearance and activating other resident and recruited immunocompetent cells, impacting the long-term outcomes. In this study we address how EMP of asbestiform versus non-asbestiform habit affect AM responses. Max Planck Institute (MPI) cells, a non-transformed mouse line that has an AM phenotype and genotype, were treated with mass-, surface area- (s.a.), and particle number- (p.n.) equivalent concentrations of respirable asbestiform and non-asbestiform riebeckite/tremolite EMP for 24h. Cytotoxicity, cytokines secretion and transcriptional changes were evaluated. At the equal mass, asbestiform EMP were more cytotoxic, however EMP of both habits induced similar LDH leakage and decrease in viability at s.a. and p.n. equivalent doses. DNA damage assessment and cell cycle analysis revealed differences in the modes of cell death between asbestos and respective CF. There was an increase in chemokines, but not pro-inflammatory cytokines after all EMP treatments. Principal component analysis of the cytokine secretion showed close clustering for the s.a. and p.n. equivalent treatments. There were mineral- and habit-specific patterns of gene expression dysregulation at s.a. equivalent doses. Our study reveals the critical nature of EMP morphometric parameters for exposure assessment and dosing approaches used in toxicity studies. 


\subsection{Introduction}

The history of prolonged and sometimes uncontrolled exposures in occupational and natural settings has proved that, upon inhalation, airborne elongate mineral particles (EMPs) can cause pulmonary inflammation, fibrosis and cancer [1-4], signifying the healthcare and economic burden worldwide. Adverse health outcomes following exposures to asbestos - a commercial term encompassing asbestiform varieties of six different minerals - were studied the most. However, EMP itself is a much broader term, defined as "any mineral particle with a minimum aspect ratio of 3:1" [5]. That includes particles with varied crystal growth habits, such as asbestiform (long, thin, splayed ends) and non-asbestiform (usually short, thick, brittle) [6]. During mining, milling, and processing, non-asbestiform mineral varieties can break down into elongate particles, also known as cleavage fragments (CF). Sometimes that patterned breakage results in dimensions akin to asbestiform fibers. CF might be chemically identical to asbestiform variety of the same mineral, but there is no consensus between different groups (regulators and scientific communities) on whether to treat them exactly as asbestos in terms of their potential health effects. Inability to reliably predict the occurrence and development of health outcomes after exposure to inhaled EMPs poses a significant challenge to health professionals. The latest professional conference on EMPs has shown that there is still uncertainty, whether some EMPs should be "regulated" (treated similar to asbestos by regulatory agencies) or not [7]. Of particular concern are the emerging cases of workplace and incidental exposures to EMPs such as those present in vermiculite in Libby, Montana, USA [8, 9], erionite in Oregon, USA and Turkey [10], silicon carbide fibers in Norway [11], sodic amphiboles in Nevada and Arizona, USA [12, 13], and non-asbestiform EMPs in taconite, talc and gold mining [14].

Epidemiological studies in talc, taconite, and gold mine workers exposed to nonasbestiform EMPs revealed little if any risk of lung cancer or mesothelioma [15-17], but consistent findings of pneumoconiosis and cardiovascular mortality excess occur in each of these mining types $[14,17]$. Limited data exist on the health effects of tremolite and riebeckite CF exposure. There is some epidemiological evidence for tremolite CFs and short (shorter than $10 \mu \mathrm{m}$ ) tremolite asbestos fibers to be the cause of pulmonary fibrosis and lung cancer in nephrite carvers and quarry workers [18-20]. 
A number of studies have investigated the role of dimensions and physicochemical properties of asbestos particles [21-24]. There were, however, very limited efforts in elucidating the potential determinants of toxicity of non-asbestiform EMPs, mostly dating back to 1970-90s and the major biological effects found in the studies related not to the number of particles or mass, but to the surface area of the samples [25, 26]. Studies comparing short and long asbestos fibers were much more prevalent. For instance, short riebeckite asbestos fibers, fully phagocytosed by macrophages caused comparable cytotoxicity to long fibers at 24 hours when compared at similar number-based dose [27]. There is also an indication that asbestos particles shorter than 5 microns may be critical for health outcomes from the in vivo retention and translocation standpoints [28-30]. No study, however, has utilized well-characterized respirable EMP preparations.

Numerous cell populations are involved in asbestos-related pathology, with resident alveolar macrophages being one of the primary mediators of the host immune response. Their depletion during asbestos-induced lung disease exacerbates fibrosis and worsens overall prognosis [31]. Accordingly, macrophage responses, including patterns of cell damage, cytokines, chemokines, and changes in gene expression could be related to the specific features of the fibers, meaning toxicological studies must go hand in hand with detailed EMP characterization. Macrophage-based in vitro systems are uniquely important for the EMP hazard prediction [32]. They can also help minimize the comprehensive toxicity testing based on long-term animal studies and epidemiological evaluations of each type of EMP.

We hypothesized that alveolar macrophage responses (response defined as a change from the normal state) to respirable non-asbestiform EMPs that fall in the WHO "critical" fiber range are similar to asbestiform variety of the same minerals, especially when compared at equal surface area or number, rather than mass. To test this hypothesis, we exposed primary mouse alveolar macrophage-like cells (MPI cells) for 24 $\mathrm{h}$ to preparations of asbestiform (asbestos) and non-asbestiform (cleavage fragments) respirable EMPs, at doses equivalent for total mass, surface area, or number of the particles with length $>5 \mu \mathrm{m}$ and aspect ratio $>3: 1$, and evaluated the cytotoxicity, DNA damage, cytokine secretion and differential gene expression. 


\subsection{Methods}

\subsubsection{Particle preparation and characterization}

Specific particles that were investigated as part of this study included non-asbestiform tremolite, prepared by the U.S. Bureau of Mines for the National Institute of Environmental Health Sciences (NIEHS) for use in oral ingestion studies [33], Union Internationale Centre le Cancer (UICC) riebeckite asbestos (crocidolite), supplied by Research Triangle Institute (RTI International), non-asbestiform riebeckite obtained by NIOSH from Pikes Peak in Colorado Springs, Colorado, and tremolite asbestos from Lone Pine, California, also provided by NIOSH. Sample preparation is described in detail in the Chapter 2 . Briefly, the bulk material was crushed by a hydraulic press, sieved, and ground by hand until sufficient amount of EMPs with the desired dimensions were observed under polarized light microscopy (PLM). For PLM counting purposes small aliquots were suspended in a mixture of deionized water and isopropanol and filtered through $0.45 \mu \mathrm{m}$ mixed cellulose ester (MCE) filters. Particle characterization was performed using a Hitachi 7000 analytical electron microscope with AMT XR280 digital camera. Particles were measured at an on-screen magnification ranging from $4570 \mathrm{X}$ to $21,900 \mathrm{X}$. Three TEM grids were prepared from each of the mineral samples. Each grid square analyzed was traversed from left to right. At least 700 particles were measured in each sample. Length and width measurements in microns and aspect ratio for each particle were registered. From that data approximate surface areas of individual particles were calculated using the formula $4 *$ (length $*$ width $)+2 *($ width $*$ width $)$. EMP elemental composition was assessed using SEM coupled with the energy-dispersive X-ray spectroscopy (EDS).

\subsubsection{Cell culture}

The experiments were conducted in vitro and utilized alveolar macrophage-like cells, obtained and differentiated from the murine fetal livers (Max Planck Institute a.k.a. MPI cells) [34]. MPI cells are phenotypically close to alveolar macrophages, can self-renew in culture, and respond to respirable particulates [35]. MPI cell culture was a generous gift by Dr. J. Pestka from the University of Michigan, originally obtained from the fetal livers of C57BL/6J mice following the standard protocol. Cells were cultured in Roswell Park 
Memorial Institute (RPMI) medium with 10\% fetal Bovine Serum (FBS), $1 \%$ L-glutamine (HyClone), $1 \%$ penicillin-streptomycin mixture (HyClone), and $30 \mathrm{ng} / \mathrm{ml}$ of mouse recombinant GM-CSF (R\&D Systems). Humidified incubator (Fisher Scientific) at $37^{\circ} \mathrm{C}$ and an atmosphere of $5 \% \mathrm{v} / \mathrm{v} \mathrm{CO} 2$ was used. Cells were routinely passaged when reaching 75\% confluence, using Accutase (Innovative Cell Technologies, San Diego, CA) detachment solution. Passages between 4 and 8 were used for the studies. Phenotypic profile of MPI cells was confirmed using flow cytometry as follows: cells at passage 5 were detached using Accutase, suspended in staining buffer and stained with fluorochrome-conjugated antibodies versus CD45 (Clone: 30-F11, BD), Siglec F (Clone: E50-2440, BD Horizon ${ }^{\mathrm{TM}}$ ), CD11C (Clone: N418, eBioscience ${ }^{\mathrm{TM}}$ ), CD64 (Clone: X545/7.1, Biolegend) and CD24 (Clone: M1/69, BD) (all obtained from Fischer Scientific, Pittsburgh, PA). Samples were run on Amnis FlowSight imaging flow cytometer (Luminex Corp., Austin, TX) and analyzed using IDEAS 6.2 software. Alveolar macrophage genotype was confirmed using the Mouse Cell Atlas [36] by uploading the raw counts from bulk Next Gen RNA Sequencing.

\subsubsection{Treatment details}

Dry EMP preparations were heated to $220^{\circ} \mathrm{C}$ for $2 \mathrm{~h}$ to inactivate endotoxin. Endotoxin presence was further investigated in the stock suspensions using Limulus amebocyte lysate (LAL) chromogenic endpoint assay kit (Hycult biotech, Inc., Plymouth Meeting, PA). Stock particle suspensions were prepared in $\mathrm{Ca}^{2+}, \mathrm{Mg}^{2+}$-free phosphate-buffered saline (PBS, pH 7.4) at the concentrations of $1.0 \mathrm{mg} / \mathrm{ml}$. The EMPs were serially diluted in phenol-free RPMI medium with $1 \% \mathrm{FBS}, 1 \%$ penicillin/streptomycin and $30 \mathrm{ng} / \mathrm{ml}$ of GMCSF (treatment medium) at appropriate concentrations. Immediately before dilution, stock suspensions were sonicated in a $20 \mathrm{kHz}$ Q500 sonicator with 5.5" cup horn (QSonica LLC, Newtown, CT). The settings were set to six pulses, ten seconds each, with five seconds intervals between, at 30\% amplitude, for a total delivered energy of $\sim 625$ Joules/ml per sample.

The current consensus is that EMPs with greater than $5 \mu \mathrm{m}$ lengths should be prioritized in terms of the possible health effects, thus for dosing we accounted for the number and total surface area of the fibers of sufficient length and greater than 3:1 aspect 
ratio, using the approach described in the Chapter 2. The importance of the surface area of the critical fibers parameter have been established by a number of robust and highly cited studies [23, 37-39]. The example of critical fiber number and surface area values per unit of mass $(120 \mu \mathrm{g})$ is shown in Table 3.1. MPI cells, grown in 6-well and 96-well plates, were washed with PBS and treated with the mass-equivalent $\left(9 \mu \mathrm{g} / \mathrm{cm}^{2}\right.$ for riebeckite asbestos and $\mathrm{CF}$ and $5 \mu \mathrm{g} / \mathrm{cm}^{2}$ for tremolite asbestos and CF), fibers surface area-equivalent ( 9 and $40 \mu \mathrm{g} / \mathrm{cm}^{2}$ for riebeckite asbestos and CF respectively, 5 and 60 $\mu \mathrm{g} / \mathrm{cm}^{2}$ for tremolite asbestos and CF respectively), and fibers number-equivalent ( 6 and $40 \mu \mathrm{g} / \mathrm{cm}^{2}$ for riebeckite asbestos and CF respectively, 1.2 and $60 \mu \mathrm{g} / \mathrm{cm}^{2}$ for tremolite asbestos and CF respectively) doses of asbestiform/non-asbestiform riebeckite or tremolite EMPs for 24 hours. There were no equal mass comparisons between riebeckite and tremolite minerals, but $5 \mu \mathrm{g} / \mathrm{cm}^{2}$ tremolite asbestos and $9 \mu \mathrm{g} / \mathrm{cm}^{2}$ riebeckite asbestos doses had similar total surface areas of critical fibers between each other. The fiber number for all equivalent doses utilized in our study were within the number concentrations used in other studies and relevant to exposed workers' lifetimeaccumulated number of fibers (See Chapter 2: Dose calculations).

\subsubsection{Cytotoxicity assessment}

For cytotoxicity assessment MPI cells were plated at a density of $3 \times 10^{4}$ cells per well in 96-well microplates one day prior to EMP treatments. 24 hours after the start of treatment, cell membrane damage was assessed using commercially available lactate dehydrogenase (LDH) assay (Pointe Scientific, Lincoln Park, MI) by monitoring the reduction of NAD+ in the presence of lactate in the supernatants at $340 \mathrm{~nm}$ in a Synergy H1 plate reader (Biotek, Winooski, VT). Multi-Tox Fluor kit (Promega, Madison, WI) was used to evaluate the viability following EMP treatment per the assay instructions. $1 \mu \mathrm{M}$ staurosporine (Sigma-Aldrich, St. Louis, MO) was chosen as positive control, since apoptosis was suspected to be the major cell death mechanism following exposure to the studied EMPs. Staurosporine was also previously used in murine macrophage in vitro LDH and viability assays [40]. Cytotoxicity experiments were performed three times, with at least eight technical replicates (wells) per treatment per experiment. 


\subsubsection{Assessment of DNA double-strand breaks via 2-color flow cytometric analysis}

Formation of double strand DNA breaks (DSB) triggers phosphorylation of the histone variant $\mathrm{H} 2 \mathrm{AX}$ at Ser-139, producing $\mathrm{YH} 2 \mathrm{AX}$. By measuring the amount of phosphorylation, we can estimate the extent of DNA damage. MPI cells at passage six were seeded in 6-well plates at the density of $1 \times 10^{6}$ cells per well one day prior to EMP treatments. 24 hours after the start of treatment, supernatants from each well were taken for the cytokine measurements, while cells were washed with PBS and detached using the Accutase detachment solution. After collection, $20 \mu$ of cell suspension was taken for counting using Trypan Blue exclusion method on a Countess FL II automated cell counter, and the rest were centrifuged at $300 \times \mathrm{g}$, and washed once with PBS. Cells were then fixed and permeabilized using FOXP3 Fix/Perm solution (Invitrogen, Carlsbad, CA), and stained with anti-Phospho-Histone H2A.X(Ser139) antibody conjugated with eFluor® 660 fluorophore (Invitrogen, Carlsbad, CA) together with Hoechst 33342 nuclear dye (Invitrogen, Carlsbad, CA) per supplied protocols. Samples were processed on an Amnis FlowSight imaging flow cytometer (Luminex Corp., Austin, TX) and analyzed using IDEAS 6.2 software. 50000 cells per sample were collected for analysis. Tthe median Max Pixel intensity parameter in the cells exhibiting higher than threshold amount of $\mathrm{yH} 2 \mathrm{AX}$ (greater than $98.5 \%$ of control cells) was recorded. $500 \mu \mathrm{M} \mathrm{H}_{2} \mathrm{O}_{2}$ treatment was used as a positive control. Sub-G1 cell populations were additionally evaluated as a marker of apoptosis/secondary necrosis. Gating strategy is visualized in Figure 3.1. Three technical replicates (three wells across three 6-well plates) per treatment were used. 

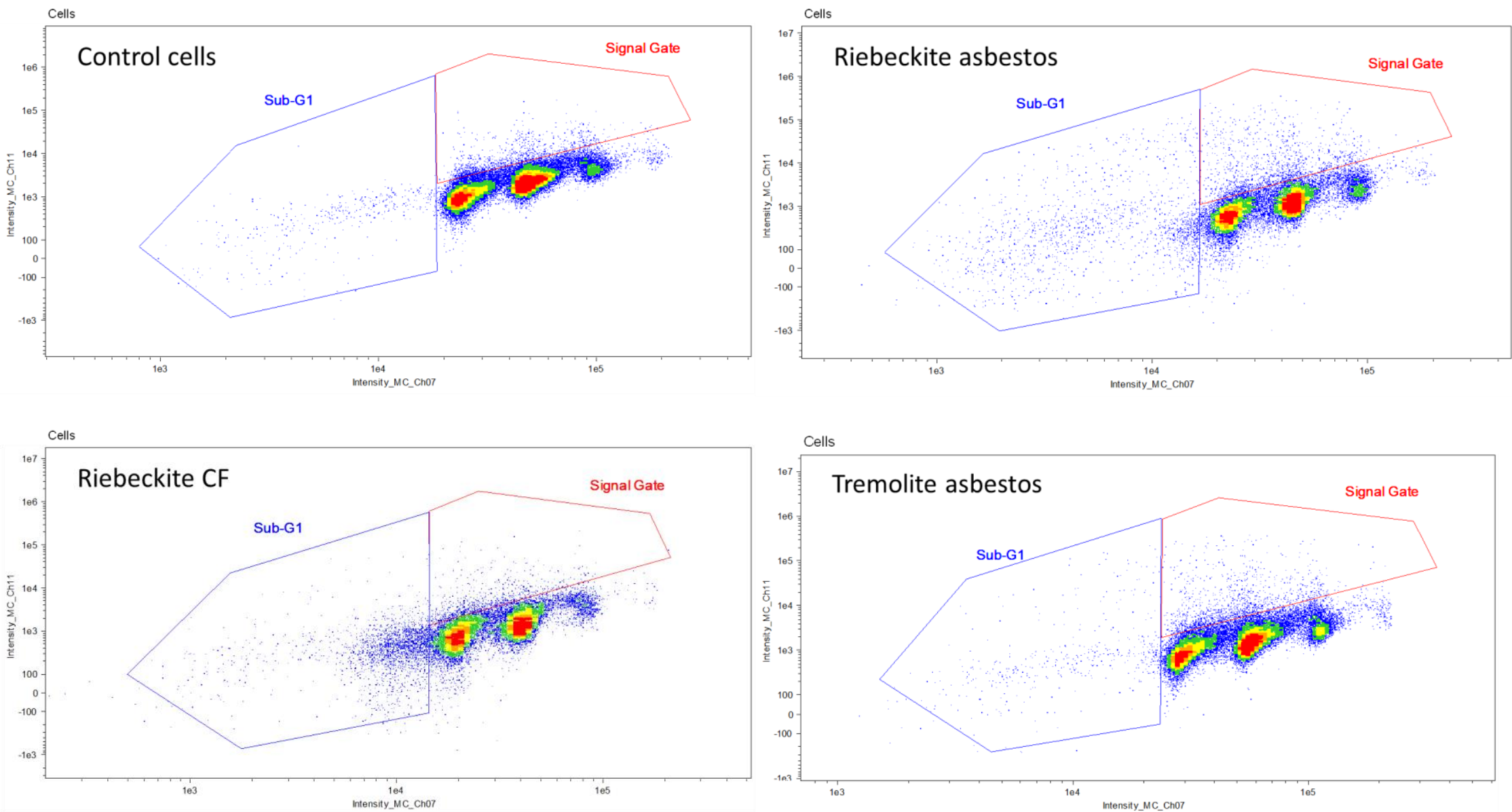

Figure 3.1. Gating strategy for the flow cytometric analysis. Individual cells were gated out from debris using Area vs. Aspect ratio chart. Signal Gate was based on the cell population having pH2AX signal intensity $>98.5 \%$ of control cells. $Y$ axis - yH2AX fuorescence signal intensity, $X$ axis - nuclear dye (Hoechst 33342) signal intensity. CF - cleavage fragments 


\subsubsection{Cytokine secretion in the supernatants}

Cell supernatants from the 6-well plates used for $\mathrm{yH} 2 \mathrm{AX}$ staining (see above) were collected and snap-frozen until the further analysis. Secreted cytokine profiles were determined in the supernatants using Bio-Plex Pro Mouse Cytokine 23-plex Assay on a Bio-Plex 200 Reader (Bio-Rad Laboratories, Hercules, CA) following manufacturer's directions, with three technical replicates allocated per each of three wells per sample. Prior to measurements supernatant samples were centrifuged at $2500 \mathrm{~g}$. Cytokine quantities was normalized per total number of live cells in each well at the collection time. For each cytokine, out of range (OOR)-low results were set equal to $80 \%$ of the minimum within-range value, while OOR-high results were set equal to $125 \%$ of the maximum within-range value, if applicable. Hierarchical clustering analysis of the secreted cytokines was performed using Clustvis [41], with Euclidean distance similarity and Ward's clustering method.

\subsubsection{Next generation RNA sequencing}

A different set of cells was plated in 6-well plates and treated with an equivalent surface area of the critical fibers-based doses, with three replicates (wells) per each treatment group. 24 hours post-exposure cells were washed with PBS, lysed with the TRIzol ${ }^{\mathrm{TM}}$ reagent (Invitrogen, Carlsbad, CA) and stored at $-80^{\circ} \mathrm{C}$ in RNAse/DNAse-free tubes for further analysis. RNA was purified using RNeasy MiniKits (Qiagen, Mississauga, ON, Canada) as described by the manufacturer, quantified using Thermo Scientific ${ }^{\text {TM }}$ Nanodrop $^{\mathrm{TM}}$ ND-1000 and qualified by agarose gel electrophoresis. The mRNA was enriched by oligo(dT) magnetic beads. Illumina kits were used for the RNA-seq library preparation, which included procedures of RNA fragmentation, random hexamer primed first strand cDNA synthesis, dUTP based second strand cDNA synthesis, end-repairing, A-tailing, adaptor ligation and library PCR amplification. Finally, the prepared RNA-seq libraries were qualified using Agilent 2100 Bioanalyzer (Agilent Technologies, Santa Clara, CA) and quantified by qPCR absolute quantification method. The sequencing was performed on Illumina NovaSeq 6000 (Illumina, San Diego, CA). The expression level (FPKM value) of known genes and transcripts were calculated using ballgown through the transcript abundances estimated with StringTie. Principal Component Analysis was 
performed with genes that have the ANOVA $p$ value $\leq 0.05$ on FPKM abundance estimations. The number of identified genes and transcripts per group was calculated based on the mean of FPKM in group $\geq 0.5$. Genes showing expression changes of at least 1.5 -fold in either direction compared to their controls, having $p<0.05$ and $q$ (false discovery rate adjusted $p$-value) $\leq 0.1$ were considered significantly differentially expressed and were considered for further analysis. All gene expression data were uploaded to NCBI's Gene Expression Omnibus and are accessible via accession number GSE157922.

\subsubsection{Enrichment of KEGG pathways and GO enrichment analysis}

Pathway analysis for the differentially expressed genes was carried out based on the latest KEGG (Kyoto Encyclopedia of Genes and Genomes) database. The analysis allows users to determine whether the differentially expressed mRNAs are enriched in certain biological pathways. The $p$-values calculated by Fisher's exact test were used to estimate the statistical significance of the enrichment of the pathways between the two groups. A $p$ value cutoff of $<0.05$ was considered significant. We also investigated whether specific Gene Ontology (GO) terms were more likely to be associated with the DEGs. A Fisher's exact test is used to estimate the statistical significance of such enrichment of terms between the two groups (EMP and control). The $p$-value denotes the significance of GO Term enrichment in the differentially expressed gene list. All analyses with the differentially expressed genes were performed in R, Python or shell environment for statistical computing and graphics.

\subsubsection{Statistical analysis}

Statistical analysis was performed using SigmaPlot 14.0 (San Jose, CA). Treatment related differences were evaluated using Student's t-test or one-way ANOVA, as appropriate. A $p<0.05$ was considered to be statistically significant. Data are presented as Mean $\pm S E$. Principal component analysis and hierarchical clustering analysis were performed using online tool (www.clustvis.org).

\subsection{Results}




\subsubsection{Particle characteristics}

Summary of the EMP size and dimensions is listed in Table 3.1. Detailed tables for every sample can be found in Chapter 2. Asbestos samples had smaller median widths and higher aspect ratios, compared to cleavage fragments, but median lengths of all samples were around $5 \mu \mathrm{m}$ as seen on the size distribution charts (See Appendix A.). The EDS analysis showed elemental signatures to be predominantly $\mathrm{Si}, \mathrm{Fe}, \mathrm{Mg}, \mathrm{Na}$, and $\mathrm{O}$ for riebeckite EMPs, and $\mathrm{Si}, \mathrm{Ca}, \mathrm{Mg}$, and $\mathrm{O}$ with only trace $\mathrm{Fe}$ for tremolite particles. $\mathrm{Cu}$ signal comes from the copper grids utilized in the process.

Table 3.1. Morphological characteristics of the studied EMPs, calculated from the detailed TEM analysis of at least 700 particles per sample. A.R. - aspect ratio

\begin{tabular}{|l|c|c|c|c|}
\hline & Riebeckite & Tremolite & $\begin{array}{l}\text { Riebeckite } \\
\text { CF }\end{array}$ & $\begin{array}{l}\text { Tremolite } \\
\text { CF }\end{array}$ \\
\hline Median length, $\boldsymbol{\mu m}$ & 4.43 & 4.65 & 5.45 & 5.59 \\
\hline $\begin{array}{l}\text { Length Range (Min-Max), } \\
\boldsymbol{\mu m}\end{array}$ & $0.67-63.2$ & $0.61-55$ & $0.96-23.7$ & $0.7-33.7$ \\
\hline Median width, $\boldsymbol{\mu m}$ & 0.264 & 0.254 & 1.74 & 1.11 \\
\hline Width Range (Min-Max), $\boldsymbol{\mu m}$ & $0.03-3.26$ & $0.02-2.14$ & $0.14-6.58$ & $0.01-13.4$ \\
\hline Median A.R. & 15.7 & 17.2 & 3.2 & 4.93 \\
\hline A.R. Range (Min-Max) & $2.7-636.4$ & $2-362$ & $1.12-18.5$ & $1-126.07$ \\
\hline
\end{tabular}

\subsubsection{EMP cytotoxicity}

Cytotoxicity was observed for all treatments at $24 \mathrm{~h}$ with the normalized ratio of viable-todead cells significantly decreasing to $90-70 \%$ of untreated controls (Figure 3.2). 

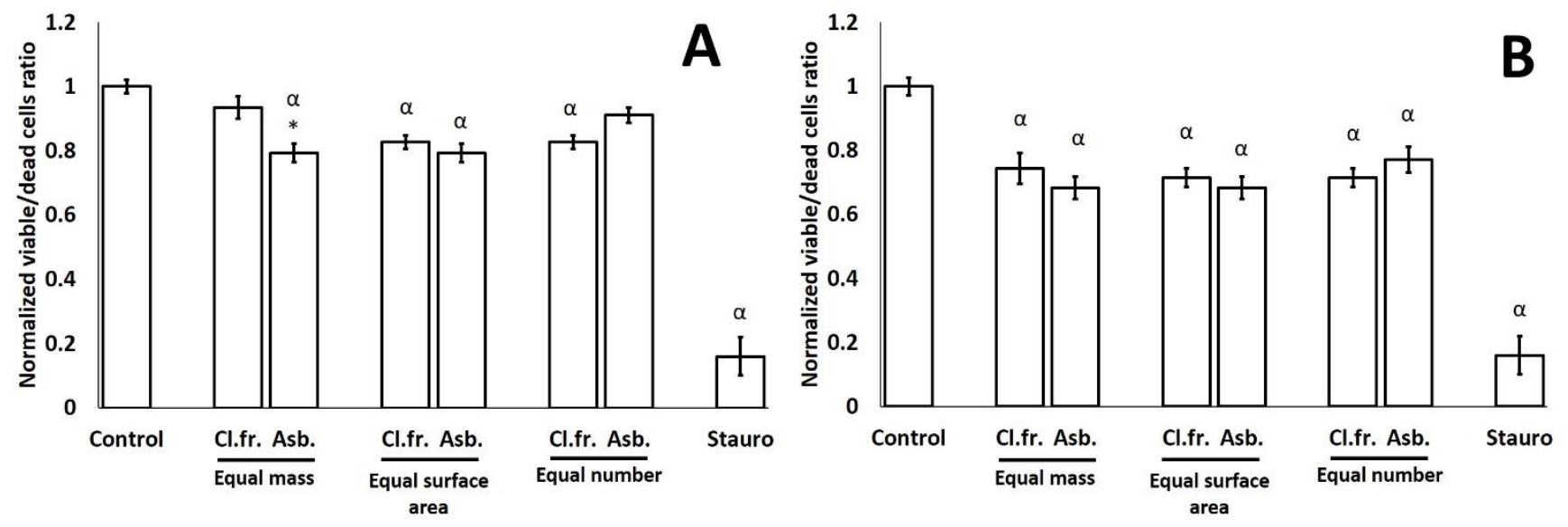

Figure 3.2. Normalized viable/dead cells ratios, 24h exposure to riebeckite (A) or tremolite (B) EMPs. Values are expressed as mean \pm SEM from 3 independent experiments. Stauro $-1 \mu \mathrm{M}$ of staurosporine. Equal mass: $9 \mu \mathrm{g} / \mathrm{cm}^{2}$ for both riebeckite asbestos and cleavage fragments (CF); $5 \mu \mathrm{g} / \mathrm{cm}^{2}$ for both tremolite asbestos and CF; Equal surface area of critical fibers: 9 and $40 \mu \mathrm{g} / \mathrm{cm}^{2}$ for riebeckite asbestos and CF, 5

and $60 \mu \mathrm{g} / \mathrm{cm}^{2}$ for tremolite asbestos and CF; Equal number: 6 and $40 \mu \mathrm{g} / \mathrm{cm}^{2}$ for riebeckite asbestos and CF, 1.2 and $60 \mu \mathrm{g} / \mathrm{cm}^{2}$ for tremolite asbestos and CF. ${ }^{\alpha} \mathrm{p}<0.05$ vs. control; * $p<0.05$ vs. cleavage fragments equivalent.

Riebeckite cleavage fragments were less cytotoxic than asbestos at the equivalent mass doses, however significant difference between the growth habits was observed only for the equal mass doses of riebeckite (Figure 3.2.A.). At the equal mass, asbestiform EMPs clearly caused significantly greater LDH leakage (Figure 3.3.).
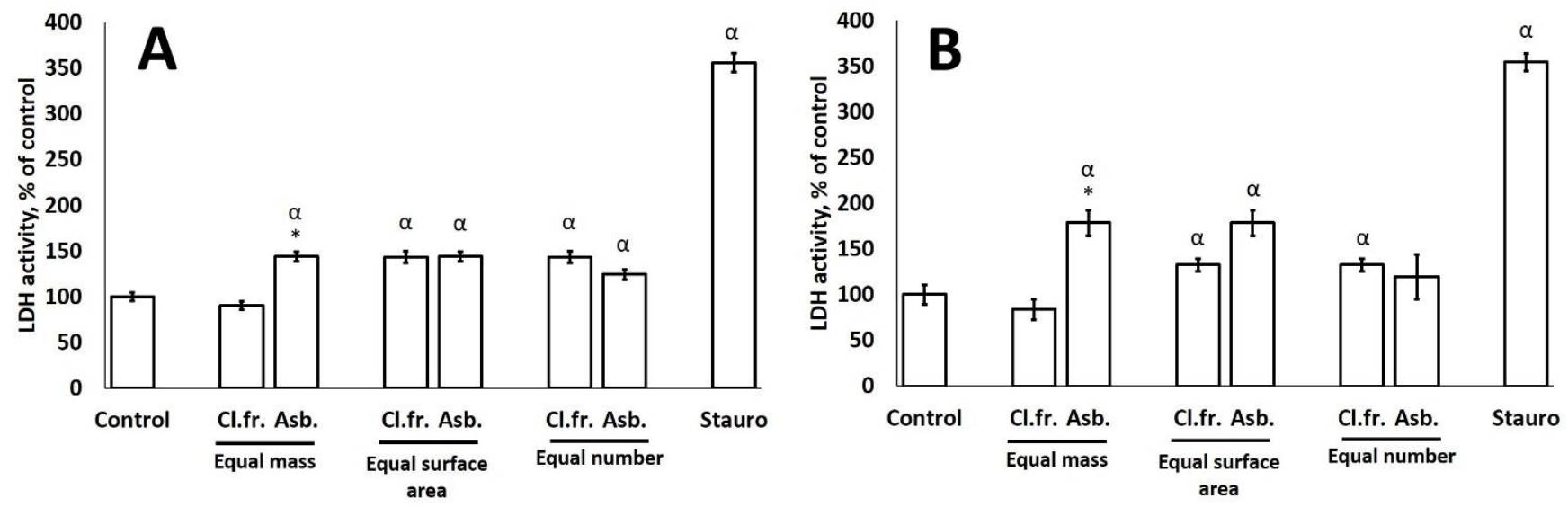

Figure 3.3. LDH activity in the supernatant, as percentage of untreated cell values. $24 \mathrm{~h}$ exposure to riebeckite $(A)$ or tremolite (B) EMPs. Values are expressed as mean \pm SEM from 3 independent experiments. Stauro $-1 \mu \mathrm{M}$ of staurosporine. Equal mass: $9 \mu \mathrm{g} / \mathrm{cm}^{2}$ for both riebeckite asbestos and cleavage fragments (CF); $5 \mu \mathrm{g} / \mathrm{cm}^{2}$ for both tremolite asbestos and CF; Equal surface area of critical fibers: 9 and $40 \mu \mathrm{g} / \mathrm{cm}^{2}$ for riebeckite 
asbestos and CF, 5 and $60 \mu \mathrm{g} / \mathrm{cm}^{2}$ for tremolite asbestos and CF; Equal number: 6 and $40 \mu \mathrm{g} / \mathrm{cm}^{2}$ for riebeckite asbestos and CF, 1.2 and $60 \mu \mathrm{g} / \mathrm{cm}^{2}$ for tremolite asbestos and CF. ${ }^{\alpha} p<0.05$ vs. control; ${ }^{*} p<0.05$ vs. cleavage fragments equivalent.

For riebeckite EMPs, LDH leakage from the cells was similar at the calculated surface area equivalent doses. When treated with equal particle numbers, CF trended to have more pronounced cytotoxic effects, compared to respective asbestiform analogues, however never reaching statistical significance.

\subsubsection{Relative amount of the $\mathrm{yH} 2 \mathrm{AX}$ staining and nuclear staining analysis}

Isolated particles were excluded from the analysis through initial size/aspect ratio scatterplot. Further, the imaging flow cytometry allows checking the visuals of every registered event. We spotted only several large enough isolated particles, all cleavage fragments, in the data collection gates amongst thousands of cells across all samples. Hoechst 33342 binding to the particles was negligent. Individual cell $\mathrm{yH} 2 \mathrm{AX}$ signal was highest in asbestos-treated cells, specifically riebeckite asbestos. There was no difference between tremolite asbestos and CF treatments at number-equivalent dose. Cleavage fragments were not as efficient in inducing the H2AX phosphorylation in general (Figure 3.4.).
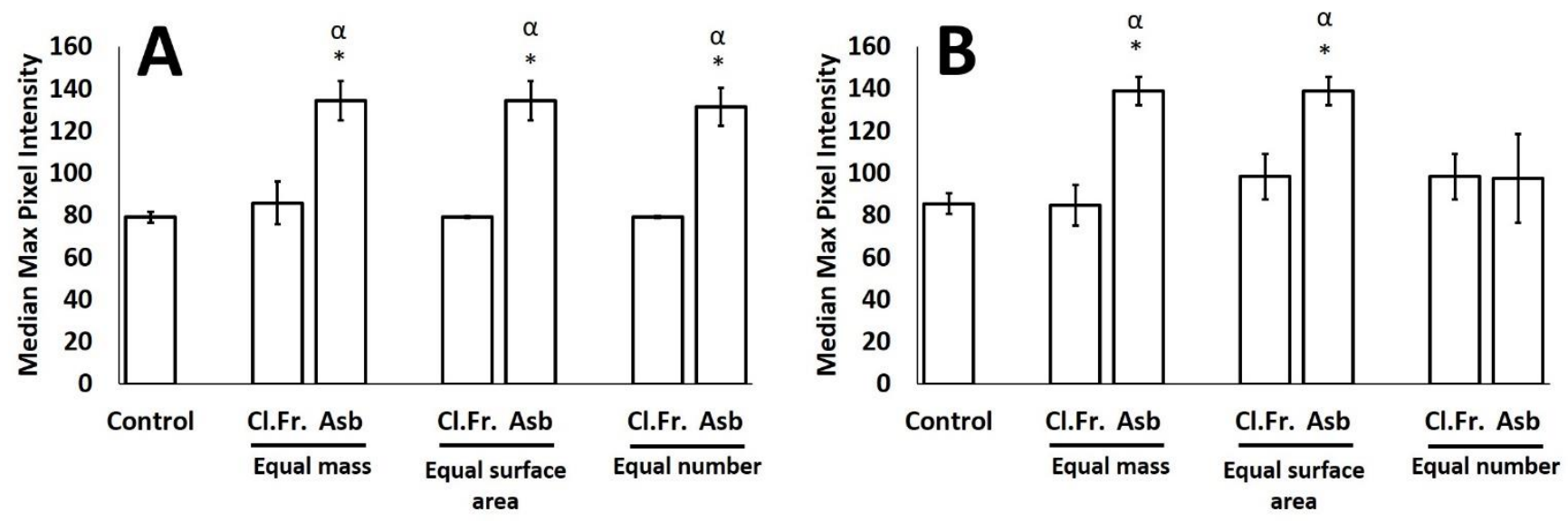

Figure 3.4. Median Max Pixel intensity (arbitrary units) of the $\mathrm{yH} 2 \mathrm{AX}$ fluorescence staining in the signal gate, $24 \mathrm{~h}$ exposure to riebeckite $(\mathrm{A})$ or tremolite $(\mathrm{B})$. Values are expressed as mean of three biological replicates \pm SEM. Equal mass: $9 \mu \mathrm{g} / \mathrm{cm}^{2}$ for both riebeckite asbestos and cleavage fragments $(\mathrm{CF}) ; 5 \mu \mathrm{g} / \mathrm{cm}^{2}$ for both tremolite asbestos and CF; Equal surface area of critical fibers: 9 and $40 \mu \mathrm{g} / \mathrm{cm}^{2}$ for riebeckite asbestos and $\mathrm{CF}, 5$ and $60 \mu \mathrm{g} / \mathrm{cm}^{2}$ for tremolite asbestos and CF; Equal number: 6 and 40 
$\mu \mathrm{g} / \mathrm{cm}^{2}$ for riebeckite asbestos and CF, 1.2 and $60 \mu \mathrm{g} / \mathrm{cm}^{2}$ for tremolite asbestos and CF. ${ }^{\alpha} p<0.05$ vs. control; * $p<0.05$ vs. cleavage fragments equivalent.

Nuclear staining revealed increased number of cells found in the sub G-1 region of the dot plots (Figure 3.5.) for riebeckite CF, tremolite CF, and riebeckite asbestos.
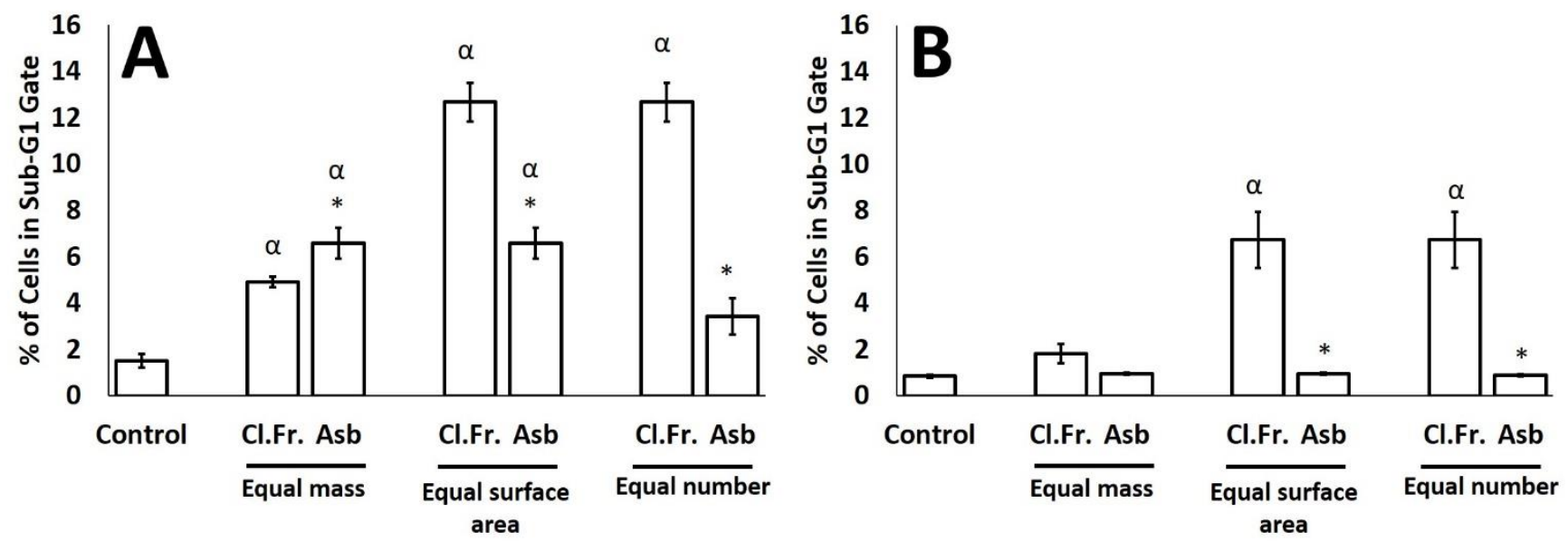

Figure 3.5. \% of cells in the sub-G1 gate, relative to total cells, $24 \mathrm{~h}$ exposure to riebeckite $(A)$ or tremolite $(B)$. Values are expressed as mean of three biological replicates \pm SEM. Equal mass: $9 \mu \mathrm{g} / \mathrm{cm}^{2}$ for both riebeckite asbestos and cleavage fragments (CF); $5 \mu \mathrm{g} / \mathrm{cm}^{2}$ for both tremolite asbestos and CF; Equal surface area of critical fibers: 9 and $40 \mu \mathrm{g} / \mathrm{cm}^{2}$ for riebeckite asbestos and CF, 5 and $60 \mu \mathrm{g} / \mathrm{cm}^{2}$ for tremolite asbestos and CF; Equal number: 6 and $40 \mu \mathrm{g} / \mathrm{cm}^{2}$ for riebeckite asbestos and $\mathrm{CF}, 1.2$ and $60 \mu \mathrm{g} / \mathrm{cm}^{2}$ for tremolite asbestos and CF. ${ }^{\alpha} p<0.05$ vs. control; ${ }^{*} p<0.05$ vs.

cleavage fragments equivalent.

Riebeckite CF had lower sub-G1 cells than riebeckite asbestos at mass-equivalent doses, and higher at surface area-equivalents. Tremolite asbestos treatment did not significantly increased the Sub-G1 population of cells compared to controls.

\subsubsection{Cytokine secretion}

All EMP treatments provoked significant secretion of IL-1 $1 \alpha$, MCP-1, MIP1 $\alpha$ and MIP1 $\beta$ and KC (mouse analog of IL-8), but not other cytokines, such as IL-6 or TNF- $\alpha$ (Table 3.2.). Hierarchical cluster analysis of the cytokine/chemokine secretion was performed for the cytokines/chemokines, showing significant difference $(p<0.05)$ in at least 3 different

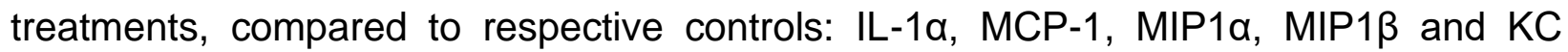
cytokines, and showed close clustering for the surface area and fiber number equivalent treatments (Figure 3.6.). 
Table 3.2. Pooled cytokine values for MPI cells, following treatment with various elongated mineral particles (EMPs) in pg/10^6 viable cells. RCF - Riebeckite Cleavage Fragmetns, RAsb - Riebeckite Asbestos, TCF - Tremolite Cleavage Fragments, TAsb - Tremolite Asbestos. OOR = Out of Range; OOR $>=$ Out of Range Above; OOR $<=$ Out of Range

Below. The cytokines/chemokines values, showing significant difference $(p<0.05)$ compared to respective controls have a red font color. Cytokines with at least 3 different EMP samples, significantly different, compared to respective controls, are highlighted in yellow.

\begin{tabular}{|c|c|c|c|c|c|c|c|c|c|c|c|c|c|c|c|c|c|c|c|c|c|c|c|}
\hline Value type & Treatment & IL-1a & IL-1b & IL-2 & IL-3 & IL-4 & IL-5 & IL-6 & IL-9 & \begin{tabular}{l|l} 
IL-10 & I \\
\end{tabular} & IL-12(p40) & IL-12(p70) & IL-13 & \begin{tabular}{|l|l|} 
IL-17 \\
\end{tabular} & Eotaxin & G-CSF & IFN-g & KC & MCP-1 & MIP-1a & MIP-1b & RANTES & TNF-a \\
\hline \multirow{5}{*}{ Mean } & Control & 8.56 & 10.56 & 16.51 & 6.33 & 11.27 & 8.98 & 20.38 & 21.98 & 23.90 & 43.40 & 138.85 & 86.26 & 13.49 & 16.93 & 29.37 & 18.46 & 45.11 & 268.57 & 408.09 & 259.39 & 7.36 & 45.72 \\
\hline & RCF $40 \mu \mathrm{g} / \mathrm{cm} 2$ & 15.01 & 10.92 & 15.80 & 6.61 & 12.51 & 8.47 & 12.74 & 20.21 & 23.98 & 36.14 & 148.06 & 62.95 & 12.59 & 15.57 & 28.72 & 15.35 & 83.98 & 614.23 & 751.20 & 464.64 & 6.13 & 13.51 \\
\hline & RCF $9 \mu \mathrm{g} / \mathrm{cm} 2$ & 8.68 & 9.44 & 14.06 & 5.90 & 11.02 & 7.23 & 11.09 & 18.46 & 20.23 & 24.26 & 115.38 & 64.62 & 11.27 & 14.26 & 26.78 & 15.48 & 30.83 & 261.72 & 348.10 & 259.55 & 6.29 & 38.72 \\
\hline & RAsb $9 \mu \mathrm{g} / \mathrm{cm} 2$ & 18.49 & 11.31 & 14.72 & 6.20 & 13.07 & 6.76 & 11.34 & 19.70 & 22.38 & 29.51 & 142.47 & 62.75 & 11.48 & 15.03 & 25.46 & 12.60 & 76.46 & 728.08 & 1233.12 & 1115.46 & 6.12 & 37.41 \\
\hline & RAsb $6 \mu \mathrm{g} / \mathrm{cm} 2$ & 13.78 & 9.01 & 12.97 & 5.45 & 11.06 & 6.39 & 9.25 & 18.10 & 19.60 & 21.57 & 123.79 & 57.78 & 10.40 & 12.84 & 23.05 & 12.42 & 56.05 & 500.06 & 785.75 & 761.88 & 5.28 & 35.11 \\
\hline \multirow{5}{*}{$\begin{array}{c}\text { Standard } \\
\text { Error of } \\
\text { Mean } \\
\text { (SEM) }\end{array}$} & Control & 0.40 & 0.44 & 0.70 & 0.24 & 0.57 & 0.47 & 2.79 & 1.92 & 1.24 & 1.53 & 9.25 & 6.22 & 0.62 & 1.02 & 2.16 & 1.04 & 5.36 & 13.40 & 14.67 & 22.98 & 0.80 & 3.24 \\
\hline & RCF $40 \mu \mathrm{g} / \mathrm{cm} 2$ & 0.48 & 0.43 & 1.07 & 0.21 & 0.37 & 0.85 & 0.98 & 1.18 & 1.80 & 1.19 & 7.85 & 4.99 & 0.80 & 1.39 & 1.25 & 1.57 & 4.99 & 16.13 & 42.75 & 11.44 & 0.19 & 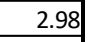 \\
\hline & RCF $9 \mu \mathrm{g} / \mathrm{cm} 2$ & 0.19 & 0.37 & 0.71 & 0.17 & 0.21 & 0.71 & 0.58 & 0.89 & 1.27 & 2.23 & 6.25 & 3.71 & 0.33 & 0.73 & 0.47 & 1.04 & 1.57 & 12.21 & 11.41 & 12.28 & 0.12 & 1.41 \\
\hline & RAsb $9 \mu \mathrm{g} / \mathrm{cm} 2$ & 0.55 & 0.29 & 0.88 & 0.25 & 0.37 & 0.51 & 0.28 & 1.01 & 1.32 & 0.29 & 7.65 & 5.02 & 0.73 & 1.14 & 1.04 & 1.39 & 1.26 & 12.04 & 19.37 & 11.81 & 0.18 & 2.3 \\
\hline & RAsb $6 \mu \mathrm{g} / \mathrm{cm} 2$ & 0.23 & 0.37 & 0.49 & 0.16 & 0.40 & 0.25 & 0.59 & 0.93 & 0.59 & 1.04 & 2.41 & 2.67 & 0.36 & 0.85 & 0.85 & 0.67 & 1.81 & 3.59 & 35.04 & 17.61 & 0.09 & 1.58 \\
\hline Ialue type & Treatment & IL-1a & IL-1b & IL-2 & IL-3 & IL-4 & IL-5 & IL-6 & IL-9 & \begin{tabular}{l|l|} 
IL-10 & I \\
\end{tabular} & IL-12(p40) & $12(\mathrm{p} 70)$ & IL-13 & \begin{tabular}{|l|l|} 
IL-17 \\
\end{tabular} & Eotaxin & G-CSF & IFN-g & KC & MCP-1 & MIP-1a & MIP-1b & \begin{tabular}{|l|} 
RANTES \\
\end{tabular} & TNF-a \\
\hline \multirow{5}{*}{ Mean } & Control & 9.80 & 7.14 & 8.60 & 2.99 & 2.31 & 10.53 & 19.75 & 24.93 & 23.30 & .42 & 6.11 & 112.59 & 2.27 & 10.91 & 25.54 & 18.71 & 29.41 & 161.76 & 639.15 & 92.07 & 1.97 & 32.3 \\
\hline & TCF $60 \mu \mathrm{g} / \mathrm{cm} 2$ & 29.22 & 12.98 & 11.72 & 5.93 & 9.18 & 12.17 & 22.63 & 26.63 & 25.81 & 24.72 & 9.16 & 98.93 & 3.07 & 1.32 & 14.81 & 15.69 & 117.05 & 73.09 & 2042.70 & 473.89 & 2.89 & 40.1 \\
\hline & TCF $5 \mu \mathrm{g} / \mathrm{cm} 2$ & 15.37 & 10.84 & 12.55 & 4.11 & 3.55 & \begin{tabular}{l|l}
15.52 \\
\end{tabular} & 22.11 & 29.87 & 31.48 & 23.11 & 4.19 & 168.62 & 3.55 & 5.82 & 32.91 & 25.02 & 45.02 & 272.87 & 839.78 & 147.86 & 2.59 & 40.8 \\
\hline & TAsb $5 \mu \mathrm{g} / \mathrm{cm} 2$ & 37.11 & 14.51 & 7.14 & 2.15 & 3.10 & 2.95 & 21.17 & 21.88 & 24.85 & 26.58 & 5.13 & 76.41 & 3.18 & 10.47 & 15.87 & 11.76 & 130.75 & 1323.66 & 3160.84 & 1177.37 & 2.82 & 28.3 \\
\hline & TAsb $1.2 \mu \mathrm{g} / \mathrm{cm} 2$ & 20.39 & 10.10 & 8.91 & 2.78 & 2.71 & $8.87 \mid$ & 18.62 & 24.35 & 23.62 & 20.38 & 13.45 & 101.30 & 3.09 & 10.10 & 19.92 & 16.44 & 50.56 & 478.11 & 1005.84 & 402.49 & 2.58 & 32.70 \\
\hline \multirow{5}{*}{$\begin{array}{l}\text { Standard } \\
\text { Error of } \\
\text { Mean } \\
\text { (SEM) }\end{array}$} & Control & 0.57 & 0.54 & 0.86 & 0.52 & 0.12 & 1.52 & 1.89 & 3.31 & 1.55 & 1.29 & 5.98 & 12.64 & 2.27 & 1.16 & 2.25 & 2.06 & 2.53 & 11.48 & 22.40 & 2.60 & 0.22 & 3.5 \\
\hline & TCF $60 \mu \varepsilon$ & 2.16 & 0.69 & 0.44 & 0.60 & 0.54 & 1.49 & 2.04 & 2.22 & 1.53 & 1.10 & 6.29 & 8.66 & 3.07 & 0.30 & 3.10 & 2.22 & 0.62 & 38.92 & 190.69 & 11.59 & 0.15 & 1.8 \\
\hline & TCF $5 \mu \mathrm{g} / \mathrm{cm} 2$ & 1.35 & 1.48 & 1.97 & 0.79 & 0.61 & 4.23 & 3.62 & 5.71 & 3.27 & 3.10 & 11.89 & 27.92 & 2.90 & 2.56 & 8.36 & 4.08 & 4.77 & 12.21 & 17.17 & 2.55 & 0.25 & 5.8 \\
\hline & TAsb $5 \mu \mathrm{g} / \mathrm{cm} 2$ & 0.60 & 0.43 & 0.14 & 0.09 & 0.23 & 0.73 & 0.97 & 2.01 & 0.61 & $1.0 /$ & 3.85 & 1.7 & 3.18 & 0.23 & 2.40 & 1.36 & 4.35 & 10.53 & 84.50 & 8.60 & 0.02 & 2.9 \\
\hline & TAsb $1.2 \mu \mathrm{g} / \mathrm{cm} 2$ & 0.52 & 0.63 & 0.60 & 0.21 & 0.20 & 0.42 & 0.51 & 1.40 & 1.04 & 1.78 & 3.20 & 4.46 & 3.09 & 0.58 & 1.03 & 0.31 & 1.38 & 13.33 & 17.31 & 4.32 & 0.16 & 1.1 \\
\hline
\end{tabular}




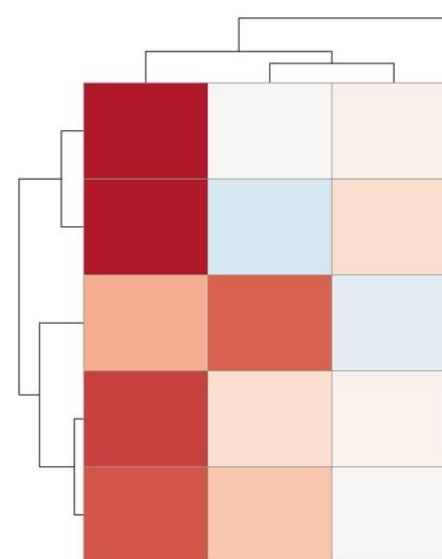

RF $9 \quad \mathrm{RC} 40 \quad \mathrm{RF} 6$ $\mu \mathrm{g} / \mathrm{cm}^{2}$ $\mu \mathrm{g} / \mathrm{cm}^{2}$ $\mathrm{RF} 6$
$\mu \mathrm{g} / \mathrm{cm}^{2}$ Control

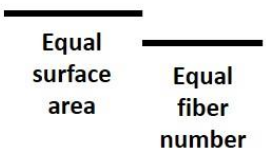

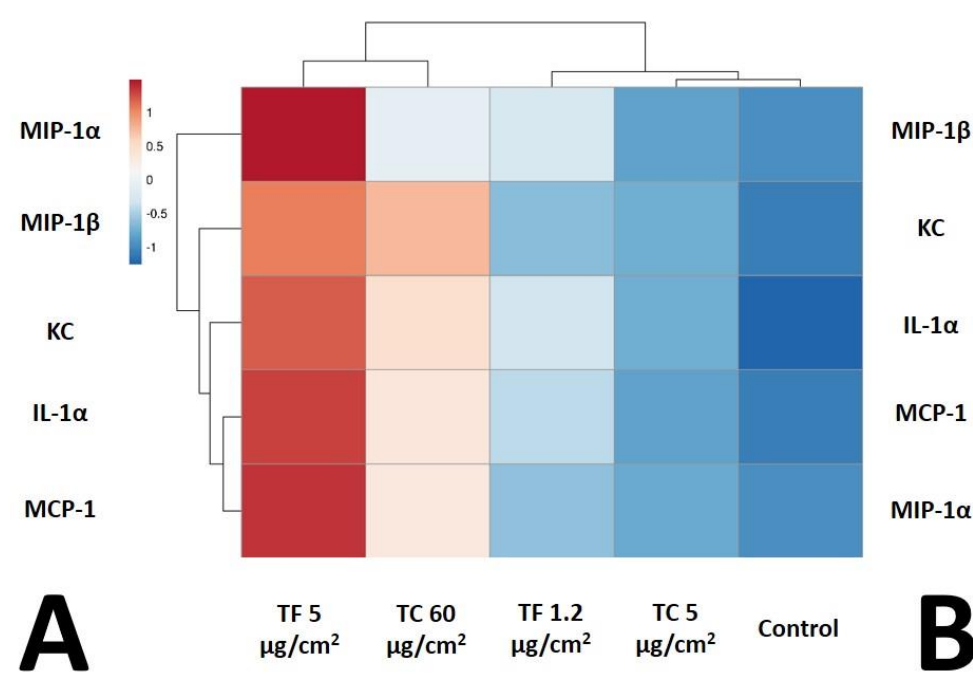

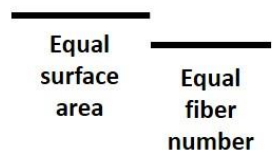

Figure 3.6. Hierarachical clustering of the secreted cytokine profiles for the MPI cells exposeed to riebeckite $(\mathrm{A})$ or tremolite $(\mathrm{B}) \mathrm{EMPs}$. RF - riebeckite asbestos, $\mathrm{RC}$ riebeckite cleavage fragments, TF - tremolite asbestos, TC - tremolite cleavage fragments. Rows are centered; unit variance scaling is applied to rows. Both rows and columns are clustered using Euclidean distance and Ward linkage. Heatmap reflects unit variance.

\subsubsection{Next generation RNA sequencing}

Principal component analysis (PCA) showed a distinguishable gene expression profiling among the samples (Figure 3.7.). 


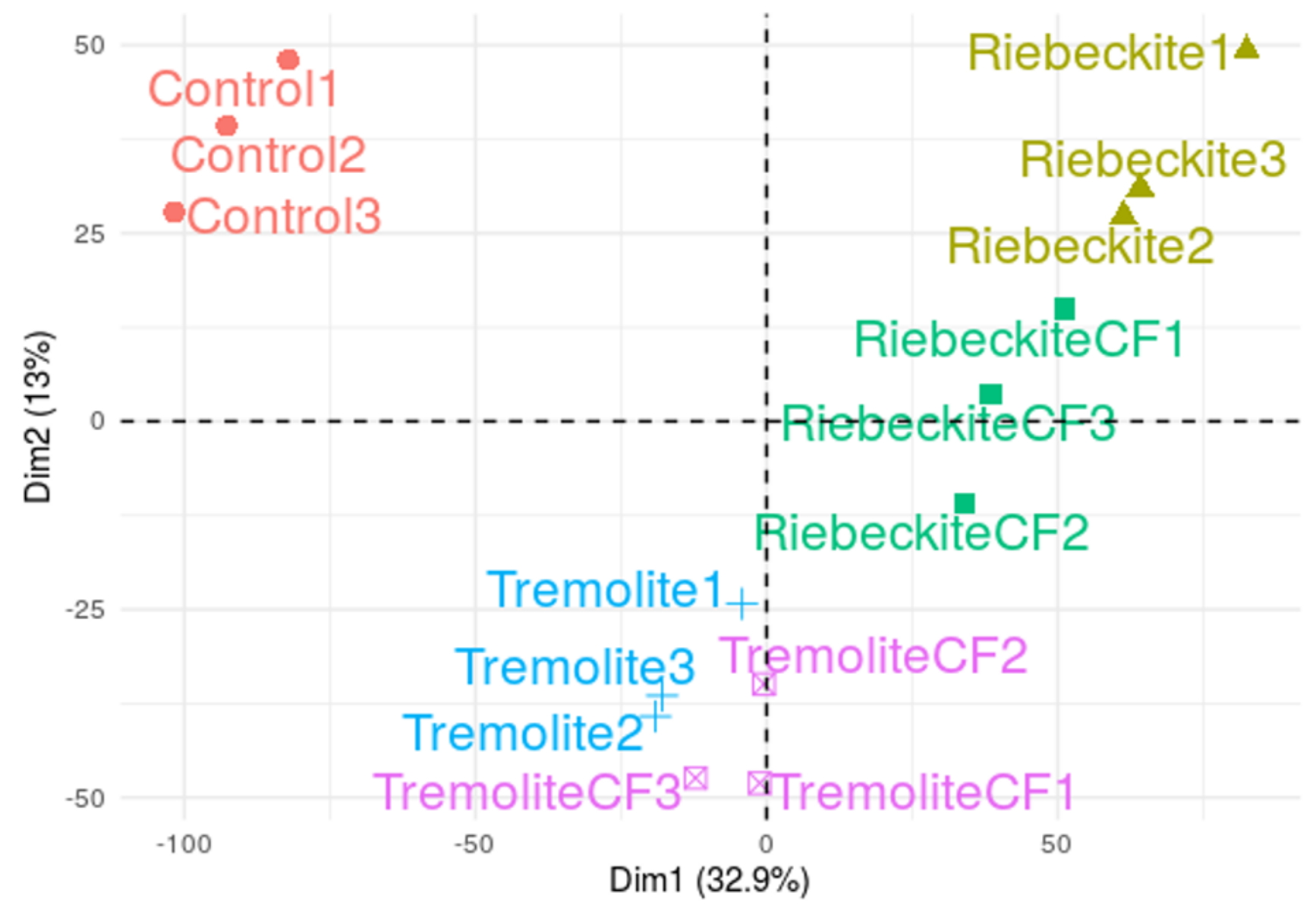

Figure 3.7. Principal component analysis of the gene expression profiles in MPI cells, treated with critical fibers' surface area-equivalent doses of riebeckite and tremolite asbestiform and non-asbetiform EMPs. CF - cleavage fragments.

PCA also demonstrated expected grouping among replicates within samples and also sample groups with different treatment spread across the first two PC dimensions. The Pearson R2 correlation of gene expression between replicates was well over 0.92 Figure 3.8.) suggesting an inter- and intragroup variablity, consistent with each group belonging to the same cell and exposure type. 


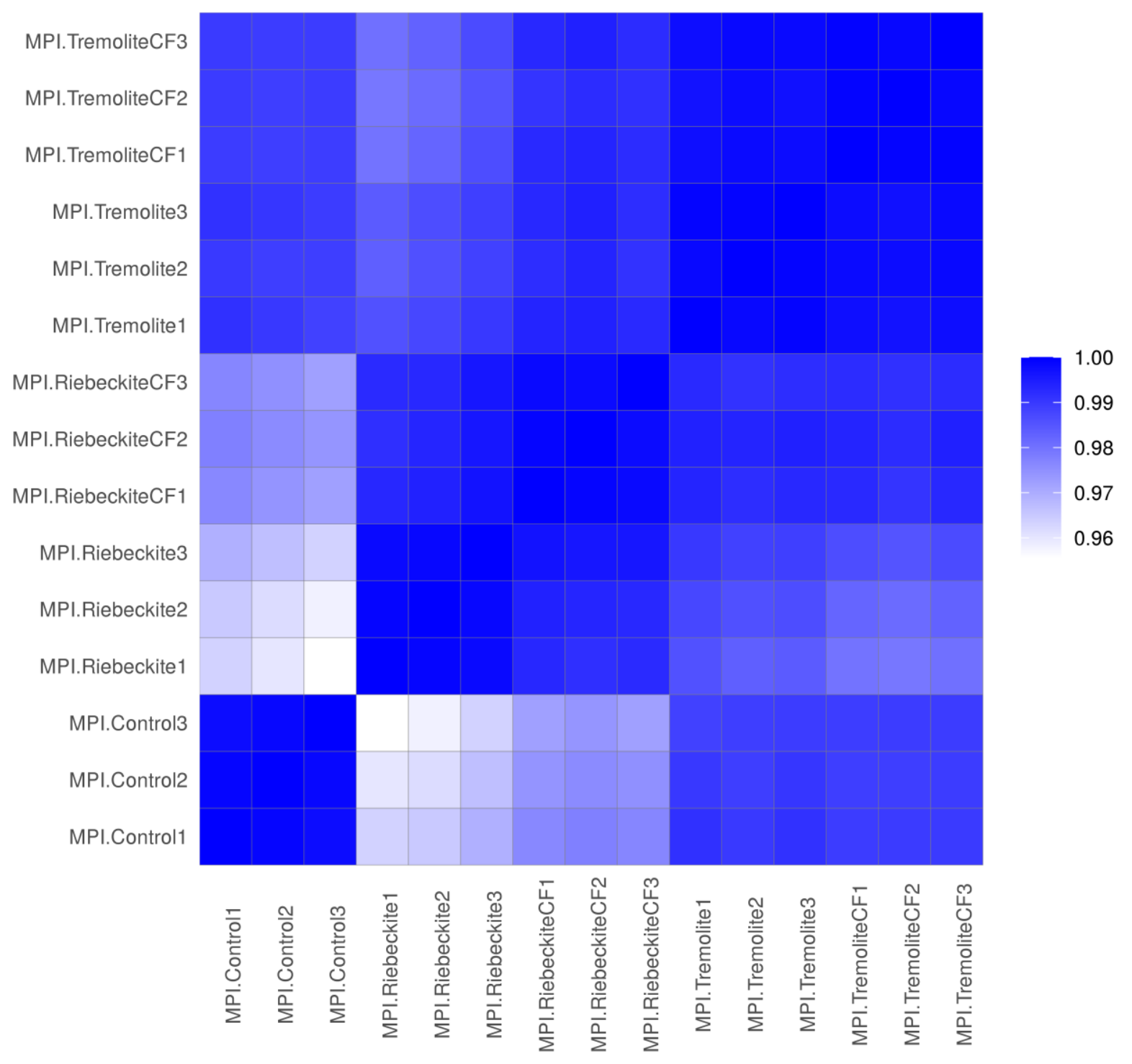

Figure 3.8. Heatmap of Pearson R2 correlation of gene expression between biological replicates. Blue colors indicate high Pearson correlation, and white colors indicate low correlation. Per ENCODE Consortium guidelines RNA sequencing experiments should be performed with two or more biological replicates, unless there is a compelling reason why this is impractical or wasteful. Typically, the Pearson R2 correlation of gene expression between two biological replicates should be over 0.92. CF - Cleavage Fragments

Detailed comparative analysis of all differentially expressed genes (DEG) revealed $492 \uparrow / 302 \downarrow, 374 \uparrow / 220 \downarrow, 224 \uparrow / 70 \downarrow$ or $258 \uparrow / 118 \downarrow$ up $(\uparrow) /$ down $(\downarrow)$ regulated genes with a 
significant fold change $\geq \pm 1.5$ in response to riebeckite asbestos, riebeckite $C F$, tremolite asbestos and tremolite CF, respectively (Figure 3.9).
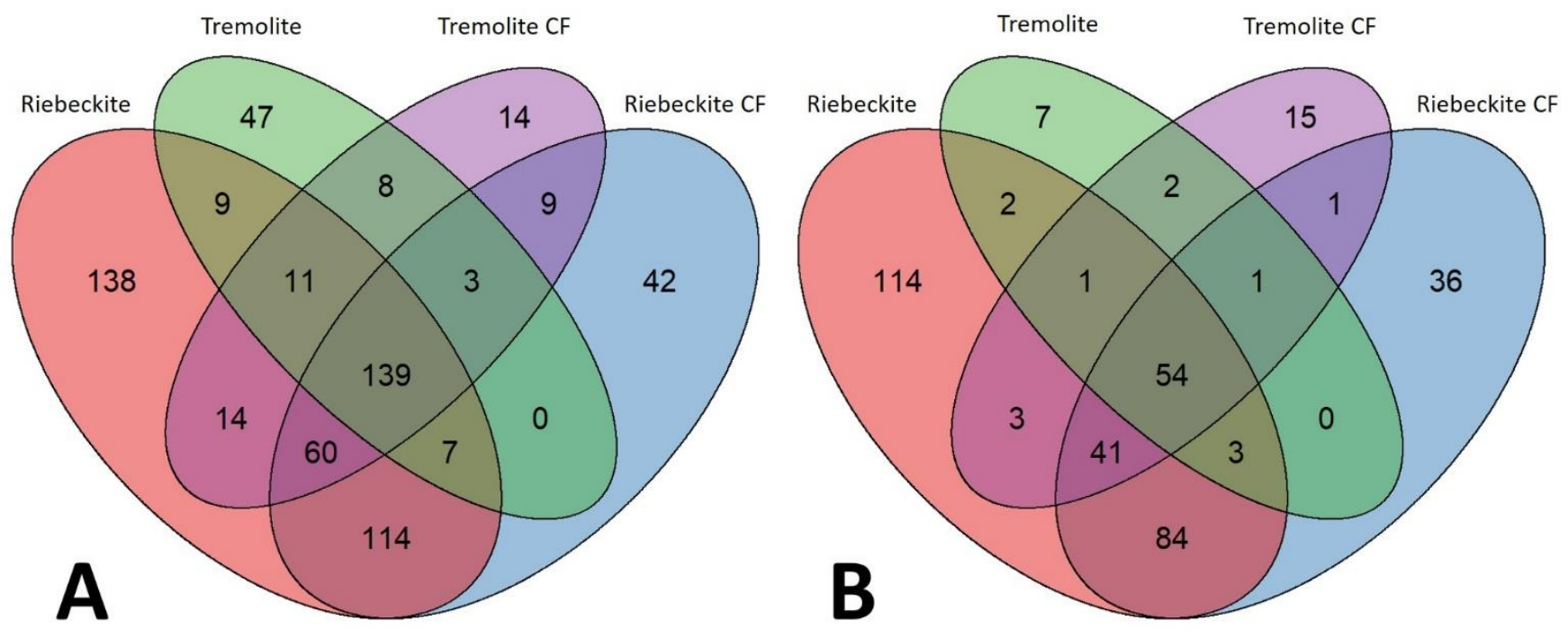

Figure 3.9. Venn Diagrams for upregulated $(A)$ and downregulated genes $(B)$ of MIP cells, treated with critical fibers' surface area-equivalent doses of riebeckite and tremolite asbestiform and non-asbetiform EMPs, compared to untreated cells.

There were more uniquely dysregulated genes common for the riebeckite EMP samples (198), compared to tremolite exposures (10). Among the top 10 DEGs, all 4 materials upregulated 5 (H2-M2, Inhba, Cfb, Acp5, Ear2) and down-regulated 5 (Cfh, Clec4a, Ifitm6, Sell, Clec12a) common genes, with several others common for 2 or 3 of the EMPs (Table 3.3). H2-M2 (MHC-II) was the most upregulated gene. Acod1 was highly upregulated in asbestos and less so in cleavage fragments. Complement factors $\mathrm{B}(\mathrm{Cfb})$ and $\mathrm{H}(\mathrm{Cfh})$ had opposite regulation status.

Table 3.3 The top 10 most significantly up- and down-regulated genes. Bold font indicates dysregulated genes common for all treatments.

\begin{tabular}{|c|c|c|c|}
\hline \multicolumn{5}{|c|}{ Gene Symbol } \\
\hline Riebeckite & Riebeckite CF & Tremolite & Tremolite CF \\
\hline \multicolumn{4}{|c|}{ Top 10 UP Regulated Genes (Log 2 Fold Change) } \\
\hline H2-m2 (4.783) & H2-m2 (3.406) & H2-m2 (3.969) & H2-m2 (2.837) \\
\hline
\end{tabular}




\begin{tabular}{|l|l|l|l|} 
Acod1 (3.622) & Ear2 (3.157) & Cfb (2.575) & Inhba (2.723) \\
\hline Inhba (3.475) & Acp5 (2.908) & Acod1 (2.503) & Ear2 (2.488) \\
\hline Cfb (3.396) & Cfb (2.688) & Inhba (2.415) & Krt79 (2.428) \\
\hline Acp5 (3.186) & Inhba (2.614) & Ear2 (2.321) & Cfb (2.298) \\
\hline Hp (2.846) & Krt79 (2.588) & Tmsb15b2 (1.948) & Tgfbi (2.009) \\
\hline Slc6a12 (2.776) & Cxcr2 (2.506) & Tnfrsf9 (1.913) & Serpine1 (1.974) \\
\hline Ear2 (2.766) & Siglec8 (2.274) & Acp5 (1.839) & Mmp12 (1.816) \\
\hline Krt79 (2.641) & Serpine1 (2.206) & II7r (1.826) & Acp5 (1.792) \\
\hline Pdpn (2.544) & Hp (2.196) & Emp1 (1.626) & Pdpn (1.791) \\
\hline \multicolumn{2}{|l|}{ Top 10 DOWN Regulated Genes (Log2 Fold Change) } \\
\hline Cfh (-2.616) & Cfh (-2.423) & Ifitm6 (-1.979) & Cfh (-2.132) \\
\hline Adgre4 (-2.330) & Adgre4 (-2.253) & Cfh (-1.898) & Ifitm6 (-2.085) \\
\hline Clec4a3 (-2.254) & Ifitm6 (-2.077) & Sell (-1.784) & Sell (-1.860) \\
\hline Ifitm6 (-2.184) & Sell (-1.926) & Pram1 (-1.431) & Pram1 (-1.600) \\
\hline Ms4a8 (-2.128) & Ch25h (-1.911) & F5 (-1.109) & Adgre4 (-1.536) \\
\hline Pram1 (-2.123) & Emilin2 (-1.870) & Tarm1 (-1.105) & Clec12a (-1.373) \\
\hline Sell(-1.949) & Olfm1 (-1.835) & Clec4a3 (-1.102) & Ccn3 (-1.367) \\
\hline Elovl6 (-1.904) & Clec12a (-1.794) & Gda (-1.078) & Clec4a3 (-1.345) \\
\hline Olfm1 (-1.770) & Clec4a3 (-1.785) & Clec12a (-1.064) & Ccnd1 (-1.271) \\
\hline Clec12a (-1.767) & Klf2 (-1.759) & Cd300lg (-1.000) & Klk3 (-1.254) \\
\hline
\end{tabular}

\subsubsection{KEGG pathway enrichment analysis}

Pathways analysis of DEGs following 24 hours of exposure to riebeckite asbestos, riebeckite $\mathrm{CF}$, tremolite asbestos and tremolite $\mathrm{CF}$ predicted the involvement of a total of $61,21,44$ and 25 pathways $(p<0.05)$, respectively. 11 of them were common to all exposure groups (Supplementary Table 1). Those were associated with the immune cell differentiation, inflammation, complement activation, cancer, and granulomatous lesions. Cytokine-cytokine receptor interaction was one of the most uniformly enriched pathways across all groups. NF-kB signaling, and Phagosome were enriched for all groups except riebeckite CF. Th1 and Th2 cell differentiation was exclusive for asbestiform EMPs. Riebeckite asbestos had the most number of uniquely enriched pathways, including 
Regulation of actin cytoskeleton, FC gamma R-mediated phagocytosis, Galactose metabolism, Natural killer cell mediated cytotoxicity, Lysosome, B cell receptor signaling pathway, MAPK signaling pathway, HIF-1 signaling pathway, and Ferroptosis. Pathway associated with NOD-like receptor signaling was uniquely represented only upon tremolite asbestos exposure. JAK-STAT and PPAR signaling pathways were unique for riebeckite EMPs and tremolite CF, while PI3K-Akt signaling pathways was shared only by riebeckite samples. There was also a marked difference between asbestiform and nonasbestiform riebeckite, the former having 41 enriched pathways, not registered in CF. There were also notable differences between tremolite asbestos and CF, and the only common term unique for tremolite mineral EMPs was Transcriptional misregulation in cancer.

\subsubsection{Gene Ontology term enrichment analysis}

GO analysis revealed significant enrichment of the upregulated DEGs in a lot of specific biological processes (BP), most of them tied with the immune responses (Supplementary Table 2). Asbestiform EMPs had overall higher enrichment scores compared to their nonasbestiform counterparts. Tremolite asbestos and cleavage fragments had more distinctions between each other than corresponding riebeckite EMPs. Specific GO biological processes, having much larger scores for the riebeckite samples were those related to apoptosis (GO:0010942, GO:0043065, GO:0097190), intracellular transport (GO:0071702), response to toxic substance (GO:0009636) and others. Tremolite had distinctively enriched BPs related to innate immunity (GO:0002252, GO:0045087) and viral defense (GO:0009615, GO:0051607, GO:0045071 etc.). 


\subsection{Discussion}

Epidemiology of asbestos-related diseases and biological effects of asbestos fibers have been extensively studied since mid-twentieth century, resulting in a firm belief, that "a worldwide ban of asbestos would eventually virtually eliminate its associated diseases" $[42,43]$. Still, decades after becoming known to general public, conditions caused by asbestos exposures contribute most to the global occupational cancer burden and are responsible for the increasing mortality for occupational respiratory diseases [44], with 243,000 deaths attributable to asbestos in 2017 worldwide [45]. In addition, while in vitro studies provided important information on asbestos-induced cyto- and genotoxicity, the essential knowledge of the significance and role of different features and characteristics of fibers, that define responses, is still missing.

There currently is a consensus that among critical determinants of the fibers' pathogenicity are their respirability (ability to deposit into the deep lung), geometric dimensions [46], durability and surface reactivity [1]. The latter is important for toxic effects due to the presence of reactive sites on EMP surface, which was reviewed extensively elsewhere [38]. There is evidence that surface properties of asbestiform and non-asbestiform habits are quite similar for respective riebeckite and tremolite mineral $[47,48]$. Whether growth habit itself is a determinant of EMP toxicity is the critical question that exists in the field of fiber toxicology. There were very limited efforts in elucidating the potential determinants of toxicity of non-asbestiform EMPs, with the general opinion leaning towards their non-toxic nature [49]. One of the major issues with the studies so far was inadequate preparation and characterization of EMPs, which lead to comparisons between vastly different asbestiform and non-asbestiform populations. In our study we: 1) attempted to refine the treatment approach by utilizing pre-made respirable asbestiform and non-asbestiform EMP formulations with the specific dimensional parameters, 2) included three dosing approaches: equivalent mass, surface area and particle number of the critical fibers, and 3) used relevant cell model by employing MPI cells, that are phenotypically close to alveolar macrophages (allowing us to forego using multiple animals for isolating alveolar macrophages from bronchoalveolar lavage). Fiber numbers for all equivalent doses utilized in our study were well within the number concentrations 
used in other studies and are within the exposed workers' lifetime-accumulated number of fibers (Chapter 2). We were not aiming at elucidating the precise mechanisms of asbestos-induced lung disease, due to its complexity and model limitations [50].

Particle dimensions are important due to their established role in fiber toxicity paradigm. In case of human asbestos exposures, thinner fibers $(<0.1 \mu \mathrm{m}$ thick) are associated with pleural plaques and mesothelioma, whilst those having width $0.1-3 \mu \mathrm{m}$ - with fibrosis and lung cancer [51]. Lengthwise, $5 \mu \mathrm{m}$ is considered a "critical" fiber length by the health agencies $[52,53]$. Our sample preparations included EMPs within respirable range, with median lengths close to $5 \mu \mathrm{m}$ (see Appendix A for detailed distribution charts), and cumulative frequency of EMPs with diameter $<3 \mu \mathrm{m}$ at $\sim 90 \%$. Although not part of this study aims, it is important to make parallels with the short vs. long asbestos fibers toxicity paradigm, especially since significantly more studies focused on the shorter vs. longer asbestos rather than asbestiform vs. non-asbestiform EMP comparisons. The earliest evidence led to a prevailing opinion that long asbestos fibers in vitro are more cytotoxic to macrophages than short ones [27]. The situation can be quite different in vivo, however, since EMPs longer than $20 \mu \mathrm{m}$ rarely penetrates deep into the alveolar region. Thus, in vitro studies utilizing non-respirable EMPs should be evaluated having in mind this serious limitation. For non-fibrogenic fibers Castranova et al. found that short and thin glass fibers are more cytotoxic than thick and long [46] while Padmore et al. discovered that shorter fibers are less potent in inducing the inflammatory responses [21]. However, both short and long riebeckite asbestos fibers were able to induce $\mathrm{H}_{2} \mathrm{O}_{2}$ production by macrophages and cause cell death [27].

Airborne particles deposited in the airways and respiratory compartments can be recognized and cleared by macrophages - innate immune cells with a range of molecular tools to deal with newcomers, be it microorganisms, inorganic dust or EMPs [54]. MPI cells have been utilized before to assess the alveolar macrophage response to infectious agents, such as $P$. Aeruginosa and $S$. pneumoniae [55], M. tuberculosis [56], B. thailandensis [57], and adenoviruses [58] as well as nanoparticles [35]. Previous functional study revealed that phagocytosis of fibrous particles, even longer than the cell itself, does not lead to the immediate loss of membrane integrity and death in macrophages, but pulling the fiber out (by other macrophage, for instance) does [24]. In 
our case we noticed a uniform decrease in the ratio of live/dead cells across the treatment groups, except the lower dose of riebeckite CF (mass-equivalent to riebeckite asbestos). At the same time, there was a significant increase in the LDH leaked from the cells, which was similar for riebeckite CF and asbestos if compared at the calculated surface areaand particle number-equivalent doses. Despite statistically significant decrease in the ratio of viable to dead cells for both higher and lower doses, the lower tremolite CF dose $\left(5 \mu \mathrm{g} / \mathrm{cm}^{2}\right)$ did not increased the LDH activity in supernatants. The difference may have to do with the excessive LDH leakage from the cells that were not yet dead in the other treatment groups. The cytotoxicity methods utilized, does not discriminate between necrosis and the consequences of a programmed cell death - apoptosis [59].

Differences between AM responses to riebeckite and tremolite can be approached by first looking at the redox behavior of respective minerals. EDS analysis confirmed the abundance of iron in riebeckite samples, but only a very small amount in tremolite asbestos and no detectable iron in tremolite CF. However, previously it was found that both riebeckite and tremolite fibers exhibit sustained surface reactivity, and in both studied minerals free radical production does not depend on total iron content, but rather on specific $\mathrm{Fe}^{2+}$ and $\mathrm{Fe}^{3+}$ sites on the surface [47]. Upon incubation with $\mathrm{H}_{2} \mathrm{O}_{2}-$ simulating the lysosomal conditions - hydroxyl radical yield from tremolite significantly drops by 24 hours, as opposed to significant increase in riebeckite fibers, but sustained radical reactivity of tremolite continues (especially the COO-• production) for quite a long time [47]. Increased genotoxicity of riebeckite over tremolite was previously observed in A549 cells [22], but not in macrophages, which are capable of more prominent "oxidative bursts". To look deeper into the particle-specific cellular responses, we decided to measure the extent of DNA damage. Asbestos exposures had long been found causing double-strand DNA breaks (DSBs), mostly through mechanisms involving redox stress [60-63]. DSBs are the most deleterious DNA lesions, which, if left unrepaired, may have severe consequences for cell survival, as they lead to chromosome aberrations, genomic instability, or cell death. Cells respond to DNA damage by activating the so-called DNA damage response (DDR), a complex molecular mechanism developed to detect and repair DNA damage. The formation of DSBs triggers activation of many factors, including phosphorylation of the histone variant $\mathrm{H} 2 \mathrm{AX}$, producing $\mathrm{YH} 2 \mathrm{AX}$. By measuring the 
amount of phosphorylation, we can estimate the extent of DDR. It should be noted, however, that H2AX phosphorylation also occurs under basal conditions, and can increase, for example during the cell division. There was a clear surge in median $\mathrm{yH} 2 \mathrm{AX}$ signal in the asbestos-treated cells, compared to control and cleavage fragments, except for the lower dose of tremolite (equivalent for particle number to respective cleavage fragments). Equal surface area did not play role in this case. The plausible explanation being that relatively small but potent population of asbestiform EMPs, longer than $20 \mu \mathrm{m}$ (about $5 \%$ in riebeckite and $4 \%$ in tremolite asbestos samples), can cause the most deleterious lesions or affect the DNA repair processes more severely [64]. Cell apoptosis also leads to the formation of DSBs during the DNA fragmentation. In permeabilized cells, the fragmented 182bp DNA multimers may leak outside, resulting in a reduced DNA population of cells (sub-G1 peak on a cell-cycle histogram). Analysis of the nuclear staining signal revealed increased sub-G1 populations for most of the treatments, more so in riebeckite EMPs, with cleavage fragments having the highest values. However, upon closer inspection (Figure3.1.), it can be seen that sub-G1 populations in CF samples are confined closer to G1 itself, which is characteristic of necrotic cells, and do not exhibit significant $\mathrm{YH} 2 \mathrm{AX}$ signal, while in riebeckite asbestos the sub-G1 cells localize away from the $\mathrm{G} 1$, many of them having high $\mathrm{yH} 2 \mathrm{AX}$, which is characteristic of cells at different stages of programmed cell death $[65,66]$. Substantial presence of apoptotic cells is further supplemented by the specific enrichment of GO BP terms related to apoptosis in riebeckite-treated cells. The combined results still do not allow us to make confident assumptions regarding the prevalent mode of death in each treatment case. More extensive testing, focusing specifically on the hallmarks of cell deaths is required, since alveolar macrophage apoptosis has been implicated in the development of pneumoconiosis [67] and asbestosis [68].

The "tolerant" nature of the AM majority prevents overreaction and excessive activation. That being said, AM population is not homogenous and includes genotypically and functionally different varieties. [69-71]. Not all of them are strictly immunosuppressive and as early as in 1996 researchers hypothesized that the disbalance of suppressive vs. reactive subtypes (i.e. caused by the excessive apoptosis of the former subtype) is what constitutes the development of lung disease [68]. MPI cells themselves are more than 
capable of acute pro-inflammatory reaction to pathogens, such as live $M$. tuberculosis [56]. In our study, compared to basal conditions, EMP-treatments only slightly upregulated secretion of alarmins, such as IL-1 $\alpha$, and IL-1 $\beta$, but not TNF- $\alpha$ or IL-6, while at the same time caused significant increase in chemokines (MIP-1a, MIP-1b, MCP-1 and $\mathrm{KC})$. This was previously observed ex vivo as well where alveolar macrophage obtained from the healthy human volunteers secreted minuscule amount of cytokines compared to the blood monocytes from the same subjects, after stimulation with 4 different types of asbestos, which was attributed to the translational block [72]. Hierarchical cluster analysis of the cytokine/chemokine secretion pattern showed close clustering for the surface area and particle number equivalent treatments, with significantly more chemokines secreted by asbestos-treated cells compared to cleavage fragments (Table B1, Appendix B). Secretion of chemokines/chemoattractant proteins is a major event happening during cellfiber interaction. $\mathrm{KC}$ in particular is responsible for neutrophils chemotaxis, which plays a major role in the asbestosis pathogenesis [73]. Although important from the macrophage response standpoint, these results cannot be reliably translated into the in vivo settings, as shown by multiple studies that assessed the cytokine secretion profiles of the AMs. It is established that, in humans with asbestosis, alveolar macrophages secrete proinflammatory cytokines and are overresponsive to the other stimuli $[74,75]$. Driscoll et al. reported considerable IL-1 and TNF- $\alpha$ secretion by rat alveolar macrophages at day 3 post exposure to crocidolite, which decreased substantially on days 7,14 , and 28 [76]. The increased cytokine secretion observed in humans and animals, however, has not been reproduced in vitro [74], just like in our study.

Detectable changes in macrophage gene expression happen within 6-24 hours post-stimuli [77], thus we performed the next generation RNA sequencing of the MPI cells 24 hours post exposure to surface area-equivalent doses of riebeckite and tremolite EMPs to see if AM immediate transcriptional reprogramming patterns are intrinsic for different minerals and/or crystallization habit. We decided to go with the surface areaequivalency, since it was more uniformly predictive of cytotoxicity for both riebeckite and tremolite, than fiber number equivalent doses. RNAseq revealed that MPI cells responded to EMP treatment by upregulating a significant number of genes responsible for the acute phase response, inflammation, antigen processing etc. Riebeckite asbestos 
had the most significantly dysregulated genes compared to control, followed by riebeckite $\mathrm{CF}$, tremolite asbestos and tremolite CF. Genes involved in iron handling, such as haptoglobin $(H p)$, ferritin light chain $(F t / 1)$, and heme oxygenase 1 (Hmox1) were prevalently upregulated by riebeckite asbestos treatment, although we cannot reliably tie it up with the higher iron content in this mineral, for instance, it can be just the part of an acute response response, such as inhibiting the pro-inflammatory HMGB1 molecules [78]. However, transcriptional upregulation of both ferritin and heme oxygenase 1 have been previously implicated in asbestos-related pathology [79, 80]. Acod1 is a gene, which is upregulated in the macrophages upon a plethora of stimuli, and is coregulated together by TNF- $\alpha$ and IFN-gamma [81]. Complement factor B (Cfb) was significantly upregulated in all groups, while its competitor - complement factor $\mathrm{H}(\mathrm{Cfh})$ - downregulated. Downregulation of the Cfh can be related to the excessive NFkB and IL- $1 \beta$ signaling (through the microRNAs), seen across the samples. While it might be beneficial for the initial innate responses, sustained Cfh deficits may eventually result in pathogenic complement activation, chronic inflammation and autoimmunity, all seen in human asbestos exposures [82]. The role of $C f$ in lung diseases is still not clear, however some lung cancers upregulate Cfh expression to avoid cell lysis through the complement activation [83]. A set of Ifit genes (ifit3, ifit1b, ifit2) was uniquely upregulated only in tremolite asbestos-exposed cells. This is peculiar, since those are mostly induced by type I (IFN- $\alpha / \beta)$ and type III (IFN- $\lambda s$ ) interferons whereas type II IFN (IFN- $\gamma$ ) is much less potent [84]. Ifit proteins lack enzymatic activity but bind a variety of RNAs and other macromolecules, contributing to the viral defense. Both KEGG pathway and GO BP analysis also revealed several highly enriched virus response pathways in tremolite asbestos samples. Type I interferons play an important role in lung homeostasis and can downplay the immune-mediated pathology [85], which is important for chronic conditions, such as asbestosis, and was already confirmed for silicosis [86]. KEGG analysis revealed that both asbestiform and non-asbestiform riebeckite EMPs induced JAK-STAT, PPAR, and PI3K-Akt signaling pathways, which may signify the close intracellular response patterns to that particular mineral - something we have not observed in tremolite-treated cells. Nevertheless, riebeckite asbestos had 41 enriched pathways, not present in respective CFs, including those related to NF-kB and MAPK signaling, cell adhesion 
molecules, as well as phagosome/lysosome function. GO BP also revealed more sophisticated transcriptional response to riebeckite asbestos, compared to CF. The fact that NOD-like receptor signaling KEGG pathway was enriched only in tremolite also requires further attestation by the functional assays, since we have observed the same in our mouse experiment at 7 days post-treatment with tremolite, but not riebeckite [87].

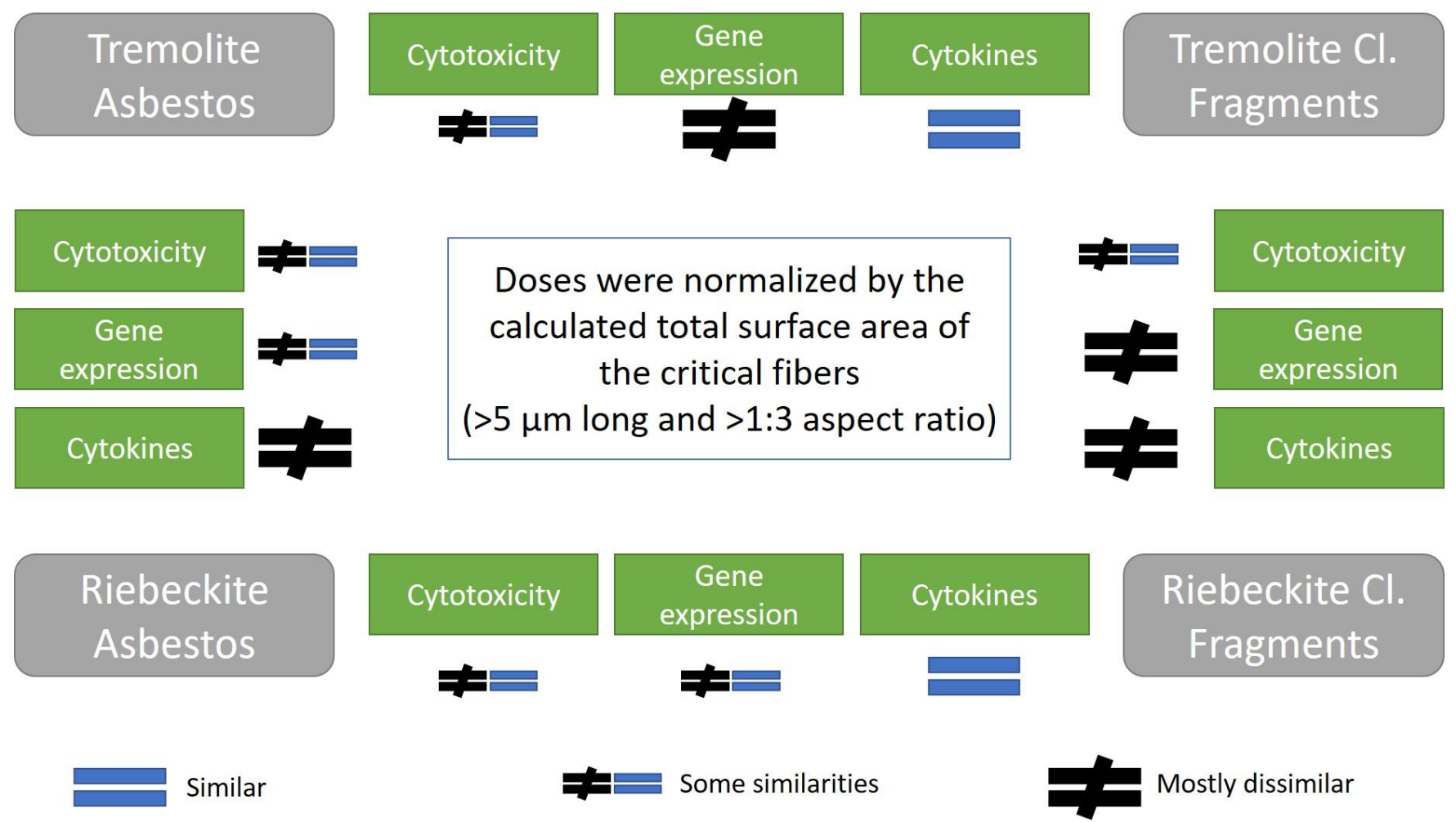

Figure 3.10. Summary of the alveolar macrophages' responses to asbestiform and nonasbestiform EMPS if compared at the critical fibers' surface area-equivalent doses.

Overall, magnitude and direction of the gene expression dysregulation was the highest in riebeckite asbestos-treated cells and followed the similar patterns for riebeckite asbestos and cleavage fragments but was quite divergent for tremolite polymorphs. Together with the cytotoxicity and cytokine secretion data, a pattern emerges, when if compared at the equivalent surface area of critical fibers, asbestiform and nonasbestiform EMP preparations show some similarity in how AMs respond to them in a short time-frame of 24 hours (Figure 3.10.). The similarity is more pronounced for the riebeckite mineral than for tremolite, which may have to do with the potential differences in surface reactivity. The observed AM response patterns align with the threshold paradigm outlined by Cox et al. [88]: individual cellular endpoints, such as membrane or 
even DNA damage cannot serve as reliable predictors of an outcome. The notable differences in cell responses to riebeckite vs. tremolite mineral EMPs, including respective cleavage fragments might have to do with the variable iron content, presence of silanol groups, particle opsonization by specific proteins etc. It is more likely that only upon accumulation of different signals and the overcoming of activation threshold, the specific outcome can be observed. The combinations of signals may as well be different for different minerals: based on our results, growth habit might play bigger role for ones (tremolite) and be a less significant determinant for others (riebeckite).

Studies in vitro have intrinsic limitations and cannot address all the complexity of interactions among tissues and organs, and do not account for the modifying effects of deposition patterns and clearance by mucociliary actions as well as contribution from biopersistence. Specialists in the field all agree that "....what happens at the lung level is based on a population of fibers getting to the deep part of the lung and not based on one EMP interacting with one lung cell" [89]. Artificial approach to the sample preparation, although necessary for adequate comparisons, is not exactly representative of the typical human exposures. In in vivo settings, shorter EMPs, including non-asbestform mineral analogues can be cleared more easily, but it does not mean they are less potent in causing cell damage in the sustained exposure scenario. Further studies focusing on the EMP-evoked free radical production and time-resolved cell death are necessary to complement the results of this study.

\subsection{Conclusions}

Our study is the first one that attempted to determine the toxicological profiles of comparable asbestiform and non-asbestiform EMPs populations in vitro, utilizing different dose metrics in a relevant alveolar macrophage model. We only partially confirmed the initial hypothesis. While equal mass-based doses resulted in markedly differential responses between asbestos and CF, at equal fiber surface area-based doses asbestos and corresponding CF had similar cytotoxic effects. However, when further comparing equivalent surface-area based treatments, there were distinct transcriptional reprogramming patterns and DNA damage, also specific for the mineral type, suggesting 
that asbestiform habit itself may be an important determinant for some minerals, like tremolite. Altogether, the accumulated evidence points us in the direction of the selective approach to choosing relevant EMP parameters for hazard identification step of risk assessment. Further understanding the factors and mechanisms by which EMP exert toxicity may lead to the emerging of new paradigm, where aside from determining the number of EMPs per volume of air, other parameters, such as surface area of the "critical" fibers should be accounted for. Future studies that account for that selective approach may help improve preventive and therapeutic measures for an ultimate goal of the reduction of pulmonary disease caused by EMPs. The results of such studies may contribute towards development of sampling and analytical methods that closely measure the characteristics important for toxicity, development of appropriate recommendations for worker protection and determination of criteria that could be used to predict the potential risk associated with exposure to any particular type of EMP. Finally, the results may help fill in knowledge gaps beyond EMPs - exposure to other elongate particles, including inorganic and organic manufactured materials.

\subsection{References}

1. Lippmann, M., Toxicological and epidemiological studies on effects of airborne fibers: coherence and public [corrected] health implications. Crit Rev Toxicol, 2014. 44(8): p. 643-95.

2. Cancer, I.A.f.R.o., A Review of Human Carcinogens: Arsenic, metals, fibres, and dusts. 2012: International Agency for Research on Cancer.

3. Cancer, I.A.f.R.o., Some Nanomaterials and Some Fibres. 2017: World Health Organization.

4. Manning, C.B., V. Vallyathan, and B.T. Mossman, Diseases caused by asbestos: mechanisms of injury and disease development. Int Immunopharmacol, 2002. 2(2-3): p. 191-200.

5. Middendorf, P., et al., Current intelligence bulletin 62: asbestos fibers and other elongate mineral particles: state of the science and roadmap for research. 2011, U.S. Department of Health and Human Services, Public Health Service, Centers for Disease Control and Prevention, National Institute for Occupational Safety and Health, DHHS (NIOSH) Cincinnati, OH. p. 173.

6. Belluso, E., et al., Crystal habit of mineral fibres, in Mineral Fibres: Crystal Chemistry, Chemical-Physical Properties, Biological Interaction and Toxicity. 2017, Mineralogical Society of Great Britain and Ireland. p. 0.

7. Berman, D.W., P. Hibbs, and M. Lippmann, Proceedings of the the Monticello Conference on Elongated Mineral Particles. Session III: Human exposure, effects \& risk. Toxicology and Applied Pharmacology, 2018. 361: p. 145-148. 
8. Dunning, K.K., et al., Mesothelioma associated with commercial use of vermiculite containing Libby amphibole. J Occup Environ Med, 2012. 54(11): p. 1359-63.

9. Miller, A., "Not your grandfather's pleural disease": rapid progression, ventilatory impairment, and chronic pleuritic pain from Libby vermiculite/amphibole. Am J Ind Med, 2014. 57(11): p. 1195-6.

10. Dikensoy, O., Mesothelioma due to environmental exposure to erionite in Turkey. Curr Opin Pulm Med, 2008. 14(4): p. 322-5.

11. Bugge, M.D., et al., Lung cancer incidence among Norwegian silicon carbide industry workers: associations with particulate exposure factors. Occup Environ Med, 2012. 69(8): p. 527-33.

12. Metcalf, R.V. and B.J. Buck, Genesis and health risk implications of an unusual occurrence of fibrous NaFe3+-amphibole. Geology, 2015. 43(1): p. 63-66.

13. Pfau, J.C., et al., Comparative health effects in mice of Libby amphibole asbestos and a fibrous amphibole from Arizona. Toxicol Appl Pharmacol, 2017. 334: p. 2434.

14. Mandel, J.H., B.H. Alexander, and G. Ramachandran, A review of mortality associated with elongate mineral particle (EMP) exposure in occupational epidemiology studies of gold, talc, and taconite mining. Am J Ind Med, 2016. 59(12): p. 1047-1060.

15. Allen, E.M., et al., Occupational exposures and lung cancer risk among Minnesota taconite mining workers. Occup Environ Med, 2015. 72(9): p. 633-9.

16. Garabrant, D.H. and S.T. Pastula, A comparison of asbestos fiber potency and elongate mineral particle (EMP) potency for mesothelioma in humans. Toxicol Appl Pharmacol, 2018. 361: p. 127-136.

17. Pira, E., et al., Mortality of Talc Miners and Millers From Val Chisone, Northern Italy: An Updated Cohort Study. J Occup Environ Med, 2017. 59(7): p. 659-664.

18. Yang, H.Y., R.H. Shie, and P.C. Chen, Pulmonary fibrosis in workers exposed to non-asbestiform tremolite asbestos minerals. Epidemiology, 2013. 24(1): p. 1439.

19. Yang, H.Y., R.H. Shie, and P.C. Chen, Carving of non-asbestiform tremolite and the risk of lung cancer: a follow-up mortality study in a historical nephrite processing cohort. Occup Environ Med, 2013. 70(12): p. 852-7.

20. Kohyama, N., et al., Lung cancer in a patient with predominantly short tremolite fibers in his lung. Am J Ind Med, 2017. 60(9): p. 831-838.

21. Padmore, T., et al., Quantitative analysis of the role of fiber length on phagocytosis and inflammatory response by alveolar macrophages. Biochim Biophys Acta Gen Subj, 2017. 1861(2): p. 58-67.

22. Pacella, A., et al., Iron topochemistry and surface reactivity of amphibole asbestos: relations with in vitro toxicity. Anal Bioanal Chem, 2012. 402(2): p. 87181.

23. Duncan, K.E., et al., In vitro determinants of asbestos fiber toxicity: effect on the relative toxicity of Libby amphibole in primary human airway epithelial cells. Part Fibre Toxicol, 2014. 11: p. 2.

24. Ishida, T., et al., Live-cell imaging of macrophage phagocytosis of asbestos fibers under fluorescence microscopy. Genes Environ, 2019. 41: p. 14. 
25. Castranova, V., et al., Comparative Cytotoxic Effects of Crocidolite and its NonAsbestiform Polymorph on Rat Alveolar Macrophages. The Annals of Occupational Hygiene, 1994. 38(inhaled_particles_VII): p. 665-673.

26. Palekar, L.D., C.M. Spooner, and D.L. Coffin, Influence of crystallization habit of minerals on in vitro cytotoxicity. Ann N Y Acad Sci, 1979. 330: p. 673-86.

27. Goodglick, L.A. and A.B. Kane, Cytotoxicity of long and short crocidolite asbestos fibers in vitro and in vivo. Cancer Res, 1990. 50(16): p. 5153-63.

28. Miserocchi, G., et al., Translocation pathways for inhaled asbestos fibers. Environ Health, 2008. 7: p. 4.

29. Adib, G., et al., Short, fine and WHO asbestos fibers in the lungs of quebec workers with an asbestos-related disease. Am J Ind Med, 2013. 56(9): p. 100114.

30. Dodson, R.F., M.A.L. Atkinson, and J.L. Levin, Asbestos fiber length as related to potential pathogenicity: A critical review. 2003. 44(3): p. 291-297.

31. Joshi, N., et al., A spatially restricted fibrotic niche in pulmonary fibrosis is sustained by M-CSF/M-CSFR signalling in monocyte-derived alveolar macrophages. Eur Respir J, 2020. 55(1).

32. Oberdorster, G. and U. Graham, Predicting EMP hazard: Lessons from studies with inhaled fibrous and non-fibrous nano- and micro-particles. Toxicol Appl Pharmacol, 2018. 361: p. 50-61.

33. National Toxicology, P., NTP Toxicology and Carcinogenesis Studies of Tremolite (CAS No. 14567-73-8) in F344/N Rats (Feed Studies). Natl Toxicol Program Tech Rep Ser, 1990. 277: p. 1-183.

34. Fejer, G., et al., Nontransformed, GM-CSF-dependent macrophage lines are a unique model to study tissue macrophage functions. Proc Natl Acad Sci U S A, 2013. 110(24): p. E2191-8.

35. Deville, S., et al., Time-resolved characterization of the mechanisms of toxicity induced by silica and amino-modified polystyrene on alveolar-like macrophages. Arch Toxicol, 2020. 94(1): p. 173-186.

36. Suo, S., et al., Revealing the Critical Regulators of Cell Identity in the Mouse Cell Atlas. Cell Rep, 2018. 25(6): p. 1436-1445 e3.

37. Davis, J.M., et al., Variations in the carcinogenicity of tremolite dust samples of differing morphology. Ann N Y Acad Sci, 1991. 643: p. 473-90.

38. Aust, A.E., P.M. Cook, and R.F. Dodson, Morphological and chemical mechanisms of elongated mineral particle toxicities. J Toxicol Environ Health B Crit Rev, 2011. 14(1-4): p. 40-75.

39. Mossman, B.T., et al., Pulmonary endpoints (lung carcinomas and asbestosis) following inhalation exposure to asbestos. J Toxicol Environ Health B Crit Rev, 2011. 14(1-4): p. 76-121.

40. Spencer, D.M., J. Gauley, and D.S. Pisetsky, The properties of microparticles from RAW 264.7 macrophage cells undergoing in vitro activation or apoptosis. Innate Immun, 2014. 20(3): p. 239-48.

41. Metsalu, T. and J. Vilo, ClustVis: a web tool for visualizing clustering of multivariate data using Principal Component Analysis and heatmap. Nucleic Acids Res, 2015. 43(W1): p. W566-70. 
42. Schraufnagel, D.E. and A.T. Society, Breathing in America: Diseases, Progress, and Hope. 2010: American Thoracic Society.

43. Vincenten, J., et al., Barriers and Facilitators to the Elimination of Asbestos Related Diseases-Stakeholders' Perspectives. Int J Environ Res Public Health, 2017. 14(10).

44. De Matteis, S., et al., Current and new challenges in occupational lung diseases. Eur Respir Rev, 2017. 26(146).

45. Collaborators, G.B.D.R.F., Global, regional, and national comparative risk assessment of 84 behavioural, environmental and occupational, and metabolic risks or clusters of risks for 195 countries and territories, 1990-2017: a systematic analysis for the Global Burden of Disease Study 2017. Lancet, 2018.

392(10159): p. 1923-1994.

46. Castranova, V., et al., In vitro effects of large and small glass fibers on rat alveolar macrophages. J Toxicol Environ Health, 1996. 49(4): p. 357-69.

47. Andreozzi, G.B., et al., Surface reactivity of amphibole asbestos: a comparison between crocidolite and tremolite. Sci Rep, 2017. 7(1): p. 14696.

48. Schiller, J.E., S.L. Payne, and S.E. Khalafalla, Surface charge heterogeneity in amphibole cleavage fragments and asbestos fibers. Science, 1980. 209(4464): $p$. 1530-2.

49. Mossman, B.T., Assessment of the pathogenic potential of asbestiform vs. nonasbestiform particulates (cleavage fragments) in in vitro (cell or organ culture) models and bioassays. Regul Toxicol Pharmacol, 2008. 52(1 Suppl): p. S200-3.

50. Kamp, D.W. and S.A. Weitzman, The molecular basis of asbestos induced lung injury. Thorax, 1999. 54(7): p. 638-52.

51. Lippmann, M., Asbestos exposure indices. Environ Res, 1988. 46(1): p. 86-106.

52. Group, E.R., Report on the Expert Panel on Health Effects of Asbestos and Synthetic Vitreous Fibers: The Influence of Fiber Length 2003: Lexington, MA 02421 p. 229.

53. World Health, O., Air quality guidelines for Europe. WHO Reg Publ Eur Ser, 2000(91): p. V-X, 1-273.

54. Laskin, D.L., R. Malaviya, and J.D. Laskin, Pulmonary macrophages, in Comparative biology of the normal lung, R.A. Parent, Editor. 2015, Elsevier/AP, Academic Press is an imprint of Elsevier: Amsterdam ; Boston. p. 629-649.

55. Bastaert, F., et al., Pseudomonas aeruginosa LasB Subverts Alveolar Macrophage Activity by Interfering With Bacterial Killing Through Downregulation of Innate Immune Defense, Reactive Oxygen Species Generation, and Complement Activation. Front Immunol, 2018. 9: p. 1675.

56. Woo, M., et al., Mycobacterium tuberculosis Infection and Innate Responses in a New Model of Lung Alveolar Macrophages. Front Immunol, 2018. 9: p. 438.

57. Chen, J., et al., Glycan targeted polymeric antibiotic prodrugs for alveolar macrophage infections. Biomaterials, 2019. 195: p. 38-50.

58. Stichling, N., et al., Lung macrophage scavenger receptor SR-A6 (MARCO) is an adenovirus type-specific virus entry receptor. PLoS Pathog, 2018. 14(3): $\mathrm{p}$. e1006914.

59. Chan, F.K., K. Moriwaki, and M.J. De Rosa, Detection of necrosis by release of lactate dehydrogenase activity. Methods Mol Biol, 2013. 979: p. 65-70. 
60. Okayasu, R., et al., Asbestos and DNA double strand breaks. Cancer Res, 1999. 59(2): p. 298-300.

61. Msiska, Z., et al., DNA double-strand breaks by asbestos, silica, and titanium dioxide: possible biomarker of carcinogenic potential? Am J Respir Cell Mol Biol, 2010. 43(2): p. 210-9.

62. Marczynski, B., et al., Increased incidence of DNA double-strand breaks and anti-ds DNA antibodies in blood of workers occupationally exposed to asbestos. Hum Exp Toxicol, 1994. 13(1): p. 3-9.

63. Moyer, V.D., et al., Oxygen radicals and asbestos carcinogenesis. Environ Health Perspect, 1994. 102 Suppl 10: p. 131-6.

64. Levresse, V., et al., DNA breakage in asbestos-treated normal and transformed (TSV40) rat pleural mesothelial cells. Mutagenesis, 2000. 15(3): p. 239-244.

65. Wlodkowic, D., J. Skommer, and Z. Darzynkiewicz, Cytometry in cell necrobiology revisited. Recent advances and new vistas. Cytometry A, 2010. 77(7): p. 591-606.

66. Darzynkiewicz, Z., et al., Cytometry in cell necrobiology: analysis of apoptosis and accidental cell death (necrosis). Cytometry, 1997. 27(1): p. 1-20.

67. Borges, V.M., et al., Fas ligand triggers pulmonary silicosis. J Exp Med, 2001. 194(2): p. 155-64.

68. Hamilton, R.F., L.L. Iyer, and A. Holian, Asbestos induces apoptosis in human alveolar macrophages. Am J Physiol, 1996. 271(5 Pt 1): p. L813-9.

69. Joshi, N., J.M. Walter, and A.V. Misharin, Alveolar Macrophages. Cell Immunol, 2018. 330: p. 86-90.

70. Holt, P.G., Down-regulation of immune responses in the lower respiratory tract: the role of alveolar macrophages. Clin Exp Immunol, 1986. 63(2): p. 261-70.

71. Alber, A., et al., The role of macrophages in healing the wounded lung. Int J Exp Pathol, 2012. 93(4): p. 243-51.

72. Geist, L.J., et al., Asbestos stimulation triggers differential cytokine release from human monocytes and alveolar macrophages. Exp Lung Res, 2000. 26(1): p. 4156.

73. Broser, M., et al., Elevated interleukin-8 in the alveolitis of individuals with asbestos exposure. Int Arch Occup Environ Health, 1996. 68(2): p. 109-14.

74. Perkins, R.C., et al., Human alveolar macrophage cytokine release in response to in vitro and in vivo asbestos exposure. Exp Lung Res, 1993. 19(1): p. 55-65.

75. Holian, A., et al., Asbestos and silica-induced changes in human alveolar macrophage phenotype. Environ Health Perspect, 1997. 105 Suppl 5: p. 113942.

76. Driscoll, K.E., et al., Alveolar macrophage cytokine and growth factor production in a rat model of crocidolite-induced pulmonary inflammation and fibrosis. $\mathrm{J}$ Toxicol Environ Health, 1995. 46(2): p. 155-69.

77. Schneider, A., et al., Growth hormone-mediated reprogramming of macrophage transcriptome and effector functions. Scientific Reports, 2019. 9(1): p. 19348.

78. Yang, $\mathrm{H}$., et al., The haptoglobin beta subunit sequesters HMGB1 toxicity in sterile and infectious inflammation. J Intern Med, 2017. 282(1): p. 76-93.

79. Ghio, A.J., et al., Iron homeostasis in the lung following asbestos exposure. Antioxid Redox Signal, 2008. 10(2): p. 371-7. 
80. Nagatomo, $\mathrm{H}$., et al., Change of heme oxygenase-1 expression in lung injury induced by chrysotile asbestos in vivo and in vitro. Inhal Toxicol, 2007. 19(4): p. 317-23.

81. Degrandi, D., et al., The proinflammatory cytokine-induced IRG1 protein associates with mitochondria. J Interferon Cytokine Res, 2009. 29(1): p. 55-67.

82. Alexander, J.J. and R.J. Quigg, The simple design of complement factor $\mathrm{H}$ : Looks can be deceiving. Mol Immunol, 2007. 44(1-3): p. 123-32.

83. Cui, T., et al., Human complement factor $\mathrm{H}$ is a novel diagnostic marker for lung adenocarcinoma. Int J Oncol, 2011. 39(1): p. 161-8.

84. Fensterl, V. and G.C. Sen, Interferon-induced Ifit proteins: their role in viral pathogenesis. J Virol, 2015. 89(5): p. 2462-8.

85. Divangahi, M., I.L. King, and E. Pernet, Alveolar macrophages and type I IFN in airway homeostasis and immunity. Trends Immunol, 2015. 36(5): p. 307-14.

86. Giordano, G., et al., Type I interferon signaling contributes to chronic inflammation in a murine model of silicosis. Toxicol Sci, 2010. 116(2): p. 682-92.

87. Yanamala, N., et al., Characterization of pulmonary responses in mice to asbestos/asbestiform fibers using gene expression profiles. J Toxicol Environ Health A, 2018. 81(4): p. 60-79.

88. Cox, L.A.T., Jr., Biological mechanisms of non-linear dose-response for respirable mineral fibers. Toxicol Appl Pharmacol, 2018. 361: p. 137-144.

89. Weill, D., Proceedings of The Monticello Conference on Elongate Mineral Particles (EMP). Toxicology and Applied Pharmacology, 2018. 361: p. 1-2. 


\section{Supplementary Materials}

\begin{tabular}{|c|c|c|c|c|c|}
\hline \multirow[b]{3}{*}{ term_id } & \multirow[b]{3}{*}{ term_name } & \multirow{2}{*}{\multicolumn{4}{|c|}{-log10(p-value) vs untreated cells }} \\
\hline & & & & & \\
\hline & & Riebeckite & Riebeckite CF & Tremolite & Tremolite CF \\
\hline KEGG:04640 & Hematopoietic cell lineage & 6.146 & 4.680 & 2.738 & 5.549 \\
\hline KEGG:04060 & Cytokine-cytokine receptor interaction & 3.080 & 4.499 & 3.962 & 5.368 \\
\hline KEGG:04630 & JAK-STAT signaling pathway & 2.874 & 3.818 & - & 2.260 \\
\hline KEGG:04933 & AGE-RAGE signaling pathway in diabetic complications & 4.357 & 2.869 & 1.717 & 1.754 \\
\hline KEGG:03320 & PPAR signaling pathway & 3.222 & 2.762 & - & 1.556 \\
\hline KEGG:05200 & Pathways in cancer & 3.820 & 2.681 & 1.768 & 2.297 \\
\hline KEGG:05221 & Acute myeloid leukemia & 3.184 & 2.573 & 1.808 & 2.297 \\
\hline KEGG:04659 & Th17 cell differentiation & 2.297 & 2.385 & 2.012 & 1.721 \\
\hline KEGG:05321 & Inflammatory bowel disease (IBD) & 3.078 & 2.385 & 1.963 & - \\
\hline KEGG:04610 & Complement and coagulation cascades & 1.829 & 2.297 & 1.820 & 2.297 \\
\hline KEGG:04625 & C-type lectin receptor signaling pathway & 3.844 & 2.201 & 1.934 & 1.618 \\
\hline KEGG:04975 & Fat digestion and absorption & 2.317 & 2.049 & 1.378 & - \\
\hline KEGG:04380 & Osteoclast differentiation & 5.421 & 1.923 & 2.145 & 1.797 \\
\hline KEGG:05152 & Tuberculosis & 4.482 & 1.828 & 1.769 & 1.721 \\
\hline KEGG:05205 & Proteoglycans in cancer & 4.311 & 1.808 & - & 1.489 \\
\hline KEGG:04620 & Toll-like receptor signaling pathway & 1.702 & 1.659 & 1.754 & - \\
\hline KEGG:05140 & Leishmaniasis & 4.779 & 1.503 & 2.856 & 2.297 \\
\hline KEGG:05219 & Bladder cancer & 1.427 & 1.503 & - & - \\
\hline KEGG:05418 & Fluid shear stress and atherosclerosis & 2.697 & 1.449 & 2.210 & - \\
\hline KEGG:04151 & PI3K-Akt signaling pathway & 1.586 & 1.425 & - & - \\
\hline KEGG:05133 & Pertussis & - & 1.354 & - & - \\
\hline KEGG:04514 & Cell adhesion molecules (CAMs) & 3.321 & - & 1.619 & 1.618 \\
\hline KEGG:04145 & Phagosome & 2.519 & - & 1.462 & 2.072 \\
\hline KEGG:04371 & Apelin signaling pathway & 2.504 & - & - & - \\
\hline
\end{tabular}




\begin{tabular}{|c|c|c|c|c|c|}
\hline KEGG:05134 & Legionellosis & 2.504 & - & 1.963 & 1.704 \\
\hline KEGG:05323 & Rheumatoid arthritis & 2.350 & - & 2.923 & 2.003 \\
\hline KEGG:04072 & Phospholipase D signaling pathway & 2.185 & - & - & - \\
\hline KEGG:05230 & Central carbon metabolism in cancer & 2.155 & - & - & - \\
\hline KEGG:04510 & Focal adhesion & 2.115 & - & - & - \\
\hline KEGG:04064 & NF-kappa B signaling pathway & 2.115 & - & 1.963 & 2.003 \\
\hline KEGG:04810 & Regulation of actin cytoskeleton & 2.069 & - & - & - \\
\hline KEGG:04666 & Fc gamma R-mediated phagocytosis & 1.971 & - & - & - \\
\hline KEGG:00071 & Fatty acid degradation & 1.949 & - & - & - \\
\hline KEGG:04658 & Th1 and Th2 cell differentiation & 1.949 & - & 1.462 & - \\
\hline KEGG:05146 & Amoebiasis & 1.878 & - & - & - \\
\hline KEGG:05163 & Human cytomegalovirus infection & 1.829 & - & 1.454 & - \\
\hline KEGG:00052 & Galactose metabolism & 1.820 & - & - & - \\
\hline KEGG:04672 & Intestinal immune network for IgA production & 1.815 & - & - & - \\
\hline KEGG:05144 & Malaria & 1.807 & - & 2.103 & - \\
\hline KEGG:05332 & Graft-versus-host disease & 1.767 & - & 2.738 & 2.290 \\
\hline KEGG:05166 & Human T-cell leukemia virus 1 infection & 1.705 & - & - & - \\
\hline KEGG:05169 & Epstein-Barr virus infection & 1.704 & - & 6.740 & - \\
\hline KEGG:04650 & Natural killer cell mediated cytotoxicity & 1.669 & - & - & - \\
\hline KEGG:04929 & GnRH secretion & 1.669 & - & - & - \\
\hline KEGG:05143 & African trypanosomiasis & 1.644 & - & - & - \\
\hline KEGG:05150 & Staphylococcus aureus infection & 1.626 & - & 1.847 & 1.898 \\
\hline KEGG:01212 & Fatty acid metabolism & 1.586 & - & - & - \\
\hline KEGG:05225 & Hepatocellular carcinoma & 1.586 & - & - & - \\
\hline KEGG:04142 & Lysosome & 1.579 & - & - & - \\
\hline KEGG:04940 & Type I diabetes mellitus & 1.561 & - & 2.481 & 2.072 \\
\hline KEGG:04722 & Neurotrophin signaling pathway & 1.561 & - & - & - \\
\hline KEGG:04662 & B cell receptor signaling pathway & 1.556 & - & - & - \\
\hline KEGG:04010 & MAPK signaling pathway & 1.535 & - & - & - \\
\hline KEGG:04066 & HIF-1 signaling pathway & 1.453 & - & - & - \\
\hline
\end{tabular}




\begin{tabular}{|c|c|c|c|c|c|}
\hline KEGG:04668 & TNF signaling pathway & 1.453 & - & 1.547 & 1.618 \\
\hline KEGG:05223 & Non-small cell lung cancer & 1.453 & - & - & - \\
\hline KEGG:04270 & Vascular smooth muscle contraction & 1.453 & - & - & - \\
\hline KEGG:04216 & Ferroptosis & 1.427 & - & - & - \\
\hline KEGG:05206 & MicroRNAs in cancer & 1.387 & - & - & - \\
\hline KEGG:04670 & Leukocyte transendothelial migration & 1.376 & - & - & - \\
\hline KEGG:04920 & Adipocytokine signaling pathway & 1.309 & - & - & 1.898 \\
\hline KEGG:05213 & Endometrial cancer & 1.309 & - & - & - \\
\hline KEGG:04657 & IL-17 signaling pathway & - & - & 1.869 & - \\
\hline KEGG:05145 & Toxoplasmosis & - & - & 1.557 & - \\
\hline KEGG:05168 & Herpes simplex virus 1 infection & - & - & 1.963 & - \\
\hline KEGG:05162 & Measles & - & - & 4.450 & - \\
\hline KEGG:05160 & Hepatitis C & - & - & 3.458 & - \\
\hline KEGG:05330 & Allograft rejection & - & - & 1.597 & - \\
\hline KEGG:05164 & Influenza A & - & - & 4.450 & - \\
\hline KEGG:04623 & Cytosolic DNA-sensing pathway & - & - & 1.963 & - \\
\hline KEGG:04622 & RIG-I-like receptor signaling pathway & - & - & 2.226 & - \\
\hline KEGG:04621 & NOD-like receptor signaling pathway & - & - & 3.616 & - \\
\hline KEGG:05202 & Transcriptional misregulation in cancer & - & - & 1.462 & 1.708 \\
\hline KEGG:04061 & Viral protein interaction with cytokine and cytokine receptor & - & - & 1.754 & - \\
\hline KEGG:04115 & p53 signaling pathway & - & - & 1.754 & - \\
\hline KEGG:05416 & Viral myocarditis & - & - & 1.579 & - \\
\hline KEGG:04612 & Antigen processing and presentation & - & - & 1.511 & - \\
\hline KEGG:05167 & Kaposi sarcoma-associated herpesvirus infection & - & - & 1.462 & - \\
\hline
\end{tabular}




\begin{tabular}{|c|c|c|c|c|c|}
\hline \multicolumn{6}{|c|}{$\begin{array}{l}\text { Supplementary Table 2. Gene Ontology Biological Pathways enrichment analysis of the gene expression data from MPI } \\
\text { cells treated with various elongate mineral particles (EMPs) at the doses equivalent for total critical fibers surface area }\end{array}$} \\
\hline \multirow[b]{2}{*}{ term_id } & \multirow[b]{2}{*}{ term_name } & \multicolumn{4}{|c|}{-log10(p-value) } \\
\hline & & Riebeckite & $\begin{array}{l}\text { Riebeckite } \\
\text { CF }\end{array}$ & Tremolite & $\begin{array}{l}\text { Tremolite } \\
\text { CF }\end{array}$ \\
\hline GO:0002376 & immune system process & 18.136 & 15.270 & 26.955 & 14.758 \\
\hline GO:0016477 & cell migration & 15.859 & 14.077 & 9.964 & 11.244 \\
\hline GO:0048583 & regulation of response to stimulus & 16.298 & 14.077 & 9.964 & 12.436 \\
\hline GO:0051239 & regulation of multicellular organismal process & 13.996 & 13.920 & 12.453 & 10.381 \\
\hline GO:0032879 & regulation of localization & 14.558 & 13.871 & 5.539 & 7.334 \\
\hline GO:0009605 & response to external stimulus & 18.136 & 13.807 & 17.838 & 9.362 \\
\hline GO:0006952 & defense response & 15.241 & 13.795 & 22.707 & 10.639 \\
\hline GO:0051179 & localization & 17.796 & 13.252 & 5.134 & 7.978 \\
\hline GO:0051674 & localization of cell & 14.515 & 13.252 & 8.936 & 11.000 \\
\hline GO:0048870 & cell motility & 14.515 & 13.252 & 8.936 & 11.000 \\
\hline GO:0007166 & cell surface receptor signaling pathway & 13.707 & 13.192 & 9.698 & 8.935 \\
\hline GO:0070887 & cellular response to chemical stimulus & 17.371 & 13.024 & 12.435 & 10.931 \\
\hline GO:0051240 & positive regulation of multicellular organismal process & 12.350 & 12.938 & 10.141 & 7.316 \\
\hline GO:0030334 & regulation of cell migration & 12.784 & 12.884 & 8.936 & 7.834 \\
\hline GO:0006950 & response to stress & 16.660 & 12.746 & 18.120 & 11.235 \\
\hline GO:0034097 & response to cytokine & 17.134 & 12.374 & 18.572 & 9.728 \\
\hline GO:0048518 & positive regulation of biological process & 12.529 & 12.322 & 6.730 & 8.319 \\
\hline GO:0040011 & locomotion & 15.213 & 12.189 & 7.758 & 10.381 \\
\hline GO:2000145 & regulation of cell motility & 11.737 & 11.898 & 8.307 & 7.205 \\
\hline GO:0040012 & regulation of locomotion & 12.670 & 11.898 & 8.269 & 7.519 \\
\hline GO:0048646 & anatomical structure formation involved in morphogenesis & 11.737 & 11.898 & 6.763 & 8.722 \\
\hline GO:0006955 & immune response & 12.350 & 11.898 & 18.120 & 10.984 \\
\hline GO:0009611 & response to wounding & 13.964 & 11.869 & 5.863 & 7.205 \\
\hline GO:0048584 & positive regulation of response to stimulus & 10.893 & 11.626 & 8.632 & 8.935 \\
\hline GO:0035295 & tube development & 10.957 & 11.319 & 7.621 & 7.978 \\
\hline
\end{tabular}




\begin{tabular}{|c|c|c|c|c|c|}
\hline GO:0006954 & inflammatory response & 14.113 & 11.194 & 12.535 & 12.537 \\
\hline GO:0023051 & regulation of signaling & 12.586 & 11.165 & 5.061 & 8.537 \\
\hline GO:0010646 & regulation of cell communication & 12.736 & 11.002 & 5.117 & 8.598 \\
\hline GO:0048731 & system development & 12.010 & 10.962 & 6.976 & 8.537 \\
\hline GO:0051270 & regulation of cellular component movement & 10.883 & 10.526 & 7.709 & 6.510 \\
\hline GO:0035239 & tube morphogenesis & 10.737 & 10.448 & 7.075 & 7.978 \\
\hline GO:0001816 & cytokine production & 12.899 & 10.236 & 13.066 & 7.455 \\
\hline GO:0042060 & wound healing & 12.973 & 10.151 & 6.332 & 7.600 \\
\hline GO:0071310 & cellular response to organic substance & 12.133 & 10.149 & 10.842 & 7.849 \\
\hline GO:0002682 & regulation of immune system process & 12.338 & 10.139 & 12.453 & 8.722 \\
\hline GO:0007275 & multicellular organism development & 9.954 & 9.781 & 5.668 & 8.598 \\
\hline GO:0032103 & positive regulation of response to external stimulus & 10.584 & 9.770 & 9.351 & 8.238 \\
\hline GO:0006928 & movement of cell or subcellular component & 10.723 & 9.761 & 6.732 & 8.434 \\
\hline GO:0001525 & angiogenesis & 8.225 & 9.651 & 7.033 & 7.046 \\
\hline GO:0071345 & cellular response to cytokine stimulus & 14.262 & 9.651 & 13.397 & 7.664 \\
\hline GO:0050896 & response to stimulus & 9.211 & 9.586 & 8.724 & 7.666 \\
\hline GO:0009966 & regulation of signal transduction & 11.706 & 9.365 & 5.247 & 6.851 \\
\hline GO:0032101 & regulation of response to external stimulus & 9.587 & 9.306 & 7.909 & 6.984 \\
\hline GO:0048519 & negative regulation of biological process & 10.522 & 9.287 & 7.296 & 7.026 \\
\hline GO:0051707 & response to other organism & 12.322 & 8.863 & 18.120 & 5.933 \\
\hline GO:0098542 & defense response to other organism & 9.954 & 8.838 & 14.090 & 5.127 \\
\hline GO:0043207 & response to external biotic stimulus & 12.274 & 8.838 & 18.120 & 5.923 \\
\hline GO:0048522 & positive regulation of cellular process & 8.809 & 8.817 & 3.843 & 5.710 \\
\hline GO:0009888 & tissue development & 8.595 & 8.817 & 4.789 & 5.492 \\
\hline GO:0009607 & response to biotic stimulus & 12.419 & 8.817 & 17.746 & 5.681 \\
\hline GO:0010033 & response to organic substance & 11.792 & 8.816 & 12.818 & 7.399 \\
\hline GO:0042127 & regulation of cell population proliferation & 11.051 & 8.746 & 7.659 & 6.984 \\
\hline GO:0008283 & cell population proliferation & 9.608 & 8.746 & 6.877 & 7.858 \\
\hline GO:0001568 & blood vessel development & 8.259 & 8.741 & 7.587 & 8.424 \\
\hline GO:0032502 & developmental process & 9.338 & 8.717 & 3.359 & 6.714 \\
\hline
\end{tabular}




\begin{tabular}{|c|c|c|c|c|c|}
\hline GO:0072359 & circulatory system development & 9.449 & 8.664 & 6.779 & 7.978 \\
\hline GO:0002684 & positive regulation of immune system process & 8.585 & 8.560 & 12.099 & 7.858 \\
\hline GO:0048856 & anatomical structure development & 8.909 & 8.499 & 3.898 & 7.196 \\
\hline GO:0051049 & regulation of transport & 10.605 & 8.477 & 2.869 & 4.082 \\
\hline GO:0050663 & cytokine secretion & 10.255 & 8.449 & 7.857 & 7.617 \\
\hline GO:0015718 & monocarboxylic acid transport & 11.842 & 8.442 & 2.972 & 5.341 \\
\hline GO:0048514 & blood vessel morphogenesis & 7.959 & 8.408 & 6.730 & 7.952 \\
\hline GO:0043068 & positive regulation of programmed cell death & 7.854 & 8.408 & 3.546 & 4.402 \\
\hline GO:0010647 & positive regulation of cell communication & 7.559 & 8.408 & 4.551 & 5.097 \\
\hline GO:0007155 & cell adhesion & 11.051 & 8.357 & 8.938 & 8.332 \\
\hline GO:0023056 & positive regulation of signaling & 7.486 & 8.353 & 4.525 & 5.056 \\
\hline GO:0065008 & regulation of biological quality & 13.735 & 8.226 & 5.650 & 5.923 \\
\hline GO:0022610 & biological adhesion & 11.217 & 8.216 & 10.388 & 8.595 \\
\hline GO:0009653 & anatomical structure morphogenesis & 8.953 & 8.216 & 4.800 & 7.535 \\
\hline GO:0044419 & interspecies interaction between organisms & 11.737 & 8.198 & 16.579 & 5.417 \\
\hline GO:0001944 & vasculature development & 8.774 & 8.180 & 7.173 & 7.978 \\
\hline GO:0048513 & animal organ development & 8.846 & 8.166 & 6.814 & 5.661 \\
\hline GO:0010942 & positive regulation of cell death & 8.560 & 8.164 & 3.835 & 4.568 \\
\hline GO:0001817 & regulation of cytokine production & 11.807 & 8.161 & 11.881 & 7.091 \\
\hline GO:0043065 & positive regulation of apoptotic process & 7.559 & 8.072 & 3.160 & 4.030 \\
\hline GO:0051046 & regulation of secretion & 6.932 & 7.972 & 4.738 & 5.834 \\
\hline GO:2000026 & regulation of multicellular organismal development & 7.445 & 7.972 & 6.117 & 5.712 \\
\hline GO:0072358 & cardiovascular system development & 8.513 & 7.972 & 7.022 & 7.846 \\
\hline GO:0048523 & negative regulation of cellular process & 9.296 & 7.945 & 5.061 & 6.261 \\
\hline GO:0048869 & cellular developmental process & 7.559 & 7.938 & 2.898 & 4.932 \\
\hline GO:0035556 & intracellular signal transduction & 9.348 & 7.851 & 3.127 & 5.596 \\
\hline GO:0046942 & carboxylic acid transport & 12.770 & 7.834 & 2.897 & 5.406 \\
\hline GO:0030154 & cell differentiation & 7.576 & 7.787 & 2.928 & 4.824 \\
\hline GO:0015849 & organic acid transport & 12.670 & 7.745 & 2.869 & 5.354 \\
\hline GO:0051716 & cellular response to stimulus & 7.137 & 7.711 & 3.944 & 6.151 \\
\hline
\end{tabular}




\begin{tabular}{|c|c|c|c|c|c|}
\hline GO:0050707 & regulation of cytokine secretion & 9.127 & 7.702 & 7.173 & 7.843 \\
\hline GO:0030155 & regulation of cell adhesion & 8.491 & 7.565 & 7.441 & 5.976 \\
\hline GO:0080134 & regulation of response to stress & 7.777 & 7.551 & 7.481 & 7.859 \\
\hline GO:0030335 & positive regulation of cell migration & 7.296 & 7.262 & 4.074 & 3.471 \\
\hline GO:0051094 & positive regulation of developmental process & 6.552 & 7.201 & 2.931 & 2.767 \\
\hline GO:0045765 & regulation of angiogenesis & 5.155 & 7.147 & 3.889 & 5.354 \\
\hline GO:0023061 & signal release & 6.379 & 7.093 & 3.939 & 5.427 \\
\hline GO:0023052 & signaling & 6.477 & 7.079 & 2.514 & 5.605 \\
\hline GO:0002791 & regulation of peptide secretion & 7.716 & 7.051 & 4.485 & 5.710 \\
\hline GO:0050793 & regulation of developmental process & 6.693 & 7.029 & 4.317 & 5.912 \\
\hline GO:0050776 & regulation of immune response & 7.587 & 6.990 & 7.974 & 6.324 \\
\hline GO:0002790 & peptide secretion & 7.036 & 6.955 & 4.563 & 5.488 \\
\hline GO:0007154 & cell communication & 6.596 & 6.934 & 2.384 & 5.590 \\
\hline GO:0071692 & protein localization to extracellular region & 6.727 & 6.839 & 5.539 & 5.982 \\
\hline GO:0060429 & epithelium development & 6.526 & 6.821 & 3.043 & 4.404 \\
\hline GO:2000147 & positive regulation of cell motility & 6.776 & 6.799 & 3.855 & 3.213 \\
\hline GO:0042325 & regulation of phosphorylation & 7.363 & 6.751 & 2.633 & 5.933 \\
\hline GO:0009967 & positive regulation of signal transduction & 6.366 & 6.751 & 3.637 & 3.658 \\
\hline GO:0050715 & positive regulation of cytokine secretion & 8.268 & 6.750 & 7.476 & 6.936 \\
\hline GO:0090087 & regulation of peptide transport & 7.361 & 6.702 & 2.635 & 5.169 \\
\hline GO:0002252 & immune effector process & 6.657 & 6.660 & 15.659 & 4.750 \\
\hline GO:0045087 & innate immune response & 7.925 & 6.638 & 11.881 & 3.679 \\
\hline GO:1901342 & regulation of vasculature development & 6.381 & 6.629 & 4.404 & 6.227 \\
\hline GO:0015711 & organic anion transport & 11.566 & 6.621 & 2.319 & 4.981 \\
\hline GO:0019220 & regulation of phosphate metabolic process & 6.981 & 6.621 & 2.600 & 5.531 \\
\hline GO:0002526 & acute inflammatory response & 5.692 & 6.619 & 4.166 & 5.590 \\
\hline GO:0051174 & regulation of phosphorus metabolic process & 6.971 & 6.619 & 2.596 & 5.527 \\
\hline GO:0010941 & regulation of cell death & 6.481 & 6.586 & 2.936 & 4.798 \\
\hline GO:0009306 & protein secretion & 6.507 & 6.573 & 5.117 & 5.659 \\
\hline GO:0043067 & regulation of programmed cell death & 5.522 & 6.559 & 2.799 & 4.213 \\
\hline
\end{tabular}




\begin{tabular}{|c|c|c|c|c|c|}
\hline GO:0035592 & establishment of protein localization to extracellular region & 6.486 & 6.559 & 5.107 & 5.647 \\
\hline GO:0050708 & regulation of protein secretion & 7.017 & 6.552 & 5.005 & 5.858 \\
\hline GO:0040017 & positive regulation of locomotion & 6.455 & 6.525 & 3.702 & 3.049 \\
\hline GO:0046903 & secretion & 6.567 & 6.498 & 4.217 & 4.783 \\
\hline GO:0006468 & protein phosphorylation & 8.090 & 6.489 & 2.311 & 5.225 \\
\hline GO:1902531 & regulation of intracellular signal transduction & 8.358 & 6.489 & 3.939 & 5.222 \\
\hline GO:0016310 & phosphorylation & 7.762 & 6.489 & 2.057 & 5.056 \\
\hline GO:1903530 & regulation of secretion by cell & 5.936 & 6.488 & 3.809 & 5.127 \\
\hline GO:0008219 & cell death & 7.181 & 6.463 & 3.691 & 4.742 \\
\hline GO:0007165 & signal transduction & 5.736 & 6.408 & 2.258 & 4.575 \\
\hline GO:0051272 & positive regulation of cellular component movement & 6.327 & 6.408 & 3.638 & 2.978 \\
\hline GO:0001932 & regulation of protein phosphorylation & 7.128 & 6.397 & 2.982 & 5.681 \\
\hline GO:0001819 & positive regulation of cytokine production & 7.965 & 6.390 & 10.056 & 6.485 \\
\hline GO:0008284 & positive regulation of cell population proliferation & 6.396 & 6.351 & 4.800 & 3.137 \\
\hline GO:0022603 & regulation of anatomical structure morphogenesis & 5.273 & 6.321 & 2.658 & 4.761 \\
\hline GO:0042981 & regulation of apoptotic process & 5.289 & 6.234 & 2.656 & 4.082 \\
\hline GO:0051223 & regulation of protein transport & 6.708 & 6.228 & 2.916 & 5.230 \\
\hline GO:0051050 & positive regulation of transport & 8.778 & 6.200 & 3.411 & 4.921 \\
\hline GO:0019221 & cytokine-mediated signaling pathway & 7.021 & 6.142 & 7.974 & 4.981 \\
\hline GO:0006810 & transport & 9.678 & 6.142 & 2.385 & 2.464 \\
\hline GO:0007162 & negative regulation of cell adhesion & 4.900 & 6.125 & 4.525 & 2.856 \\
\hline GO:0001775 & cell activation & 8.268 & 6.083 & 4.048 & 4.091 \\
\hline GO:0050900 & leukocyte migration & 6.842 & 6.047 & 4.085 & 5.976 \\
\hline GO:0031349 & positive regulation of defense response & 7.963 & 6.018 & 8.357 & 7.240 \\
\hline GO:0097190 & apoptotic signaling pathway & 5.191 & 5.993 & 1.825 & 1.738 \\
\hline GO:0012501 & programmed cell death & 5.606 & 5.916 & 2.774 & 3.420 \\
\hline GO:0065009 & regulation of molecular function & 6.708 & 5.916 & 4.503 & 4.082 \\
\hline GO:0002274 & myeloid leukocyte activation & 7.168 & 5.857 & 4.539 & 5.328 \\
\hline GO:0070201 & regulation of establishment of protein localization & 6.245 & 5.793 & 2.744 & 4.935 \\
\hline
\end{tabular}




\begin{tabular}{|c|c|c|c|c|c|}
\hline GO:0050789 & regulation of biological process & 5.005 & 5.766 & 3.726 & 4.014 \\
\hline GO:0006915 & apoptotic process & 5.581 & 5.757 & 2.710 & 3.401 \\
\hline GO:0051234 & establishment of localization & 9.408 & 5.743 & 2.080 & 2.083 \\
\hline GO:0000165 & MAPK cascade & 6.732 & 5.730 & 4.016 & 4.190 \\
\hline GO:0002793 & positive regulation of peptide secretion & 6.737 & 5.728 & 5.117 & 5.463 \\
\hline GO:0050679 & positive regulation of epithelial cell proliferation & 4.939 & 5.717 & 5.542 & 4.400 \\
\hline GO:1903036 & positive regulation of response to wounding & 5.167 & 5.698 & 2.306 & 3.152 \\
\hline GO:0071702 & organic substance transport & 8.909 & 5.678 & 1.708 & 2.857 \\
\hline GO:0051222 & positive regulation of protein transport & 6.441 & 5.643 & 4.044 & 5.122 \\
\hline GO:0065007 & biological regulation & 4.856 & 5.640 & 3.434 & 3.526 \\
\hline GO:0002237 & response to molecule of bacterial origin & 10.230 & 5.640 & 8.405 & 5.324 \\
\hline GO:0006796 & phosphate-containing compound metabolic process & 7.575 & 5.588 & 1.882 & 4.460 \\
\hline GO:0032880 & regulation of protein localization & 5.606 & 5.588 & 1.722 & 3.548 \\
\hline GO:0050714 & positive regulation of protein secretion & 6.315 & 5.521 & 5.751 & 5.548 \\
\hline GO:0051047 & positive regulation of secretion & 6.299 & 5.464 & 3.652 & 4.460 \\
\hline GO:0098754 & detoxification & 6.544 & 5.464 & 2.004 & 1.952 \\
\hline GO:0051241 & negative regulation of multicellular organismal process & 5.581 & 5.450 & 5.625 & 4.837 \\
\hline GO:0023014 & signal transduction by protein phosphorylation & 6.399 & 5.446 & 3.856 & 4.001 \\
\hline GO:0006793 & phosphorus metabolic process & 7.371 & 5.434 & 2.001 & 4.351 \\
\hline GO:0043408 & regulation of MAPK cascade & 5.952 & 5.395 & 2.898 & 3.972 \\
\hline GO:0050729 & positive regulation of inflammatory response & 8.222 & 5.349 & 6.573 & 9.158 \\
\hline GO:1904951 & positive regulation of establishment of protein localization & 6.081 & 5.339 & 3.873 & 4.897 \\
\hline GO:0031347 & regulation of defense response & 6.473 & 5.272 & 7.313 & 5.636 \\
\hline GO:0090303 & positive regulation of wound healing & 4.985 & 5.270 & 2.852 & 3.986 \\
\hline GO:0140352 & export from cell & 5.553 & 5.269 & 2.936 & 4.014 \\
\hline GO:0007267 & cell-cell signaling & 4.627 & 5.246 & 2.491 & 4.434 \\
\hline GO:0010648 & negative regulation of cell communication & 6.930 & 5.238 & 3.835 & 5.755 \\
\hline GO:0023057 & negative regulation of signaling & 6.872 & 5.194 & 3.813 & 5.719 \\
\hline GO:0032940 & secretion by cell & 5.295 & 5.168 & 2.905 & 4.056 \\
\hline
\end{tabular}




\begin{tabular}{|c|c|c|c|c|c|}
\hline GO:0044093 & positive regulation of molecular function & 4.999 & 5.051 & 1.570 & 3.065 \\
\hline GO:0002697 & regulation of immune effector process & 5.155 & 4.972 & 7.587 & 4.147 \\
\hline GO:0097529 & myeloid leukocyte migration & 6.375 & 4.913 & 4.051 & 4.900 \\
\hline GO:0009987 & cellular process & 6.215 & 4.905 & 2.503 & 2.382 \\
\hline GO:0009636 & response to toxic substance & 5.972 & 4.868 & 1.509 & 1.997 \\
\hline GO:0061041 & regulation of wound healing & 6.473 & 4.864 & 2.905 & 3.424 \\
\hline GO:0051247 & positive regulation of protein metabolic process & 5.049 & 4.812 & 1.409 & 5.169 \\
\hline GO:0061061 & muscle structure development & 3.379 & 4.802 & 2.654 & 2.703 \\
\hline GO:0045937 & positive regulation of phosphate metabolic process & 4.927 & 4.787 & 1.588 & 5.206 \\
\hline GO:0010562 & positive regulation of phosphorus metabolic process & 4.927 & 4.787 & 1.588 & 5.206 \\
\hline GO:1903034 & regulation of response to wounding & 5.930 & 4.736 & 2.280 & 2.577 \\
\hline GO:0006820 & anion transport & 9.463 & 4.729 & 1.673 & 3.517 \\
\hline GO:0030595 & leukocyte chemotaxis & 4.008 & 4.708 & 2.769 & 3.517 \\
\hline GO:0050794 & regulation of cellular process & 3.642 & 4.691 & 2.610 & 3.227 \\
\hline GO:0009617 & response to bacterium & 7.886 & 4.687 & 10.842 & 5.026 \\
\hline GO:0050790 & regulation of catalytic activity & 5.292 & 4.680 & 3.701 & 3.012 \\
\hline GO:1903532 & positive regulation of secretion by cell & 5.812 & 4.671 & 3.750 & 4.222 \\
\hline GO:0042327 & positive regulation of phosphorylation & 4.729 & 4.657 & 1.633 & 5.492 \\
\hline GO:0045859 & regulation of protein kinase activity & 4.939 & 4.649 & 3.691 & 3.587 \\
\hline GO:0097530 & granulocyte migration & 4.323 & 4.603 & 3.426 & 3.911 \\
\hline GO:0043085 & positive regulation of catalytic activity & 4.513 & 4.599 & - & 2.533 \\
\hline GO:0051246 & regulation of protein metabolic process & 4.416 & 4.558 & 1.517 & 3.719 \\
\hline GO:0007596 & blood coagulation & 6.445 & 4.529 & 2.445 & 3.408 \\
\hline GO:0032496 & response to lipopolysaccharide & 8.585 & 4.517 & 8.731 & 5.565 \\
\hline GO:0031399 & regulation of protein modification process & 5.105 & 4.509 & 2.081 & 4.082 \\
\hline GO:0001934 & positive regulation of protein phosphorylation & 5.077 & 4.495 & 1.678 & 5.047 \\
\hline GO:0007599 & hemostasis & 6.367 & 4.464 & 2.420 & 3.359 \\
\hline GO:0098609 & cell-cell adhesion & 7.213 & 4.450 & 4.749 & 5.277 \\
\hline GO:0009968 & negative regulation of signal transduction & 5.350 & 4.450 & 3.318 & 4.571 \\
\hline GO:0050817 & coagulation & 6.327 & 4.435 & 2.406 & 3.337 \\
\hline
\end{tabular}




\begin{tabular}{|c|c|c|c|c|c|}
\hline GO:0032270 & positive regulation of cellular protein metabolic process & 4.722 & 4.434 & 1.358 & 4.997 \\
\hline GO:0009893 & positive regulation of metabolic process & 5.868 & 4.430 & 2.565 & 3.909 \\
\hline GO:0072001 & renal system development & 4.655 & 4.419 & 3.039 & 3.468 \\
\hline GO:0006935 & chemotaxis & 5.606 & 4.395 & 1.546 & 2.318 \\
\hline GO:0051048 & negative regulation of secretion & 4.405 & 4.395 & 3.638 & 5.354 \\
\hline GO:0042592 & homeostatic process & 5.577 & 4.372 & 4.520 & 2.532 \\
\hline GO:1901700 & response to oxygen-containing compound & 8.313 & 4.370 & 5.251 & 4.578 \\
\hline GO:0050678 & regulation of epithelial cell proliferation & 3.177 & 4.352 & 4.509 & 3.732 \\
\hline GO:0042330 & taxis & 6.327 & 4.352 & 1.819 & 2.297 \\
\hline GO:0048871 & multicellular organismal homeostasis & 6.202 & 4.328 & 5.005 & 3.078 \\
\hline GO:0022407 & regulation of cell-cell adhesion & 5.316 & 4.318 & 4.906 & 4.001 \\
\hline GO:1990266 & neutrophil migration & 4.222 & 4.296 & 3.336 & 3.969 \\
\hline GO:0001822 & kidney development & 4.517 & 4.196 & 2.710 & 3.141 \\
\hline GO:0015908 & fatty acid transport & 4.397 & 4.190 & 1.463 & 2.722 \\
\hline GO:0045321 & leukocyte activation & 5.581 & 4.180 & 3.825 & 3.035 \\
\hline GO:0010604 & positive regulation of macromolecule metabolic process & 5.574 & 4.147 & 2.440 & 3.834 \\
\hline GO:0045597 & positive regulation of cell differentiation & 3.920 & 4.126 & 2.289 & 1.479 \\
\hline GO:0045766 & positive regulation of angiogenesis & 3.683 & 4.124 & 1.360 & 2.560 \\
\hline GO:0032501 & multicellular organismal process & 3.124 & 4.082 & 2.715 & 3.734 \\
\hline GO:0032757 & positive regulation of interleukin-8 production & 8.493 & 4.065 & 4.074 & 3.492 \\
\hline GO:1904018 & positive regulation of vasculature development & 4.517 & 4.051 & 1.548 & 2.702 \\
\hline GO:0043549 & regulation of kinase activity & 4.659 & 4.041 & 3.271 & 4.117 \\
\hline GO:0032268 & regulation of cellular protein metabolic process & 3.374 & 4.039 & 1.476 & 3.164 \\
\hline GO:0048585 & negative regulation of response to stimulus & 5.581 & 3.991 & 3.530 & 4.425 \\
\hline GO:0050878 & regulation of body fluid levels & 5.781 & 3.991 & 4.026 & 5.377 \\
\hline GO:0071705 & nitrogen compound transport & 5.156 & 3.991 & 1.597 & 2.097 \\
\hline GO:0050673 & epithelial cell proliferation & 3.060 & 3.987 & 4.652 & 3.749 \\
\hline GO:0001655 & urogenital system development & 4.441 & 3.973 & 2.999 & 3.300 \\
\hline GO:1901701 & cellular response to oxygen-containing compound & 7.011 & 3.946 & 4.358 & 3.514 \\
\hline GO:0030856 & regulation of epithelial cell differentiation & 4.244 & 3.915 & 4.051 & 5.923 \\
\hline
\end{tabular}




\begin{tabular}{|c|c|c|c|c|c|}
\hline GO:0048002 & antigen processing and presentation of peptide antigen & 5.168 & 3.903 & 2.601 & 2.074 \\
\hline GO:0044281 & small molecule metabolic process & 6.319 & 3.832 & 2.574 & 2.957 \\
\hline GO:0045860 & positive regulation of protein kinase activity & 3.716 & 3.796 & 1.579 & 2.611 \\
\hline GO:0050818 & regulation of coagulation & 4.093 & 3.785 & 2.182 & 2.273 \\
\hline GO:1902533 & positive regulation of intracellular signal transduction & 4.849 & 3.763 & 2.420 & 2.964 \\
\hline GO:0051338 & regulation of transferase activity & 4.349 & 3.760 & 2.884 & 3.888 \\
\hline GO:0042221 & response to chemical & 4.973 & 3.719 & 6.106 & 3.210 \\
\hline GO:0048729 & tissue morphogenesis & 3.427 & 3.689 & - & 2.259 \\
\hline GO:0006801 & superoxide metabolic process & 4.900 & 3.678 & 3.251 & 1.414 \\
\hline GO:0030593 & neutrophil chemotaxis & 3.741 & 3.614 & 2.391 & 2.394 \\
\hline GO:0060055 & angiogenesis involved in wound healing & 3.060 & 3.614 & 1.745 & 2.317 \\
\hline GO:0002009 & morphogenesis of an epithelium & 2.816 & 3.596 & - & 1.682 \\
\hline GO:0061042 & vascular wound healing & 3.106 & 3.574 & - & 1.918 \\
\hline GO:2001235 & positive regulation of apoptotic signaling pathway & 2.371 & 3.574 & 1.368 & - \\
\hline GO:0071900 & regulation of protein serine/threonine kinase activity & 5.047 & 3.573 & 3.106 & 2.712 \\
\hline GO:0007159 & leukocyte cell-cell adhesion & 6.014 & 3.571 & 3.850 & 3.693 \\
\hline GO:0060326 & cell chemotaxis & 3.489 & 3.571 & 2.631 & 3.037 \\
\hline GO:0071219 & cellular response to molecule of bacterial origin & 7.965 & 3.559 & 8.385 & 4.804 \\
\hline GO:0043436 & oxoacid metabolic process & 4.967 & 3.559 & - & 1.926 \\
\hline GO:0090184 & positive regulation of kidney development & 2.817 & 3.536 & - & - \\
\hline GO:0006953 & acute-phase response & 3.563 & 3.536 & 4.364 & 3.771 \\
\hline GO:0042326 & negative regulation of phosphorylation & 3.854 & 3.533 & 3.082 & 3.526 \\
\hline GO:1901564 & organonitrogen compound metabolic process & 4.692 & 3.524 & 1.525 & 1.926 \\
\hline GO:2001233 & regulation of apoptotic signaling pathway & 3.775 & 3.512 & 2.138 & 2.297 \\
\hline GO:0045630 & positive regulation of T-helper 2 cell differentiation & 1.936 & 3.509 & 1.633 & - \\
\hline GO:0050730 & regulation of peptidyl-tyrosine phosphorylation & 4.488 & 3.471 & - & 2.665 \\
\hline GO:0097191 & extrinsic apoptotic signaling pathway & 3.802 & 3.459 & 5.076 & 2.819 \\
\hline GO:0071621 & granulocyte chemotaxis & 3.430 & 3.459 & 2.574 & 1.952 \\
\hline GO:0008285 & negative regulation of cell population proliferation & 5.610 & 3.427 & 4.476 & 4.837 \\
\hline GO:0002831 & regulation of response to biotic stimulus & 4.278 & 3.419 & 2.346 & 1.603 \\
\hline
\end{tabular}




\begin{tabular}{|c|c|c|c|c|c|}
\hline GO:0001933 & negative regulation of protein phosphorylation & 3.915 & 3.408 & 3.059 & 3.615 \\
\hline GO:0018212 & peptidyl-tyrosine modification & 3.755 & 3.407 & - & 2.090 \\
\hline GO:1902622 & regulation of neutrophil migration & 3.421 & 3.407 & 2.427 & 2.735 \\
\hline GO:0050727 & regulation of inflammatory response & 6.029 & 3.407 & 6.274 & 6.307 \\
\hline GO:0010876 & lipid localization & 6.756 & 3.397 & 2.634 & 4.058 \\
\hline GO:0050778 & positive regulation of immune response & 4.176 & 3.369 & 5.276 & 4.001 \\
\hline GO:0033036 & macromolecule localization & 5.119 & 3.363 & 1.769 & 2.398 \\
\hline GO:1990748 & cellular detoxification & 4.684 & 3.363 & 2.259 & - \\
\hline GO:0045595 & regulation of cell differentiation & 3.632 & 3.363 & 2.883 & 2.575 \\
\hline GO:0002520 & immune system development & 4.655 & 3.333 & 5.209 & 2.033 \\
\hline GO:1902624 & positive regulation of neutrophil migration & 3.467 & 3.303 & 2.883 & 2.425 \\
\hline GO:0001906 & cell killing & 2.526 & 3.294 & 2.642 & 2.392 \\
\hline GO:0006082 & organic acid metabolic process & 4.600 & 3.294 & - & 1.808 \\
\hline GO:0015909 & long-chain fatty acid transport & 3.843 & 3.290 & - & 1.560 \\
\hline GO:0033029 & regulation of neutrophil apoptotic process & 2.882 & 3.251 & 1.546 & 1.331 \\
\hline GO:0060054 & $\begin{array}{l}\text { positive regulation of epithelial cell proliferation involved in } \\
\text { wound healing }\end{array}$ & 2.882 & 3.251 & 4.244 & 3.904 \\
\hline GO:0002685 & regulation of leukocyte migration & 3.671 & 3.246 & 2.331 & 2.050 \\
\hline GO:0030097 & hemopoiesis & 4.024 & 3.228 & 4.888 & 1.885 \\
\hline GO:0030193 & regulation of blood coagulation & 3.578 & 3.215 & 1.623 & 1.769 \\
\hline GO:0071222 & cellular response to lipopolysaccharide & 7.061 & 3.215 & 8.565 & 4.935 \\
\hline GO:0071396 & cellular response to lipid & 4.961 & 3.195 & 6.171 & 3.854 \\
\hline GO:1900046 & regulation of hemostasis & 3.529 & 3.171 & 1.605 & 1.748 \\
\hline GO:0060562 & epithelial tube morphogenesis & 3.319 & 3.164 & - & - \\
\hline GO:0090322 & regulation of superoxide metabolic process & 4.166 & 3.157 & 2.787 & - \\
\hline GO:0043405 & regulation of MAP kinase activity & 4.365 & 3.156 & 2.217 & 1.815 \\
\hline GO:0072006 & nephron development & 3.477 & 3.155 & - & 1.541 \\
\hline GO:0043410 & positive regulation of MAPK cascade & 3.319 & 3.150 & 1.623 & 2.210 \\
\hline GO:0007167 & enzyme linked receptor protein signaling pathway & 3.374 & 3.140 & - & 1.843 \\
\hline GO:1903531 & negative regulation of secretion by cell & 3.001 & 3.131 & 2.027 & 3.659 \\
\hline
\end{tabular}




\begin{tabular}{|c|c|c|c|c|c|}
\hline GO:0097237 & cellular response to toxic substance & 4.356 & 3.126 & 2.135 & - \\
\hline GO:0006869 & lipid transport & 5.581 & 3.126 & 1.964 & 2.969 \\
\hline GO:0031401 & positive regulation of protein modification process & 3.903 & 3.120 & 1.308 & 4.463 \\
\hline GO:0042116 & macrophage activation & 3.287 & 3.093 & 1.855 & 2.469 \\
\hline GO:0002700 & $\begin{array}{l}\text { regulation of production of molecular mediator of immune } \\
\text { response }\end{array}$ & 3.534 & 3.086 & 4.340 & 1.781 \\
\hline GO:0010628 & positive regulation of gene expression & 4.983 & 3.061 & 3.923 & 1.953 \\
\hline GO:0071216 & cellular response to biotic stimulus & 8.162 & 3.061 & 7.725 & 4.283 \\
\hline GO:0018108 & peptidyl-tyrosine phosphorylation & 3.447 & 3.061 & - & 1.811 \\
\hline GO:0031663 & lipopolysaccharide-mediated signaling pathway & 5.407 & 3.058 & 3.939 & 3.337 \\
\hline GO:0048534 & hematopoietic or lymphoid organ development & 4.564 & 3.056 & 4.888 & 1.876 \\
\hline GO:0071902 & $\begin{array}{l}\text { positive regulation of protein serine/threonine kinase } \\
\text { activity }\end{array}$ & 3.778 & 3.055 & 1.756 & 2.097 \\
\hline GO:0032677 & regulation of interleukin-8 production & 6.635 & 3.055 & 4.174 & 2.706 \\
\hline GO:0002699 & positive regulation of immune effector process & 3.744 & 3.055 & 4.689 & 2.535 \\
\hline GO:1900048 & positive regulation of hemostasis & 2.506 & 3.039 & 1.516 & 1.970 \\
\hline GO:0010563 & negative regulation of phosphorus metabolic process & 3.604 & 3.039 & 2.515 & 2.696 \\
\hline GO:0007399 & nervous system development & 3.887 & 3.039 & - & 2.317 \\
\hline GO:0002819 & regulation of adaptive immune response & 4.551 & 3.039 & 3.637 & 1.809 \\
\hline GO:0045936 & negative regulation of phosphate metabolic process & 3.604 & 3.039 & 2.515 & 2.696 \\
\hline GO:0030194 & positive regulation of blood coagulation & 2.506 & 3.039 & 1.516 & 1.970 \\
\hline GO:2000484 & positive regulation of interleukin- 8 secretion & 7.218 & 3.031 & - & 2.612 \\
\hline GO:0002830 & positive regulation of type 2 immune response & 1.742 & 3.031 & 1.958 & - \\
\hline GO:0030855 & epithelial cell differentiation & 3.803 & 3.031 & 3.032 & 3.986 \\
\hline GO:0045785 & positive regulation of cell adhesion & 5.155 & 2.980 & 3.781 & 3.434 \\
\hline GO:0006865 & amino acid transport & 4.878 & 2.979 & 2.009 & 1.876 \\
\hline GO:0002688 & regulation of leukocyte chemotaxis & 2.071 & 2.977 & 1.527 & - \\
\hline GO:0022408 & negative regulation of cell-cell adhesion & 3.124 & 2.971 & 2.232 & 1.614 \\
\hline GO:0022008 & neurogenesis & 2.886 & 2.925 & - & 2.046 \\
\hline GO:0009887 & animal organ morphogenesis & 3.305 & 2.925 & 2.693 & 2.036 \\
\hline
\end{tabular}




\begin{tabular}{|c|c|c|c|c|c|}
\hline GO:0002521 & leukocyte differentiation & 3.043 & 2.915 & 4.142 & 2.053 \\
\hline GO:0051347 & positive regulation of transferase activity & 2.796 & 2.909 & - & 2.706 \\
\hline GO:0042886 & amide transport & 3.330 & 2.909 & 1.421 & 1.826 \\
\hline GO:0033674 & positive regulation of kinase activity & 2.731 & 2.905 & - & 2.717 \\
\hline GO:0006629 & lipid metabolic process & 6.459 & 2.902 & 1.944 & 3.695 \\
\hline GO:0019222 & regulation of metabolic process & 2.882 & 2.895 & 1.944 & 1.445 \\
\hline GO:0050820 & positive regulation of coagulation & 2.352 & 2.876 & 1.450 & 1.892 \\
\hline GO:0090023 & positive regulation of neutrophil chemotaxis & 2.352 & 2.876 & 1.450 & - \\
\hline GO:0001781 & neutrophil apoptotic process & 2.508 & 2.863 & 1.409 & - \\
\hline GO:0019752 & carboxylic acid metabolic process & 4.647 & 2.844 & - & 1.907 \\
\hline GO:0044092 & negative regulation of molecular function & 2.512 & 2.837 & 2.586 & 2.074 \\
\hline GO:0034113 & heterotypic cell-cell adhesion & 4.195 & 2.807 & 2.852 & 3.986 \\
\hline GO:0030217 & T cell differentiation & 2.640 & 2.805 & 2.760 & 1.586 \\
\hline GO:0001818 & negative regulation of cytokine production & 4.329 & 2.805 & 4.453 & 2.368 \\
\hline GO:0002478 & $\begin{array}{l}\text { antigen processing and presentation of exogenous peptide } \\
\text { antigen }\end{array}$ & 3.297 & 2.805 & - & - \\
\hline GO:0007369 & gastrulation & 2.526 & 2.805 & 1.669 & 2.913 \\
\hline GO:0001889 & liver development & 2.614 & 2.805 & 3.631 & 3.994 \\
\hline GO:0032637 & interleukin-8 production & 6.187 & 2.803 & 3.939 & 2.521 \\
\hline GO:1905039 & carboxylic acid transmembrane transport & 6.399 & 2.802 & - & - \\
\hline GO:1903825 & organic acid transmembrane transport & 6.399 & 2.802 & - & - \\
\hline GO:0072073 & kidney epithelium development & 3.166 & 2.796 & - & - \\
\hline GO:0044706 & multi-multicellular organism process & 2.255 & 2.768 & - & 2.779 \\
\hline GO:0002687 & positive regulation of leukocyte migration & 2.665 & 2.768 & 2.731 & 2.041 \\
\hline GO:0002456 & $\mathrm{T}$ cell mediated immunity & 2.746 & 2.741 & 3.093 & 1.876 \\
\hline GO:0050921 & positive regulation of chemotaxis & 1.835 & 2.741 & - & - \\
\hline GO:0072593 & reactive oxygen species metabolic process & 7.486 & 2.740 & 5.185 & 2.905 \\
\hline GO:0061008 & hepaticobiliary system development & 2.539 & 2.734 & 3.570 & 3.925 \\
\hline GO:0071624 & positive regulation of granulocyte chemotaxis & 2.227 & 2.730 & 1.398 & - \\
\hline GO:0090183 & regulation of kidney development & 2.080 & 2.720 & - & - \\
\hline
\end{tabular}




\begin{tabular}{|c|c|c|c|c|c|}
\hline GO:0002833 & positive regulation of response to biotic stimulus & 3.578 & 2.720 & 2.150 & - \\
\hline GO:0001935 & endothelial cell proliferation & 2.617 & 2.720 & 1.640 & 2.534 \\
\hline GO:0040007 & growth & 2.263 & 2.720 & 1.650 & 2.599 \\
\hline GO:0051345 & positive regulation of hydrolase activity & 3.223 & 2.719 & - & 1.389 \\
\hline GO:0002703 & regulation of leukocyte mediated immunity & 2.631 & 2.717 & 4.791 & 1.774 \\
\hline GO:2000379 & $\begin{array}{l}\text { positive regulation of reactive oxygen species metabolic } \\
\text { process }\end{array}$ & 5.924 & 2.716 & 2.838 & 2.785 \\
\hline GO:0033993 & response to lipid & 4.798 & 2.716 & 5.547 & 3.436 \\
\hline GO:0051051 & negative regulation of transport & 5.087 & 2.712 & 3.092 & 2.575 \\
\hline GO:0002367 & cytokine production involved in immune response & 2.955 & 2.706 & 4.053 & - \\
\hline GO:0008625 & $\begin{array}{l}\text { extrinsic apoptotic signaling pathway via death domain } \\
\text { receptors }\end{array}$ & 3.095 & 2.691 & 3.013 & 1.823 \\
\hline GO:0030858 & positive regulation of epithelial cell differentiation & 2.617 & 2.681 & - & 2.229 \\
\hline GO:0110110 & positive regulation of animal organ morphogenesis & 2.386 & 2.671 & - & - \\
\hline GO:0048659 & smooth muscle cell proliferation & 2.470 & 2.671 & 2.881 & 1.309 \\
\hline GO:0002828 & regulation of type 2 immune response & - & 2.667 & 1.368 & - \\
\hline GO:0009628 & response to abiotic stimulus & 4.683 & 2.625 & 2.073 & 2.086 \\
\hline GO:0006873 & cellular ion homeostasis & 2.419 & 2.623 & 1.934 & - \\
\hline GO:0150076 & neuroinflammatory response & 1.936 & 2.612 & - & 1.787 \\
\hline GO:0001936 & regulation of endothelial cell proliferation & 2.607 & 2.612 & 1.858 & 2.299 \\
\hline GO:0002690 & positive regulation of leukocyte chemotaxis & 1.471 & 2.602 & 1.368 & - \\
\hline GO:0070120 & ciliary neurotrophic factor-mediated signaling pathway & - & 2.602 & - & - \\
\hline GO:0050731 & positive regulation of peptidyl-tyrosine phosphorylation & 3.120 & 2.602 & - & 2.722 \\
\hline GO:0071221 & cellular response to bacterial lipopeptide & 3.843 & 2.602 & - & 1.653 \\
\hline GO:0071220 & cellular response to bacterial lipoprotein & 3.843 & 2.602 & - & 1.653 \\
\hline GO:0070339 & response to bacterial lipopeptide & 3.843 & 2.602 & - & 1.653 \\
\hline GO:0035879 & plasma membrane lactate transport & 5.796 & 2.602 & - & 1.653 \\
\hline GO:0010035 & response to inorganic substance & 3.427 & 2.596 & 2.786 & 1.958 \\
\hline GO:0051093 & negative regulation of developmental process & 3.655 & 2.589 & 3.354 & 3.049 \\
\hline
\end{tabular}




\begin{tabular}{|c|c|c|c|c|c|}
\hline GO:0002702 & $\begin{array}{l}\text { positive regulation of production of molecular mediator of } \\
\text { immune response }\end{array}$ & 2.292 & 2.575 & 1.882 & - \\
\hline GO:0006469 & negative regulation of protein kinase activity & 2.206 & 2.571 & 2.687 & 2.368 \\
\hline GO:0006957 & complement activation, alternative pathway & 2.227 & 2.570 & 3.572 & 3.166 \\
\hline GO:1902287 & $\begin{array}{l}\text { semaphorin-plexin signaling pathway involved in axon } \\
\text { guidance }\end{array}$ & 2.227 & 2.570 & - & - \\
\hline GO:0048771 & tissue remodeling & 3.072 & 2.562 & 2.471 & 1.399 \\
\hline GO:0061900 & glial cell activation & 1.936 & 2.555 & - & 2.127 \\
\hline GO:2000377 & regulation of reactive oxygen species metabolic process & 7.247 & 2.541 & 4.209 & 2.687 \\
\hline GO:0051173 & $\begin{array}{l}\text { positive regulation of nitrogen compound metabolic } \\
\text { process }\end{array}$ & 2.957 & 2.524 & - & 2.112 \\
\hline GO:0015833 & peptide transport & 2.838 & 2.524 & 1.346 & 1.601 \\
\hline GO:0048468 & cell development & 3.039 & 2.520 & - & 1.963 \\
\hline GO:0097435 & supramolecular fiber organization & 2.510 & 2.484 & 1.862 & 2.480 \\
\hline GO:0032611 & interleukin- 1 beta production & 2.206 & 2.479 & 2.423 & 2.446 \\
\hline GO:0050772 & positive regulation of axonogenesis & 1.766 & 2.479 & - & - \\
\hline GO:0030003 & cellular cation homeostasis & 2.321 & 2.470 & 2.009 & 1.329 \\
\hline GO:0002792 & negative regulation of peptide secretion & 2.340 & 2.458 & 1.997 & 1.865 \\
\hline GO:0007565 & female pregnancy & 1.780 & 2.456 & - & 2.280 \\
\hline GO:0030098 & lymphocyte differentiation & 2.578 & 2.456 & 3.259 & 1.554 \\
\hline GO:0009790 & embryo development & 2.219 & 2.450 & 1.417 & 1.910 \\
\hline GO:0001780 & neutrophil homeostasis & 1.398 & 2.450 & - & - \\
\hline GO:0022409 & positive regulation of cell-cell adhesion & 3.088 & 2.447 & 2.792 & 1.972 \\
\hline GO:0015031 & protein transport & 2.673 & 2.443 & 1.476 & 1.603 \\
\hline GO:0038094 & Fc-gamma receptor signaling pathway & 2.106 & 2.441 & - & 1.918 \\
\hline GO:1902285 & $\begin{array}{l}\text { semaphorin-plexin signaling pathway involved in neuron } \\
\text { projection guidance }\end{array}$ & 3.106 & 2.441 & - & - \\
\hline GO:0045628 & regulation of T-helper 2 cell differentiation & 1.324 & 2.441 & - & - \\
\hline
\end{tabular}




\begin{tabular}{|c|c|c|c|c|c|}
\hline GO:0002822 & $\begin{array}{l}\text { regulation of adaptive immune response based on somatic } \\
\text { recombination of immune receptors built from } \\
\text { immunoglobulin superfamily domains }\end{array}$ & 3.049 & 2.436 & 3.287 & 1.978 \\
\hline GO:0002437 & inflammatory response to antigenic stimulus & 3.605 & 2.435 & 2.573 & 3.552 \\
\hline GO:0060255 & regulation of macromolecule metabolic process & 2.151 & 2.388 & 2.111 & 1.324 \\
\hline GO:0009719 & response to endogenous stimulus & 2.751 & 2.369 & 2.275 & 1.722 \\
\hline GO:0048017 & inositol lipid-mediated signaling & 2.660 & 2.369 & - & - \\
\hline GO:0090022 & regulation of neutrophil chemotaxis & 2.549 & 2.353 & - & - \\
\hline GO:0032835 & glomerulus development & 2.275 & 2.349 & - & 1.999 \\
\hline GO:0032493 & response to bacterial lipoprotein & 3.433 & 2.348 & - & 1.523 \\
\hline GO:0032680 & regulation of tumor necrosis factor production & 3.086 & 2.348 & 3.643 & 1.806 \\
\hline GO:0007178 & $\begin{array}{l}\text { transmembrane receptor protein serine/threonine kinase } \\
\text { signaling pathway }\end{array}$ & 2.315 & 2.343 & 3.287 & 1.909 \\
\hline GO:0150078 & positive regulation of neuroinflammatory response & - & 2.317 & - & 1.853 \\
\hline GO:0034616 & response to laminar fluid shear stress & 1.993 & 2.317 & 2.157 & 2.913 \\
\hline GO:0009914 & hormone transport & 1.672 & 2.305 & - & 2.372 \\
\hline GO:0061564 & axon development & 2.123 & 2.304 & - & - \\
\hline GO:1903555 & $\begin{array}{l}\text { regulation of tumor necrosis factor superfamily cytokine } \\
\text { production }\end{array}$ & 3.034 & 2.303 & 3.609 & 1.780 \\
\hline GO:0019884 & antigen processing and presentation of exogenous antigen & 2.662 & 2.295 & - & - \\
\hline GO:0032928 & regulation of superoxide anion generation & 2.662 & 2.295 & - & - \\
\hline GO:0031113 & regulation of microtubule polymerization & 2.979 & 2.295 & 1.525 & - \\
\hline GO:0031325 & positive regulation of cellular metabolic process & 2.771 & 2.292 & - & 2.022 \\
\hline GO:0010952 & positive regulation of peptidase activity & 2.461 & 2.290 & - & - \\
\hline GO:0071560 & $\begin{array}{l}\text { cellular response to transforming growth factor beta } \\
\text { stimulus }\end{array}$ & - & 2.288 & 2.294 & 2.015 \\
\hline GO:0048660 & regulation of smooth muscle cell proliferation & 2.165 & 2.287 & 2.396 & - \\
\hline GO:0006811 & ion transport & 5.655 & 2.287 & - & - \\
\hline GO:0002718 & $\begin{array}{l}\text { regulation of cytokine production involved in immune } \\
\text { response }\end{array}$ & 2.204 & 2.280 & 4.051 & - \\
\hline
\end{tabular}




\begin{tabular}{|c|c|c|c|c|c|}
\hline GO:0002064 & epithelial cell development & 3.391 & 2.260 & 2.019 & 3.079 \\
\hline GO:0001706 & endoderm formation & 2.290 & 2.253 & - & 2.430 \\
\hline GO:0008630 & $\begin{array}{l}\text { intrinsic apoptotic signaling pathway in response to DNA } \\
\text { damage }\end{array}$ & 2.939 & 2.248 & 1.702 & - \\
\hline GO:0032963 & collagen metabolic process & - & 2.248 & 3.633 & - \\
\hline GO:0034109 & homotypic cell-cell adhesion & 4.021 & 2.244 & - & 1.929 \\
\hline GO:0032640 & tumor necrosis factor production & 2.946 & 2.244 & 3.548 & 1.741 \\
\hline GO:0008152 & metabolic process & 3.349 & 2.239 & 1.465 & - \\
\hline GO:0010575 & $\begin{array}{l}\text { positive regulation of vascular endothelial growth factor } \\
\text { production }\end{array}$ & - & 2.228 & 2.406 & - \\
\hline GO:0009892 & negative regulation of metabolic process & 2.372 & 2.228 & 2.023 & - \\
\hline GO:2000482 & regulation of interleukin-8 secretion & 5.473 & 2.228 & - & 2.015 \\
\hline GO:0051336 & regulation of hydrolase activity & 2.235 & 2.228 & - & - \\
\hline GO:0051017 & actin filament bundle assembly & 1.444 & 2.226 & 2.893 & 2.668 \\
\hline GO:0048661 & positive regulation of smooth muscle cell proliferation & 1.952 & 2.225 & 2.259 & - \\
\hline GO:0007517 & muscle organ development & - & 2.225 & - & 1.733 \\
\hline GO:0006875 & cellular metal ion homeostasis & 1.811 & 2.225 & 2.057 & - \\
\hline GO:0071559 & response to transforming growth factor beta & - & 2.222 & 2.255 & 1.968 \\
\hline GO:2000106 & regulation of leukocyte apoptotic process & 2.031 & 2.221 & - & - \\
\hline GO:0090594 & inflammatory response to wounding & 1.913 & 2.221 & - & - \\
\hline GO:0071622 & regulation of granulocyte chemotaxis & 2.247 & 2.220 & 1.480 & - \\
\hline GO:0071704 & organic substance metabolic process & 3.149 & 2.219 & 1.461 & - \\
\hline GO:0043407 & negative regulation of MAP kinase activity & 2.668 & 2.217 & 1.751 & 1.352 \\
\hline GO:0001909 & leukocyte mediated cytotoxicity & 1.507 & 2.211 & 1.420 & - \\
\hline GO:0045444 & fat cell differentiation & 4.195 & 2.205 & 1.977 & - \\
\hline GO:0033673 & negative regulation of kinase activity & 1.850 & 2.205 & 2.420 & 2.074 \\
\hline GO:0002218 & activation of innate immune response & - & 2.205 & - & - \\
\hline GO:0001938 & positive regulation of endothelial cell proliferation & 1.996 & 2.195 & - & - \\
\hline GO:0002366 & leukocyte activation involved in immune response & 3.128 & 2.195 & 2.603 & 1.815 \\
\hline GO:0071706 & tumor necrosis factor superfamily cytokine production & 2.864 & 2.195 & 3.483 & 1.704 \\
\hline
\end{tabular}




\begin{tabular}{|c|c|c|c|c|c|}
\hline GO:0001659 & temperature homeostasis & 4.900 & 2.195 & 2.864 & 2.112 \\
\hline GO:0019538 & protein metabolic process & 2.376 & 2.192 & - & - \\
\hline GO:0033002 & muscle cell proliferation & 1.835 & 2.192 & 2.897 & - \\
\hline GO:0071901 & $\begin{array}{l}\text { negative regulation of protein serine/threonine kinase } \\
\text { activity }\end{array}$ & 2.242 & 2.192 & 2.439 & 1.853 \\
\hline GO:0019882 & antigen processing and presentation & 4.590 & 2.181 & 1.656 & - \\
\hline GO:0006898 & receptor-mediated endocytosis & 3.408 & 2.177 & - & 1.931 \\
\hline GO:0061572 & actin filament bundle organization & 1.403 & 2.177 & 2.852 & 2.611 \\
\hline GO:0050709 & negative regulation of protein secretion & 2.126 & 2.177 & 2.102 & 1.969 \\
\hline GO:0071499 & cellular response to laminar fluid shear stress & 1.936 & 2.166 & 1.633 & 2.606 \\
\hline GO:0046883 & regulation of hormone secretion & 1.692 & 2.166 & - & 2.296 \\
\hline GO:0010533 & regulation of activation of Janus kinase activity & 1.936 & 2.166 & - & 1.414 \\
\hline GO:0042092 & type 2 immune response & - & 2.161 & - & - \\
\hline GO:0002263 & cell activation involved in immune response & 3.070 & 2.152 & 2.570 & 1.792 \\
\hline GO:0098771 & inorganic ion homeostasis & 2.278 & 2.146 & 1.789 & - \\
\hline GO:0002449 & lymphocyte mediated immunity & 1.483 & 2.134 & 2.550 & - \\
\hline GO:0050920 & regulation of chemotaxis & 2.151 & 2.107 & - & - \\
\hline GO:0072080 & nephron tubule development & 2.386 & 2.107 & - & - \\
\hline GO:0002709 & regulation of $\mathrm{T}$ cell mediated immunity & 1.516 & 2.107 & 2.562 & - \\
\hline GO:0050865 & regulation of cell activation & 3.498 & 2.107 & 2.255 & 1.997 \\
\hline GO:0048699 & generation of neurons & 2.206 & 2.107 & - & 1.602 \\
\hline GO:0048608 & reproductive structure development & 1.961 & 2.106 & 2.613 & 1.929 \\
\hline GO:0072009 & nephron epithelium development & 2.257 & 2.105 & - & - \\
\hline GO:0044255 & cellular lipid metabolic process & 4.381 & 2.104 & - & 1.823 \\
\hline GO:2000448 & $\begin{array}{l}\text { positive regulation of macrophage migration inhibitory } \\
\text { factor signaling pathway }\end{array}$ & 1.952 & 2.093 & - & - \\
\hline GO:0045404 & positive regulation of interleukin- 4 biosynthetic process & 1.952 & 2.093 & - & - \\
\hline GO:0072573 & tolerance induction to lipopolysaccharide & 1.952 & 2.093 & 2.630 & 2.392 \\
\hline GO:0038112 & interleukin-8-mediated signaling pathway & 1.952 & 2.093 & 2.630 & 2.392 \\
\hline GO:0071938 & vitamin A transport & 1.952 & 2.093 & - & - \\
\hline
\end{tabular}




\begin{tabular}{|c|c|c|c|c|c|}
\hline GO:0071939 & vitamin A import & 1.952 & 2.093 & - & - \\
\hline GO:0048878 & chemical homeostasis & 2.874 & 2.087 & 2.232 & 1.550 \\
\hline GO:0045582 & positive regulation of $\mathrm{T}$ cell differentiation & 1.899 & 2.086 & 1.921 & - \\
\hline GO:0002706 & regulation of lymphocyte mediated immunity & 1.339 & 2.084 & 2.768 & - \\
\hline GO:0043030 & regulation of macrophage activation & - & 2.072 & 1.409 & 2.263 \\
\hline GO:0002443 & leukocyte mediated immunity & 1.933 & 2.066 & 3.873 & 1.346 \\
\hline GO:0043406 & positive regulation of MAP kinase activity & 2.821 & 2.063 & 1.316 & - \\
\hline GO:0061458 & reproductive system development & 1.921 & 2.055 & 2.573 & 1.900 \\
\hline GO:0031099 & regeneration & 2.076 & 2.045 & - & 1.479 \\
\hline GO:0043409 & negative regulation of MAPK cascade & 2.662 & 2.045 & 2.221 & 2.491 \\
\hline GO:0045064 & T-helper 2 cell differentiation & - & 2.045 & - & - \\
\hline GO:0030950 & $\begin{array}{l}\text { establishment or maintenance of actin cytoskeleton } \\
\text { polarity }\end{array}$ & - & 2.045 & - & - \\
\hline GO:0032305 & positive regulation of icosanoid secretion & 2.575 & 2.045 & 1.958 & 2.612 \\
\hline GO:0048598 & embryonic morphogenesis & 1.627 & 2.039 & - & 1.791 \\
\hline GO:0050801 & ion homeostasis & 2.446 & 2.035 & 1.701 & 1.399 \\
\hline GO:0001503 & ossification & 1.443 & 2.035 & 3.158 & 1.501 \\
\hline GO:0008104 & protein localization & 3.387 & 2.023 & - & 1.331 \\
\hline GO:0055080 & cation homeostasis & 2.201 & 2.018 & 1.862 & - \\
\hline GO:0045862 & positive regulation of proteolysis & 2.230 & 2.015 & - & 1.376 \\
\hline GO:0007179 & transforming growth factor beta receptor signaling pathway & - & 2.015 & 1.525 & 1.439 \\
\hline GO:0001704 & formation of primary germ layer & 2.152 & 2.012 & - & 2.052 \\
\hline GO:0061043 & regulation of vascular wound healing & 1.783 & 2.010 & - & 1.331 \\
\hline GO:0035873 & lactate transmembrane transport & 4.264 & 2.010 & - & 1.331 \\
\hline GO:0042590 & $\begin{array}{l}\text { antigen processing and presentation of exogenous peptide } \\
\text { antigen via MHC class I }\end{array}$ & 1.783 & 2.010 & - & - \\
\hline GO:2000698 & $\begin{array}{l}\text { positive regulation of epithelial cell differentiation involved } \\
\text { in kidney development }\end{array}$ & 1.783 & 2.010 & - & 1.331 \\
\hline GO:0002246 & wound healing involved in inflammatory response & 1.783 & 2.010 & 1.546 & 1.331 \\
\hline
\end{tabular}




\begin{tabular}{|c|c|c|c|c|c|}
\hline GO:0015727 & lactate transport & 4.264 & 2.010 & - & 1.331 \\
\hline GO:0061326 & renal tubule development & 2.261 & 2.010 & - & - \\
\hline GO:0071276 & cellular response to cadmium ion & - & 2.000 & - & - \\
\hline GO:0048015 & phosphatidylinositol-mediated signaling & 2.317 & 2.000 & - & - \\
\hline GO:0031649 & heat generation & 2.288 & 2.000 & 2.227 & 1.855 \\
\hline GO:0072606 & interleukin-8 secretion & 4.927 & 2.000 & - & 1.855 \\
\hline GO:0032612 & interleukin-1 production & 2.576 & 1.994 & 3.336 & 2.608 \\
\hline GO:0072503 & cellular divalent inorganic cation homeostasis & 1.588 & 1.992 & 1.370 & - \\
\hline GO:0051224 & negative regulation of protein transport & 1.770 & 1.989 & 2.358 & 2.074 \\
\hline GO:0035987 & endodermal cell differentiation & 2.110 & 1.986 & - & 2.015 \\
\hline GO:0071495 & cellular response to endogenous stimulus & 1.846 & 1.969 & - & - \\
\hline GO:0050710 & negative regulation of cytokine secretion & 1.961 & 1.969 & 1.977 & 2.163 \\
\hline GO:0010038 & response to metal ion & 2.367 & 1.969 & 1.546 & 1.449 \\
\hline GO:0034111 & negative regulation of homotypic cell-cell adhesion & - & 1.968 & - & - \\
\hline GO:0031664 & $\begin{array}{l}\text { regulation of lipopolysaccharide-mediated signaling } \\
\text { pathway }\end{array}$ & 3.426 & 1.968 & - & 1.610 \\
\hline GO:0019233 & sensory perception of pain & 1.613 & 1.958 & - & - \\
\hline GO:1903039 & positive regulation of leukocyte cell-cell adhesion & 2.803 & 1.956 & 2.331 & - \\
\hline GO:0060627 & regulation of vesicle-mediated transport & 3.404 & 1.956 & 1.605 & 1.551 \\
\hline GO:0045184 & establishment of protein localization & 2.550 & 1.953 & - & 1.309 \\
\hline GO:0030574 & collagen catabolic process & - & 1.944 & 2.185 & - \\
\hline GO:0045429 & positive regulation of nitric oxide biosynthetic process & 2.690 & 1.944 & 2.427 & 2.735 \\
\hline GO:0051146 & striated muscle cell differentiation & - & 1.942 & - & - \\
\hline GO:1904950 & negative regulation of establishment of protein localization & 1.707 & 1.921 & 2.306 & 2.023 \\
\hline GO:2001056 & positive regulation of cysteine-type endopeptidase activity & 1.590 & 1.914 & - & - \\
\hline GO:0016042 & lipid catabolic process & 1.981 & 1.913 & - & - \\
\hline GO:0050764 & regulation of phagocytosis & 4.387 & 1.905 & 2.391 & 3.776 \\
\hline GO:1904407 & positive regulation of nitric oxide metabolic process & 2.640 & 1.905 & 2.401 & 2.706 \\
\hline
\end{tabular}




\begin{tabular}{|c|c|c|c|c|c|}
\hline GO:1903793 & positive regulation of anion transport & 3.720 & 1.905 & 1.316 & 2.097 \\
\hline GO:1901652 & response to peptide & 2.954 & 1.905 & 1.599 & - \\
\hline GO:0002673 & regulation of acute inflammatory response & 2.014 & 1.905 & - & 2.706 \\
\hline GO:0032623 & interleukin-2 production & 1.904 & 1.905 & 1.316 & - \\
\hline GO:0002720 & $\begin{array}{l}\text { positive regulation of cytokine production involved in } \\
\text { immune response }\end{array}$ & 1.493 & 1.905 & 2.401 & - \\
\hline GO:0032635 & interleukin-6 production & 3.532 & 1.905 & 5.001 & 1.791 \\
\hline GO:0007568 & aging & 3.157 & 1.905 & 1.887 & 2.577 \\
\hline GO:0050819 & negative regulation of coagulation & - & 1.905 & - & 1.329 \\
\hline GO:0002523 & leukocyte migration involved in inflammatory response & - & 1.899 & - & - \\
\hline GO:0002902 & regulation of B cell apoptotic process & 2.366 & 1.899 & - & - \\
\hline GO:0048384 & retinoic acid receptor signaling pathway & 2.164 & 1.899 & 2.143 & 1.781 \\
\hline GO:0062197 & cellular response to chemical stress & 3.510 & 1.899 & 1.527 & 1.504 \\
\hline GO:0060099 & regulation of phagocytosis, engulfment & 1.606 & 1.899 & - & 2.456 \\
\hline GO:0071498 & cellular response to fluid shear stress & 1.606 & 1.899 & 1.850 & 2.456 \\
\hline GO:0072112 & glomerular visceral epithelial cell differentiation & 1.606 & 1.899 & - & 1.554 \\
\hline GO:0043032 & positive regulation of macrophage activation & - & 1.899 & 1.368 & 1.781 \\
\hline GO:0038093 & Fc receptor signaling pathway & 1.606 & 1.899 & - & 1.554 \\
\hline GO:0061318 & renal filtration cell differentiation & 1.606 & 1.899 & - & 1.554 \\
\hline GO:0033032 & regulation of myeloid cell apoptotic process & 2.164 & 1.899 & 1.368 & - \\
\hline GO:1904894 & positive regulation of receptor signaling pathway via STAT & 1.693 & 1.892 & - & 2.382 \\
\hline GO:0014065 & phosphatidylinositol 3-kinase signaling & 1.991 & 1.889 & - & - \\
\hline GO:0051128 & regulation of cellular component organization & 3.070 & 1.886 & - & 3.090 \\
\hline GO:0007015 & actin filament organization & 1.470 & 1.880 & 1.633 & 2.459 \\
\hline GO:2001057 & reactive nitrogen species metabolic process & 4.678 & 1.867 & 3.572 & 2.217 \\
\hline GO:0001776 & leukocyte homeostasis & 2.563 & 1.867 & - & - \\
\hline GO:0002285 & lymphocyte activation involved in immune response & 2.411 & 1.867 & 2.080 & 1.476 \\
\hline GO:0019216 & regulation of lipid metabolic process & 2.625 & 1.862 & - & - \\
\hline GO:0031400 & negative regulation of protein modification process & 2.845 & 1.858 & 2.284 & 2.086 \\
\hline GO:0040008 & regulation of growth & 1.426 & 1.858 & 1.400 & 2.280 \\
\hline
\end{tabular}




\begin{tabular}{|c|c|c|c|c|c|}
\hline GO:0071407 & cellular response to organic cyclic compound & 2.337 & 1.858 & 2.284 & 1.566 \\
\hline GO:0051130 & positive regulation of cellular component organization & 3.229 & 1.855 & 1.511 & 1.722 \\
\hline GO:0030036 & actin cytoskeleton organization & 3.456 & 1.851 & 1.640 & 2.915 \\
\hline GO:0042832 & defense response to protozoan & 2.821 & 1.850 & 4.011 & 1.745 \\
\hline GO:0010574 & regulation of vascular endothelial growth factor production & - & 1.850 & 2.102 & - \\
\hline GO:0003158 & endothelium development & 2.371 & 1.848 & 1.974 & 3.065 \\
\hline GO:0051101 & regulation of DNA binding & - & 1.848 & - & - \\
\hline GO:0055065 & metal ion homeostasis & 1.764 & 1.846 & 1.921 & - \\
\hline GO:0006631 & fatty acid metabolic process & 2.798 & 1.846 & - & 1.365 \\
\hline GO:0010950 & positive regulation of endopeptidase activity & 1.767 & 1.846 & - & - \\
\hline GO:0010605 & negative regulation of macromolecule metabolic process & 1.819 & 1.844 & 1.977 & - \\
\hline GO:0010243 & response to organonitrogen compound & 3.403 & 1.835 & - & - \\
\hline GO:0010043 & response to zinc ion & 2.536 & 1.835 & - & - \\
\hline GO:1905153 & regulation of membrane invagination & 1.544 & 1.830 & - & 2.386 \\
\hline GO:0072311 & glomerular epithelial cell differentiation & 1.544 & 1.830 & - & 1.512 \\
\hline GO:1903037 & regulation of leukocyte cell-cell adhesion & 3.713 & 1.824 & 2.294 & 1.554 \\
\hline GO:0000302 & response to reactive oxygen species & 1.818 & 1.824 & 2.884 & 1.688 \\
\hline GO:0071248 & cellular response to metal ion & 1.986 & 1.824 & - & - \\
\hline GO:0042110 & $\mathrm{T}$ cell activation & 3.357 & 1.824 & 2.232 & - \\
\hline GO:0043627 & response to estrogen & 1.701 & 1.821 & 2.096 & - \\
\hline GO:0097755 & positive regulation of blood vessel diameter & 2.897 & 1.821 & - & - \\
\hline GO:0045428 & regulation of nitric oxide biosynthetic process & 5.029 & 1.821 & 3.321 & 2.706 \\
\hline GO:0120162 & positive regulation of cold-induced thermogenesis & 3.870 & 1.821 & 1.510 & - \\
\hline GO:0072507 & divalent inorganic cation homeostasis & 1.420 & 1.818 & - & - \\
\hline GO:0030182 & neuron differentiation & 1.882 & 1.817 & - & 1.686 \\
\hline GO:0046631 & alpha-beta $T$ cell activation & 2.617 & 1.816 & 1.640 & - \\
\hline GO:0071354 & cellular response to interleukin- 6 & - & 1.808 & 1.311 & - \\
\hline GO:0034110 & regulation of homotypic cell-cell adhesion & 2.043 & 1.808 & - & - \\
\hline GO:0034405 & response to fluid shear stress & 1.462 & 1.808 & 2.066 & 2.473 \\
\hline
\end{tabular}




\begin{tabular}{|c|c|c|c|c|c|}
\hline GO:0002920 & regulation of humoral immune response & 2.043 & 1.808 & 2.922 & 2.473 \\
\hline GO:0071347 & cellular response to interleukin-1 & 2.975 & 1.805 & 2.289 & - \\
\hline GO:0032787 & monocarboxylic acid metabolic process & 2.336 & 1.804 & - & - \\
\hline GO:0010718 & positive regulation of epithelial to mesenchymal transition & 1.403 & 1.803 & 2.298 & 1.868 \\
\hline GO:0051480 & regulation of cytosolic calcium ion concentration & - & 1.799 & 1.440 & - \\
\hline GO:0043069 & negative regulation of programmed cell death & 1.734 & 1.799 & 1.750 & 1.751 \\
\hline GO:0046879 & hormone secretion & 1.324 & 1.795 & - & 2.059 \\
\hline GO:0032147 & activation of protein kinase activity & 1.710 & 1.795 & 1.337 & 1.414 \\
\hline GO:0150063 & visual system development & - & 1.795 & 1.964 & 2.163 \\
\hline GO:0051348 & negative regulation of transferase activity & 1.462 & 1.795 & 2.102 & 1.775 \\
\hline GO:0045621 & positive regulation of lymphocyte differentiation & 1.589 & 1.784 & 1.702 & - \\
\hline GO:1901222 & regulation of NIK/NF-kappaB signaling & 1.974 & 1.784 & - & - \\
\hline GO:0046546 & development of primary male sexual characteristics & 1.779 & 1.782 & 2.118 & 2.498 \\
\hline GO:1901698 & response to nitrogen compound & 3.046 & 1.782 & - & - \\
\hline GO:1901724 & $\begin{array}{l}\text { positive regulation of cell proliferation involved in kidney } \\
\text { development }\end{array}$ & 1.561 & 1.773 & - & - \\
\hline GO:0030952 & establishment or maintenance of cytoskeleton polarity & - & 1.771 & - & - \\
\hline GO:2000193 & positive regulation of fatty acid transport & 2.201 & 1.771 & 1.745 & 2.317 \\
\hline GO:0150105 & protein localization to cell-cell junction & 1.486 & 1.771 & - & 1.460 \\
\hline GO:0002474 & $\begin{array}{l}\text { antigen processing and presentation of peptide antigen via } \\
\text { MHC class I }\end{array}$ & 2.201 & 1.771 & - & - \\
\hline GO:0050702 & interleukin- 1 beta secretion & - & 1.770 & - & - \\
\hline GO:0033028 & myeloid cell apoptotic process & 1.986 & 1.766 & - & - \\
\hline GO:0002292 & T cell differentiation involved in immune response & 2.236 & 1.766 & 1.819 & - \\
\hline GO:0010573 & vascular endothelial growth factor production & - & 1.766 & 2.026 & - \\
\hline GO:0050866 & negative regulation of cell activation & 3.049 & 1.750 & - & - \\
\hline GO:0035691 & macrophage migration inhibitory factor signaling pathway & 1.606 & 1.749 & - & - \\
\hline GO:0043066 & negative regulation of apoptotic process & 1.710 & 1.749 & 1.600 & 1.628 \\
\hline
\end{tabular}




\begin{tabular}{|c|c|c|c|c|c|}
\hline GO:2000768 & $\begin{array}{l}\text { positive regulation of nephron tubule epithelial cell } \\
\text { differentiation }\end{array}$ & 1.606 & 1.749 & - & - \\
\hline GO:0031110 & $\begin{array}{l}\text { regulation of microtubule polymerization or } \\
\text { depolymerization }\end{array}$ & 2.061 & 1.749 & - & - \\
\hline GO:0048880 & sensory system development & - & 1.749 & 1.921 & 2.109 \\
\hline GO:0070494 & $\begin{array}{l}\text { regulation of thrombin-activated receptor signaling } \\
\text { pathway }\end{array}$ & 1.606 & 1.749 & - & 2.015 \\
\hline GO:0042231 & interleukin- 13 biosynthetic process & 1.606 & 1.749 & - & - \\
\hline GO:0042097 & interleukin- 4 biosynthetic process & 1.606 & 1.749 & - & - \\
\hline GO:0010124 & phenylacetate catabolic process & 1.606 & 1.749 & - & - \\
\hline GO:0098758 & response to interleukin- 8 & 3.157 & 1.749 & 2.264 & 2.015 \\
\hline GO:0098759 & cellular response to interleukin- 8 & 3.157 & 1.749 & 2.264 & 2.015 \\
\hline GO:0046865 & terpenoid transport & 1.606 & 1.749 & - & - \\
\hline GO:0046864 & isoprenoid transport & 1.606 & 1.749 & - & - \\
\hline GO:0002752 & cell surface pattern recognition receptor signaling pathway & 1.606 & 1.749 & - & - \\
\hline GO:0003331 & $\begin{array}{l}\text { positive regulation of extracellular matrix constituent } \\
\text { secretion }\end{array}$ & 1.606 & 1.749 & - & - \\
\hline GO:1904035 & regulation of epithelial cell apoptotic process & 2.564 & 1.749 & 2.034 & 2.722 \\
\hline GO:0090101 & $\begin{array}{l}\text { negative regulation of transmembrane receptor protein } \\
\text { serine/threonine kinase signaling pathway }\end{array}$ & 1.545 & 1.749 & 1.672 & - \\
\hline GO:2000446 & $\begin{array}{l}\text { regulation of macrophage migration inhibitory factor } \\
\text { signaling pathway }\end{array}$ & 1.606 & 1.749 & - & - \\
\hline GO:0033030 & negative regulation of neutrophil apoptotic process & 1.606 & 1.749 & 2.264 & - \\
\hline GO:0045402 & regulation of interleukin- 4 biosynthetic process & 1.606 & 1.749 & - & - \\
\hline GO:2000295 & regulation of hydrogen peroxide catabolic process & 1.606 & 1.749 & - & 2.015 \\
\hline GO:0034633 & retinol transport & 1.606 & 1.749 & - & - \\
\hline GO:1904444 & regulation of establishment of Sertoli cell barrier & 1.606 & 1.749 & - & 2.015 \\
\hline GO:0070358 & actin polymerization-dependent cell motility & 1.606 & 1.749 & - & 2.015 \\
\hline GO:0070495 & $\begin{array}{l}\text { negative regulation of thrombin-activated receptor } \\
\text { signaling pathway }\end{array}$ & 1.606 & 1.749 & - & 2.015 \\
\hline
\end{tabular}




\begin{tabular}{|c|c|c|c|c|c|}
\hline GO:0072139 & glomerular parietal epithelial cell differentiation & 1.606 & 1.749 & - & - \\
\hline GO:0071725 & response to triacyl bacterial lipopeptide & 3.157 & 1.749 & - & - \\
\hline GO:0071727 & cellular response to triacyl bacterial lipopeptide & 3.157 & 1.749 & - & - \\
\hline GO:0007492 & endoderm development & 1.606 & 1.736 & - & 1.550 \\
\hline GO:0050892 & intestinal absorption & 1.398 & 1.732 & - & - \\
\hline GO:0001562 & response to protozoan & 2.614 & 1.732 & 3.831 & 1.639 \\
\hline GO:0006638 & neutral lipid metabolic process & 1.459 & 1.728 & - & - \\
\hline GO:0048568 & embryonic organ development & 1.658 & 1.725 & - & - \\
\hline GO:0032675 & regulation of interleukin- 6 production & 3.387 & 1.723 & 4.545 & 1.929 \\
\hline GO:2001236 & regulation of extrinsic apoptotic signaling pathway & 2.465 & 1.723 & 3.186 & 2.425 \\
\hline GO:0032303 & regulation of icosanoid secretion & 2.950 & 1.722 & 1.701 & 2.250 \\
\hline GO:0042509 & regulation of tyrosine phosphorylation of STAT protein & - & 1.722 & 1.772 & 1.929 \\
\hline GO:0014068 & $\begin{array}{l}\text { positive regulation of phosphatidylinositol 3-kinase } \\
\text { signaling }\end{array}$ & 1.676 & 1.722 & - & - \\
\hline GO:0002704 & negative regulation of leukocyte mediated immunity & 1.780 & 1.712 & 2.218 & - \\
\hline GO:0015807 & L-amino acid transport & 3.291 & 1.688 & - & - \\
\hline GO:0070555 & response to interleukin-1 & 3.059 & 1.686 & 1.844 & 1.339 \\
\hline GO:0071526 & semaphorin-plexin signaling pathway & 1.897 & 1.685 & - & - \\
\hline GO:0072182 & regulation of nephron tubule epithelial cell differentiation & 1.470 & 1.682 & - & - \\
\hline GO:0045088 & regulation of innate immune response & 1.913 & 1.682 & 1.320 & - \\
\hline GO:0045086 & positive regulation of interleukin-2 biosynthetic process & 1.470 & 1.682 & 1.346 & - \\
\hline GO:0051923 & sulfation & 1.470 & 1.682 & - & - \\
\hline GO:0002883 & regulation of hypersensitivity & 1.470 & 1.682 & - & 2.074 \\
\hline GO:0002253 & activation of immune response & 1.583 & 1.682 & - & 2.049 \\
\hline GO:0031392 & regulation of prostaglandin biosynthetic process & 1.470 & 1.682 & - & - \\
\hline GO:0001774 & microglial cell activation & 1.743 & 1.678 & - & 1.769 \\
\hline GO:0048589 & developmental growth & 1.890 & 1.678 & - & 1.425 \\
\hline GO:0002269 & leukocyte activation involved in inflammatory response & 1.743 & 1.678 & - & 1.769 \\
\hline GO:0031175 & neuron projection development & 1.699 & 1.676 & - & - \\
\hline GO:0055082 & cellular chemical homeostasis & 1.835 & 1.674 & 1.368 & - \\
\hline
\end{tabular}




\begin{tabular}{|c|c|c|c|c|c|}
\hline GO:0016525 & negative regulation of angiogenesis & - & 1.672 & 1.356 & 1.781 \\
\hline GO:0071887 & leukocyte apoptotic process & 1.470 & 1.668 & - & - \\
\hline GO:0050766 & positive regulation of phagocytosis & 2.631 & 1.665 & 3.106 & 4.082 \\
\hline GO:0072010 & glomerular epithelium development & 1.398 & 1.664 & - & 1.376 \\
\hline GO:0045624 & positive regulation of T-helper cell differentiation & - & 1.664 & - & - \\
\hline GO:0032753 & positive regulation of interleukin-4 production & 2.846 & 1.664 & - & - \\
\hline GO:0032616 & interleukin-13 production & - & 1.664 & - & - \\
\hline GO:0006925 & inflammatory cell apoptotic process & 1.398 & 1.664 & - & - \\
\hline GO:0097193 & intrinsic apoptotic signaling pathway & 2.116 & 1.659 & - & - \\
\hline GO:0031331 & positive regulation of cellular catabolic process & 1.402 & 1.658 & - & - \\
\hline GO:0008360 & regulation of cell shape & 2.361 & 1.657 & - & - \\
\hline GO:0030029 & actin filament-based process & 3.408 & 1.657 & 1.743 & 2.530 \\
\hline GO:2001238 & positive regulation of extrinsic apoptotic signaling pathway & - & 1.650 & 2.157 & - \\
\hline GO:0042531 & $\begin{array}{l}\text { positive regulation of tyrosine phosphorylation of STAT } \\
\text { protein }\end{array}$ & - & 1.650 & 1.480 & 2.392 \\
\hline GO:0042554 & superoxide anion generation & 2.488 & 1.650 & - & - \\
\hline GO:0042267 & natural killer cell mediated cytotoxicity & - & 1.650 & - & - \\
\hline GO:1901571 & fatty acid derivative transport & 2.247 & 1.650 & - & 1.741 \\
\hline GO:0071715 & icosanoid transport & 2.247 & 1.650 & - & 1.741 \\
\hline GO:0052547 & regulation of peptidase activity & - & 1.647 & - & - \\
\hline GO:0006809 & nitric oxide biosynthetic process & 4.567 & 1.642 & 3.906 & 2.491 \\
\hline GO:0007260 & tyrosine phosphorylation of STAT protein & - & 1.642 & 1.710 & 1.867 \\
\hline GO:0033554 & cellular response to stress & 2.505 & 1.632 & 1.302 & 1.597 \\
\hline GO:0060541 & respiratory system development & - & 1.622 & 1.624 & 2.163 \\
\hline GO:1905954 & positive regulation of lipid localization & 4.081 & 1.621 & 4.823 & 4.014 \\
\hline GO:0035710 & CD4-positive, alpha-beta T cell activation & 1.493 & 1.621 & 2.537 & - \\
\hline GO:0032722 & positive regulation of chemokine production & 4.267 & 1.615 & 2.883 & - \\
\hline GO:0014070 & response to organic cyclic compound & 2.714 & 1.613 & 2.790 & 2.086 \\
\hline GO:0031589 & cell-substrate adhesion & 1.882 & 1.610 & 1.523 & 1.815 \\
\hline
\end{tabular}




\begin{tabular}{|c|c|c|c|c|c|}
\hline GO:0001894 & tissue homeostasis & 1.399 & 1.609 & - & - \\
\hline GO:0070741 & response to interleukin- 6 & - & 1.609 & - & - \\
\hline GO:0015812 & gamma-aminobutyric acid transport & 1.344 & 1.607 & - & - \\
\hline GO:1903708 & positive regulation of hemopoiesis & 1.723 & 1.605 & 3.397 & - \\
\hline GO:2000181 & negative regulation of blood vessel morphogenesis & - & 1.600 & 1.771 & 2.724 \\
\hline GO:0050713 & negative regulation of interleukin- 1 beta secretion & - & 1.594 & - & - \\
\hline GO:0001660 & fever generation & 1.399 & 1.594 & 3.572 & 3.166 \\
\hline GO:0016264 & gap junction assembly & 2.227 & 1.594 & 2.307 & - \\
\hline GO:0072160 & nephron tubule epithelial cell differentiation & 1.399 & 1.594 & - & - \\
\hline GO:2001279 & regulation of unsaturated fatty acid biosynthetic process & 1.399 & 1.594 & - & - \\
\hline GO:0002683 & negative regulation of immune system process & 6.278 & 1.594 & 3.289 & - \\
\hline GO:0031324 & negative regulation of cellular metabolic process & 2.206 & 1.593 & 1.743 & 1.338 \\
\hline GO:0038061 & NIK/NF-kappaB signaling & 2.609 & 1.591 & - & - \\
\hline GO:0002250 & adaptive immune response & 3.094 & 1.589 & 1.844 & - \\
\hline GO:0050732 & negative regulation of peptidyl-tyrosine phosphorylation & - & 1.587 & - & - \\
\hline GO:0036211 & protein modification process & 2.340 & 1.576 & - & 1.551 \\
\hline GO:0032755 & positive regulation of interleukin- 6 production & 2.292 & 1.576 & 3.939 & 1.929 \\
\hline GO:1902903 & regulation of supramolecular fiber organization & 2.915 & 1.576 & 1.638 & 1.876 \\
\hline GO:0002262 & myeloid cell homeostasis & - & 1.576 & 1.943 & - \\
\hline GO:0006575 & cellular modified amino acid metabolic process & 2.249 & 1.576 & - & - \\
\hline GO:0006464 & cellular protein modification process & 2.340 & 1.576 & - & 1.551 \\
\hline GO:0003382 & epithelial cell morphogenesis & 1.755 & 1.573 & - & - \\
\hline GO:0007043 & cell-cell junction assembly & 1.722 & 1.573 & 1.547 & 1.562 \\
\hline GO:0044070 & regulation of anion transport & 3.617 & 1.573 & 1.547 & 2.608 \\
\hline GO:0007584 & response to nutrient & 2.481 & 1.566 & - & 1.909 \\
\hline GO:0043367 & CD4-positive, alpha-beta T cell differentiation & 1.521 & 1.564 & - & - \\
\hline GO:0015850 & organic hydroxy compound transport & 4.461 & 1.561 & - & 2.207 \\
\hline GO:1902532 & negative regulation of intracellular signal transduction & 2.321 & 1.561 & 2.345 & 1.978 \\
\hline GO:2000116 & regulation of cysteine-type endopeptidase activity & - & 1.560 & - & - \\
\hline GO:0001654 & eye development & - & 1.559 & 1.630 & 1.864 \\
\hline
\end{tabular}




\begin{tabular}{|c|c|c|c|c|c|}
\hline GO:0050873 & brown fat cell differentiation & 3.384 & 1.559 & - & - \\
\hline GO:0002228 & natural killer cell mediated immunity & - & 1.559 & - & - \\
\hline GO:0001843 & neural tube closure & 1.431 & 1.559 & - & - \\
\hline GO:0048872 & homeostasis of number of cells & 2.288 & 1.559 & 2.768 & - \\
\hline GO:0002221 & pattern recognition receptor signaling pathway & 3.821 & 1.552 & 7.441 & 3.294 \\
\hline GO:0070371 & ERK1 and ERK2 cascade & 2.669 & 1.552 & 2.218 & 1.444 \\
\hline GO:0002694 & regulation of leukocyte activation & 2.681 & 1.550 & 2.210 & 1.501 \\
\hline GO:0009896 & positive regulation of catabolic process & 1.399 & 1.546 & - & - \\
\hline GO:0034612 & response to tumor necrosis factor & 1.952 & 1.539 & 3.907 & 1.978 \\
\hline GO:0050870 & positive regulation of $T$ cell activation & 1.734 & 1.538 & 1.633 & - \\
\hline GO:0045601 & regulation of endothelial cell differentiation & 2.315 & 1.538 & 1.831 & 3.964 \\
\hline GO:0098869 & cellular oxidant detoxification & 2.233 & 1.538 & 1.326 & - \\
\hline GO:0002369 & T cell cytokine production & - & 1.538 & 2.622 & - \\
\hline GO:0060606 & tube closure & 1.409 & 1.538 & - & - \\
\hline GO:0031109 & microtubule polymerization or depolymerization & 2.071 & 1.537 & - & - \\
\hline GO:0009991 & response to extracellular stimulus & 2.201 & 1.536 & - & 1.771 \\
\hline GO:0001794 & type Ila hypersensitivity & 1.403 & 1.532 & - & 1.812 \\
\hline GO:0071409 & cellular response to cycloheximide & 1.403 & 1.532 & - & - \\
\hline GO:0071724 & response to diacyl bacterial lipopeptide & 2.658 & 1.532 & - & 1.812 \\
\hline GO:0071726 & cellular response to diacyl bacterial lipopeptide & 2.658 & 1.532 & - & 1.812 \\
\hline GO:0055085 & transmembrane transport & 3.108 & 1.532 & - & - \\
\hline GO:1901529 & positive regulation of anion channel activity & 1.403 & 1.532 & - & 1.812 \\
\hline GO:0002894 & positive regulation of type II hypersensitivity & 1.403 & 1.532 & - & 1.812 \\
\hline GO:0000320 & re-entry into mitotic cell cycle & 1.403 & 1.532 & - & - \\
\hline GO:0010536 & positive regulation of activation of Janus kinase activity & 1.403 & 1.532 & - & - \\
\hline GO:0001798 & positive regulation of type lla hypersensitivity & 1.403 & 1.532 & - & 1.812 \\
\hline GO:0038165 & oncostatin-M-mediated signaling pathway & - & 1.532 & - & - \\
\hline GO:0001796 & regulation of type Ila hypersensitivity & 1.403 & 1.532 & - & 1.812 \\
\hline GO:0044789 & modulation by host of viral release from host cell & 1.403 & 1.532 & - & - \\
\hline GO:0060548 & negative regulation of cell death & 1.790 & 1.532 & 1.545 & 1.868 \\
\hline
\end{tabular}




\begin{tabular}{|c|c|c|c|c|c|}
\hline GO:0002892 & regulation of type II hypersensitivity & 1.403 & 1.532 & - & 1.812 \\
\hline GO:0044791 & positive regulation by host of viral release from host cell & 1.403 & 1.532 & - & - \\
\hline GO:0048861 & leukemia inhibitory factor signaling pathway & - & 1.532 & - & - \\
\hline GO:0045917 & positive regulation of complement activation & 1.403 & 1.532 & 2.036 & 1.812 \\
\hline GO:0007354 & zygotic determination of anterior/posterior axis, embryo & 1.403 & 1.532 & - & - \\
\hline GO:0002445 & type II hypersensitivity & 1.403 & 1.532 & - & 1.812 \\
\hline GO:0033031 & positive regulation of neutrophil apoptotic process & - & 1.532 & - & - \\
\hline GO:0032929 & negative regulation of superoxide anion generation & 1.403 & 1.532 & - & - \\
\hline GO:0002886 & regulation of myeloid leukocyte mediated immunity & 2.080 & 1.532 & 2.052 & 1.639 \\
\hline GO:1904714 & regulation of chaperone-mediated autophagy & 1.403 & 1.532 & - & 1.812 \\
\hline GO:0014902 & myotube differentiation & - & 1.530 & - & - \\
\hline GO:0046209 & nitric oxide metabolic process & 4.980 & 1.530 & 3.730 & 2.356 \\
\hline GO:0002821 & positive regulation of adaptive immune response & 2.315 & 1.530 & 2.225 & - \\
\hline GO:0046785 & microtubule polymerization & 2.391 & 1.530 & - & - \\
\hline GO:1904892 & regulation of receptor signaling pathway via STAT & - & 1.529 & 1.441 & 1.769 \\
\hline GO:0006968 & cellular defense response & 1.324 & 1.528 & - & - \\
\hline GO:1903980 & positive regulation of microglial cell activation & - & 1.528 & - & 1.918 \\
\hline GO:1903961 & positive regulation of anion transmembrane transport & 1.324 & 1.528 & - & - \\
\hline GO:0002524 & hypersensitivity & 1.324 & 1.528 & - & 1.918 \\
\hline GO:2000347 & positive regulation of hepatocyte proliferation & 2.106 & 1.528 & 2.232 & 1.918 \\
\hline GO:0007423 & sensory organ development & - & 1.525 & - & - \\
\hline GO:0034114 & regulation of heterotypic cell-cell adhesion & - & 1.523 & 3.426 & 2.952 \\
\hline GO:0001783 & B cell apoptotic process & 1.844 & 1.523 & - & - \\
\hline GO:0034762 & regulation of transmembrane transport & 1.644 & 1.517 & - & - \\
\hline GO:1902107 & positive regulation of leukocyte differentiation & 1.471 & 1.515 & 1.877 & - \\
\hline GO:0010508 & positive regulation of autophagy & 1.315 & 1.514 & - & - \\
\hline GO:0046427 & $\begin{array}{l}\text { positive regulation of receptor signaling pathway via JAK- } \\
\text { STAT }\end{array}$ & - & 1.509 & - & 1.864 \\
\hline GO:0032890 & regulation of organic acid transport & 3.529 & 1.507 & 1.605 & 2.324 \\
\hline GO:0010468 & regulation of gene expression & 1.889 & 1.502 & 2.133 & - \\
\hline
\end{tabular}




\begin{tabular}{|c|c|c|c|c|c|}
\hline GO:0048666 & neuron development & 1.511 & 1.501 & - & - \\
\hline GO:0007204 & positive regulation of cytosolic calcium ion concentration & - & 1.494 & 1.437 & - \\
\hline GO:0017015 & $\begin{array}{l}\text { regulation of transforming growth factor beta receptor } \\
\text { signaling pathway }\end{array}$ & 1.362 & 1.486 & - & 1.348 \\
\hline GO:0030278 & regulation of ossification & - & 1.486 & 2.210 & - \\
\hline GO:1903428 & $\begin{array}{l}\text { positive regulation of reactive oxygen species biosynthetic } \\
\text { process }\end{array}$ & 2.571 & 1.485 & 2.001 & 2.195 \\
\hline GO:0010812 & negative regulation of cell-substrate adhesion & - & 1.485 & 2.001 & 1.587 \\
\hline GO:0050701 & interleukin-1 secretion & 1.524 & 1.485 & 1.370 & 1.587 \\
\hline GO:0034614 & cellular response to reactive oxygen species & - & 1.484 & 1.859 & - \\
\hline GO:1903169 & regulation of calcium ion transmembrane transport & - & 1.484 & - & - \\
\hline GO:0002460 & $\begin{array}{l}\text { adaptive immune response based on somatic } \\
\text { recombination of immune receptors built from } \\
\text { immunoglobulin superfamily domains }\end{array}$ & 2.040 & 1.481 & 2.060 & - \\
\hline GO:0051154 & negative regulation of striated muscle cell differentiation & - & 1.478 & - & - \\
\hline GO:0010829 & negative regulation of glucose transmembrane transport & 2.506 & 1.472 & - & - \\
\hline GO:0046649 & lymphocyte activation & 2.332 & 1.468 & 1.600 & - \\
\hline GO:0001890 & placenta development & - & 1.468 & - & - \\
\hline GO:0050767 & regulation of neurogenesis & 2.236 & 1.468 & - & - \\
\hline GO:0048145 & regulation of fibroblast proliferation & 1.343 & 1.468 & - & - \\
\hline GO:0006641 & triglyceride metabolic process & 1.693 & 1.468 & - & - \\
\hline GO:0032269 & negative regulation of cellular protein metabolic process & 1.337 & 1.464 & 1.607 & - \\
\hline GO:0009612 & response to mechanical stimulus & 3.335 & 1.462 & 2.656 & 1.528 \\
\hline GO:0007010 & cytoskeleton organization & 3.049 & 1.462 & - & 2.022 \\
\hline GO:0032642 & regulation of chemokine production & 3.430 & 1.460 & 2.182 & - \\
\hline GO:0030512 & $\begin{array}{l}\text { negative regulation of transforming growth factor beta } \\
\text { receptor signaling pathway }\end{array}$ & 1.493 & 1.458 & 1.353 & 1.560 \\
\hline GO:0043010 & camera-type eye development & - & 1.456 & 1.597 & 1.909 \\
\hline GO:0045216 & cell-cell junction organization & 1.411 & 1.455 & - & - \\
\hline GO:0007409 & axonogenesis & - & 1.454 & - & - \\
\hline
\end{tabular}




\begin{tabular}{|c|c|c|c|c|c|}
\hline GO:0048732 & gland development & 1.766 & 1.453 & 3.704 & 3.190 \\
\hline GO:0048308 & organelle inheritance & - & 1.453 & - & - \\
\hline GO:0048313 & Golgi inheritance & - & 1.453 & - & - \\
\hline GO:0032736 & positive regulation of interleukin- 13 production & - & 1.453 & - & - \\
\hline GO:0002468 & dendritic cell antigen processing and presentation & - & 1.453 & - & - \\
\hline GO:0042976 & activation of Janus kinase activity & - & 1.453 & - & - \\
\hline GO:0010817 & regulation of hormone levels & 1.913 & 1.453 & - & 1.335 \\
\hline GO:0030336 & negative regulation of cell migration & 2.564 & 1.453 & 2.947 & 2.963 \\
\hline GO:0050777 & negative regulation of immune response & 3.578 & 1.453 & 2.694 & - \\
\hline GO:0051098 & regulation of binding & - & 1.453 & 1.882 & - \\
\hline GO:0030162 & regulation of proteolysis & - & 1.453 & - & - \\
\hline GO:1903844 & $\begin{array}{l}\text { regulation of cellular response to transforming growth } \\
\text { factor beta stimulus }\end{array}$ & 1.324 & 1.453 & - & 1.329 \\
\hline GO:0035850 & $\begin{array}{l}\text { epithelial cell differentiation involved in kidney } \\
\text { development }\end{array}$ & 1.602 & 1.450 & - & 1.396 \\
\hline GO:0046460 & neutral lipid biosynthetic process & - & 1.450 & - & - \\
\hline GO:0046463 & acylglycerol biosynthetic process & - & 1.450 & - & - \\
\hline GO:0042692 & muscle cell differentiation & - & 1.445 & - & - \\
\hline GO:0071241 & cellular response to inorganic substance & 1.525 & 1.442 & - & - \\
\hline GO:0008584 & male gonad development & 1.470 & 1.438 & 1.633 & 1.999 \\
\hline GO:0035456 & response to interferon-beta & 1.936 & 1.436 & 5.302 & 1.541 \\
\hline GO:0002438 & acute inflammatory response to antigenic stimulus & 1.734 & 1.434 & - & 1.929 \\
\hline GO:2000108 & positive regulation of leukocyte apoptotic process & - & 1.434 & - & - \\
\hline GO:0014020 & primary neural tube formation & 1.302 & 1.434 & - & - \\
\hline GO:0048144 & fibroblast proliferation & 1.302 & 1.434 & - & - \\
\hline GO:0051085 & chaperone cofactor-dependent protein refolding & - & 1.434 & - & - \\
\hline GO:0043280 & $\begin{array}{l}\text { positive regulation of cysteine-type endopeptidase activity } \\
\text { involved in apoptotic process }\end{array}$ & - & 1.428 & - & - \\
\hline GO:0051172 & $\begin{array}{l}\text { negative regulation of nitrogen compound metabolic } \\
\text { process }\end{array}$ & 1.644 & 1.424 & 1.563 & - \\
\hline
\end{tabular}




\begin{tabular}{|c|c|c|c|c|c|}
\hline GO:1901343 & negative regulation of vasculature development & - & 1.423 & 1.623 & 2.498 \\
\hline GO:0009725 & response to hormone & 1.627 & 1.421 & - & - \\
\hline GO:1904427 & positive regulation of calcium ion transmembrane transport & - & 1.420 & - & - \\
\hline GO:0043086 & negative regulation of catalytic activity & 1.516 & 1.419 & 2.099 & 1.760 \\
\hline GO:0007157 & $\begin{array}{l}\text { heterophilic cell-cell adhesion via plasma membrane cell } \\
\text { adhesion molecules }\end{array}$ & 1.562 & 1.418 & - & 1.369 \\
\hline GO:0030195 & negative regulation of blood coagulation & - & 1.418 & - & - \\
\hline GO:0010259 & multicellular organism aging & - & 1.418 & - & 2.015 \\
\hline GO:2000241 & regulation of reproductive process & 1.992 & 1.418 & 1.368 & 2.577 \\
\hline GO:0046661 & male sex differentiation & 1.386 & 1.418 & 1.796 & 2.074 \\
\hline GO:0010720 & positive regulation of cell development & 1.427 & 1.413 & - & - \\
\hline GO:1903845 & $\begin{array}{l}\text { negative regulation of cellular response to transforming } \\
\text { growth factor beta stimulus }\end{array}$ & 1.442 & 1.412 & 1.316 & 1.523 \\
\hline GO:0061448 & connective tissue development & 1.368 & 1.412 & 2.017 & - \\
\hline GO:0001667 & ameboidal-type cell migration & 3.091 & 1.408 & 1.641 & 1.809 \\
\hline GO:0060284 & regulation of cell development & 2.236 & 1.403 & - & - \\
\hline GO:0030279 & negative regulation of ossification & 1.347 & 1.398 & - & - \\
\hline GO:0050867 & positive regulation of cell activation & 1.606 & 1.390 & 1.771 & 1.304 \\
\hline GO:1902235 & $\begin{array}{l}\text { regulation of endoplasmic reticulum stress-induced } \\
\text { intrinsic apoptotic signaling pathway }\end{array}$ & - & 1.390 & - & - \\
\hline GO:0002695 & negative regulation of leukocyte activation & 3.176 & 1.390 & - & - \\
\hline GO:0042119 & neutrophil activation & 2.352 & 1.390 & 2.265 & 2.735 \\
\hline GO:1901722 & $\begin{array}{l}\text { regulation of cell proliferation involved in kidney } \\
\text { development }\end{array}$ & - & 1.390 & - & - \\
\hline GO:0042178 & xenobiotic catabolic process & 1.913 & 1.390 & - & - \\
\hline GO:0002861 & regulation of inflammatory response to antigenic stimulus & 1.676 & 1.390 & - & 1.892 \\
\hline GO:0032673 & regulation of interleukin-4 production & 2.352 & 1.390 & - & - \\
\hline GO:1902042 & $\begin{array}{l}\text { negative regulation of extrinsic apoptotic signaling pathway } \\
\text { via death domain receptors }\end{array}$ & 1.676 & 1.390 & 1.450 & 1.892 \\
\hline
\end{tabular}




\begin{tabular}{|c|c|c|c|c|c|}
\hline GO:0050872 & white fat cell differentiation & - & 1.390 & - & - \\
\hline GO:0015802 & basic amino acid transport & - & 1.390 & - & - \\
\hline GO:0042537 & benzene-containing compound metabolic process & 1.676 & 1.390 & - & - \\
\hline GO:0045137 & development of primary sexual characteristics & 1.940 & 1.390 & 2.265 & 1.924 \\
\hline GO:0002863 & $\begin{array}{l}\text { positive regulation of inflammatory response to antigenic } \\
\text { stimulus }\end{array}$ & 1.913 & 1.390 & - & 1.787 \\
\hline GO:0071294 & cellular response to zinc ion & 1.913 & 1.390 & - & - \\
\hline GO:0032720 & negative regulation of tumor necrosis factor production & 2.391 & 1.390 & 1.899 & - \\
\hline GO:1900047 & negative regulation of hemostasis & - & 1.390 & - & - \\
\hline GO:0043277 & apoptotic cell clearance & 1.525 & 1.390 & 2.427 & 1.978 \\
\hline GO:0010830 & regulation of myotube differentiation & - & 1.390 & - & - \\
\hline GO:0032892 & positive regulation of organic acid transport & 2.690 & 1.390 & - & 1.340 \\
\hline GO:0002220 & $\begin{array}{l}\text { innate immune response activating cell surface receptor } \\
\text { signaling pathway }\end{array}$ & - & 1.387 & - & - \\
\hline GO:0007264 & small GTPase mediated signal transduction & - & 1.387 & - & - \\
\hline GO:0006931 & $\begin{array}{l}\text { substrate-dependent cell migration, cell attachment to } \\
\text { substrate }\end{array}$ & - & 1.387 & - & - \\
\hline GO:0019087 & transformation of host cell by virus & - & 1.387 & - & - \\
\hline GO:0031328 & positive regulation of cellular biosynthetic process & 1.740 & 1.387 & - & - \\
\hline GO:0002904 & positive regulation of $B$ cell apoptotic process & - & 1.387 & - & - \\
\hline GO:1903596 & regulation of gap junction assembly & 2.340 & 1.387 & 1.870 & - \\
\hline GO:0046898 & response to cycloheximide & - & 1.387 & - & - \\
\hline GO:0061073 & ciliary body morphogenesis & - & 1.387 & - & - \\
\hline GO:0035470 & positive regulation of vascular wound healing & - & 1.387 & - & - \\
\hline GO:0010138 & pyrimidine ribonucleotide salvage & - & 1.387 & - & - \\
\hline GO:0001905 & activation of membrane attack complex & - & 1.387 & 1.870 & 1.653 \\
\hline GO:0008655 & pyrimidine-containing compound salvage & - & 1.387 & - & - \\
\hline GO:0008643 & carbohydrate transport & 2.081 & 1.387 & - & - \\
\hline GO:0043433 & $\begin{array}{l}\text { negative regulation of DNA-binding transcription factor } \\
\text { activity }\end{array}$ & - & 1.387 & - & - \\
\hline
\end{tabular}




\begin{tabular}{|c|c|c|c|c|c|}
\hline GO:0120161 & regulation of cold-induced thermogenesis & 3.716 & 1.387 & 1.409 & - \\
\hline GO:0051387 & $\begin{array}{l}\text { negative regulation of neurotrophin TRK receptor signaling } \\
\text { pathway }\end{array}$ & - & 1.387 & - & - \\
\hline GO:0099039 & sphingolipid translocation & - & 1.387 & - & 1.653 \\
\hline GO:2000468 & regulation of peroxidase activity & - & 1.387 & - & 1.653 \\
\hline GO:0006639 & acylglycerol metabolic process & - & 1.387 & - & - \\
\hline GO:0010827 & regulation of glucose transmembrane transport & 2.161 & 1.387 & - & - \\
\hline GO:0060161 & positive regulation of dopamine receptor signaling pathway & - & 1.387 & - & - \\
\hline GO:0006477 & protein sulfation & - & 1.387 & - & 1.653 \\
\hline GO:0044206 & UMP salvage & - & 1.387 & - & - \\
\hline GO:0042117 & monocyte activation & - & 1.387 & - & - \\
\hline GO:0002440 & production of molecular mediator of immune response & 1.909 & 1.387 & 2.707 & - \\
\hline GO:0032262 & pyrimidine nucleotide salvage & - & 1.387 & - & - \\
\hline GO:0106106 & cold-induced thermogenesis & 3.716 & 1.387 & 1.409 & - \\
\hline GO:0032602 & chemokine production & 3.250 & 1.387 & 2.096 & - \\
\hline GO:0031667 & response to nutrient levels & 1.882 & 1.386 & - & 1.731 \\
\hline GO:0090092 & $\begin{array}{l}\text { regulation of transmembrane receptor protein } \\
\text { serine/threonine kinase signaling pathway }\end{array}$ & 1.451 & 1.386 & 2.095 & 1.446 \\
\hline GO:0010629 & negative regulation of gene expression & 1.688 & 1.386 & 1.772 & - \\
\hline GO:0051960 & regulation of nervous system development & 2.643 & 1.379 & - & - \\
\hline GO:0034341 & response to interferon-gamma & 4.461 & 1.379 & 4.545 & 1.929 \\
\hline GO:0010770 & $\begin{array}{l}\text { positive regulation of cell morphogenesis involved in } \\
\text { differentiation }\end{array}$ & - & 1.377 & - & - \\
\hline GO:0048146 & positive regulation of fibroblast proliferation & 1.399 & 1.376 & - & - \\
\hline GO:0045089 & positive regulation of innate immune response & - & 1.375 & - & - \\
\hline GO:1901653 & cellular response to peptide & 1.561 & 1.375 & - & - \\
\hline GO:0050769 & positive regulation of neurogenesis & 1.359 & 1.375 & - & - \\
\hline GO:0019725 & cellular homeostasis & 1.516 & 1.374 & - & - \\
\hline
\end{tabular}




\begin{tabular}{|c|c|c|c|c|c|}
\hline GO:1902041 & $\begin{array}{l}\text { regulation of extrinsic apoptotic signaling pathway via } \\
\text { death domain receptors }\end{array}$ & 1.493 & 1.371 & 1.656 & 1.950 \\
\hline GO:0140353 & lipid export from cell & 1.493 & 1.371 & 1.656 & 1.329 \\
\hline GO:0002675 & positive regulation of acute inflammatory response & 2.288 & 1.364 & 1.420 & 2.695 \\
\hline GO:0007507 & heart development & - & 1.364 & - & - \\
\hline GO:0098656 & anion transmembrane transport & 3.096 & 1.363 & - & - \\
\hline GO:0009891 & positive regulation of biosynthetic process & 1.782 & 1.361 & - & - \\
\hline GO:0000902 & cell morphogenesis & 2.029 & 1.359 & - & - \\
\hline GO:0043149 & stress fiber assembly & - & 1.357 & 2.859 & 1.716 \\
\hline GO:0030038 & contractile actin filament bundle assembly & - & 1.357 & 2.859 & 1.716 \\
\hline GO:0045446 & endothelial cell differentiation & 1.936 & 1.357 & 1.672 & 3.519 \\
\hline GO:1903556 & $\begin{array}{l}\text { negative regulation of tumor necrosis factor superfamily } \\
\text { cytokine production }\end{array}$ & 2.315 & 1.352 & 1.862 & - \\
\hline GO:0033627 & cell adhesion mediated by integrin & 3.550 & 1.352 & - & 1.454 \\
\hline GO:0001885 & endothelial cell development & 2.315 & 1.352 & 1.862 & 2.706 \\
\hline GO:0010832 & negative regulation of myotube differentiation & - & 1.342 & - & - \\
\hline GO:0048711 & positive regulation of astrocyte differentiation & - & 1.342 & - & - \\
\hline GO:0030449 & regulation of complement activation & - & 1.342 & 2.019 & 1.729 \\
\hline GO:0071285 & cellular response to lithium ion & 1.818 & 1.342 & 2.019 & 1.729 \\
\hline GO:1901550 & regulation of endothelial cell development & 2.681 & 1.342 & - & 2.706 \\
\hline GO:1903140 & regulation of establishment of endothelial barrier & 2.681 & 1.342 & - & 2.706 \\
\hline GO:0062099 & negative regulation of programmed necrotic cell death & - & 1.342 & 2.019 & - \\
\hline GO:0070102 & interleukin-6-mediated signaling pathway & - & 1.342 & - & - \\
\hline GO:1905155 & positive regulation of membrane invagination & - & 1.342 & - & 1.729 \\
\hline GO:0060100 & positive regulation of phagocytosis, engulfment & - & 1.342 & - & 1.729 \\
\hline GO:0002864 & $\begin{array}{l}\text { regulation of acute inflammatory response to antigenic } \\
\text { stimulus }\end{array}$ & - & 1.342 & - & 1.729 \\
\hline GO:0002922 & positive regulation of humoral immune response & 1.818 & 1.342 & 3.092 & 2.706 \\
\hline GO:0032231 & regulation of actin filament bundle assembly & - & 1.341 & 2.224 & 1.697 \\
\hline GO:0007160 & cell-matrix adhesion & 1.755 & 1.337 & - & - \\
\hline
\end{tabular}




\begin{tabular}{|c|c|c|c|c|c|}
\hline GO:1902105 & regulation of leukocyte differentiation & 1.493 & 1.335 & - & - \\
\hline GO:0051248 & negative regulation of protein metabolic process & 1.525 & 1.335 & 1.398 & - \\
\hline GO:0048708 & astrocyte differentiation & - & 1.333 & - & - \\
\hline GO:0051962 & positive regulation of nervous system development & 1.544 & 1.333 & - & - \\
\hline GO:0071417 & cellular response to organonitrogen compound & 1.933 & 1.333 & - & - \\
\hline GO:0046330 & positive regulation of JNK cascade & 1.757 & 1.333 & 1.368 & 1.339 \\
\hline GO:0031645 & negative regulation of nervous system process & 1.589 & 1.330 & 2.185 & 2.630 \\
\hline GO:0002724 & regulation of $\mathrm{T}$ cell cytokine production & - & 1.330 & 2.185 & - \\
\hline GO:0050869 & negative regulation of $B$ cell activation & 2.227 & 1.330 & - & - \\
\hline GO:0043372 & $\begin{array}{l}\text { positive regulation of CD4-positive, alpha-beta T cell } \\
\text { differentiation }\end{array}$ & - & 1.330 & - & - \\
\hline GO:0031116 & positive regulation of microtubule polymerization & 2.227 & 1.330 & 1.398 & - \\
\hline GO:0002825 & regulation of T-helper 1 type immune response & 2.227 & 1.330 & 1.398 & - \\
\hline GO:0014047 & glutamate secretion & - & 1.330 & - & - \\
\hline GO:2000146 & negative regulation of cell motility & 2.318 & 1.327 & 2.788 & 2.746 \\
\hline GO:0002286 & $\mathrm{T}$ cell activation involved in immune response & 2.315 & 1.326 & 1.641 & - \\
\hline GO:0007417 & central nervous system development & 1.761 & 1.326 & - & - \\
\hline GO:0010632 & regulation of epithelial cell migration & - & 1.321 & 1.606 & 1.765 \\
\hline GO:0043412 & macromolecule modification & 1.952 & 1.318 & - & - \\
\hline GO:0034599 & cellular response to oxidative stress & 1.990 & 1.316 & - & - \\
\hline GO:0051056 & regulation of small GTPase mediated signal transduction & - & 1.316 & - & - \\
\hline GO:0032309 & icosanoid secretion & 1.936 & 1.316 & - & - \\
\hline GO:0006970 & response to osmotic stress & 1.606 & 1.316 & - & - \\
\hline GO:0090207 & regulation of triglyceride metabolic process & 1.429 & 1.316 & - & - \\
\hline GO:0048812 & neuron projection morphogenesis & - & 1.316 & - & - \\
\hline GO:1902904 & negative regulation of supramolecular fiber organization & - & 1.312 & - & 1.439 \\
\hline GO:0090407 & organophosphate biosynthetic process & 1.699 & 1.309 & - & - \\
\hline GO:1901699 & cellular response to nitrogen compound & 1.573 & 1.305 & - & - \\
\hline GO:1903426 & regulation of reactive oxygen species biosynthetic process & 4.340 & - & 2.368 & 1.826 \\
\hline GO:0003013 & circulatory system process & 3.661 & - & 2.081 & 1.504 \\
\hline
\end{tabular}




\begin{tabular}{|c|c|c|c|c|c|}
\hline GO:0002224 & toll-like receptor signaling pathway & 3.610 & - & 5.302 & 2.957 \\
\hline GO:1903409 & reactive oxygen species biosynthetic process & 3.579 & - & 2.645 & 1.550 \\
\hline GO:1990845 & adaptive thermogenesis & 3.269 & - & - & - \\
\hline GO:0008015 & blood circulation & 3.259 & - & 2.186 & 1.331 \\
\hline GO:0003018 & vascular process in circulatory system & 3.120 & - & 1.570 & - \\
\hline GO:2000351 & regulation of endothelial cell apoptotic process & 2.921 & - & 1.505 & 2.430 \\
\hline GO:0032970 & regulation of actin filament-based process & 2.892 & - & 1.699 & 1.864 \\
\hline GO:0035296 & regulation of tube diameter & 2.874 & - & - & - \\
\hline GO:0097746 & regulation of blood vessel diameter & 2.874 & - & - & - \\
\hline GO:0035150 & regulation of tube size & 2.845 & - & - & - \\
\hline GO:1905952 & regulation of lipid localization & 2.838 & - & 2.852 & 2.097 \\
\hline GO:0006979 & response to oxidative stress & 2.826 & - & 1.732 & 1.537 \\
\hline GO:0043270 & positive regulation of ion transport & 2.785 & - & - & - \\
\hline GO:0030168 & platelet activation & 2.746 & - & - & - \\
\hline GO:0042311 & vasodilation & 2.746 & - & 1.311 & - \\
\hline GO:0071346 & cellular response to interferon-gamma & 2.714 & - & 2.456 & - \\
\hline GO:0072577 & endothelial cell apoptotic process & 2.705 & - & 1.421 & 2.297 \\
\hline GO:0051250 & negative regulation of lymphocyte activation & 2.689 & - & - & - \\
\hline GO:0031666 & $\begin{array}{l}\text { positive regulation of lipopolysaccharide-mediated } \\
\text { signaling pathway }\end{array}$ & 2.672 & - & - & - \\
\hline GO:0019915 & lipid storage & 2.668 & - & 2.749 & 2.163 \\
\hline GO:0031334 & positive regulation of protein-containing complex assembly & 2.668 & - & - & - \\
\hline GO:1902475 & L-alpha-amino acid transmembrane transport & 2.662 & - & - & - \\
\hline GO:0032370 & positive regulation of lipid transport & 2.631 & - & 3.106 & 2.521 \\
\hline GO:0008217 & regulation of blood pressure & 2.630 & - & 1.546 & 1.389 \\
\hline GO:1901570 & fatty acid derivative biosynthetic process & 2.617 & - & - & - \\
\hline GO:0007249 & I-kappaB kinase/NF-kappaB signaling & 2.584 & - & 2.221 & 1.931 \\
\hline GO:0045730 & respiratory burst & 2.581 & - & - & - \\
\hline GO:0045410 & positive regulation of interleukin- 6 biosynthetic process & 2.575 & - & - & - \\
\hline
\end{tabular}




\begin{tabular}{|c|c|c|c|c|c|}
\hline GO:0006066 & alcohol metabolic process & 2.566 & - & 1.566 & 1.873 \\
\hline GO:0042089 & cytokine biosynthetic process & 2.548 & - & 2.068 & - \\
\hline GO:0070527 & platelet aggregation & 2.536 & - & - & - \\
\hline GO:0071260 & cellular response to mechanical stimulus & 2.511 & - & - & - \\
\hline GO:0043254 & regulation of protein-containing complex assembly & 2.511 & - & 1.537 & - \\
\hline GO:1902563 & regulation of neutrophil activation & 2.508 & - & 1.409 & 2.184 \\
\hline GO:0044539 & long-chain fatty acid import into cell & 2.471 & - & - & - \\
\hline GO:0045019 & negative regulation of nitric oxide biosynthetic process & 2.471 & - & - & - \\
\hline GO:0140354 & lipid import into cell & 2.471 & - & - & - \\
\hline GO:0001976 & $\begin{array}{l}\text { nervous system process involved in regulation of systemic } \\
\text { arterial blood pressure }\end{array}$ & 2.471 & - & - & - \\
\hline GO:1904406 & negative regulation of nitric oxide metabolic process & 2.471 & - & - & - \\
\hline GO:0042035 & regulation of cytokine biosynthetic process & 2.433 & - & - & - \\
\hline GO:0072604 & interleukin- 6 secretion & 2.433 & - & 3.983 & - \\
\hline GO:0045600 & positive regulation of fat cell differentiation & 2.391 & - & - & - \\
\hline GO:2000378 & $\begin{array}{l}\text { negative regulation of reactive oxygen species metabolic } \\
\text { process }\end{array}$ & 2.391 & - & - & - \\
\hline GO:0045123 & cellular extravasation & 2.351 & - & - & 2.734 \\
\hline GO:0002396 & MHC protein complex assembly & 2.340 & - & 1.870 & - \\
\hline GO:0042107 & cytokine metabolic process & 2.319 & - & 1.942 & - \\
\hline GO:0045408 & regulation of interleukin- 6 biosynthetic process & 2.288 & - & - & - \\
\hline GO:0050670 & regulation of lymphocyte proliferation & 2.277 & - & - & - \\
\hline GO:0051493 & regulation of cytoskeleton organization & 2.259 & - & - & 1.665 \\
\hline GO:0042226 & interleukin- 6 biosynthetic process & 2.227 & - & - & - \\
\hline GO:0045080 & positive regulation of chemokine biosynthetic process & 2.227 & - & - & - \\
\hline GO:0032944 & regulation of mononuclear cell proliferation & 2.226 & - & - & - \\
\hline GO:0032368 & regulation of lipid transport & 2.222 & - & 1.880 & 1.380 \\
\hline GO:0042108 & positive regulation of cytokine biosynthetic process & 2.204 & - & - & - \\
\hline GO:0003333 & amino acid transmembrane transport & 2.196 & - & - & - \\
\hline GO:0090066 & regulation of anatomical structure size & 2.176 & - & - & - \\
\hline
\end{tabular}




\begin{tabular}{|c|c|c|c|c|c|}
\hline GO:0032355 & response to estradiol & 2.175 & - & 1.633 & - \\
\hline GO:0002260 & lymphocyte homeostasis & 2.165 & - & - & - \\
\hline GO:2000191 & regulation of fatty acid transport & 2.164 & - & 1.368 & 1.781 \\
\hline GO:0032956 & regulation of actin cytoskeleton organization & 2.164 & - & 1.398 & 1.963 \\
\hline GO:0032649 & regulation of interferon-gamma production & 2.148 & - & 3.039 & - \\
\hline GO:0040013 & negative regulation of locomotion & 2.135 & - & 2.439 & 2.372 \\
\hline GO:0001676 & long-chain fatty acid metabolic process & 2.115 & - & - & - \\
\hline GO:0006837 & serotonin transport & 2.115 & - & - & 1.414 \\
\hline GO:2000343 & $\begin{array}{l}\text { positive regulation of chemokine ( } \mathrm{C}-\mathrm{X}-\mathrm{C} \text { motif) ligand } 2 \\
\text { production }\end{array}$ & 2.110 & - & - & - \\
\hline GO:1903706 & regulation of hemopoiesis & 2.104 & - & 2.098 & - \\
\hline GO:0104004 & cellular response to environmental stimulus & 2.103 & - & - & - \\
\hline GO:0001782 & B cell homeostasis & 2.103 & - & - & - \\
\hline GO:0071214 & cellular response to abiotic stimulus & 2.103 & - & - & - \\
\hline GO:0060322 & head development & 2.085 & - & - & - \\
\hline GO:1901568 & fatty acid derivative metabolic process & 2.081 & - & - & - \\
\hline GO:0032091 & negative regulation of protein binding & 2.057 & - & - & - \\
\hline GO:0016192 & vesicle-mediated transport & 2.057 & - & - & - \\
\hline GO:0005975 & carbohydrate metabolic process & 2.057 & - & - & - \\
\hline GO:0034330 & cell junction organization & 2.057 & - & - & 1.660 \\
\hline GO:0045598 & regulation of fat cell differentiation & 2.045 & - & 1.321 & - \\
\hline GO:0015749 & monosaccharide transmembrane transport & 2.044 & - & - & - \\
\hline GO:0016043 & cellular component organization & 2.043 & - & - & 1.960 \\
\hline GO:0032271 & regulation of protein polymerization & 2.041 & - & - & - \\
\hline GO:0051955 & regulation of amino acid transport & 2.014 & - & - & 1.329 \\
\hline GO:0042088 & T-helper 1 type immune response & 2.014 & - & - & - \\
\hline GO:0031650 & regulation of heat generation & 1.993 & - & - & - \\
\hline GO:2000778 & positive regulation of interleukin- 6 secretion & 1.986 & - & 4.977 & 1.669 \\
\hline GO:0001773 & myeloid dendritic cell activation & 1.986 & - & - & - \\
\hline GO:0051953 & negative regulation of amine transport & 1.986 & - & - & 1.669 \\
\hline
\end{tabular}




\begin{tabular}{|c|c|c|c|c|c|}
\hline GO:0051180 & vitamin transport & 1.986 & - & - & - \\
\hline GO:0070663 & regulation of leukocyte proliferation & 1.968 & - & - & - \\
\hline GO:0034219 & carbohydrate transmembrane transport & 1.968 & - & - & - \\
\hline GO:2000353 & positive regulation of endothelial cell apoptotic process & 1.963 & - & - & 1.335 \\
\hline GO:0034121 & regulation of toll-like receptor signaling pathway & 1.961 & - & 1.977 & - \\
\hline GO:0060935 & cardiac fibroblast cell differentiation & 1.952 & - & - & - \\
\hline GO:0042495 & detection of triacyl bacterial lipopeptide & 1.952 & - & - & - \\
\hline GO:0001579 & medium-chain fatty acid transport & 1.952 & - & - & - \\
\hline GO:2000334 & positive regulation of blood microparticle formation & 1.952 & - & 2.630 & 2.392 \\
\hline GO:1903038 & negative regulation of leukocyte cell-cell adhesion & 1.952 & - & - & - \\
\hline GO:0030329 & prenylcysteine metabolic process & 1.952 & - & - & - \\
\hline GO:0030328 & prenylcysteine catabolic process & 1.952 & - & - & - \\
\hline GO:0031930 & mitochondria-nucleus signaling pathway & 1.952 & - & - & - \\
\hline GO:0045017 & glycerolipid biosynthetic process & 1.952 & - & - & - \\
\hline GO:0060940 & $\begin{array}{l}\text { epithelial to mesenchymal transition involved in cardiac } \\
\text { fibroblast development }\end{array}$ & 1.952 & - & - & - \\
\hline GO:0072564 & blood microparticle formation & 1.952 & - & 2.630 & 2.392 \\
\hline GO:0060939 & epicardium-derived cardiac fibroblast cell development & 1.952 & - & - & - \\
\hline GO:0060938 & epicardium-derived cardiac fibroblast cell differentiation & 1.952 & - & - & - \\
\hline GO:0060936 & cardiac fibroblast cell development & 1.952 & - & - & - \\
\hline GO:2000332 & regulation of blood microparticle formation & 1.952 & - & 2.630 & 2.392 \\
\hline GO:2000417 & negative regulation of eosinophil migration & 1.952 & - & - & 2.392 \\
\hline GO:1901615 & organic hydroxy compound metabolic process & 1.950 & - & 1.450 & 1.779 \\
\hline GO:0036230 & granulocyte activation & 1.941 & - & 1.993 & 2.382 \\
\hline GO:0031112 & $\begin{array}{l}\text { positive regulation of microtubule polymerization or } \\
\text { depolymerization }\end{array}$ & 1.941 & - & - & - \\
\hline GO:1901552 & positive regulation of endothelial cell development & 1.936 & - & - & 1.414 \\
\hline GO:1904464 & regulation of matrix metallopeptidase secretion & 1.936 & - & - & 1.414 \\
\hline GO:1903142 & positive regulation of establishment of endothelial barrier & 1.936 & - & - & 1.414 \\
\hline GO:0014812 & muscle cell migration & 1.936 & - & - & - \\
\hline
\end{tabular}




\begin{tabular}{|c|c|c|c|c|c|}
\hline GO:1990773 & matrix metallopeptidase secretion & 1.936 & - & - & 1.414 \\
\hline GO:0019637 & organophosphate metabolic process & 1.930 & - & - & - \\
\hline GO:0002827 & positive regulation of T-helper 1 type immune response & 1.913 & - & 1.581 & - \\
\hline GO:0001820 & serotonin secretion & 1.913 & - & - & - \\
\hline GO:0045073 & regulation of chemokine biosynthetic process & 1.913 & - & - & - \\
\hline GO:0042033 & chemokine biosynthetic process & 1.913 & - & - & - \\
\hline GO:0046634 & regulation of alpha-beta $T$ cell activation & 1.899 & - & 1.382 & - \\
\hline GO:0061028 & establishment of endothelial barrier & 1.899 & - & - & 1.868 \\
\hline GO:0032633 & interleukin-4 production & 1.897 & - & - & - \\
\hline GO:0055076 & transition metal ion homeostasis & 1.890 & - & - & - \\
\hline GO:0030100 & regulation of endocytosis & 1.857 & - & - & 1.538 \\
\hline GO:0051090 & regulation of DNA-binding transcription factor activity & 1.856 & - & 2.271 & - \\
\hline GO:0033622 & integrin activation & 1.844 & - & - & - \\
\hline GO:0044087 & regulation of cellular component biogenesis & 1.842 & - & 1.825 & 1.818 \\
\hline GO:0007229 & integrin-mediated signaling pathway & 1.840 & - & - & - \\
\hline GO:0050868 & negative regulation of $\mathrm{T}$ cell activation & 1.833 & - & - & - \\
\hline GO:0051271 & negative regulation of cellular component movement & 1.825 & - & 2.420 & 2.348 \\
\hline GO:2001234 & negative regulation of apoptotic signaling pathway & 1.822 & - & 1.343 & 1.522 \\
\hline GO:0051044 & $\begin{array}{l}\text { positive regulation of membrane protein ectodomain } \\
\text { proteolysis }\end{array}$ & 1.818 & - & - & - \\
\hline GO:0046651 & lymphocyte proliferation & 1.817 & - & - & - \\
\hline GO:0060324 & face development & 1.814 & - & - & - \\
\hline GO:0043618 & $\begin{array}{l}\text { regulation of transcription from RNA polymerase II } \\
\text { promoter in response to stress }\end{array}$ & 1.814 & - & - & - \\
\hline GO:0050672 & negative regulation of lymphocyte proliferation & 1.811 & - & - & - \\
\hline GO:0071229 & cellular response to acid chemical & 1.811 & - & - & 1.707 \\
\hline GO:0043900 & regulation of multi-organism process & 1.811 & - & 2.182 & - \\
\hline GO:0043269 & regulation of ion transport & 1.807 & - & - & - \\
\hline GO:0045596 & negative regulation of cell differentiation & 1.797 & - & 1.437 & - \\
\hline GO:0043647 & inositol phosphate metabolic process & 1.796 & - & - & - \\
\hline
\end{tabular}




\begin{tabular}{|c|c|c|c|c|c|}
\hline GO:0009056 & catabolic process & 1.787 & - & - & - \\
\hline GO:0070542 & response to fatty acid & 1.786 & - & - & 1.398 \\
\hline GO:0032609 & interferon-gamma production & 1.784 & - & 2.731 & - \\
\hline GO:1904019 & epithelial cell apoptotic process & 1.784 & - & 1.590 & 2.086 \\
\hline GO:0097368 & establishment of Sertoli cell barrier & 1.783 & - & - & 1.331 \\
\hline GO:0060586 & multicellular organismal iron ion homeostasis & 1.783 & - & 2.762 & 1.331 \\
\hline GO:0032945 & negative regulation of mononuclear cell proliferation & 1.783 & - & - & - \\
\hline GO:0002035 & brain renin-angiotensin system & 1.783 & - & - & - \\
\hline GO:0110095 & cellular detoxification of aldehyde & 1.783 & - & - & - \\
\hline GO:0044089 & positive regulation of cellular component biogenesis & 1.783 & - & - & - \\
\hline GO:0006644 & phospholipid metabolic process & 1.782 & - & - & - \\
\hline GO:0032943 & mononuclear cell proliferation & 1.780 & - & - & - \\
\hline GO:0032653 & regulation of interleukin-10 production & 1.780 & - & 1.525 & - \\
\hline GO:0050863 & regulation of T cell activation & 1.767 & - & - & - \\
\hline GO:0031623 & receptor internalization & 1.766 & - & - & - \\
\hline GO:0070372 & regulation of ERK1 and ERK2 cascade & 1.766 & - & 1.977 & - \\
\hline GO:0030099 & myeloid cell differentiation & 1.766 & - & 2.604 & 1.408 \\
\hline GO:0015804 & neutral amino acid transport & 1.755 & - & - & - \\
\hline GO:0071840 & cellular component organization or biogenesis & 1.752 & - & - & 1.950 \\
\hline GO:0008610 & lipid biosynthetic process & 1.743 & - & - & - \\
\hline GO:0033623 & regulation of integrin activation & 1.742 & - & - & - \\
\hline GO:0035461 & vitamin transmembrane transport & 1.742 & - & - & - \\
\hline GO:0002495 & $\begin{array}{l}\text { antigen processing and presentation of peptide antigen via } \\
\text { MHC class II }\end{array}$ & 1.742 & - & - & - \\
\hline GO:0008406 & gonad development & 1.734 & - & 1.890 & 1.628 \\
\hline GO:0072575 & epithelial cell proliferation involved in liver morphogenesis & 1.734 & - & 1.480 & 1.929 \\
\hline GO:0072574 & hepatocyte proliferation & 1.734 & - & 1.480 & 1.929 \\
\hline GO:0089718 & amino acid import across plasma membrane & 1.734 & - & - & - \\
\hline GO:0055072 & iron ion homeostasis & 1.732 & - & 1.525 & - \\
\hline
\end{tabular}




\begin{tabular}{|c|c|c|c|c|c|}
\hline GO:1904659 & glucose transmembrane transport & 1.722 & - & - & - \\
\hline GO:0051403 & stress-activated MAPK cascade & 1.721 & - & - & - \\
\hline GO:0046456 & icosanoid biosynthetic process & 1.710 & - & - & - \\
\hline GO:0098657 & import into cell & 1.707 & - & - & - \\
\hline GO:0008645 & hexose transmembrane transport & 1.699 & - & - & - \\
\hline GO:0071356 & cellular response to tumor necrosis factor & 1.699 & - & 3.726 & 1.864 \\
\hline GO:0110053 & regulation of actin filament organization & 1.696 & - & 1.328 & 1.411 \\
\hline GO:0031348 & negative regulation of defense response & 1.688 & - & - & - \\
\hline GO:0045893 & positive regulation of transcription, DNA-templated & 1.681 & - & - & - \\
\hline GO:0045807 & positive regulation of endocytosis & 1.676 & - & 1.527 & 1.536 \\
\hline GO:0002824 & $\begin{array}{l}\text { positive regulation of adaptive immune response based on } \\
\text { somatic recombination of immune receptors built from } \\
\text { immunoglobulin superfamily domains }\end{array}$ & 1.675 & - & 2.307 & - \\
\hline GO:0043620 & $\begin{array}{l}\text { regulation of DNA-templated transcription in response to } \\
\text { stress }\end{array}$ & 1.672 & - & - & - \\
\hline GO:0042398 & cellular modified amino acid biosynthetic process & 1.667 & - & - & - \\
\hline GO:0060644 & mammary gland epithelial cell differentiation & 1.667 & - & - & - \\
\hline GO:0045986 & negative regulation of smooth muscle contraction & 1.667 & - & - & - \\
\hline GO:0032516 & positive regulation of phosphoprotein phosphatase activity & 1.667 & - & - & 1.610 \\
\hline GO:0002504 & $\begin{array}{l}\text { antigen processing and presentation of peptide or } \\
\text { polysaccharide antigen via MHC class II }\end{array}$ & 1.667 & - & - & - \\
\hline GO:0033631 & cell-cell adhesion mediated by integrin & 1.667 & - & - & - \\
\hline GO:0072567 & chemokine ( $\mathrm{C}-\mathrm{X}-\mathrm{C}$ motif) ligand 2 production & 1.657 & - & - & - \\
\hline GO:2000341 & regulation of chemokine ( $\mathrm{C}-\mathrm{X}-\mathrm{C}$ motif) ligand 2 production & 1.657 & - & - & - \\
\hline GO:0019886 & $\begin{array}{l}\text { antigen processing and presentation of exogenous peptide } \\
\text { antigen via MHC class II }\end{array}$ & 1.657 & - & - & - \\
\hline GO:0006914 & autophagy & 1.655 & - & - & - \\
\hline GO:0061919 & process utilizing autophagic mechanism & 1.655 & - & - & - \\
\hline GO:0007254 & JNK cascade & 1.649 & - & - & - \\
\hline
\end{tabular}




\begin{tabular}{|c|c|c|c|c|c|}
\hline GO:0070664 & negative regulation of leukocyte proliferation & 1.649 & - & - & - \\
\hline GO:0045453 & bone resorption & 1.646 & - & - & - \\
\hline GO:0032613 & interleukin-10 production & 1.636 & - & 2.102 & - \\
\hline GO:0001649 & osteoblast differentiation & 1.631 & - & 2.503 & 1.414 \\
\hline GO:0006897 & endocytosis & 1.627 & - & - & - \\
\hline GO:0001763 & morphogenesis of a branching structure & 1.627 & - & - & - \\
\hline GO:0007548 & sex differentiation & 1.626 & - & 2.261 & 1.864 \\
\hline GO:0000038 & very long-chain fatty acid metabolic process & 1.624 & - & - & - \\
\hline GO:0072576 & liver morphogenesis & 1.624 & - & 1.420 & 1.855 \\
\hline GO:0001666 & response to hypoxia & 1.613 & - & - & - \\
\hline GO:0019751 & polyol metabolic process & 1.609 & - & - & - \\
\hline GO:0046474 & glycerophospholipid biosynthetic process & 1.606 & - & - & - \\
\hline GO:0046890 & regulation of lipid biosynthetic process & 1.606 & - & - & - \\
\hline GO:0050728 & negative regulation of inflammatory response & 1.606 & - & - & - \\
\hline GO:0070340 & detection of bacterial lipopeptide & 1.606 & - & - & - \\
\hline GO:1904466 & positive regulation of matrix metallopeptidase secretion & 1.606 & - & - & - \\
\hline GO:0099178 & $\begin{array}{l}\text { regulation of retrograde trans-synaptic signaling by } \\
\text { endocanabinoid }\end{array}$ & 1.606 & - & - & - \\
\hline GO:1904705 & $\begin{array}{l}\text { regulation of vascular associated smooth muscle cell } \\
\text { proliferation }\end{array}$ & 1.606 & - & - & - \\
\hline GO:1904996 & $\begin{array}{l}\text { positive regulation of leukocyte adhesion to vascular } \\
\text { endothelial cell }\end{array}$ & 1.606 & - & - & 1.554 \\
\hline GO:1990874 & vascular associated smooth muscle cell proliferation & 1.606 & - & - & - \\
\hline GO:0060559 & positive regulation of calcidiol 1-monooxygenase activity & 1.606 & - & 2.264 & 2.015 \\
\hline GO:0060557 & positive regulation of vitamin $\mathrm{D}$ biosynthetic process & 1.606 & - & 2.264 & 2.015 \\
\hline GO:0051956 & negative regulation of amino acid transport & 1.606 & - & 1.850 & 1.554 \\
\hline GO:0045664 & regulation of neuron differentiation & 1.606 & - & - & - \\
\hline GO:1903598 & positive regulation of gap junction assembly & 1.606 & - & - & - \\
\hline GO:1901329 & regulation of odontoblast differentiation & 1.606 & - & - & - \\
\hline GO:0030327 & prenylated protein catabolic process & 1.606 & - & - & - \\
\hline
\end{tabular}




\begin{tabular}{|c|c|c|c|c|c|}
\hline GO:0006690 & icosanoid metabolic process & 1.606 & - & - & - \\
\hline GO:0033033 & negative regulation of myeloid cell apoptotic process & 1.606 & - & 1.850 & - \\
\hline GO:0043506 & regulation of JUN kinase activity & 1.606 & - & - & - \\
\hline GO:0045082 & positive regulation of interleukin-10 biosynthetic process & 1.606 & - & - & - \\
\hline GO:0002397 & MHC class I protein complex assembly & 1.606 & - & - & - \\
\hline GO:0002086 & diaphragm contraction & 1.606 & - & - & - \\
\hline GO:0001966 & thigmotaxis & 1.606 & - & - & - \\
\hline GO:0002755 & MyD88-dependent toll-like receptor signaling pathway & 1.606 & - & - & - \\
\hline GO:0046718 & viral entry into host cell & 1.602 & - & 2.358 & - \\
\hline GO:0002686 & negative regulation of leukocyte migration & 1.602 & - & - & - \\
\hline GO:0019058 & viral life cycle & 1.597 & - & 5.831 & - \\
\hline GO:0043087 & regulation of GTPase activity & 1.595 & - & - & - \\
\hline GO:0045932 & negative regulation of muscle contraction & 1.589 & - & - & - \\
\hline GO:0032891 & negative regulation of organic acid transport & 1.589 & - & 2.185 & 1.812 \\
\hline GO:0045824 & negative regulation of innate immune response & 1.585 & - & 1.409 & - \\
\hline GO:0002698 & negative regulation of immune effector process & 1.585 & - & 1.974 & - \\
\hline GO:0031032 & actomyosin structure organization & 1.584 & - & 2.442 & 2.177 \\
\hline GO:0045637 & regulation of myeloid cell differentiation & 1.583 & - & 1.755 & - \\
\hline GO:0044283 & small molecule biosynthetic process & 1.583 & - & - & - \\
\hline GO:0034329 & cell junction assembly & 1.571 & - & - & - \\
\hline GO:0032874 & positive regulation of stress-activated MAPK cascade & 1.569 & - & - & 1.405 \\
\hline GO:2001242 & regulation of intrinsic apoptotic signaling pathway & 1.569 & - & - & - \\
\hline GO:0031098 & stress-activated protein kinase signaling cascade & 1.563 & - & - & - \\
\hline GO:0002820 & negative regulation of adaptive immune response & 1.562 & - & - & - \\
\hline GO:0032958 & inositol phosphate biosynthetic process & 1.562 & - & - & - \\
\hline GO:1902579 & multi-organism localization & 1.561 & - & 1.409 & - \\
\hline GO:0110096 & cellular response to aldehyde & 1.561 & - & - & - \\
\hline GO:0044766 & multi-organism transport & 1.561 & - & 1.409 & - \\
\hline GO:0090237 & regulation of arachidonic acid secretion & 1.561 & - & - & - \\
\hline GO:0071223 & cellular response to lipoteichoic acid & 1.561 & - & 1.409 & - \\
\hline
\end{tabular}




\begin{tabular}{|c|c|c|c|c|c|}
\hline GO:0070391 & response to lipoteichoic acid & 1.561 & - & 1.409 & - \\
\hline GO:0046794 & transport of virus & 1.561 & - & 1.409 & - \\
\hline GO:0071398 & cellular response to fatty acid & 1.554 & - & - & - \\
\hline GO:0051447 & negative regulation of meiotic cell cycle & 1.544 & - & - & 1.512 \\
\hline GO:0032495 & response to muramyl dipeptide & 1.544 & - & 2.769 & 1.512 \\
\hline GO:0006656 & phosphatidylcholine biosynthetic process & 1.544 & - & - & - \\
\hline GO:1905898 & $\begin{array}{l}\text { positive regulation of response to endoplasmic reticulum } \\
\text { stress }\end{array}$ & 1.543 & - & - & - \\
\hline GO:0051235 & maintenance of location & 1.543 & - & 1.469 & - \\
\hline GO:0002691 & regulation of cellular extravasation & 1.543 & - & - & - \\
\hline GO:1902905 & positive regulation of supramolecular fiber organization & 1.538 & - & - & - \\
\hline GO:0070304 & $\begin{array}{l}\text { positive regulation of stress-activated protein kinase } \\
\text { signaling cascade }\end{array}$ & 1.535 & - & - & 1.380 \\
\hline GO:0008277 & regulation of G protein-coupled receptor signaling pathway & 1.525 & - & - & - \\
\hline GO:0032768 & regulation of monooxygenase activity & 1.525 & - & 1.684 & - \\
\hline GO:0033003 & regulation of mast cell activation & 1.525 & - & - & - \\
\hline GO:0043300 & regulation of leukocyte degranulation & 1.525 & - & 1.684 & - \\
\hline GO:0046328 & regulation of JNK cascade & 1.525 & - & - & - \\
\hline GO:0032922 & circadian regulation of gene expression & 1.524 & - & - & - \\
\hline GO:0030888 & regulation of $B$ cell proliferation & 1.524 & - & - & - \\
\hline GO:0042093 & T-helper cell differentiation & 1.524 & - & - & - \\
\hline GO:0046486 & glycerolipid metabolic process & 1.521 & - & - & - \\
\hline GO:0051100 & negative regulation of binding & 1.520 & - & 1.463 & - \\
\hline GO:0042310 & vasoconstriction & 1.516 & - & - & - \\
\hline GO:0044267 & cellular protein metabolic process & 1.515 & - & - & - \\
\hline GO:0034220 & ion transmembrane transport & 1.511 & - & - & - \\
\hline GO:0032273 & positive regulation of protein polymerization & 1.507 & - & - & - \\
\hline GO:1903827 & regulation of cellular protein localization & 1.499 & - & - & - \\
\hline GO:0043304 & regulation of mast cell degranulation & 1.496 & - & - & - \\
\hline
\end{tabular}




\begin{tabular}{|c|c|c|c|c|c|}
\hline GO:0046640 & regulation of alpha-beta $T$ cell proliferation & 1.496 & - & 2.102 & - \\
\hline GO:0009595 & detection of biotic stimulus & 1.496 & - & - & - \\
\hline GO:1901224 & positive regulation of NIK/NF-kappaB signaling & 1.494 & - & - & - \\
\hline GO:0072088 & nephron epithelium morphogenesis & 1.494 & - & - & - \\
\hline GO:0044409 & entry into host & 1.494 & - & 2.264 & - \\
\hline GO:0007169 & $\begin{array}{l}\text { transmembrane receptor protein tyrosine kinase signaling } \\
\text { pathway }\end{array}$ & 1.494 & - & - & - \\
\hline GO:0002294 & $\begin{array}{l}\text { CD4-positive, alpha-beta T cell differentiation involved in } \\
\text { immune response }\end{array}$ & 1.493 & - & - & - \\
\hline GO:2001237 & negative regulation of extrinsic apoptotic signaling pathway & 1.493 & - & 1.382 & 1.462 \\
\hline GO:0070661 & leukocyte proliferation & 1.493 & - & - & - \\
\hline GO:2000345 & regulation of hepatocyte proliferation & 1.486 & - & 1.745 & 1.460 \\
\hline GO:0090276 & regulation of peptide hormone secretion & 1.486 & - & - & 1.855 \\
\hline GO:0046641 & positive regulation of alpha-beta $\mathrm{T}$ cell proliferation & 1.486 & - & - & - \\
\hline GO:0010743 & regulation of macrophage derived foam cell differentiation & 1.486 & - & 1.745 & - \\
\hline GO:0046325 & negative regulation of glucose import & 1.486 & - & - & - \\
\hline GO:0140112 & extracellular vesicle biogenesis & 1.486 & - & - & - \\
\hline GO:0050755 & chemokine metabolic process & 1.486 & - & - & - \\
\hline GO:0051258 & protein polymerization & 1.483 & - & - & - \\
\hline GO:0036293 & response to decreased oxygen levels & 1.483 & - & - & - \\
\hline GO:0060993 & kidney morphogenesis & 1.471 & - & - & - \\
\hline GO:0002532 & $\begin{array}{l}\text { production of molecular mediator involved in inflammatory } \\
\text { response }\end{array}$ & 1.471 & - & 1.623 & - \\
\hline GO:0097278 & complement-dependent cytotoxicity & 1.470 & - & 1.346 & - \\
\hline GO:0044764 & multi-organism cellular process & 1.470 & - & 1.346 & - \\
\hline GO:2000121 & regulation of removal of superoxide radicals & 1.470 & - & 2.406 & - \\
\hline GO:0010958 & regulation of amino acid import across plasma membrane & 1.470 & - & - & - \\
\hline
\end{tabular}




\begin{tabular}{|c|c|c|c|c|c|}
\hline GO:0002293 & $\begin{array}{l}\text { alpha-beta T cell differentiation involved in immune } \\
\text { response }\end{array}$ & 1.470 & - & - & - \\
\hline GO:0014911 & positive regulation of smooth muscle cell migration & 1.470 & - & - & - \\
\hline GO:1903789 & regulation of amino acid transmembrane transport & 1.470 & - & - & - \\
\hline GO:0015800 & acidic amino acid transport & 1.470 & - & - & 1.541 \\
\hline GO:0032725 & $\begin{array}{l}\text { positive regulation of granulocyte macrophage colony- } \\
\text { stimulating factor production }\end{array}$ & 1.470 & - & 2.406 & - \\
\hline GO:0032308 & positive regulation of prostaglandin secretion & 1.470 & - & 1.346 & - \\
\hline GO:0090557 & establishment of endothelial intestinal barrier & 1.470 & - & - & - \\
\hline GO:1903508 & positive regulation of nucleic acid-templated transcription & 1.468 & - & - & - \\
\hline GO:0032872 & regulation of stress-activated MAPK cascade & 1.463 & - & - & - \\
\hline GO:1902680 & positive regulation of RNA biosynthetic process & 1.463 & - & - & - \\
\hline GO:0043090 & amino acid import & 1.462 & - & - & - \\
\hline GO:0010543 & regulation of platelet activation & 1.462 & - & - & - \\
\hline GO:0097242 & amyloid-beta clearance & 1.462 & - & 1.311 & - \\
\hline GO:0050832 & defense response to fungus & 1.462 & - & - & - \\
\hline GO:0050999 & regulation of nitric-oxide synthase activity & 1.462 & - & 2.066 & - \\
\hline GO:0033006 & $\begin{array}{l}\text { regulation of mast cell activation involved in immune } \\
\text { response }\end{array}$ & 1.462 & - & - & - \\
\hline GO:0051701 & interaction with host & 1.459 & - & 1.870 & - \\
\hline GO:0014909 & smooth muscle cell migration & 1.455 & - & - & - \\
\hline GO:0072028 & nephron morphogenesis & 1.451 & - & - & - \\
\hline GO:0046635 & positive regulation of alpha-beta $T$ cell activation & 1.442 & - & - & - \\
\hline GO:0002287 & alpha-beta $T$ cell activation involved in immune response & 1.442 & - & - & - \\
\hline GO:0080135 & regulation of cellular response to stress & 1.442 & - & - & 1.504 \\
\hline GO:2000810 & regulation of bicellular tight junction assembly & 1.432 & - & 1.701 & 2.250 \\
\hline GO:0051043 & regulation of membrane protein ectodomain proteolysis & 1.432 & - & - & - \\
\hline GO:0032930 & positive regulation of superoxide anion generation & 1.432 & - & - & - \\
\hline GO:0060252 & positive regulation of glial cell proliferation & 1.432 & - & - & - \\
\hline GO:0061912 & selective autophagy & 1.429 & - & - & - \\
\hline
\end{tabular}




\begin{tabular}{|c|c|c|c|c|c|}
\hline GO:0060612 & adipose tissue development & 1.429 & - & - & - \\
\hline GO:0070302 & $\begin{array}{l}\text { regulation of stress-activated protein kinase signaling } \\
\text { cascade }\end{array}$ & 1.423 & - & - & - \\
\hline GO:0030509 & BMP signaling pathway & 1.420 & - & - & - \\
\hline GO:1903427 & $\begin{array}{l}\text { negative regulation of reactive oxygen species biosynthetic } \\
\text { process }\end{array}$ & 1.418 & - & - & - \\
\hline GO:1903959 & regulation of anion transmembrane transport & 1.418 & - & - & - \\
\hline GO:0045576 & mast cell activation & 1.412 & - & - & - \\
\hline GO:0007610 & behavior & 1.410 & - & - & 1.351 \\
\hline GO:0000187 & activation of MAPK activity & 1.409 & - & - & - \\
\hline GO:1990830 & cellular response to leukemia inhibitory factor & 1.409 & - & - & - \\
\hline GO:0003073 & regulation of systemic arterial blood pressure & 1.409 & - & - & - \\
\hline GO:1990823 & response to leukemia inhibitory factor & 1.409 & - & - & - \\
\hline GO:0044057 & regulation of system process & 1.408 & - & - & - \\
\hline GO:0034395 & $\begin{array}{l}\text { regulation of transcription from RNA polymerase II } \\
\text { promoter in response to iron }\end{array}$ & 1.403 & - & 2.036 & - \\
\hline GO:0002501 & peptide antigen assembly with MHC protein complex & 1.403 & - & - & - \\
\hline GO:0002351 & serotonin production involved in inflammatory response & 1.403 & - & - & - \\
\hline GO:0002442 & serotonin secretion involved in inflammatory response & 1.403 & - & - & - \\
\hline GO:0071881 & $\begin{array}{l}\text { adenylate cyclase-inhibiting adrenergic receptor signaling } \\
\text { pathway }\end{array}$ & 1.403 & - & - & - \\
\hline GO:0002159 & desmosome assembly & 1.403 & - & - & - \\
\hline GO:0007412 & axon target recognition & 1.403 & - & - & - \\
\hline GO:0070836 & caveola assembly & 1.403 & - & - & - \\
\hline GO:0006663 & platelet activating factor biosynthetic process & 1.403 & - & - & - \\
\hline GO:0006659 & phosphatidylserine biosynthetic process & 1.403 & - & - & - \\
\hline GO:0006636 & unsaturated fatty acid biosynthetic process & 1.403 & - & - & - \\
\hline GO:0003011 & involuntary skeletal muscle contraction & 1.403 & - & - & - \\
\hline GO:0002906 & negative regulation of mature $B$ cell apoptotic process & 1.403 & - & - & - \\
\hline GO:0002905 & regulation of mature B cell apoptotic process & 1.403 & - & - & - \\
\hline
\end{tabular}




\begin{tabular}{|c|c|c|c|c|c|}
\hline GO:1903613 & regulation of protein tyrosine phosphatase activity & 1.403 & - & - & - \\
\hline GO:1904612 & response to 2,3,7,8-tetrachlorodibenzodioxine & 1.403 & - & - & - \\
\hline GO:0051896 & regulation of protein kinase $B$ signaling & 1.403 & - & - & - \\
\hline GO:0002901 & mature B cell apoptotic process & 1.403 & - & - & - \\
\hline GO:0001922 & B-1 B cell homeostasis & 1.403 & - & - & - \\
\hline GO:0001712 & ectodermal cell fate commitment & 1.403 & - & - & - \\
\hline GO:0019932 & second-messenger-mediated signaling & 1.403 & - & - & - \\
\hline GO:0018197 & peptidyl-aspartic acid modification & 1.403 & - & - & - \\
\hline GO:0043456 & regulation of pentose-phosphate shunt & 1.403 & - & - & - \\
\hline GO:0016259 & selenocysteine metabolic process & 1.403 & - & - & - \\
\hline GO:0032632 & interleukin-3 production & 1.403 & - & - & - \\
\hline GO:0000904 & cell morphogenesis involved in differentiation & 1.403 & - & - & - \\
\hline GO:0042494 & detection of bacterial lipoprotein & 1.403 & - & - & - \\
\hline GO:0075509 & endocytosis involved in viral entry into host cell & 1.403 & - & - & - \\
\hline GO:0019065 & receptor-mediated endocytosis of virus by host cell & 1.403 & - & - & - \\
\hline GO:0002764 & immune response-regulating signaling pathway & 1.402 & - & - & - \\
\hline GO:0052126 & movement in host environment & 1.401 & - & 1.838 & - \\
\hline GO:0002573 & myeloid leukocyte differentiation & 1.401 & - & 1.413 & - \\
\hline GO:0001657 & ureteric bud development & 1.401 & - & - & - \\
\hline GO:0002016 & regulation of blood volume by renin-angiotensin & 1.399 & - & - & - \\
\hline GO:0046324 & regulation of glucose import & 1.399 & - & - & - \\
\hline GO:0002903 & negative regulation of $B$ cell apoptotic process & 1.399 & - & - & - \\
\hline GO:0090209 & negative regulation of triglyceride metabolic process & 1.399 & - & - & - \\
\hline GO:0072216 & positive regulation of metanephros development & 1.399 & - & - & - \\
\hline GO:0032490 & detection of molecule of bacterial origin & 1.399 & - & - & - \\
\hline GO:0031652 & positive regulation of heat generation & 1.399 & - & - & - \\
\hline GO:0022604 & regulation of cell morphogenesis & 1.399 & - & - & - \\
\hline GO:0010737 & protein kinase A signaling & 1.398 & - & - & - \\
\hline GO:0033630 & positive regulation of cell adhesion mediated by integrin & 1.398 & - & - & - \\
\hline GO:0070498 & interleukin-1-mediated signaling pathway & 1.398 & - & - & - \\
\hline
\end{tabular}




\begin{tabular}{|c|c|c|c|c|c|}
\hline GO:0010884 & positive regulation of lipid storage & 1.398 & - & 1.656 & 1.376 \\
\hline GO:0019430 & removal of superoxide radicals & 1.398 & - & 1.656 & - \\
\hline GO:0014048 & regulation of glutamate secretion & 1.398 & - & - & 1.376 \\
\hline GO:0045780 & positive regulation of bone resorption & 1.398 & - & - & - \\
\hline GO:0009069 & serine family amino acid metabolic process & 1.398 & - & - & - \\
\hline GO:0002693 & positive regulation of cellular extravasation & 1.398 & - & - & 1.376 \\
\hline GO:0010042 & response to manganese ion & 1.398 & - & - & - \\
\hline GO:0046852 & positive regulation of bone remodeling & 1.398 & - & - & - \\
\hline GO:1901566 & organonitrogen compound biosynthetic process & 1.397 & - & - & - \\
\hline GO:0051897 & positive regulation of protein kinase $B$ signaling & 1.390 & - & - & - \\
\hline GO:0007420 & brain development & 1.389 & - & - & - \\
\hline GO:0072163 & mesonephric epithelium development & 1.386 & - & - & - \\
\hline GO:0045619 & regulation of lymphocyte differentiation & 1.386 & - & 1.368 & - \\
\hline GO:0072164 & mesonephric tubule development & 1.386 & - & - & - \\
\hline GO:0046849 & bone remodeling & 1.386 & - & - & - \\
\hline GO:0009620 & response to fungus & 1.383 & - & - & - \\
\hline GO:0006766 & vitamin metabolic process & 1.377 & - & - & 1.454 \\
\hline GO:1900180 & regulation of protein localization to nucleus & 1.365 & - & - & - \\
\hline GO:0097756 & negative regulation of blood vessel diameter & 1.362 & - & - & - \\
\hline GO:0046916 & cellular transition metal ion homeostasis & 1.362 & - & - & - \\
\hline GO:0032733 & positive regulation of interleukin-10 production & 1.356 & - & - & - \\
\hline GO:0030225 & macrophage differentiation & 1.356 & - & - & 1.603 \\
\hline GO:0097421 & liver regeneration & 1.356 & - & - & - \\
\hline GO:0061138 & morphogenesis of a branching epithelium & 1.356 & - & - & - \\
\hline GO:0044403 & symbiotic process & 1.356 & - & 6.106 & - \\
\hline GO:1904037 & positive regulation of epithelial cell apoptotic process & 1.356 & - & - & - \\
\hline GO:0051354 & negative regulation of oxidoreductase activity & 1.356 & - & - & - \\
\hline GO:0009314 & response to radiation & 1.355 & - & - & - \\
\hline GO:0090130 & tissue migration & 1.353 & - & 1.810 & 1.815 \\
\hline GO:0043542 & endothelial cell migration & 1.350 & - & 2.231 & 2.392 \\
\hline
\end{tabular}




\begin{tabular}{|c|c|c|c|c|c|}
\hline GO:0050905 & neuromuscular process & 1.349 & - & 1.527 & - \\
\hline GO:0043299 & leukocyte degranulation & 1.348 & - & - & - \\
\hline GO:0022612 & gland morphogenesis & 1.348 & - & 1.771 & - \\
\hline GO:1904994 & $\begin{array}{l}\text { regulation of leukocyte adhesion to vascular endothelial } \\
\text { cell }\end{array}$ & 1.344 & - & - & 1.335 \\
\hline GO:0051156 & glucose 6-phosphate metabolic process & 1.344 & - & - & - \\
\hline GO:0071450 & cellular response to oxygen radical & 1.344 & - & 1.621 & - \\
\hline GO:0002577 & regulation of antigen processing and presentation & 1.344 & - & - & - \\
\hline GO:0042908 & xenobiotic transport & 1.344 & - & - & 1.335 \\
\hline GO:0090330 & regulation of platelet aggregation & 1.344 & - & - & - \\
\hline GO:0071451 & cellular response to superoxide & 1.344 & - & 1.621 & - \\
\hline GO:0006909 & phagocytosis & 1.343 & - & - & 1.616 \\
\hline GO:0120036 & plasma membrane bounded cell projection organization & 1.331 & - & - & - \\
\hline GO:0009890 & negative regulation of biosynthetic process & 1.329 & - & - & - \\
\hline GO:0033043 & regulation of organelle organization & 1.324 & - & - & 1.399 \\
\hline GO:0062207 & $\begin{array}{l}\text { regulation of pattern recognition receptor signaling } \\
\text { pathway }\end{array}$ & 1.324 & - & 2.749 & - \\
\hline GO:1904478 & regulation of intestinal absorption & 1.324 & - & - & - \\
\hline GO:0001892 & embryonic placenta development & 1.324 & - & - & - \\
\hline GO:0061097 & regulation of protein tyrosine kinase activity & 1.324 & - & - & - \\
\hline GO:0050805 & negative regulation of synaptic transmission & 1.324 & - & - & 1.627 \\
\hline GO:0032645 & $\begin{array}{l}\text { regulation of granulocyte macrophage colony-stimulating } \\
\text { factor production }\end{array}$ & 1.324 & - & 2.232 & - \\
\hline GO:0032868 & response to insulin & 1.324 & - & - & - \\
\hline GO:0032604 & $\begin{array}{l}\text { granulocyte macrophage colony-stimulating factor } \\
\text { production }\end{array}$ & 1.324 & - & 2.232 & - \\
\hline GO:0045416 & positive regulation of interleukin- 8 biosynthetic process & 1.324 & - & - & - \\
\hline GO:0032306 & regulation of prostaglandin secretion & 1.324 & - & - & - \\
\hline GO:0035589 & $\begin{array}{l}\text { G protein-coupled purinergic nucleotide receptor signaling } \\
\text { pathway }\end{array}$ & 1.324 & - & - & - \\
\hline
\end{tabular}




\begin{tabular}{|c|c|c|c|c|c|}
\hline GO:0045835 & negative regulation of meiotic nuclear division & 1.324 & - & - & 1.918 \\
\hline GO:0019432 & triglyceride biosynthetic process & 1.321 & - & - & - \\
\hline GO:0010039 & response to iron ion & 1.321 & - & - & - \\
\hline GO:0046633 & alpha-beta $\mathrm{T}$ cell proliferation & 1.321 & - & 1.921 & - \\
\hline GO:0046394 & carboxylic acid biosynthetic process & 1.313 & - & - & - \\
\hline GO:0006812 & cation transport & 1.307 & - & - & - \\
\hline GO:0001823 & mesonephros development & 1.302 & - & - & - \\
\hline GO:0046136 & positive regulation of vitamin metabolic process & - & - & 1.870 & 1.653 \\
\hline GO:0060558 & regulation of calcidiol 1-monooxygenase activity & - & - & 1.633 & 1.414 \\
\hline GO:0031622 & positive regulation of fever generation & - & - & 1.546 & 1.331 \\
\hline GO:0031620 & regulation of fever generation & - & - & 1.469 & - \\
\hline GO:0060556 & regulation of vitamin $\mathrm{D}$ biosynthetic process & - & - & 1.469 & - \\
\hline GO:0042368 & vitamin $\mathrm{D}$ biosynthetic process & - & - & 1.346 & - \\
\hline GO:0034116 & positive regulation of heterotypic cell-cell adhesion & - & - & 2.157 & 1.853 \\
\hline GO:0038034 & signal transduction in absence of ligand & - & - & 2.922 & 1.769 \\
\hline GO:0097192 & extrinsic apoptotic signaling pathway in absence of ligand & - & - & 2.922 & 1.769 \\
\hline GO:0009110 & vitamin biosynthetic process & - & - & 1.701 & 1.414 \\
\hline GO:0051341 & regulation of oxidoreductase activity & - & - & 2.406 & - \\
\hline GO:0060445 & branching involved in salivary gland morphogenesis & - & - & 1.656 & 1.376 \\
\hline GO:0010893 & positive regulation of steroid biosynthetic process & - & - & 2.456 & 1.304 \\
\hline GO:0032770 & positive regulation of monooxygenase activity & - & - & 1.450 & - \\
\hline GO:0045940 & positive regulation of steroid metabolic process & - & - & 2.102 & - \\
\hline GO:0002708 & positive regulation of lymphocyte mediated immunity & - & - & 1.870 & - \\
\hline GO:0006775 & fat-soluble vitamin metabolic process & - & - & 1.311 & - \\
\hline GO:1903792 & negative regulation of anion transport & - & - & 1.862 & 1.512 \\
\hline GO:0030866 & cortical actin cytoskeleton organization & - & - & - & - \\
\hline GO:0007431 & salivary gland development & - & - & - & 1.480 \\
\hline GO:0002705 & positive regulation of leukocyte mediated immunity & - & - & 2.406 & - \\
\hline GO:0006959 & humoral immune response & - & - & 1.469 & 1.425 \\
\hline GO:0000122 & negative regulation of transcription by RNA polymerase II & - & - & 1.525 & 1.650 \\
\hline
\end{tabular}




\begin{tabular}{|c|c|c|c|c|c|}
\hline GO:0051353 & positive regulation of oxidoreductase activity & - & - & 1.463 & - \\
\hline GO:0045840 & positive regulation of mitotic nuclear division & - & - & 1.421 & - \\
\hline GO:0042742 & defense response to bacterium & - & - & 2.765 & 1.513 \\
\hline GO:0002696 & positive regulation of leukocyte activation & - & - & 1.548 & - \\
\hline GO:0002711 & positive regulation of $\mathrm{T}$ cell mediated immunity & - & - & 1.772 & - \\
\hline GO:0070427 & $\begin{array}{l}\text { nucleotide-binding oligomerization domain containing } 1 \\
\text { signaling pathway }\end{array}$ & - & - & 1.870 & 1.653 \\
\hline GO:0002678 & positive regulation of chronic inflammatory response & - & - & 1.870 & - \\
\hline GO:2000556 & positive regulation of T-helper 1 cell cytokine production & - & - & 1.739 & - \\
\hline GO:0030198 & extracellular matrix organization & - & - & 1.437 & 1.548 \\
\hline GO:0010717 & regulation of epithelial to mesenchymal transition & - & - & 1.493 & - \\
\hline GO:2000554 & regulation of T-helper 1 cell cytokine production & - & - & 1.739 & - \\
\hline GO:0043062 & extracellular structure organization & - & - & 1.420 & 1.528 \\
\hline GO:0032760 & positive regulation of tumor necrosis factor production & - & - & 1.899 & - \\
\hline GO:0070487 & monocyte aggregation & - & - & 1.633 & 1.414 \\
\hline GO:2001182 & regulation of interleukin-12 secretion & - & - & 1.633 & - \\
\hline GO:0031665 & $\begin{array}{l}\text { negative regulation of lipopolysaccharide-mediated } \\
\text { signaling pathway }\end{array}$ & - & - & 1.633 & 1.414 \\
\hline GO:0071695 & anatomical structure maturation & - & - & 1.549 & 2.509 \\
\hline GO:0021700 & developmental maturation & - & - & - & 2.259 \\
\hline GO:0010594 & regulation of endothelial cell migration & - & - & 1.796 & 2.074 \\
\hline GO:0045602 & negative regulation of endothelial cell differentiation & - & - & - & 1.918 \\
\hline GO:0010631 & epithelial cell migration & - & - & 1.882 & 1.897 \\
\hline GO:0048469 & cell maturation & - & - & - & 1.895 \\
\hline GO:0050901 & leukocyte tethering or rolling & - & - & 1.450 & 1.892 \\
\hline GO:0030212 & hyaluronan metabolic process & - & - & 2.265 & 1.892 \\
\hline GO:0090132 & epithelium migration & - & - & 1.862 & 1.869 \\
\hline GO:0030857 & negative regulation of epithelial cell differentiation & - & - & 2.298 & 1.868 \\
\hline GO:0070306 & lens fiber cell differentiation & - & - & - & 1.855 \\
\hline GO:0042551 & neuron maturation & - & - & - & 1.791 \\
\hline
\end{tabular}




\begin{tabular}{|c|c|c|c|c|c|}
\hline GO:0042493 & response to drug & - & - & - & 1.765 \\
\hline GO:0110020 & regulation of actomyosin structure organization & - & - & 1.702 & 1.748 \\
\hline GO:0030072 & peptide hormone secretion & - & - & - & 1.719 \\
\hline GO:1904467 & regulation of tumor necrosis factor secretion & - & - & 2.066 & 1.709 \\
\hline GO:0030324 & lung development & - & - & - & 1.706 \\
\hline GO:0044106 & cellular amine metabolic process & - & - & - & 1.685 \\
\hline GO:0030323 & respiratory tube development & - & - & - & 1.667 \\
\hline GO:0050711 & negative regulation of interleukin- 1 secretion & - & - & - & 1.665 \\
\hline GO:0010310 & regulation of hydrogen peroxide metabolic process & - & - & - & 1.665 \\
\hline GO:0051129 & negative regulation of cellular component organization & - & - & - & 1.664 \\
\hline GO:0070291 & $\mathrm{N}$-acylethanolamine metabolic process & - & - & - & 1.653 \\
\hline GO:0010810 & regulation of cell-substrate adhesion & - & - & 1.437 & 1.650 \\
\hline GO:1990774 & tumor necrosis factor secretion & - & - & 1.993 & 1.639 \\
\hline GO:0045786 & negative regulation of cell cycle & - & - & 1.496 & 1.623 \\
\hline GO:0007566 & embryo implantation & - & - & - & 1.612 \\
\hline GO:0048644 & muscle organ morphogenesis & - & - & - & 1.564 \\
\hline GO:1904029 & regulation of cyclin-dependent protein kinase activity & - & - & 1.997 & 1.532 \\
\hline GO:2000416 & regulation of eosinophil migration & - & - & - & 1.523 \\
\hline GO:0097696 & receptor signaling pathway via STAT & - & - & - & 1.523 \\
\hline GO:0090166 & Golgi disassembly & - & - & - & 1.523 \\
\hline GO:0060059 & embryonic retina morphogenesis in camera-type eye & - & - & - & 1.523 \\
\hline GO:0043305 & negative regulation of mast cell degranulation & - & - & - & 1.523 \\
\hline GO:1903510 & mucopolysaccharide metabolic process & - & - & 1.316 & 1.523 \\
\hline GO:0006145 & purine nucleobase catabolic process & - & - & - & 1.523 \\
\hline GO:0050830 & defense response to Gram-positive bacterium & - & - & 3.262 & 1.523 \\
\hline GO:0034201 & response to oleic acid & - & - & - & 1.523 \\
\hline GO:0061756 & leukocyte adhesion to vascular endothelial cell & - & - & - & 1.512 \\
\hline GO:0032692 & negative regulation of interleukin-1 production & - & - & - & 1.512 \\
\hline GO:2000242 & negative regulation of reproductive process & - & - & - & 1.502 \\
\hline GO:0009308 & amine metabolic process & - & - & - & 1.502 \\
\hline
\end{tabular}




\begin{tabular}{|c|c|c|c|c|c|}
\hline GO:0010470 & regulation of gastrulation & - & - & 1.831 & 1.480 \\
\hline GO:0051492 & regulation of stress fiber assembly & - & - & 1.921 & 1.462 \\
\hline GO:0050691 & regulation of defense response to virus by host & - & - & 1.797 & 1.449 \\
\hline GO:0001955 & blood vessel maturation & - & - & 1.633 & 1.414 \\
\hline GO:1905939 & regulation of gonad development & - & - & - & 1.414 \\
\hline GO:1902396 & protein localization to bicellular tight junction & - & - & - & 1.414 \\
\hline GO:1904469 & positive regulation of tumor necrosis factor secretion & - & - & 1.701 & 1.414 \\
\hline GO:0097305 & response to alcohol & - & - & - & 1.402 \\
\hline GO:0046425 & regulation of receptor signaling pathway via JAK-STAT & - & - & - & 1.393 \\
\hline GO:0021756 & striatum development & - & - & - & 1.376 \\
\hline GO:0032026 & response to magnesium ion & - & - & - & 1.376 \\
\hline GO:0051494 & negative regulation of cytoskeleton organization & - & - & - & 1.356 \\
\hline GO:0043535 & regulation of blood vessel endothelial cell migration & - & - & - & 1.348 \\
\hline GO:0001937 & negative regulation of endothelial cell proliferation & - & - & 1.684 & 1.340 \\
\hline GO:0043491 & protein kinase B signaling & - & - & - & 1.335 \\
\hline GO:1903978 & regulation of microglial cell activation & - & - & - & 1.335 \\
\hline GO:0008340 & determination of adult lifespan & - & - & - & 1.335 \\
\hline GO:0033601 & $\begin{array}{l}\text { positive regulation of mammary gland epithelial cell } \\
\text { proliferation }\end{array}$ & - & - & 1.546 & 1.331 \\
\hline GO:0002885 & positive regulation of hypersensitivity & - & - & - & 1.331 \\
\hline GO:0033007 & $\begin{array}{l}\text { negative regulation of mast cell activation involved in } \\
\text { immune response }\end{array}$ & - & - & - & 1.331 \\
\hline GO:0000820 & $\begin{array}{l}\text { regulation of glutamine family amino acid metabolic } \\
\text { process }\end{array}$ & - & - & - & 1.331 \\
\hline GO:0046113 & nucleobase catabolic process & - & - & - & 1.331 \\
\hline GO:0006108 & malate metabolic process & - & - & - & 1.331 \\
\hline GO:0060426 & lung vasculature development & - & - & - & 1.331 \\
\hline GO:0035234 & ectopic germ cell programmed cell death & - & - & 1.546 & 1.331 \\
\hline GO:0000050 & urea cycle & - & - & 1.546 & 1.331 \\
\hline
\end{tabular}




\begin{tabular}{|c|c|c|c|c|c|}
\hline GO:0010727 & $\begin{array}{l}\text { negative regulation of hydrogen peroxide metabolic } \\
\text { process }\end{array}$ & - & - & 1.546 & 1.331 \\
\hline GO:2000389 & regulation of neutrophil extravasation & - & - & - & 1.331 \\
\hline GO:2000772 & regulation of cellular senescence & - & - & - & 1.329 \\
\hline GO:1901031 & regulation of response to reactive oxygen species & - & - & 2.401 & 1.329 \\
\hline GO:0071230 & cellular response to amino acid stimulus & - & - & - & 1.305 \\
\hline GO:0010458 & exit from mitosis & - & - & - & 1.304 \\
\hline GO:0010226 & response to lithium ion & - & - & 1.581 & 1.304 \\
\hline GO:0009615 & response to virus & - & - & 13.377 & - \\
\hline GO:0051607 & defense response to virus & - & - & 10.421 & - \\
\hline GO:0045071 & negative regulation of viral genome replication & - & - & 6.730 & - \\
\hline GO:0045069 & regulation of viral genome replication & - & - & 5.754 & - \\
\hline GO:1903901 & negative regulation of viral life cycle & - & - & 5.389 & - \\
\hline GO:0019079 & viral genome replication & - & - & 5.062 & - \\
\hline GO:0016032 & viral process & - & - & 4.800 & - \\
\hline GO:0048525 & negative regulation of viral process & - & - & 4.648 & - \\
\hline GO:0060700 & regulation of ribonuclease activity & - & - & 4.509 & - \\
\hline GO:0035455 & response to interferon-alpha & - & - & 4.219 & - \\
\hline GO:1903900 & regulation of viral life cycle & - & - & 4.174 & - \\
\hline GO:0043903 & regulation of symbiotic process & - & - & 3.651 & - \\
\hline GO:0072608 & interleukin-10 secretion & - & - & 3.572 & - \\
\hline GO:0032069 & regulation of nuclease activity & - & - & 3.352 & - \\
\hline GO:0050792 & regulation of viral process & - & - & 3.340 & - \\
\hline GO:0035457 & cellular response to interferon-alpha & - & - & 3.194 & - \\
\hline GO:0034340 & response to type I interferon & - & - & 3.106 & - \\
\hline GO:0098586 & cellular response to virus & - & - & 3.106 & - \\
\hline GO:0035458 & cellular response to interferon-beta & - & - & 3.065 & - \\
\hline GO:0034138 & toll-like receptor 3 signaling pathway & - & - & 2.911 & - \\
\hline GO:2000562 & $\begin{array}{l}\text { negative regulation of CD4-positive, alpha-beta } \mathrm{T} \text { cell } \\
\text { proliferation }\end{array}$ & - & - & 2.909 & - \\
\hline
\end{tabular}




\begin{tabular}{|c|c|c|c|c|c|}
\hline GO:0002753 & cytoplasmic pattern recognition receptor signaling pathway & - & - & 2.656 & - \\
\hline GO:2000561 & regulation of CD4-positive, alpha-beta $T$ cell proliferation & - & - & 2.630 & - \\
\hline GO:0060337 & type I interferon signaling pathway & - & - & 2.543 & - \\
\hline GO:2001179 & regulation of interleukin-10 secretion & - & - & 2.507 & - \\
\hline GO:0071357 & cellular response to type I interferon & - & - & 2.461 & - \\
\hline GO:0046642 & negative regulation of alpha-beta $\mathrm{T}$ cell proliferation & - & - & 2.406 & - \\
\hline GO:0002676 & regulation of chronic inflammatory response & - & - & 2.406 & - \\
\hline GO:0035739 & CD4-positive, alpha-beta T cell proliferation & - & - & 2.406 & - \\
\hline GO:0045648 & positive regulation of erythrocyte differentiation & - & - & 2.358 & - \\
\hline GO:0006357 & regulation of transcription by RNA polymerase II & - & - & 2.307 & - \\
\hline GO:0007050 & cell cycle arrest & - & - & 2.294 & - \\
\hline GO:1900245 & positive regulation of MDA- 5 signaling pathway & - & - & 2.264 & - \\
\hline GO:0060546 & negative regulation of necroptotic process & - & - & 2.157 & - \\
\hline GO:0050688 & regulation of defense response to virus & - & - & 2.157 & - \\
\hline GO:0030213 & hyaluronan biosynthetic process & - & - & 2.157 & - \\
\hline GO:0060340 & $\begin{array}{l}\text { positive regulation of type I interferon-mediated signaling } \\
\text { pathway }\end{array}$ & - & - & 2.157 & - \\
\hline GO:0070266 & necroptotic process & - & - & 2.143 & - \\
\hline GO:0006366 & transcription by RNA polymerase II & - & - & 2.124 & - \\
\hline GO:0070098 & chemokine-mediated signaling pathway & - & - & 2.096 & - \\
\hline GO:0010712 & regulation of collagen metabolic process & - & - & 2.078 & - \\
\hline GO:2000514 & regulation of CD4-positive, alpha-beta T cell activation & - & - & 2.052 & - \\
\hline GO:0044406 & adhesion of symbiont to host & - & - & 2.019 & - \\
\hline GO:0010875 & positive regulation of cholesterol efflux & - & - & 1.958 & - \\
\hline GO:0062208 & $\begin{array}{l}\text { positive regulation of pattern recognition receptor signaling } \\
\text { pathway }\end{array}$ & - & - & 1.958 & - \\
\hline GO:0002719 & $\begin{array}{l}\text { negative regulation of cytokine production involved in } \\
\text { immune response }\end{array}$ & - & - & 1.893 & - \\
\hline GO:1990869 & cellular response to chemokine & - & - & 1.882 & - \\
\hline
\end{tabular}




\begin{tabular}{|c|c|c|c|c|c|}
\hline GO:1903557 & $\begin{array}{l}\text { positive regulation of tumor necrosis factor superfamily } \\
\text { cytokine production }\end{array}$ & - & - & 1.882 & - \\
\hline GO:1990868 & response to chemokine & - & - & 1.882 & - \\
\hline GO:0098900 & regulation of action potential & - & - & 1.879 & - \\
\hline GO:0045667 & regulation of osteoblast differentiation & - & - & 1.870 & - \\
\hline GO:0045185 & maintenance of protein location & - & - & 1.870 & - \\
\hline GO:0007219 & Notch signaling pathway & - & - & 1.870 & - \\
\hline GO:0060544 & regulation of necroptotic process & - & - & 1.850 & - \\
\hline GO:0032924 & activin receptor signaling pathway & - & - & 1.831 & - \\
\hline GO:0045639 & positive regulation of myeloid cell differentiation & - & - & 1.800 & - \\
\hline GO:0002726 & positive regulation of $\mathrm{T}$ cell cytokine production & - & - & 1.796 & - \\
\hline GO:0060547 & negative regulation of necrotic cell death & - & - & 1.796 & - \\
\hline GO:0035634 & response to stilbenoid & - & - & 1.796 & - \\
\hline GO:0097300 & programmed necrotic cell death & - & - & 1.769 & - \\
\hline GO:0036072 & direct ossification & - & - & 1.739 & - \\
\hline GO:0039533 & regulation of MDA- 5 signaling pathway & - & - & 1.739 & - \\
\hline GO:0001957 & intramembranous ossification & - & - & 1.739 & - \\
\hline GO:0032652 & regulation of interleukin-1 production & - & - & 1.718 & - \\
\hline GO:0030522 & intracellular receptor signaling pathway & - & - & 1.703 & - \\
\hline GO:0002544 & chronic inflammatory response & - & - & 1.701 & - \\
\hline GO:0039529 & RIG-I signaling pathway & - & - & 1.701 & - \\
\hline GO:0035743 & CD4-positive, alpha-beta T cell cytokine production & - & - & 1.656 & - \\
\hline GO:0062098 & regulation of programmed necrotic cell death & - & - & 1.656 & - \\
\hline GO:0032727 & positive regulation of interferon-alpha production & - & - & 1.656 & - \\
\hline GO:2001181 & positive regulation of interleukin- 10 secretion & - & - & 1.633 & - \\
\hline GO:0039530 & MDA- 5 signaling pathway & - & - & 1.633 & - \\
\hline GO:0043122 & regulation of I-kappaB kinase/NF-kappaB signaling & - & - & 1.633 & - \\
\hline GO:0045646 & regulation of erythrocyte differentiation & - & - & 1.612 & - \\
\hline GO:0090077 & foam cell differentiation & - & - & 1.581 & - \\
\hline GO:0010742 & macrophage derived foam cell differentiation & - & - & 1.581 & - \\
\hline
\end{tabular}




\begin{tabular}{|c|c|c|c|c|c|}
\hline GO:0032606 & type I interferon production & - & - & 1.568 & - \\
\hline GO:0032481 & positive regulation of type I interferon production & - & - & 1.563 & - \\
\hline GO:0070373 & negative regulation of ERK1 and ERK2 cascade & - & - & 1.549 & - \\
\hline GO:0060343 & trabecula formation & - & - & 1.546 & - \\
\hline GO:0042542 & response to hydrogen peroxide & - & - & 1.546 & - \\
\hline GO:0030214 & hyaluronan catabolic process & - & - & 1.546 & - \\
\hline GO:0034139 & regulation of toll-like receptor 3 signaling pathway & - & - & 1.546 & - \\
\hline GO:0071493 & cellular response to UV-B & - & - & 1.546 & - \\
\hline GO:0032965 & regulation of collagen biosynthetic process & - & - & 1.546 & - \\
\hline GO:0051099 & positive regulation of binding & - & - & 1.546 & - \\
\hline GO:0039528 & $\begin{array}{l}\text { cytoplasmic pattern recognition receptor signaling pathway } \\
\text { in response to virus }\end{array}$ & - & - & 1.546 & - \\
\hline GO:0007589 & body fluid secretion & - & - & 1.527 & - \\
\hline GO:0032655 & regulation of interleukin-12 production & - & - & 1.525 & - \\
\hline GO:0045668 & negative regulation of osteoblast differentiation & - & - & 1.525 & - \\
\hline GO:0000305 & response to oxygen radical & - & - & 1.516 & - \\
\hline GO:0000303 & response to superoxide & - & - & 1.516 & - \\
\hline GO:0032376 & positive regulation of cholesterol transport & - & - & 1.516 & - \\
\hline GO:0032373 & positive regulation of sterol transport & - & - & 1.516 & - \\
\hline GO:0032715 & negative regulation of interleukin- 6 production & - & - & 1.505 & - \\
\hline GO:0010883 & regulation of lipid storage & - & - & 1.505 & - \\
\hline GO:0000079 & $\begin{array}{l}\text { regulation of cyclin-dependent protein serine/threonine } \\
\text { kinase activity }\end{array}$ & - & - & 1.493 & - \\
\hline GO:0045662 & negative regulation of myoblast differentiation & - & - & 1.480 & - \\
\hline GO:2000515 & $\begin{array}{l}\text { negative regulation of CD4-positive, alpha-beta T cell } \\
\text { activation }\end{array}$ & - & - & 1.480 & - \\
\hline GO:0061082 & myeloid leukocyte cytokine production & - & - & 1.480 & - \\
\hline GO:0060338 & regulation of type I interferon-mediated signaling pathway & - & - & 1.480 & - \\
\hline GO:0032647 & regulation of interferon-alpha production & - & - & 1.480 & - \\
\hline
\end{tabular}




\begin{tabular}{|c|c|c|c|c|c|}
\hline GO:0045927 & positive regulation of growth & - & - & 1.476 & - \\
\hline GO:0014050 & negative regulation of glutamate secretion & - & - & 1.469 & - \\
\hline GO:2000172 & regulation of branching morphogenesis of a nerve & - & - & 1.469 & - \\
\hline GO:0019627 & urea metabolic process & - & - & 1.469 & - \\
\hline GO:0032615 & interleukin-12 production & - & - & 1.463 & - \\
\hline GO:0060760 & positive regulation of response to cytokine stimulus & - & - & 1.463 & - \\
\hline GO:0002701 & $\begin{array}{l}\text { negative regulation of production of molecular mediator of } \\
\text { immune response }\end{array}$ & - & - & 1.450 & - \\
\hline GO:0002832 & negative regulation of response to biotic stimulus & - & - & 1.449 & - \\
\hline GO:0001501 & skeletal system development & - & - & 1.445 & - \\
\hline GO:0060759 & regulation of response to cytokine stimulus & - & - & 1.442 & - \\
\hline GO:0051726 & regulation of cell cycle & - & - & 1.437 & - \\
\hline GO:0070265 & necrotic cell death & - & - & 1.421 & - \\
\hline GO:0006081 & cellular aldehyde metabolic process & - & - & 1.421 & - \\
\hline GO:0034101 & erythrocyte homeostasis & - & - & 1.420 & - \\
\hline GO:1900407 & regulation of cellular response to oxidative stress & - & - & 1.420 & - \\
\hline GO:0051497 & negative regulation of stress fiber assembly & - & - & 1.420 & - \\
\hline GO:0032607 & interferon-alpha production & - & - & 1.420 & - \\
\hline GO:0070848 & response to growth factor & - & - & 1.417 & - \\
\hline GO:0000082 & G1/S transition of mitotic cell cycle & - & - & 1.413 & - \\
\hline GO:1902741 & positive regulation of interferon-alpha secretion & - & - & 1.409 & - \\
\hline GO:0072641 & type I interferon secretion & - & - & 1.409 & - \\
\hline GO:1902739 & regulation of interferon-alpha secretion & - & - & 1.409 & - \\
\hline GO:1902023 & L-arginine transport & - & - & 1.409 & - \\
\hline GO:0072642 & interferon-alpha secretion & - & - & 1.409 & - \\
\hline GO:0071941 & nitrogen cycle metabolic process & - & - & 1.409 & - \\
\hline GO:1900246 & positive regulation of RIG-I signaling pathway & - & - & 1.409 & - \\
\hline GO:0072610 & interleukin-12 secretion & - & - & 1.409 & - \\
\hline GO:0035744 & T-helper 1 cell cytokine production & - & - & 1.409 & - \\
\hline GO:0070673 & response to interleukin- 18 & - & - & 1.409 & - \\
\hline
\end{tabular}




\begin{tabular}{|l|l|l|l|l|l|} 
GO:0045661 & regulation of myoblast differentiation & - & & 1.409 & - \\
\hline & negative regulation of cyclin-dependent protein kinase & & - & 1.398 & - \\
\hline GO:1904030 & activity & - & - & 1.398 & - \\
\hline GO:0032689 & negative regulation of interferon-gamma production & - & - & 1.398 & - \\
\hline GO:0033598 & mammary gland epithelial cell proliferation & - & - & 1.398 & - \\
\hline GO:0032964 & collagen biosynthetic process & - & - & 1.370 & - \\
\hline GO:0001779 & natural killer cell differentiation & - & - & 1.368 & - \\
\hline GO:0010714 & positive regulation of collagen metabolic process & - & - & 1.368 & - \\
\hline GO:0006879 & cellular iron ion homeostasis & - & - & 1.353 & - \\
\hline GO:0043301 & negative regulation of leukocyte degranulation & - & - & 1.346 & - \\
\hline GO:0032926 & negative regulation of activin receptor signaling pathway & - & - & 1.346 & - \\
\hline & nucleotide-binding oligomerization domain containing 2 & & & & \\
\hline GO:0070431 & signaling pathway & - & - & 1.346 & - \\
\hline GO:1905097 & regulation of guanyl-nucleotide exchange factor activity & - & - & 1.346 & - \\
\hline GO:0051384 & response to glucocorticoid & - & - & 1.342 & - \\
\hline GO:0043393 & regulation of protein binding & - & - & 1.333 & - \\
\hline GO:0043170 & macromolecule metabolic process & - & - & 1.320 & - \\
\hline
\end{tabular}




\section{Chapter 4. Elongate mineral particles of different growth habit elicit differential pulmonary immune cell responses in $\mathrm{A} / \mathrm{J}$ mice}

\subsection{Abstract}

In this study we focused on the long-term effects of EMP exposure, including 3- and 12months post-exposure time points. Neoplastic manifestations at 1 year were much more frequent in asbestos-treated animals, while cleavage fragments did not have significantly increased number of neoplastic lesions. Histopathology revealed hyperplasia, mild alveolar septal fibrosis and immune cell infiltration, however, no extensive lung fibrosis in asbestiform EMP groups. Cleavage fragments provoked very little histological changes and were mostly found inside the alveoli lumens. DNA damage response was higher in asbestiform EMPs with the foci of $\mathrm{YH} 2 \mathrm{AX}$ staining found in the vicinity of deposited fibers, in AMs, epithelial and lymphoid cells, while CF did not induce significant DNA double strand breaks. Increased ARG1 staining in association with elevated IL-3, IL-4, and IL-5 cytokines levels characterize the immune response to asbestos particles as leaning towards TH2-type. Flow cytometry revealed more drastic changes in the immune cell populations caused by asbestiform EMPs at the same mass doses compared to CF. There was relative depletion of resident AMs, expressing high Siglec-F surface marker, and negative for CD11b molecule, observed in all asbestos-treated groups at 3 months, and persisting at 1-year time point, but mean fluorescence intensity of CD11b on AM surface was higher than control at 12 months in all treated groups, including CF. In the asbestos-treated animals depletion of resident AMs could have exacerbated the pathologic process. In conclusion, exposure to asbestiform and non-asbestiform EMPs led to discrete pulmonary immune responses at 3- and 12-months post-exposure, leading to specific long-term fibroproliferative and carcinogenic outcomes. Asbestos induced a distinct immune response pattern, and a much stronger response than cleavage fragments at mass- and surface area-equivalent doses. The studied cleavage fragments were not as potent as asbestos in driving the fibroproliferation and cancer, most likely due to the lack of resident AM depletion. 


\subsection{Introduction}

Although various studies have suggested that fiber dimensions, surface properties, and physical durability are important criteria for the EMP fibrogenicity and carcinogenicity [1], the essential knowledge of the significance and role of different features/characteristics that define the relative risk of developing specific long-term outcomes is still missing. This is due, at least in part, to the lack of comprehensive studies that assess the adverse effects of asbestiform and non-asbestiform EMPs in relation to their physical, chemical, morphological and surface characteristics as well as their bioavailability and biopersistence. Thus, evaluating/quantifying inflammatory and pulmonary outcomes upon exposure to different asbestos/asbestiform fibers as a function of time using animal models is critical for understanding the detailed mechanisms underlying mineral fiberinduced toxicity. Such studies will also provide a unique opportunity to uncover the time dependent cellular and molecular changes associated with fiber-mediated fibro- and carcinogenesis.

In humans fibrosis induced by asbestos is characterized by the presence of socalled asbestos bodies within the fibrous tissue, and fewer myofibroblasts foci or bronchial wall fibrosis [2]. Deposition of asbestiform EMPs causes alveolar macrophage and epithelial cell apoptosis, recruitment of inflammatory mononuclear cells with subsequent M2 polarization of macrophages, as well as T-lymphocyte activation that leads to the increase in pro-fibrotic cytokines secretion [3,4]. Carcinogenicity of asbestos is probably its most worrying property. Cancer itself is a complex pathologic manifestation that takes a long time to develop from the time of the initial insult. Often this involves a sequence of gene-environment interactions in a progressive fashion and requires dysfunction of multiple systems (e.g., DNA repair, apoptosis, immune function etc.); Although it is not easy to recapitulate human asbestos-induced lung disease in rodents, first murine asbestosis models were proposed in 1980s [5, 6]. They utilized BALB/C mice and chrysotile asbestos administered via inhalation or instillation. A bolus administration of asbestiform EMPs leads to central pattern fibrosis and quite often uneven distribution of the lesions between lungs. Inhalation allows more uniform distribution pattern and is physiological, at the same time being cumbersome, time- and effort-consuming and 
posing significant health hazard to research personnel. Additionally, it requires huge amounts of test material and it is quite difficult to adequately assess the delivered dose. To account for the pros and cons of both methods, we utilized repeated pharyngeal aspiration model, where the total dose is delivered throughout the 3 weeks, twice per week, with 2-3 days breaks. This allows some time for clearance as to not overwhelm the clearance mechanisms, which can happen in bolus dose scenarios.

Animal models are indispensable for studying carcinogenic effects of asbestos/asbestiform fibers. US Environmental Protection Agency (EPA) in its OPPTS 870.8355 Health Effects Test Guidelines recommends using the rat model in the asbestos toxicity studies if the endpoints include fibrosis, lung cancer and mesothelioma. However, for our purposes of primarily assessing the immune responses in relation to fibrosis and lung cancer, but not mesothelioma, we utilized mice of the $A / J$ strain, which is a common and scientifically accepted cancer prone animal model for testing lung carcinogens. Another consideration was the 10-times larger required amount of EMP preparations for rat exposures. We wanted to assess the immune cells population dynamic,

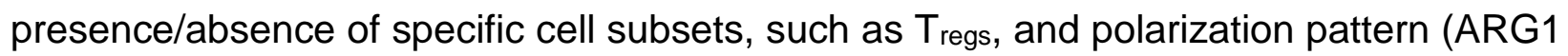
vs iNOS in macrophages). Based on the accumulated knowledge and previous studies utilizing mouse model of fibrous nanomaterials pharyngeal aspiration [7], we produced the following hypothesis: after initial stimulus and innate immune response (usually inflammatory), local immune polarization patterns emerge, accompanied by increased proliferative activity of pulmonary cells (hyperplasia). Hyperplastic outcomes in this case may be predicted not solely on structure, biopersistence and chemical composition of particles, but on the function and composition of local immune responses, which undergoes disparate changes in various type of exposures following the cellular and humoral (cytokines and chemokines) pathways. This may result in the resolution of inflammation and/or specific adverse outcomes, such as fibrosis/cancer. Towards this goal, we employed flow-cytometric analysis of lung immune cell populations, cytokine profiling, histopathology and immunohistochemistry studies to characterize subchronic (3 months) and long term (1 year) pulmonary effects associated with repeated exposure to the studied EMPs using repeated pharyngeal aspiration method. A dose, containing comparable amounts of critical fibers ( $>5 \mu \mathrm{m}$ length and $>1: 3$ aspect ratio) was selected 
(see Chapter 2). Further, we estimated a total number of fibers per gram lung dry weight along with their respective size distributions to determine the relevance of selected dose to human exposures.

\subsection{Methods}

\subsubsection{Animals}

Specific pathogen-free $\mathrm{A} / \mathrm{J}$ mice (female, 7-8-wk-old) were obtained from Jackson Laboratories (Bar Harbor, ME). A/J strain is a commonly used strain in lung cancer research. These animals develop spontaneous lung tumors and also in response to carcinogens. The number of mice requested was based on statistical requirement to determine the biological effects of different EMPs at both short-term $(n=6)$ as well as longterm $(n=8)$ post exposure time points. Statistical power analysis was performed to estimate the minimal animal group size required for each goal. While six animals per treatment group will be sufficient for carrying out the short-term study (3 months post exposure), a total of at least 8 mice per group was requested for 1-year post exposure time point. This is to account for animal loss during the course of the study due to aging and other factors such as the high potency of $\mathrm{A} / \mathrm{J}$ mice in developing spontaneous tumors and associated complications. Moreover, the request for an increase in $20 \%$ of mice was further justified by previous studies which explored the survival rate of $A / J$ mice exposed to asbestos particles and reported loss of $\sim 10-15 \%$ (depending on dose) of mice starting 300 days post exposure to crocidolite asbestos [8].

\subsubsection{Animal treatment}

A total of 196 mice were assigned to 2 sets, 14 groups in each, with $n=6$ for 3 months and $\mathrm{n}=8$ for 1 -year time points. Six different suspensions of materials: high and low dose of riebeckite asbestos (Rasb), riebeckite cleavage fragments (RCF), high and low dose of tremolite asbestos (TAsb), and tremolite cleavage fragments (TCF) were used to perform repeated pharyngeal aspiration exposures (twice a week for 3 weeks), while the corresponding control mice were administered sterile $\mathrm{Ca} 2+$ and $\mathrm{Mg} 2+$ free PBS $(50 \mu \mathrm{l})$ vehicle (Figure 4.1.). Animals were administered mass-equivalent doses of $120 \mu \mathrm{g} / \mathrm{mouse}$ for all EMPs. This dose has been chosen to be consistent across the various materials 
and allow for the cross-comparison with the other studies utilizing the same dose of asbestos. Two additional groups were given critical fiber total surface area-equivalent doses of riebeckite ( $30 \mu \mathrm{g} / \mathrm{mouse})$ and tremolite $(10 \mu \mathrm{g} / \mathrm{mouse})$. Given that occupational limits are based on "counts", number-based dosing was considered as well, however, the resulting doses would have been quite close to the total surface area-equivalent ones, thus the results would not be dramatically different. Pharyngeal aspiration provides good distribution and particle deposition in the lungs, including alveolar space, and corresponds to the inhalation studies results $[9,10]$. Number of fibers per gram dry weight of the lungs was compared with Helsinki criterion (see Chapter 2). Mice were euthanized with an overdose of $\geq 100 \mathrm{mg} / \mathrm{kg}$ of pentobarbital, and deep anesthesia was confirmed when the mouse no longer responded to a toe pinch. Exsanguination by cutting the posterior vena cava performed to make sure the animal does not wake up.

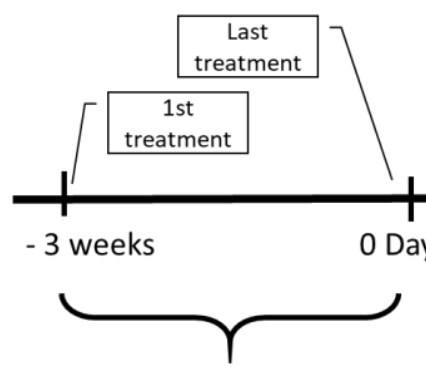

Pharyngeal aspiration 2 times a week, for 3 weeks

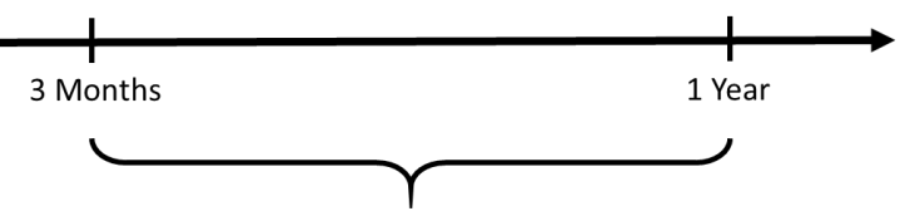

Time points of sacrifice

Figure 4.1. Experimental design of the animal study

\subsubsection{Hematological analysis}

We assessed the blood cellular composition and other the physiological parameters using ProCyte-Dx Hematology Analyzer and found slight decrease in red blood cell count as well as hemoglobin content in the treated group, however no significant differences in immune cell differentials or other parameters were observed (Supplementary table 2).

\subsubsection{Cytokine content in the lung homogenates}

23 cytokines were measured in the mouse lung homogenates and plasma using Bio-Plex Pro Mouse Cytokine 23-plex assay on a Bio-Plex 200 Reader (Bio-Rad Laboratories, Hercules, CA) following manufacturer's directions, with three technical replicates allocated for each sample. Prior to measurements, $1 \mathrm{ml}$ of PBS was added, and homogenates were centrifuged at $2500 \mathrm{~g}$. Cytokine quantities was normalized for the total 
protein measured in respective homogenates. This assay detects the levels of IL-1 $\alpha,-1 \beta,-$ $2,-3,-4,-5,-6,-9,-10,-12$ (p40),-12(p70),-13,-17, Eotaxin, G-CSF, GM-CSF, IFN- - , KC, MCP-1 (MCAF), MIP-1 $\alpha$, MIP-1 $\beta$, RANTES and TNF- $\alpha$ in the samples.

\subsubsection{Flow Cytometric analysis of the immune cell subsets:}

Half of the mice form each group had their left lungs excised and placed in PBS for immediate single-cell suspensions preparation. To prepare single-cell suspensions, large airways were dissected from the peripheral lung tissue; the latter was cut into small pieces, transferred into C-tubes (Miltenyi Biotec Inc., Auburn, CA), and processed in digestion buffer (Miltenyi Biotec Inc., Auburn, CA) using GentleMACS dissociator (Miltenyi Biotec Inc., Auburn, CA), according to the manufacturer's instructions. Single-cell suspension will be obtained by passing through $40-\mu \mathrm{m}$ nylon mesh. The remaining red blood cells will be lysed using the red cell lysis buffer (Sigma Aldrich). Single-cell suspensions from spleens and lungs will be washed and resuspended in FACS buffer (Rockland Immunochemicals Inc., Limerick, PA). Fc-block antibody will be used to reduce non-specific binding. Cells were then stained with fluorochrome-conjugated antibodies versus CD45 (Clone: 30-F11, BD), Siglec F (Clone: E50-2440, BD Horizon ${ }^{\mathrm{TM}}$ ), MHC Class II, CD11b, Ly6G, Ly6C, CD11c (Clone: N418, eBioscience ${ }^{\mathrm{TM}}$ ), CD64 (Clone: X545/7.1, Biolegend) and CD24 (Clone: M1/69, BD) (all obtained from Fischer Scientific, Pittsburgh, PA). Samples were run on Amnis FlowSight imaging flow cytometer (Luminex Corp., Austin, TX) and analyzed using IDEAS 6.2 software to distinguish specific immune cells populations in the lung: alveolar macrophages, T- and B-lymphocytes, incoming inflammatory and regulatory monocytes, neutrophils and eosinophils). Additionally, evaluating the mean fluorescent intensity (MFI) of selected markers allowed elucidating the activation state and unique phenotypic profiles of the different cell types. Gating strategy is shown in Supplementary figure.

\subsubsection{Histopathological analysis of mouse lung tissue}

Half of the mice per group per time point had their lungs inflated with buffered formalin and embedded in paraffin blocks. Lung tissue sections were stained by $\mathrm{H} \& \mathrm{E}$ and Masson's Trichrome. The slides were analyzed for a presence of fibroproliferative and neoplastic lesions. and lymphohistiocytic aggregates, specifically, parenchymal, 
peribronchial, perivascular, and subpleural aggregates. Assessment was performed by board-certified pathologist. Sample identification was coded to ensure blinded evaluation. 4.3.7. Immunohistochemistry staining of the lung tissues:

Additional formalin-fixed paraffin-embedded lung tissue sections have been further stained with antibodies against CD4, CD8, CD20, CD68, FOXP3, Arg1, iNOS, and $\mathrm{pH} 2 \mathrm{AX}$. The benefits of using IHC included visualization of individual cells and using additional parameters, such as morphological differences and compartmental translocation for the analysis of cell populations.

\subsubsection{Statistical Analyses}

Treatment-related differences in various outcomes were evaluated using two-way ANOVA, followed by pair wise comparison using the Student-Newman-Keuls tests. Results are presented as mean \pm SEM and those $p$ values $<0.05$ considered statistically significant. We used SigmaPlot 12.5 and R statistical package (http://www.r-project.org).

\subsection{Results}

\subsubsection{Cytokine production in the lungs}

Concentrations of 23 cytokines and chemokines present in the lung homogenates of mice exposed to various EMPs are shown in Table 4.1. There were no statistically significant changes in the levels of IL-1b in all groups and time points. At 3-months' time point levels of IL-9 were significantly increased in all treatment groups except $30 \mu \mathrm{g}$ RAsb compared to controls. IL-3 and IL-4 were several-fold increased in tremolite-treated animals both at 3 and 12 months. GM-CSF was increased compared to control in Tremolite-treated animals only (both asbestos and CF); in Riebeckite groups it was also increased, but with no statistical significance. Chemokines - KC, MCP-1, MIP-1a, MIP-1b were increased in several treatment groups at 3 months, while at 12 month we only observed MIP-1a in TAsb and RAsb as well as KC in Tasb. At 12 months 120 ug riebeckite asbestos only had increased IL-13, IL-17 and Eotaxin (each $p<0.05$ vs. control). Lastly, TAsb group had increased G-CSF, KC, and IL-12p70 at 12 months ( $p<0.05$ vs. control), while both TAsb and Rasb had increased IL-12p40. IL-2 was increased in CF-treated animals at 12 months compared to controls. 
Table 4.1. Detailed cytokine concentrations in the mouse lungs at 3- and 12-months post exposure, pg/mg protein. RCF Riebeckite cleavage fragments, RAsb - Riebeckite Asbestos, TCF - Tremolite cleavage fragments, TAsb - Tremolite Asbestos. Values, showing significant difference $(p<0.05)$ compared to respective controls have a red font color.

$$
3 \text { Months }
$$

\begin{tabular}{|c|c|c|c|c|c|c|c|c|c|c|c|c|c|c|c|c|c|c|c|c|c|c|c|c|}
\hline alue type & Treatment & IL-1a & IL-1b & IIL-2 & IL-3 & IL-4 & IL-5 & IL-6 & IL-9 & IL-10 & IL-12(p40) & IL-12(p70) & IL-13 & IL-17 & \begin{tabular}{|l|l|} 
Eotaxin \\
\end{tabular} & j-CSF & GM-CSF & IFN-g & KC & MCP-1 & MIP-1a & MIP-1b & RANTES & TNF-a \\
\hline \multirow{7}{*}{ Mean } & Control & 1.56 & 0.542 & 1.084 & 0.416 & 0.282 & 0.746 & 0.532 & 1.9 & 1.787 & 29.604 & 7.126 & 20.992 & 0.516 & \begin{tabular}{|l|}
117.645 \\
\end{tabular} & 4.057 & 1.754 & 2.26 & 4.681 & 19.25 & 1.7 & 4.824 & $\begin{array}{ll}93.07 \\
\end{array}$ & 5.679 \\
\hline & RAsb $120 \mu \mathrm{g}$ & 1.102 & 0.456 & 1.339 & 0.925 & 0.785 & 0.661 & 0.697 & 2.924 & 2.548 & 46.218 & 16.539 & 20.591 & 0.655 & 158.01 & 13.188 & 2.639 & 3.358 & 7.964 & 15.616 & 3.909 & 5.233 & 153.962 & 7.122 \\
\hline & RCF $120 \mu \mathrm{g}$ & 1.281 & 0.619 & 1.365 & 0.555 & 0.437 & 0.756 & 0.949 & 3.265 & 2.768 & 34.035 & \begin{tabular}{l|l|}
13.53 \\
\end{tabular} & 25.228 & 0.775 & 237.559 & 6.175 & 2.333 & 3.337 & 9.088 & 18.224 & 4.175 & 8.238 & 222.045 & 8.073 \\
\hline & RAsb 30 $\mu \mathrm{g}$ & 0.481 & 0.388 & 1.429 & 0.978 & 0.89 & 0.667 & 0.576 & 2.486 & 2.459 & 23.087 & 15.8 & 19.895 & 0.824 & 131.961 & 11.777 & 2.448 & 3.111 & 4.508 & 8.527 & 1.402 & 5.22 & 136.256 & 6.777 \\
\hline & TAsb $120 \mu \mathrm{g}$ & 0.903 & 0.481 & 1.365 & 1.514 & 1.338 & 0.796 & 0.645 & 3.141 & 3.151 & 41.479 & 19.545 & 26.348 & 0.815 & 160.537 & 14.794 & 2.652 & 4.008 & 10.076 & 14.604 & 5.51 & 6.573 & 33.866 & 8.279 \\
\hline & TCF $120 \mu \mathrm{g}$ & 0.607 & 0.38 & 1.243 & 1.427 & 1.243 & 0.681 & 0.628 & 2.764 & 2.589 & 26.008 & 19.712 & 18.097 & 0.732 & \begin{tabular}{|l|}
112.183 \\
\end{tabular} & 18.018 & 2.401 & 3.108 & 4.506 & 9.566 & 2.321 & 5.323 & 41.346 & 7.786 \\
\hline & TAsb $10 \mu \mathrm{g}$ & 0.675 & 0.425 & 1.588 & 1.587 & 1.15 & 0.705 & 0.719 & 3.047 & 2.639 & 35.89 & 18.917 & 18.844 & 0.839 & \begin{tabular}{|l|}
156.674 \\
\end{tabular} & 12.072 & 3.378 & 3.319 & 6.356 & 9.047 & 1.756 & 7.285 & 163.062 & 8.545 \\
\hline \multirow{7}{*}{$\begin{array}{c}\text { Standard } \\
\text { Error of } \\
\text { Mean } \\
\text { (SEM) }\end{array}$} & Control & 0.0791 & 0.0825 & 0.111 & 0.0271 & 0.0307 & 0.178 & 0.0212 & 0.07 & 0.285 & 2.197 & 1.239 & 4.057 & 0.158 & 12.028 & 0.432 & 0.107 & 0.364 & 0.538 & 1.583 & 0.114 & 0.125 & 10.959 & 0.697 \\
\hline & $\begin{array}{ll}\text { RAsb } 120 \mu \mathrm{g} \\
\end{array}$ & 0.0779 & \begin{tabular}{|l|l|}
0.0673 \\
\end{tabular} & 0.228 & 0.474 & 0.408 & 0.0879 & 0.0301 & 0.178 & 0.237 & 4.791 & 7.443 & 2.253 & 0.0701 & $\begin{array}{l}9.896 \\
\end{array}$ & 6.458 & 0.287 & 0.402 & 0.0579 & 1.183 & 0.0822 & 0.243 & 1.774 & 1.019 \\
\hline & RCF $120 \mu \mathrm{g}$ & 0.178 & \begin{tabular}{|l|}
0.0847 \\
\end{tabular} & 0.177 & 0.346 & 0.272 & 0.0648 & 0.129 & 0.279 & 0.0804 & 5.355 & 2.413 & 2.7 & 0.0759 & 47.464 & 1.884 & 0.158 & 0.287 & 1.426 & 2.584 & 0.268 & 1.008 & 52.9 & 0.818 \\
\hline & RAsb $30 \mu \mathrm{g}$ & 0.0583 & \begin{tabular}{|l|l|}
0.0643 \\
\end{tabular} & 0.298 & 0.374 & 0.305 & 0.0645 & 0.0847 & 0.28 & 0.311 & 1.213 & 6.956 & 2.333 & 0.117 & 13.424 & 5.396 & 0.129 & 0.43 & 0.223 & 1.661 & 0.178 & 0.0389 & 19.393 & 0.831 \\
\hline & TAsb 120 $\mu \mathrm{g}$ & 0.151 & 0.0579 & 0.231 & 0.285 & 0.274 & 0.139 & 0.057 & $\begin{array}{l}0.0796 \\
\end{array}$ & 0.153 & 5.192 & 2.574 & 1.813 & 0.0962 & 27.882 & 4.475 & 0.11 & 0.356 & 0.258 & 2.929 & 0.389 & 0.517 & 7.093 & 0.312 \\
\hline & TCF $120 \mu \mathrm{g}$ & 0.0248 & 0.047 & 0.0684 & 0.183 & 0.102 & 0.126 & 0.0373 & 0.111 & 0.0512 & 3.219 & 1.951 & 1.183 & 0.0722 & 14.473 & 2.799 & 0.0561 & 0.109 & 0.368 & 0.145 & 0.166 & 0.176 & 14.557 & 0.359 \\
\hline & TAsb $10 \mu \mathrm{g}$ & 0.0519 & 0.021 & 0.154 & 0.323 & 0.384 & 0.148 & \begin{tabular}{|l|} 
\\
\end{tabular} & 0.28 & 0.417 & 7.933 & 4.822 & 1.604 & 0.0755 & 21.733 & 1.112 & 0.3 & 0.316 & 0.645 & 0.357 & 0.249 & 0.657 & 23.929 & 0.192 \\
\hline
\end{tabular}
12 Months

\begin{tabular}{|c|c|c|c|c|c|c|c|c|c|c|c|c|c|c|c|c|c|c|c|c|c|c|c|c|}
\hline lue type & Treatment & IL-1a & IL-1b & IL-2 & IL-3 & $\mid \mathrm{IL}-4$ & IL-5 & IL-6 & $\mid$ LL-9 & IL-10 & \begin{tabular}{|l|l} 
IL-12(p40) \\
\end{tabular} & $\mid$\begin{tabular}{|l|} 
IL-12(p70) \\
\end{tabular} & IL-13 & \begin{tabular}{|l|l|} 
IL-17 \\
\end{tabular} & Eotaxin & G-CSF & \begin{tabular}{|l|} 
GM-CSF \\
\end{tabular} & IFN-g & KC & \begin{tabular}{|l|} 
MCP-1 \\
\end{tabular} & \begin{tabular}{|l|} 
MIP-1a \\
\end{tabular} & MIP-1b & RANTES & TNF-a \\
\hline \multirow{7}{*}{ Mean } & Control & 1.436 & 0.644 & 3.284 & 1.455 & 1.882 & 1.559 & 3.154 & 7.564 & 2.702 & 18.689 & 11.902 & 20.41 & 1.453 & 189.121 & 4.896 & 3.651 & 3.237 & 8.957 & 19.519 & 3.426 & 2.426 & 96.469 & 14.993 \\
\hline & \begin{tabular}{|l|} 
RAsb $120 \mu \mathrm{g}$ \\
\end{tabular} & 379 & 0.906 & 4.286 & 0.559 & 0.799 & 2.339 & 3.711 & 6.867 & 3.251 & 31.53 & 15.12 & 27.103 & 2.07 & 295.301 & 4.058 & 3.726 & 3.781 & 11.076 & 25.173 & 4.723 & 742 & 91.646 & 0.203 \\
\hline & \begin{tabular}{|l|} 
RCF $120 \mu \mathrm{g}$ \\
\end{tabular} & 1.502 & 0.923 & 5.634 & 1.052 & 1.419 & 2.156 & 2.546 & 6.85 & 4.012 & 1.878 & 9.808 & 27.381 & 1.84 & 199.085 & 4.537 & 3.488 & 3.814 & \begin{tabular}{l|l|}
9.475 \\
\end{tabular} & \begin{tabular}{|l|}
19.919 \\
\end{tabular} & 2.665 & 2.202 & 83.241 & 22.47 \\
\hline & \begin{tabular}{|l|} 
RAsb 30 $\mathrm{\mu g}$ \\
\end{tabular} & 2.31 & 0.9 & 3.425 & 2.636 & 2.636 & 1.357 & 3.576 & 7.884 & 3.172 & 205 & 11.646 & 24.16 & 1.183 & 260.065 & 6.193 & 3.361 & 3.515 & 12.31 & 21.125 & 6.884 & 3.033 & 123.857 & 5.449 \\
\hline & TAsb & 154 & 0.595 & 861 & 3.816 & 659 & 1.599 & 2.944 & 11.998 & 3.311 & 814 & 22.569 & 17.009 & 1.477 & 279.314 & 15.435 & 5.432 & \begin{tabular}{l|l}
4.583 \\
\end{tabular} & 13.684 & 16.532 & 6.611 & 2.089 & 81.232 & 7.562 \\
\hline & TCF $120 \mu \mathrm{g}$ & 335 & 0.925 & 5.176 & 2.046 & 2.728 & 2.144 & 2.866 & 10.88 & 3.266 & 24.07 & 17.96 & 27.682 & 2.234 & 314.902 & 7.423 & 4.486 & 4.633 & 9.075 & \begin{tabular}{l|}
17.689 \\
\end{tabular} & 5.737 & 3.917 & |47.197 & 5.571 \\
\hline & TAsb & & 0.849 & 3.345 & 1.013 & 1.2 & 1.502 & & 5.919 & 2.604 & 48 & 7.486 & \begin{tabular}{|l|}
25.106 \\
\end{tabular} & 1.128 & 265.464 & 3.474 & 2.689 & 2.78 & 7.87 & 20.109 & 6.06 & 455 & 19.434 & 3.27 \\
\hline \multirow{7}{*}{$\begin{array}{c}\text { Standard } \\
\text { Error of } \\
\text { Mean } \\
\text { (SEM) }\end{array}$} & Control & 0.0564 & 0.0449 & 0.213 & 0.325 & 0.38 & 0.138 & 59 & 0.345 & 0.169 & 71 & 0.69 & 1.321 & 0.17 & 6.703 & 0.422 & 0.291 & 0.148 & 0.363 & 1.393 & 0.295 & 251 & 6.712 & .987 \\
\hline & RAsb 120 $\mu \mathrm{g}$ & 0.0897 & 0.0143 & 0.733 & 0.0321 & 0.098 & 0.129 & 265 & 0.348 & 0.0983 & 379 & 0.0907 & 1.104 & .128 & 4.537 & 0.38 & 0.127 & 0.162 & \begin{tabular}{l|l}
0.43 \\
\end{tabular} & 1.238 & .735 & 494 & 8.639 & 1.863 \\
\hline & RCF 120 & 0.131 & 0.203 & 0.848 & 0.162 & 02 & 0.359 & 0.212 & 0.906 & 0.417 & 69 & 0.867 & 5.129 & 371 & \begin{tabular}{l|l|l|}
.399 \\
\end{tabular} & 0.725 & 0.589 & 0.65 & 1.134 & 3.169 & 0.312 & 282 & .852 & 2.435 \\
\hline & RAsb 33 & 495 & 0.0735 & 0.378 & 0.853 & 0.819 & 0.174 & 0.52 & 1.279 & 0.23 & 52 & 1.665 & 3.535 & 0.152 & 25.577 & 1.682 & 0.459 & 0.462 & 2.515 & 2.988 & 2.035 & 0.953 & 1.603 & - \\
\hline & TAsb 120 $\mu \mathrm{g}$ & 0.174 & 0.0306 & 0.118 & 0.455 & 1.111 & 0.0302 & 0.258 & 1.991 & 0.403 & 462 & 4.388 & 1.233 & 0.118 & 1.077 & 6.669 & 1.345 & 0.8 & 2.048 & 1.772 & 0.672 & 0.127 & 2.952 & 0.318 \\
\hline & & 0.392 & 0.119 & 0.889 & 0.715 & 0.957 & 0.289 & 0.425 & 1.51 & 0.248 & & 3.719 & 4.796 & 0.258 & 5.434 & 2.18 & 0.443 & .581 & 1.328 & 2.465 & 0.428 & 1.181 & 10.595 & 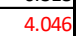 \\
\hline & TAsb $10 \mu \mathrm{g}$ & 0.274 & 0.261 & 0.328 & 0.267 & 0.307 & 0.395 & 0.83 & 0.206 & 0.656 & 2.524 & 1.638 & 5.549 & 0.226 & 30.327 & 0.591 & 0.461 & 0.631 & 0.88 & 3.59 & 1.051 & .652 & 32.301 & 14 \\
\hline
\end{tabular}




\subsubsection{Lung histopathology}

At both time-points microscopic sections in the control group revealed normal histology of conductive and respiratory airways. Exposure of $A / J$ mice to the studied EMPs led to appearance of chronic inflammatory aggregates in parenchymal, peribronchial, perivascular, and subpleural locations (Table 4.2.). All aggregates were composed of various sized mononuclear cells (lymphocytes and histiocytes). No polymorphonuclear cells (neutrophils, basophils, eosinophils) were appreciated. In Control animals these lymphohistiocytic aggregates (LHA) were rare, and either parenchymal or subpleural (see Table 4.2). In Riebeckite and Tremolite groups LHA were present in all cases in different locations. Further evaluation of cellular composition of these aggregates was be achieved by immunohistochemical analysis. Some infiltrates in asbestos-treated animals contained ferruginous bodies.

Table 4.2. Lymphohistiocytic aggregates findings in the mouse lungs at 1 -year postexposure time point. CF- cleavage fragments, LD - low dose.

\begin{tabular}{|c|c|c|c|c|c|c|}
\hline & Total & Neg & Subpleural & Parenchymal & Peribronch & Perivascul \\
\hline Control & 20 & 17 & 2 & 1 & 0 & 0 \\
\hline Riebeckite asbestos & 15 & 7 & 5 & 1 & 6 & 1 \\
\hline Riebeckite CF & 14 & 6 & 3 & 1 & 3 & 1 \\
\hline Tremolite asbestos & 16 & 4 & 2 & 5 & 3 & 2 \\
\hline \begin{tabular}{c} 
Tremolite CF \\
\hline Riebeckite asbestos LD
\end{tabular} & 14 & 6 & 0 & 4 & 4 & 1 \\
\hline Tremolite asbestos LD & 8 & 3 & 1 & 0 & 1 & 2 \\
\hline
\end{tabular}

The slides were also analyzed for a presence of fibroproliferative and neoplastic pulmonary lesions, such as adenomatous hyperplasia, adenoma, and adenocarcinoma (Table 4.3.). Adenomatous hyperplasia sites were characterized by epithelialization of alveolar walls by rounded low cuboidal cells with uniform, variably atypical nuclei, scant cytoplasm, and minimal mitotic figures. They were small lesions, ranging 0.1-0.2 mm in size (Figure 4.2. A). The margins were irregular and indiscrete but there was no compression of adjacent parenchyma and no obliteration of alveolar spaces. Adenomas were typically spherical in appearance, ranging $0.3-1 \mathrm{~mm}$ in size, and exhibited a mild 
to moderate loss of normal architecture by the proliferating cells (Figure 4.2, B). Adenoma cells were generally well differentiated but had some pleomorphism. contained a central round to oval nucleus and a moderate amount of eosinophilic stained cytoplasm and distinct cell margins. Compression of adjacent lung parenchyma was present in varying degrees. Adenocarcinomas were ranging in size from 0.5 to $5 \mathrm{~mm}$ and demonstrated a complete loss of alveolar structure (Figure 4.2, $\mathrm{C}$ and D.). Compression of adjacent lung parenchyma and invasion into adjacent parenchyma and bronchioles occurred frequently. The cells had varying degrees of differentiation and formed papillary, solid, and mixed architectural patterns.
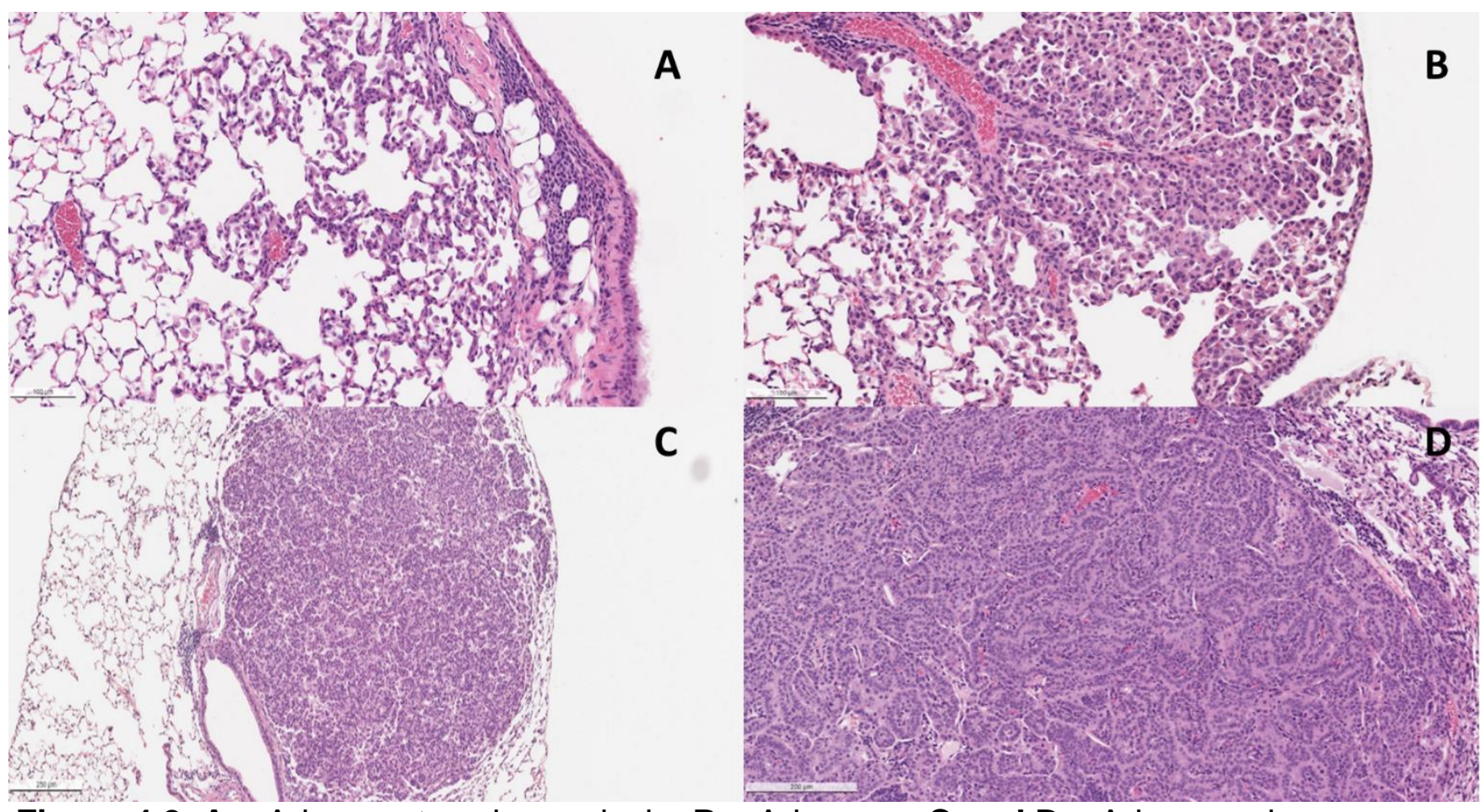

Figure 4.2. A - Adenomatous hyperplasia. B - Adenoma. C and D - Adenocarcinoma. All slides have H\&E staining.

Carcinoma cells were pleomorphic, showed nuclear hyperchromasia and had varying degrees of nuclear crowding and mitotic figures. Altogether, in control group $(n=20) 19$ cases were negative for neoplasia, and one case showed small adenocarcinoma (0.5 $\mathrm{mm}$ ). In $120 \mu \mathrm{g}$ RAsb group ( $\mathrm{n}=15) 9$ cases were negative for neoplasia, 3 cases showed adenoma, 3 cases showed adenocarcinoma ( $1 \mathrm{~mm}, 5 \mathrm{~mm}$, and $5 \mathrm{~mm}$ ). In $30 \mu \mathrm{g}$ RAsb group ( $n=8$ ) one cases was positive for adenomatous hyperplasia. In riebeckite CF group $(n=15) 12$ cases were negative for neoplasia, 1 case showed adenoma, 1 case showed 
adenocarcinoma (1 mm). In $120 \mu \mathrm{g}$ TAsb 1-year post-exposure group ( $\mathrm{n}=16) 7$ cases were negative for neoplasia, 7 cases showed adenomatous hyperplasia, 1 case showed adenoma, and 1 case showed adenocarcinoma ( $5 \mathrm{~mm})$. In $10 \mu \mathrm{g}$ TAsb $(\mathrm{n}=8)$ at 1 year 5 cases were negative for neoplasia, 2 showed adenomatous hyperplasia, 1 showed adenoma. In tremolite CF-exposed animals at 1-year time-point $(n=14) 12$ cases were negative for neoplasia, and 2 cases showed adenocarcinoma ( $3 \mathrm{~mm}, 2.5 \mathrm{~mm}$ ). Altogether, the incidence of spontaneous carcinogenesis in our $\mathrm{A} / \mathrm{J}$ mice by 1 year was low ( 1 of 20 cases $-5 \%$ ).

Table 4.3. Neoplastic lesions in the mouse lungs at 1-year post-exposure time point. CF- cleavage fragments. LD - low dose.

\begin{tabular}{|c|c|c|c|c|c|}
\hline & Total & Negative & $\begin{array}{c}\text { Adenomatous } \\
\text { hyperplasia }\end{array}$ & Adenoma & Adenocarcinoma \\
\hline Control & 20 & 19 & 0 & 0 & 1 \\
\hline Riebeckite asbestos & 15 & 9 & 0 & 3 & 3 \\
\hline Riebeckite CF & 14 & 12 & 0 & 1 & 1 \\
\hline Tremolite asbestos & 16 & 7 & 7 & 1 & 1 \\
\hline Tremolite CF & 14 & 11 & 1 & 0 & 2 \\
\hline Riebeckite asbestos LD & 8 & 5 & 2 & 1 & 0 \\
\hline Tremolite asbestos LD & 8 & 7 & 1 & 0 & 0 \\
\hline
\end{tabular}

Hyperplastic sites in asbestos-treated animals were characterized by the presence of mild fibrosis, including as seen on the slides stained with Masson trichrome (Fig.4.3.). Cleavage fragments, both riebeckite and tremolite did not cause detectable fibroproliferation (Fig.4.4.). 


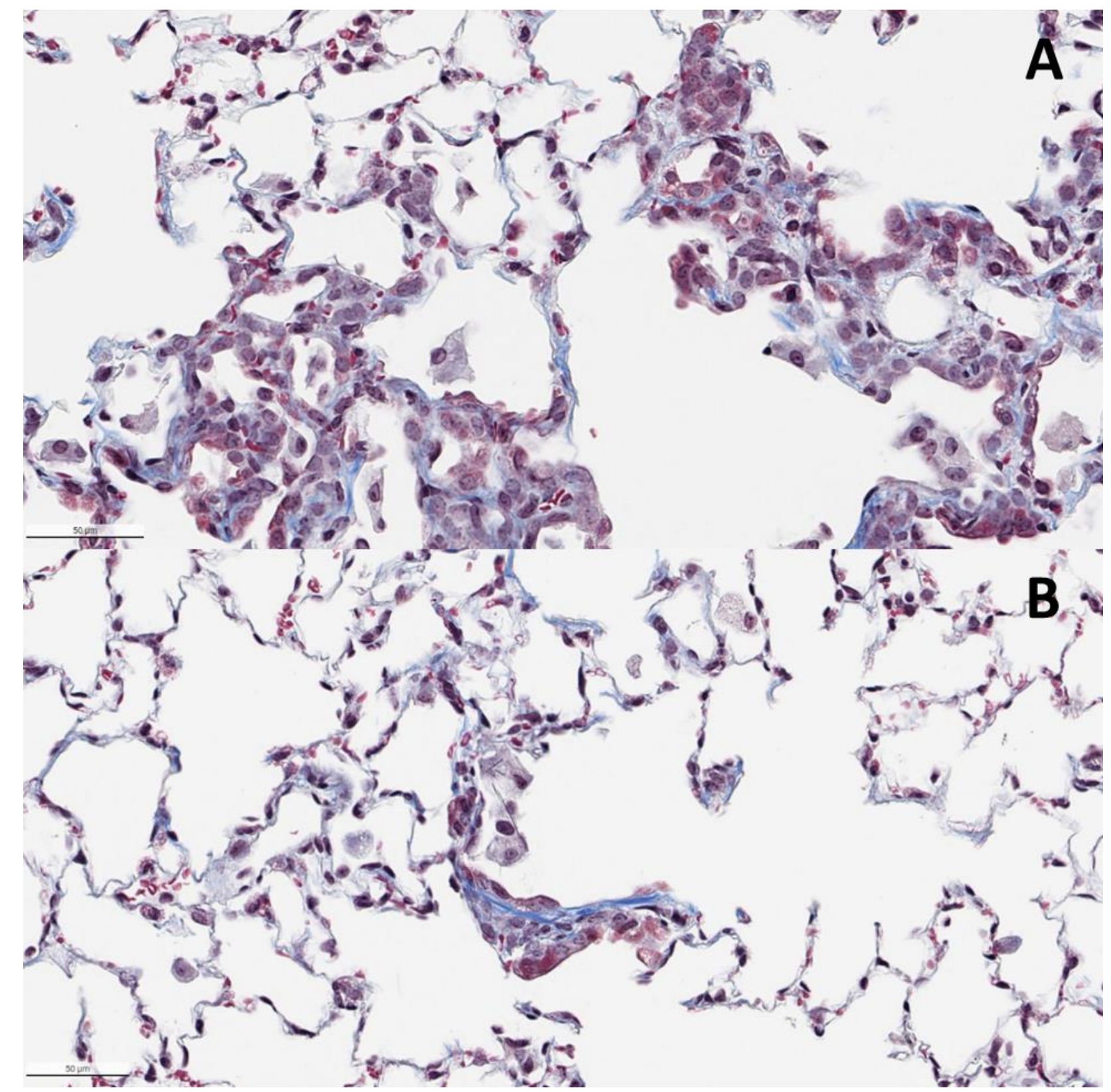

Figure 4.3. A -Multifocal adenomatous hyperplasia with mild fibrosis (blue staining). Tremolite asbestos-treated animal. B -Focal type II pneumocyte hyperplasia and mild alveolar septal fibrosis (blue staining). Riebeckite asbestos-treated animal. Both slides stained with Masson trichrome. 


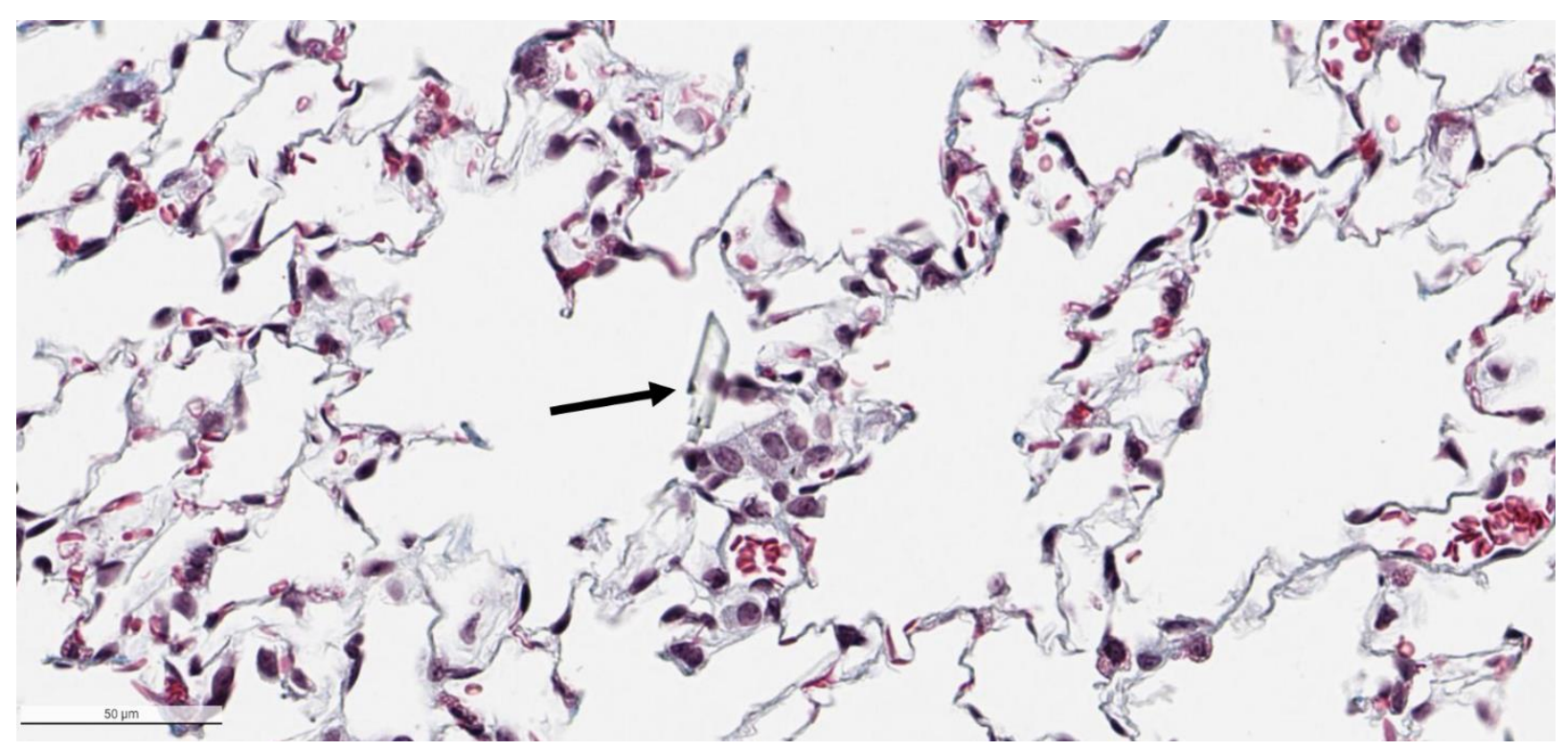

Figure 4.4. Tremolite CF-treated animal. Arrow points at the singular cleavage fragment with no fibrosis. Masson trichrome staining.

\subsubsection{Lung immunohistochemistry}

Intense ARG1 staining was revealed in macrophages that phagocytosed or surrounded asbestos fibers, but not cleavage fragments (Figure 4.5.). AMs in tumor-bearing animals also exhibited increased staining. No marked iNOS protein expression was observed in macrophages in any of the slides, except the one containing large adenocarcinoma.

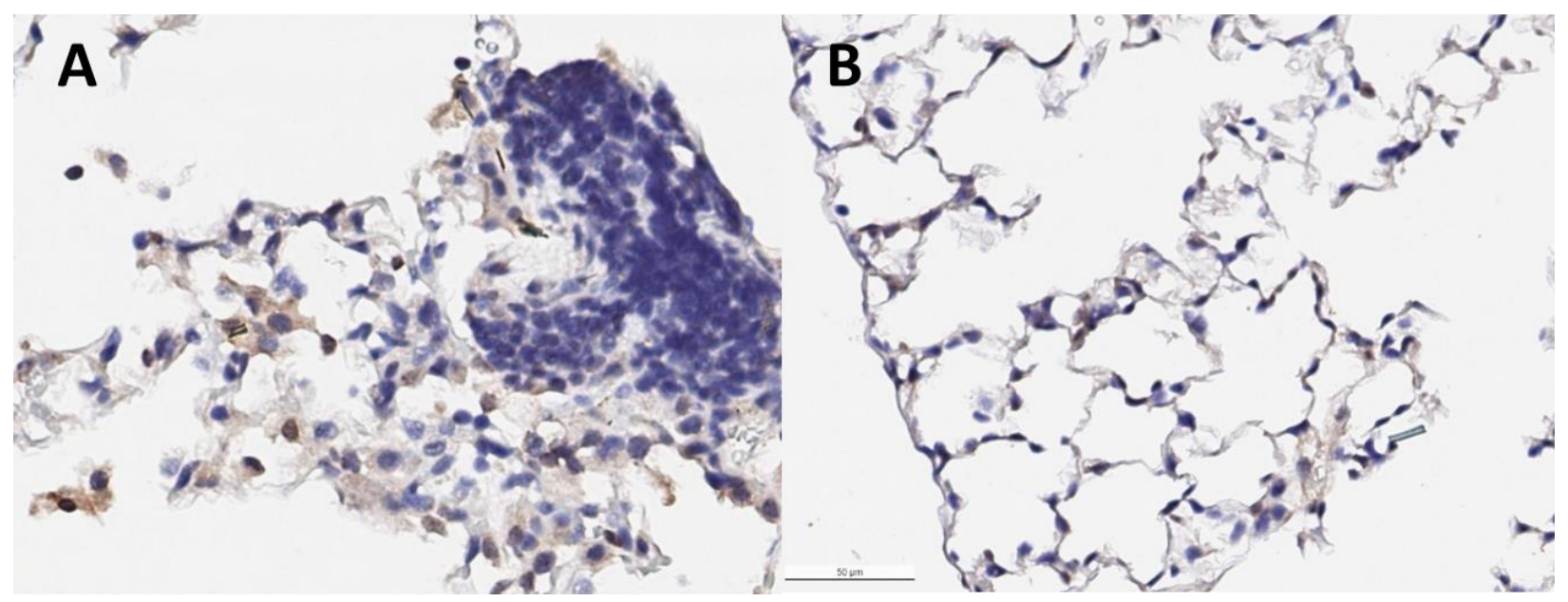

Figure 4.5. Macrophages containing riebeckite and tremolite asbestos fibers were stained positive for ARG1 (A); CF-treated animals did not exhibit much staining (B).

Foci of $\mathrm{yH} 2 \mathrm{AX}$ staining were found in asbestos-treated animals, but not cleavage fragments (Figures 4.6). 


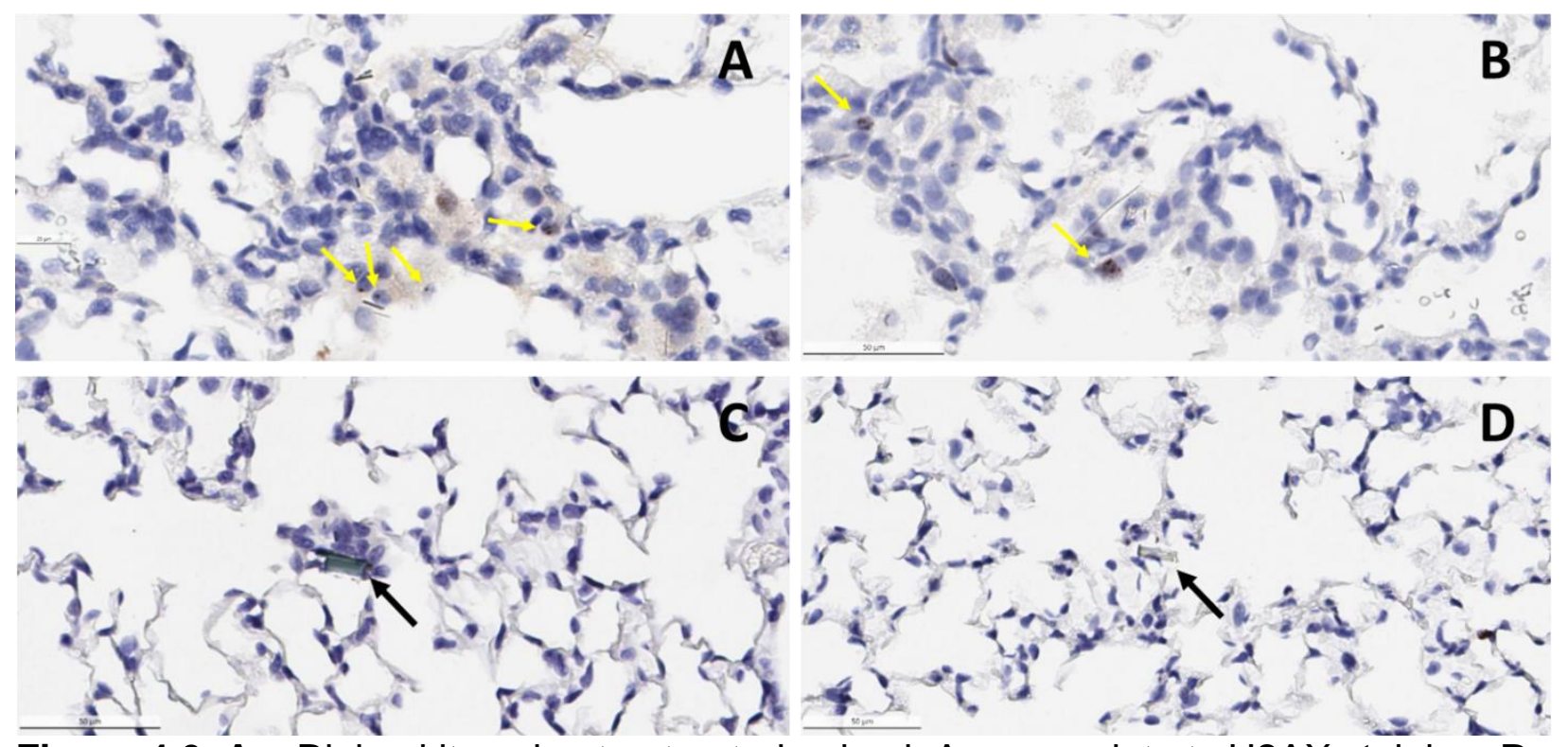

Figure 4.6. A - Riebeckite asbestos-treated animal. Arrows point at $\mathrm{\gamma H} 2 \mathrm{AX}$ staining. $\mathbf{B}$ Tremolite asbestos-treated animal. Arrows point at $\mathrm{yH} 2 \mathrm{AX}$ staining. $\mathbf{C}-$ Riebeckite CFtreated animal. Arrow points at a singular CF. No yH2AX staining to be found. D Tremolite CF-treated animal. Arrow points at a singular CF. No yH2AX staining to be found.

\subsubsection{Flow Cytometric analysis of the immune cell subsets}

The most prominent change included depletion of alveolar macrophage populations in comparison to other non-lymphocytic cells at both time points (Figure 4.6.A). This relative depletion could be seen across all asbestos groups, but not cleavage fragments. At the same time, number of AMs expressing CD11b on the cell surface increased in treated groups, in asbestos-treated animals only at 3 months, and in all treated groups at 12 months (Figure 4.7.B). 

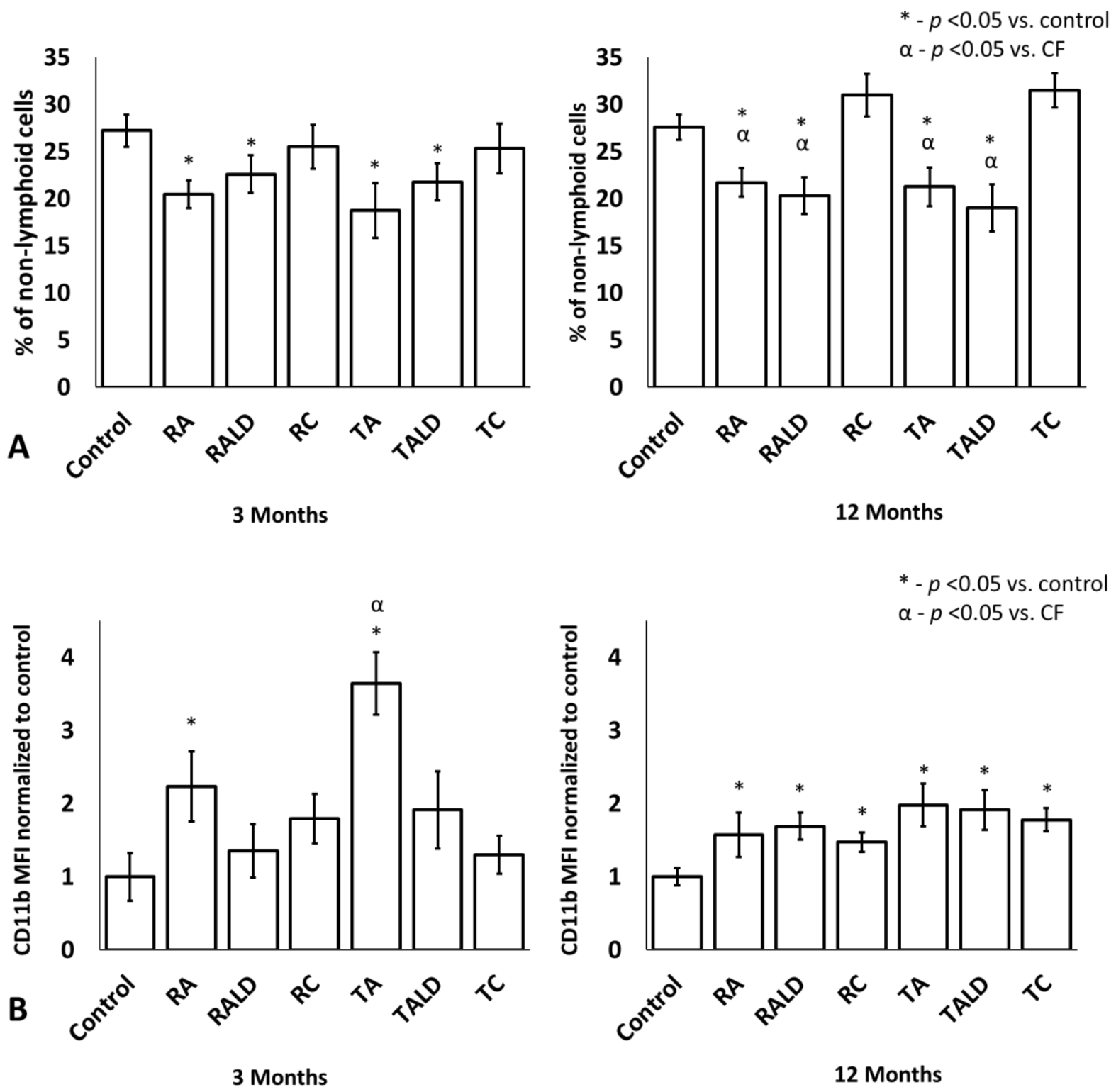

Figure 4.7. A - Alveolar Macrophage population in the mouse lungs, as a \% of nonlymphocytic cell, at 3- and 12-months' time points. B - Mean Fluorescence Intensity of CD11b surface marker in gated Alveolar Macrophages at 3- and 12-months' time points.

RA - Riebeckite asbestos, RALD - Riebeckite asbestos low dose, RC - Riebeckite cleavage fragments, TA - Tremolite asbestos, TALD - Tremolite asbestos low dose, TC - Tremolite cleavage fragments.

Relative number of eosinophils went up for riebeckite asbestos-treated groups at 3 months and persisted in the $120 \mu \mathrm{g}$ RAsb group until 1 year (Figure 4.8). Neutrophils, at the same time were elevated at 3 months in all groups except $10 \mu \mathrm{g}$ TAsb, but dropped down by 12 months post exposure, even below control values (Figure 4.9). 


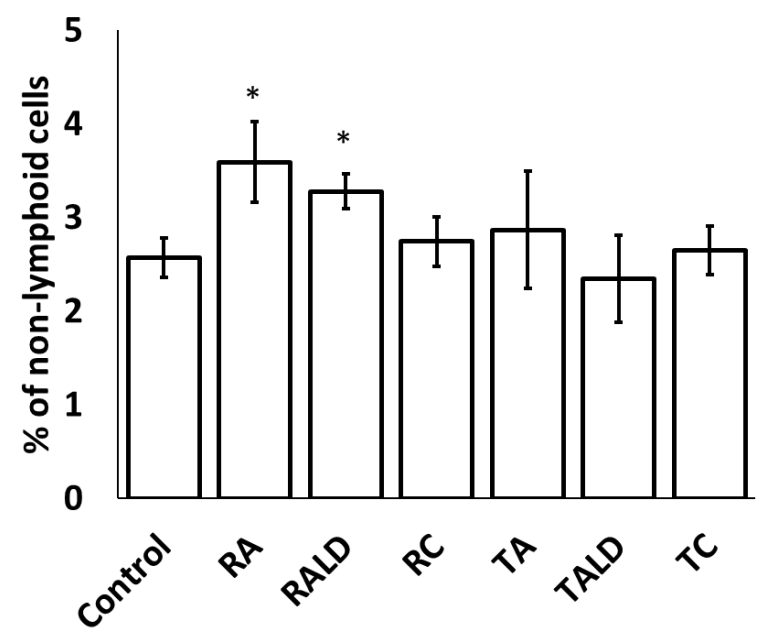

3 Months

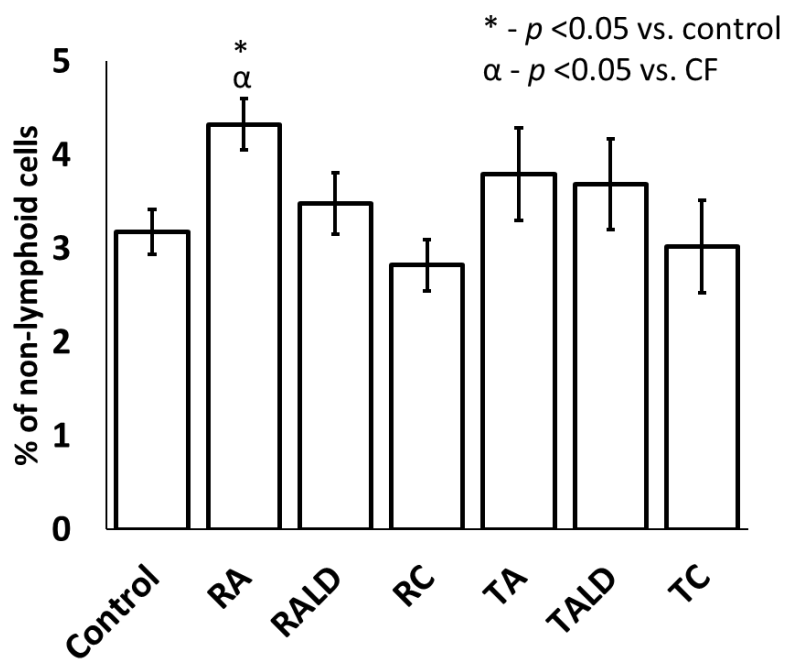

12 Months

Figure 4.8 Eosinophil populations in the mouse lungs, as a \% of non-lymphocytic cell, at 3- and 12-months' time points. RA - Riebeckite asbestos, RALD - Riebeckite asbestos low dose, $\mathrm{RC}$ - Riebeckite cleavage fragments, TA - Tremolite asbestos,

TALD - Tremolite asbestos low dose, TC - Tremolite cleavage fragments.
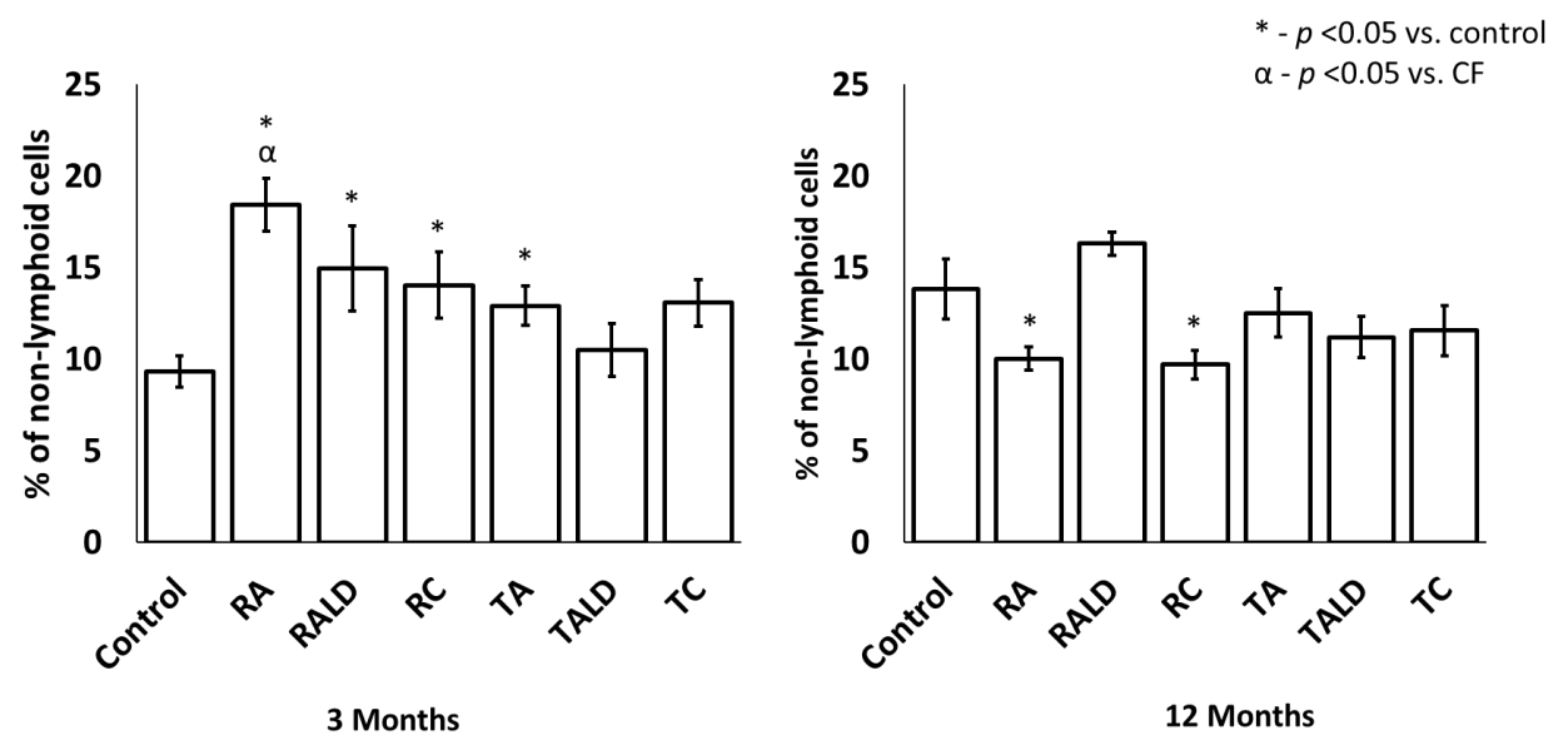

Figure 4.9. Neutrophils populations in the mouse lungs, as a \% of non-lymphocytic cell, at 3- and 12-months' time points. RA - Riebeckite asbestos, RALD - Riebeckite asbestos low dose, $\mathrm{RC}$ - Riebeckite cleavage fragments, TA - Tremolite asbestos, TALD - Tremolite asbestos low dose, TC - Tremolite cleavage fragments. 
At 3 months we were able to detect significant influx of monocytes in all $120 \mu \mathrm{g}$ asbestos- and CF-treated groups, with the biggest and statistically significant contribution of regulatory monocytes (CD11b+, Ly6C-) (Figure 4.10).

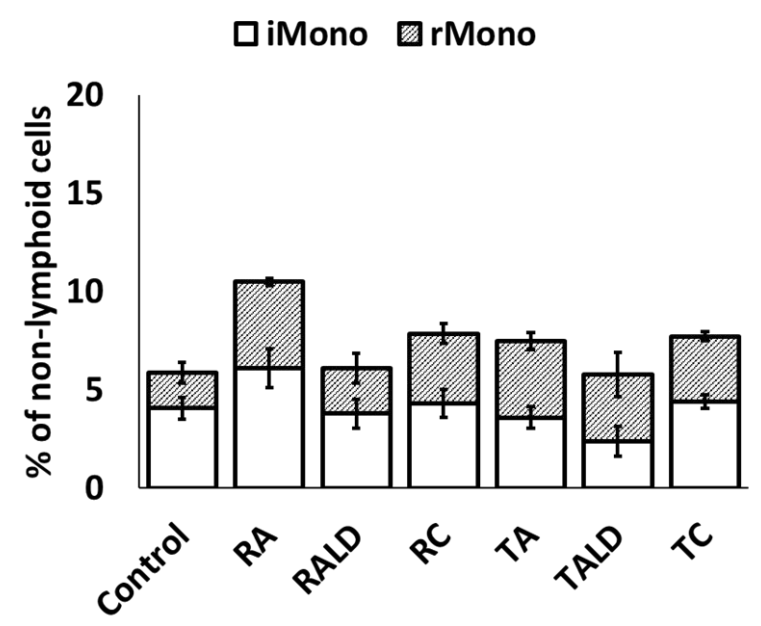

3 Months

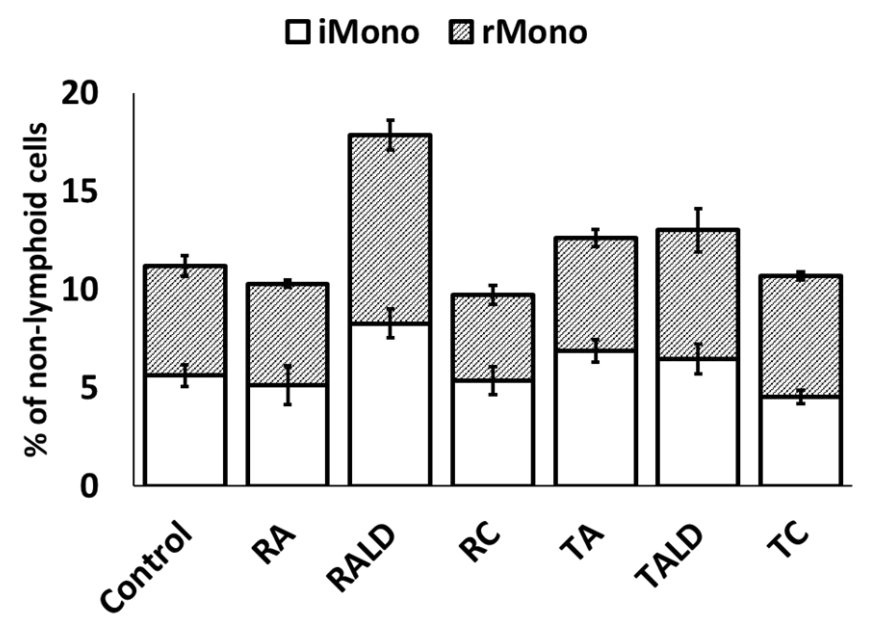

12 Months

Figure 4.10. Inflammatory (iMono) and regulatory (rMono) monocyte populations in the mouse lungs, as a \% of non-lymphocytic cell, at 3- and 12-months' time points. RA Riebeckite asbestos, RALD - Riebeckite asbestos low dose, RC - Riebeckite cleavage fragments, TA - Tremolite asbestos, TALD - Tremolite asbestos low dose, TC Tremolite cleavage fragments.

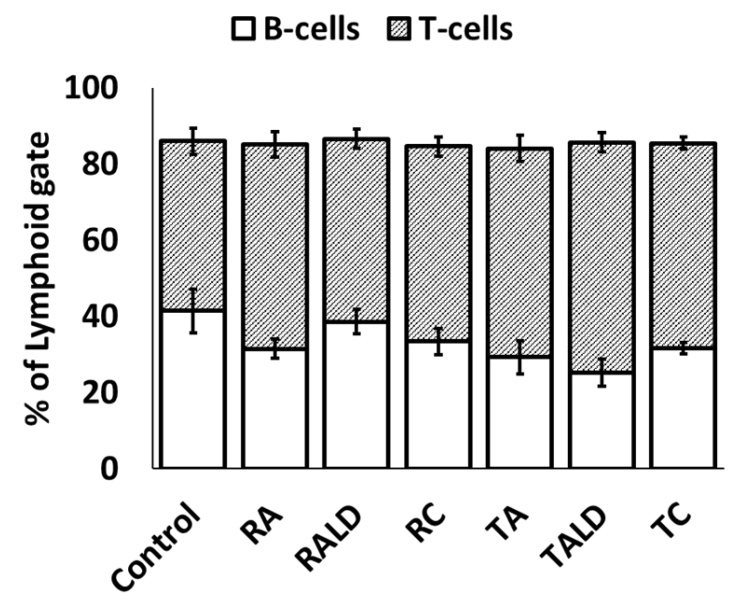

3 Months

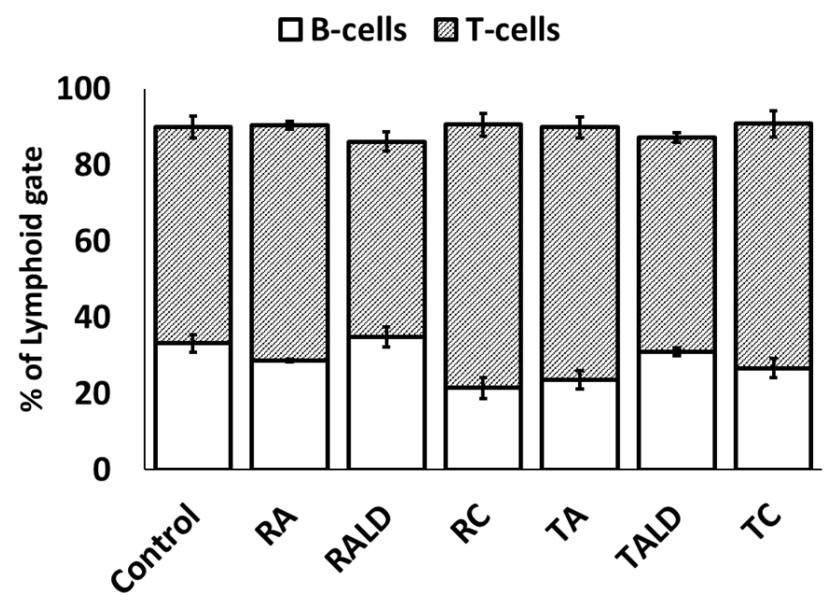

12 Months

Figure 4.11. B- and T-Cell populations in the mouse lungs, as a \% of lymphocytes in the appropriate gate, at 3- and 12-months' time points. RA - Riebeckite asbestos, RALD - Riebeckite asbestos low dose, RC - Riebeckite cleavage fragments, TA - 
Tremolite asbestos, TALD - Tremolite asbestos low dose, TC - Tremolite cleavage fragments.

In the lymphoid cell populations, major finding included relative increase of the Tcells and decrease in B-cells in asbestos-treated groups. This pattern persisted until 1 year, with RC-treated animals also exhibiting similar responses (Figure 4.11).

\subsection{Discussion}

Verified studies established a structure-activity relationship paradigm for long and thin particles with high aspect ratio. Several other factors, including chemistry, shape, surface characteristics as well as duration, frequency of exposures and individual susceptibility are also implicated in pathogenicity. Substantial evidence exists, that alterations of the immune system functions play important role in the development of asbestos pathology. For instance, lung cancer and mesothelioma following pulmonary exposure to all types of asbestos, are directly associated with immunosuppression [11]. Autoimmunity is also an issue - the impairment of phagocytic function, constant recruitment of neutrophils and cellular damage can lead to an increased secretion of host-derived antigens, that drive the autoantibodies production upon exposure to asbestos [12]. Since carcinogenesis is a lengthy process, it is quite hard to model it in short-living animals, such as most rodents. For instance in asbestos-exposed humans, decades are needed for developing lung cancer or mesothelioma $[13,14]$. The pattern of cancer progression in susceptible A/J mice follows specific path: hyperplasia to adenoma to adenocarcinoma [15]. Lung tumorigenesis is under complex genetic control involving the pulmonary adenoma susceptibility 1 (Pas1) locus and Kras [16]. In humans, Kras mutations are common in lung adenocarcinoma [17]. A/J mice were used previously in the studies of tobacco smoke-induced and welding fumes-induced carcinogenesis $[18,19]$. More so, in most cases, both human and $\mathrm{A} / \mathrm{J}$ mouse lung tumors originate from atypical hyperplastic lesions in the periphery of the lung [20]. A/J mice have higher basal cells count in the large airways - thus repair after initial injury is more effective. However, it may also contribute to the non-genotoxic tumor progression mechanisms.

Our preliminary in vivo study comparing acute pulmonary effects of several asbestiform EMPs, including tremolite and riebeckite asbestos, revealed differential 
innate inflammatory responses. For instance, it was found that tremolite elicited inflammatory responses with polymorphonuclear leukocytes (PMN) influx peaking at day 1 and eosinophil response at day 7 post-exposure. In contrast, exposure to riebeckite asbestos fibers induced a "delayed" inflammatory response with maximal influx of PMNs and eosinophils occurring on day 7 post exposure [21]. Current study focused on the longterm effects of EMP exposure, including 3- and 12-months post-exposure time points.

Neoplastic manifestations were evaluated at 1 year after exposure. A/J mice are prone to developing spontaneous lung tumors, however the deaths caused by tumors were usually seen after 1 year in previous studies [8, 22]. Histopathological examination of lung tumors revealed riebeckite asbestos as having a prominent oncogenic potential, affecting 6 of 15 animals (40\%). Proneoplastic potential was also high in tremolite asbestos, affecting 9 of 16 animals (56\%), although majority of the lesions were of lower grade compared to riebeckite. Riebeckite and Tremolite cleavage fragments did not have significantly increased number of neoplastic lesions. Only one mouse, exposed to tremolite asbestos developed mesothelial reaction. In asbestos-treated animals we could still clearly see EMP-laden macrophages 1 year post-exposure. Areas of EMP deposition were characterized by cell hyperplasia, mild alveolar septal fibrosis and immune cell infiltration, however, no extensive lung fibrosis was observed. This is probably a characteristic of $\mathrm{A} / \mathrm{J}$ mice, which have been shown to be resistant to bleomycin-induced lung fibrosis as well [23, 24]. Several incidents of squamous metaplasia were observed, which is one of the outcomes triggered by EMPs that is hypothesized to give rise to lung cancer [25]. Cleavage fragments provoked very little histological changes and were mostly found inside the alveoli with occasional AM next to it.

Immunohistochemistry allowed locating and assessing some of the changes, including specific immune cell subsets, such as ARG1 and iNOS-positive macrophages, B-lymphocytes, CD4, CD8 T-cells and Tregs.. Acute asbestos exposure was previously shown to upregulate iNOS [26], but we did not observe increase in iNOS (NOX2) macrophage staining via IHC in any group, which, together with no increase in other accompanying proinflammatory markers, such as TNF-alpha probably means that by 1 year no active inflammation is present. Myeloid Arginase 1 was shown to be responsible 
for arginine depletion related immune suppression in cancer, and we have seen increased staining in macrophages containing asbestos EMPs as well as in macrophage of animals with lung tumors. Number of T-cells, positive for FOXP3 marker was evidently higher in the asbestos-treated groups, often inside the lymphohystiocytic infiltrates and near the visible asbestos fibers.

There is an indication that asbestos-initiated chronic oxidative stress contributes to carcinogenesis and fibrosis by promoting oxidative DNA damage and regulating redox signaling pathways [27-31]. We used anti $\mathrm{yH} 2 \mathrm{AX}$ antibody to assess the potential for increased DNA double strand breaks occurrence in the exposed animals and Foci of $\mathrm{yH} 2 \mathrm{AX}$ staining were found in the vicinity of asbestos EMPs, in AMs, epithelial and lymphoid cells, while cleavage fragments did not induce significant DNA double strand breaks in vivo as shown by $\mathrm{pH} 2 \mathrm{AX}$ staining. It has to be noted that cells do not have to be phagocytosing or be in contact with asbestos fibers capable of promoting the redox reactions. DNA damage can occur through several mechanisms other than direct reactive surface-biomolecule interaction, i.e. through the oxidized lipid derivatives, arachidonic acid pathways or self-produced ROS and reactive nitrogen species [32].

By performing complete cytokine panel assessments in the lungs of the exposed animals, we were able to infer some specific immune response polarization patterns. Increased ARG1 staining in association with elevated IL-3, IL-4, and IL-5 cytokines levels

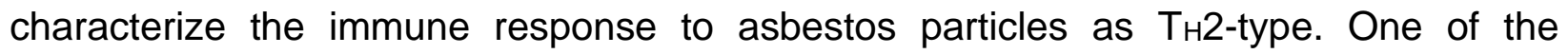
interesting observations included CF-treated, but not asbestos-treated animals showing the highest IL-2 levels and relative increase in T-lymphocyte populations at 12 months compared to control. IL-9 was elevated in all but one treatment groups. There are speculations that IL-9 has antifibrotic action and may shift the response away from $\mathrm{TH}_{\mathrm{H}} \mathrm{2}$ [33]. However, more recent studies argue that IL-9 is probably directly implicated in the

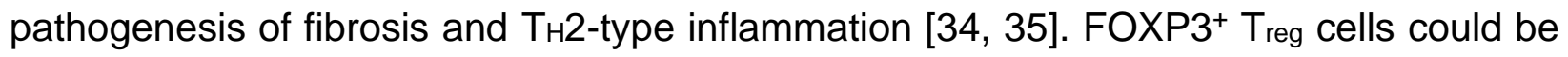
recruited to control inflammatory and effector T-cells-induced fibrotic responses. Persistent accumulation of immunosuppressive $T_{\text {reg }}$ cells in the lungs may contribute to pulmonary fibrosis by stimulating fibroblasts through the secretion of platelet-derived growth factor (PDGF)-B via a TGF- $\beta$ autocrine signaling pathway [36]. At the same time, 
Treg accumulation is what leads to the inflammation resolve. The balanced response thus is critical for positive outcome. Different asbestos fibers with different morphology and chemistry have been shown to activate NLRP-3 inflammasome through different mechanisms [37-40]. This inflammasome participates in initial inflammatory response and the chronic inflammatory conditions arising in fiber exposure settings, including driving of the IL-17 responses [41], implicated in amphibole asbestos pathogenicity [42] and specifically in the associated reduction in antitumor immunity [43]. We have not observed increased IL-1 $\beta$ production in treated animals, but IL-17 was significantly higher in riebeckite asbestos-treated animals at 12 months.

To supplement the IHC findings and cytokine data, imaging flow cytometry was used to analyze single cell suspensions from enzymatically digested mouse lungs. Imaging FC is a relatively new method, which requires slightly different approach to sample preparation, data acquisition, fluorescence compensations, compared to the nonimaging flow cytometers, and requires special software for data analysis. However, it allows to clearly distinguish between different gated events, and observe the actual fibers present, on their own or in the cells. In our study asbestos EMPs caused more drastic changes in the pulmonary immune cell populations in mice at the same mass doses compared to cleavage fragments. There was relative depletion of resident AMs, expressing high Siglec-F surface marker, and negative for CD11b molecule, observed in all asbestos-treated groups at 3 months, and persisting at 1-year time point. In all treated groups MFI of CD11b on AM surface was higher than control, due to the incoming monocytes giving origin to new AMs (CD11 $\mathrm{b}^{\text {High }}$, Siglec-Flow), and upregulation of CD11b by the resident AMs, with two distinct populations distinguishable on scatter plots at 12 months. AM death through necrosis/necrosis/apoptosis is implicated hugely in asbestosis progression [44]. Accordingly, changes in the population of AMs, which have a long turnover rate in mice [45] may lead to recruitment of phagocytes that actively participate in clearance mechanisms, proinflammatory and pro/antifibrotic signaling, contributing to the polarization of immune response. The CD11b marker was shown to characterize different stages of pulmonary inflammation [46, 47], and is proposed as a target for therapeutical interventions [48, 49]. However, in humans CD11b expression on AMs is not dichotomic, but follows rather a continuous distribution. This complicates the process 
of CD11b MFI evaluation and comparisons in humans, but it is possible to reliably compare CD11b marker expression pattern using a reference neutrophils expression values [48].

Although it has previously been noticed that in humans asbestos exposure increases the number of macrophages in the lungs [50]. this relative increase, however, may turn to depletion with time if resolution of inflammation is not achieved. AM depletion can enhance antigen-presenting function of resident phagocytes (parenchymal dendritic cells) and their migration, leading to re-activation of the T-cells [51]. Relative increase in T-cells seen in almost all groups should be regarded with caution as well, since they are the major players in immune response polarization, contributing to fibrosis, autoimmunity and/or resolution [52]. There was no statistically significant increase in PMN content detected by FC. Histopathology also did not reveal significant PMN presence. However, even if the overall number of PMNs did not change much, Kamp et al. (1994) have shown that PMNs are facilitating epithelial cell apoptosis, promoting the lung injury through, while AMs have protective role [53], thus changes in relative abundances may also have longterm implications. Eosinophils count was higher in riebeckite asbestos-treated animals, something previously observed in animal models and humans exposed to asbestos [54, 55]. By 12 months there was also increased eotaxin production in the mouse lungs. Eosinophils are known to facilitate lymphocytes-driven $\mathrm{TH}_{\mathrm{H}}$-type response. Altogether, we could see that in all treated groups resident AM population was supplemented with incoming CD11b positive cells. Apparently, this was more "successful" in CF-treated animals, but not in the asbestos-treated and the depletion of resident AMs only exacerbated the pathologic process, accompanied by the influx of eosinophils, increase of TH2 type cytokines and Treg cells. While changes were more severe at 3 months, by 12 months the whole alternative activation process was only partially alleviated, with the response shifted towards TH2-type. This comes to no surprise and correspond to the historical data.

\subsection{Conclusions}

Exposure to asbestiform and non-asbestiform EMPs led to discrete pulmonary immune responses at 3 - and 12-months post-exposure, leading to specific long-term 
fibroproliferative and carcinogenic outcomes. Of all tested articles, riebeckite and tremolite asbestos exposures were indicative of a chronic inflammation and possible $\mathrm{TH}_{\mathrm{H}} \mathrm{-}$ or TH17-type polarization. Asbestos induced a distinct immune response pattern, and a much stronger response than cleavage fragments at mass- and surface area-equivalent doses, including the evidence for continuing DNA damage as elucidated by $\mathrm{Y}-\mathrm{H} 2 \mathrm{AX}$ foci findings. The studied cleavage fragments were not as potent as asbestos in driving the fibroproliferation and cancer, most likely due to the lack of resident AM depletion. The results of this study call for further investigations of the immune cell population dynamics and contributions to the expression development of long-term carcinogenic and noncarcinogenic outcomes following exposures to various EMPs. Such approaches can aid in providing mechanistic insights into the human exposure scenario and mechanisms involved in potential human disease following inhalation exposures to EMP.

\subsection{References}

1. Hesterberg, T.W. and J.C. Barrett, Dependence of Asbestos-Induced and Mineral Dust-Induced Transformation of Mammalian-Cells in Culture on Fiber Dimension. Cancer Research, 1984. 44(5): p. 2170-2180.

2. Baur, X., et al., Asbestos, asbestosis, and cancer: The Helsinki criteria for diagnosis and attribution. Critical need for revision of the 2014 update. Am J Ind Med, 2017. 60(5): p. 411-421.

3. Kim, S.J., et al., The Role of Mitochondrial DNA in Mediating Alveolar Epithelial Cell Apoptosis and Pulmonary Fibrosis. Int J Mol Sci, 2015. 16(9): p. 21486-519.

4. Hamilton, R.F., L.L. lyer, and A. Holian, Asbestos induces apoptosis in human alveolar macrophages. Am J Physiol, 1996. 271(5 Pt 1): p. L813-9.

5. Bissonnette, E. and M. Rola-Pleszczynski, Pulmonary inflammation and fibrosis in a murine model of asbestosis and silicosis. Possible role of tumor necrosis factor. Inflammation, 1989. 13(3): p. 329-39.

6. Bozelka, B.A., et al., A murine model of asbestosis. Chest, 1983. 83(5 Suppl): p. 9S-10S.

7. Park, E.J., et al., Fibrous nanocellulose, crystalline nanocellulose, carbon nanotubes, and crocidolite asbestos elicit disparate immune responses upon pharyngeal aspiration in mice. J Immunotoxicol, 2018. 15(1): p. 12-23.

8. Koizumi, A., et al., Energy restriction that inhibits cellular proliferation by torpor can decrease susceptibility to spontaneous and asbestos-induced lung tumors in A/J mice. Lab Invest, 1993. 68(6): p. 728-39.

9. Shvedova, A.A., et al., Inhalation vs. aspiration of single-walled carbon nanotubes in C57BL/6 mice: inflammation, fibrosis, oxidative stress, and mutagenesis. Am J Physiol Lung Cell Mol Physiol, 2008. 295(4): p. L552-65. 
10. Castranova, V., P.A. Schulte, and R.D. Zumwalde, Occupational nanosafety considerations for carbon nanotubes and carbon nanofibers. Acc Chem Res, 2013. 46(3): p. 642-9.

11. Muhle, H. and F. Pott, Asbestos as reference material for fibre-induced cancer. Int Arch Occup Environ Health, 2000. 73 Suppl: p. S53-9.

12. Pfau, J.C., K.M. Serve, and C.W. Noonan, Autoimmunity and asbestos exposure. Autoimmune Dis, 2014. 2014: p. 782045.

13. Carbone, M., et al., Malignant mesothelioma: facts, myths, and hypotheses. Journal of cellular physiology, 2012. 227(1): p. 44-58.

14. Uguen, M., et al., Asbestos-related lung cancers: $A$ retrospective clinical and pathological study. Molecular and clinical oncology, 2017. 7(1): p. 135-139.

15. Witschi, H., The complexities of an apparently simple lung tumor model: The A/J mouse. Exp Toxicol Pathol, 2005. 57 Suppl 1: p. 171-81.

16. Gariboldi, M., et al., A major susceptibility locus to murine lung carcinogenesis maps on chromosome 6. Nat Genet, 1993. 3(2): p. 132-6.

17. Rodenhuis, S., et al., Incidence and possible clinical significance of K-ras oncogene activation in adenocarcinoma of the human lung. Cancer Res, 1988. 48(20): p. 5738-41.

18. Solano-Lopez, C., et al., Welding fume exposure and associated inflammatory and hyperplastic changes in the lungs of tumor susceptible a/j mice. Toxicol Pathol, 2006. 34(4): p. 364-72.

19. Falcone, L.M., et al., Inhalation of gas metal arc-stainless steel welding fume promotes lung tumorigenesis in A/J mice. Arch Toxicol, 2017. 91(8): p. 29532962.

20. Belinsky, S.A., S.A. Stefanski, and M.W. Anderson, The A/J Mouse Lung as a Model for Developing New Chemointervention Strategies. 1993. 53(2): p. 410416.

21. Yanamala, N., et al., Characterization of pulmonary responses in mice to asbestos/asbestiform fibers using gene expression profiles. J Toxicol Environ Health A, 2018. 81(4): p. 60-79.

22. Zeidler-Erdely, P.C., et al., Lung tumor production and tissue metal distribution after exposure to manual metal ARC-stainless steel welding fume in $A / J$ and C57BL/6J mice. J Toxicol Environ Health A, 2011. 74(11): p. 728-36.

23. Lemay, A.M. and C.K. Haston, Bleomycin-induced pulmonary fibrosis susceptibility genes in $A c B / B c A$ recombinant congenic mice. Physiol Genomics, 2005. 23(1): p. 54-61.

24. Paun, A., et al., Association Analysis Reveals Genetic Variation Altering Bleomycin-Induced Pulmonary Fibrosis in Mice. 2013. 48(3): p. 330-336.

25. Woodworth, C.D., B.T. Mossman, and J.E. Craighead, Induction of squamous metaplasia in organ cultures of hamster trachea by naturally occurring and synthetic fibers. Cancer Res, 1983. 43(10): p. 4906-12.

26. Dörger, M., et al., Dual role of inducible nitric oxide synthase in acute asbestosinduced lung injury. Free Radical Biology and Medicine, 2002. 33(4): p. 491-501.

27. Huang, S.X.L., et al., Role of Mutagenicity in Asbestos Fiber-Induced Carcinogenicity and Other Diseases. Journal of Toxicology and Environmental Health-Part B-Critical Reviews, 2011. 14(1-4): p. 179-245. 
28. Kamp, D.W. and S.A. Weitzman, The molecular basis of asbestos induced lung injury. Thorax, 1999. 54(7): p. 638-52.

29. Shukla, A., et al., Multiple roles of oxidants in the pathogenesis of asbestosinduced diseases. Free Radical Biology and Medicine, 2003. 34(9): p. 11171129.

30. Xu, A., et al., Mechanisms of the genotoxicity of crocidolite asbestos in mammalian cells: Implication from mutation patterns induced by reactive oxygen species. Environmental Health Perspectives, 2002. 110(10): p. 1003-1008.

31. Huang, S.X.L., et al., Mitochondria-Derived Reactive Intermediate Species Mediate Asbestos-Induced Genotoxicity and Oxidative Stress-Responsive Signaling Pathways. Environmental Health Perspectives, 2012. 120(6): p. 840847.

32. Moyer, V.D., et al., Oxygen radicals and asbestos carcinogenesis. Environ Health Perspect, 1994. 102 Suppl 10: p. 131-6.

33. Hoyle, G.W. and A.R. Brody, IL-9 and lung fibrosis: a Th2 good guy? Am J Respir Cell Mol Biol, 2001. 24(4): p. 365-7.

34. Sugimoto, N., et al., IL-9 Blockade Suppresses Silica-induced Lung Inflammation and Fibrosis in Mice. Am J Respir Cell Mol Biol, 2019. 60(2): p. 232-243.

35. Temann, U.-A., P. Ray, and R.A. Flavell, Pulmonary overexpression of IL-9 induces Th2 cytokine expression, leading to immune pathology. The Journal of clinical investigation, 2002. 109(1): p. 29-39.

36. Lo Re, S., et al., Platelet-derived growth factor-producing CD4+ Foxp3+ regulatory $T$ lymphocytes promote lung fibrosis. Am J Respir Crit Care Med, 2011. 184(11): p. 1270-81.

37. Li, M., M.E. Gunter, and N.K. Fukagawa, Differential activation of the inflammasome in THP-1 cells exposed to chrysotile asbestos and Libby "six-mix" amphiboles and subsequent activation of BEAS-2B cells. Cytokine, 2012. 60(3): p. 718-30.

38. Hillegass, J.M., et al., Asbestos and erionite prime and activate the NLRP3 inflammasome that stimulates autocrine cytokine release in human mesothelial cells. Part Fibre Toxicol, 2013. 10: p. 39.

39. Dostert, C., et al., Innate immune activation through Nalp3 inflammasome sensing of asbestos and silica. Science, 2008. 320(5876): p. 674-7.

40. Sayan, M. and B.T. Mossman, The NLRP3 inflammasome in pathogenic particle and fibre-associated lung inflammation and diseases. Part Fibre Toxicol, 2016. 13(1): p. 51.

41. Mills, K.H., et al., The role of inflammasome-derived IL-1 in driving IL-17 responses. J Leukoc Biol, 2013. 93(4): p. 489-97.

42. Ferro, A., et al., Amphibole, but not chrysotile, asbestos induces anti-nuclear autoantibodies and IL-17 in C57BL/6 mice. J Immunotoxicol, 2014. 11(3): p. 28390.

43. Maeda, M., et al., Induction of IL-17 production from human peripheral blood CD4+ cells by asbestos exposure. Int J Oncol, 2017. 50(6): p. 2024-2032.

44. Kovacikova, Z., et al., The effect of fibrous dusts on lung cells. In vitro study. Cent Eur J Public Health, 2004. 12 Suppl: p. S44-8. 
45. Maus, U.A., et al., Resident alveolar macrophages are replaced by recruited monocytes in response to endotoxin-induced lung inflammation. Am J Respir Cell Mol Biol, 2006. 35(2): p. 227-35.

46. Duan, M., et al., Distinct macrophage subpopulations characterize acute infection and chronic inflammatory lung disease. J Immunol, 2012. 189(2): p. 946-55.

47. Johnston, L.K., et al., Pulmonary macrophage subpopulations in the induction and resolution of acute lung injury. Am J Respir Cell Mol Biol, 2012. 47(4): p. 417-26.

48. Duan, M., et al., CD11b immunophenotyping identifies inflammatory profiles in the mouse and human lungs. Mucosal Immunol, 2016. 9(2): p. 550-63.

49. McCubbrey, A.L., et al., Deletion of c-FLIP from CD11b(hi) Macrophages Prevents Development of Bleomycin-induced Lung Fibrosis. Am J Respir Cell Mol Biol, 2018. 58(1): p. 66-78.

50. Spurzem, J.R., et al., Mechanisms of macrophage accumulation in the lungs of asbestos-exposed subjects. Am Rev Respir Dis, 1987. 136(2): p. 276-80.

51. Jakubzick, C., et al., Modulation of dendritic cell trafficking to and from the airways. J Immunol, 2006. 176(6): p. 3578-84.

52. Zhang, M. and S. Zhang, T Cells in Fibrosis and Fibrotic Diseases. 2020. 11(1142).

53. Kamp, D.W., et al., Contrasting effects of alveolar macrophages and neutrophils on asbestos-induced pulmonary epithelial cell injury. Am J Physiol, 1994. 266(1 Pt 1): p. L84-91.

54. Gellert, A.R., et al., Asbestosis: assessment by bronchoalveolar lavage and measurement of pulmonary epithelial permeability. Thorax, 1985. 40(7): p. 50814.

55. Robinson, B.W., et al., Alveolitis of pulmonary asbestosis. Bronchoalveolar lavage studies in crocidolite- and chrysotile-exposed individuals. Chest, 1986. 90(3): p. 396-402. 


\section{Chapter 5. Conclusions and Future Directions}

\section{1 - Conclusions}

Despite decades of research, both epidemiological and toxicological, debates regarding the potential adverse health effects of elongate mineral particles are still going on. While asbestos ban in most of the countries, and overall trend in exposure reduction instill hope, still existing and newly found cases of occupational and incidental exposures to EMPs raise new concerns. Unsolved terminological discrepancies between material and natural scientists, regulators and research agencies add to the confusion and complicate the matter further, while constant litigation battles mean that a lot of biased stakeholders are present. Asbestiform EMPs are undeniably responsible for fibrosis and cancer development in exposed humans [1]. Much less is known about non-asbestiform EMPs, such as amphibole cleavage fragments, especially if they conform to the "critical" dimensions (i.e. longer than 5 um). Some evidence for pulmonary fibrosis and extrapulmonary pathology exists, while no significant risk of mesothelioma or lung cancer is shown by current epidemiological evidence for several types of cleavage fragments (tremolite, anthophyllite, talc) [2]. It is still not feasible to name one particle characteristic the most important determinant. The importance of length was undisputed for a long time, but plenty of studies support the notion that asbestiform EMPS of all lengths can induce pathology in humans [3-5]. Particle surface area and chemical composition are also implicated in the disparity of toxicological responses[1, 6-8].

This study aimed to provide an insight into one of the knowledge gaps currently existing in the field of fiber toxicology - specifics of the immunological component of pulmonary response to inhaled EMPs of asbestiform and non-asbestiform morphologies. The principal findings from this work confirm that alveolar macrophages play a major role in responding to EMPs, and, following exposure, pulmonary immune landscape undergoes changes, that are dependent on the nature of particles in question. Both crystal growth habit and mineral composition (or type) are implicated in the outcomes.

I would like to first describe this study, highlighting strengths and limitations in the process. It was of paramount importance to obtain the test articles suitable for adequately 
addressing the knowledge gap. We chose riebeckite and tremolite amphiboles because of their similar dimensional characteristics and at the same time different chemical composition; riebeckite containing significant portion of Fe molecules in the crystal lattice. Bulk EMP samples used for the studies were all procured from the reliable sources and are relevant for the real-life exposure scenarios. The harvesting procedure, that incorporated intermittent PCM measurements during all the important steps, allowed gathering the required amounts of EMPs with the lengths of more than $5 \mu \mathrm{m}$ (Chapter 2). EMP samples were then characterized using TEM and EDS and dimensional parameters calculated to assist in doses determination for toxicological studies. The cleavage fragments harvesting/characterization approach, while being unique and providing significant benefits to toxicologists, still does not guarantee that obtained EMP populations contain more than $60 \%$ of "critical" fibers. [9]. Serpentine variety of asbestos - chrysotile - has not been evaluated in this study. Overall, artificial approach to the sample preparation is not exactly representative of the typical human exposures, but it is necessary for adequate toxicological comparisons.

Alveolar macrophages are one of the most important mediators of all immune responses in the lungs. Therefore, a significant part of the dissertation (Chapters 3 and 4) was dedicated to study macrophage-related changes. In our in vitro model (alveolar macrophage-like Max Plank Institute cells), equal mass-based doses resulted in markedly differential responses between asbestos and cleavage fragments, however, at equal fiber surface area-based doses asbestos and corresponding CF had similarities in cytotoxic effects. When we looked into the changes in gene expression, distinct transcriptional reprogramming patterns and DNA damage was observed, specific not only for the habit, but also for the mineral type, leading us to conclude that asbestiform habit itself may be an important determinant for some minerals, like tremolite. Of course, studies in vitro, do not account for the modifying effects of deposition patterns and clearance by mucociliary actions as well as contribution from biopersistence. "...what happens at the lung level is based on a population of fibers getting to the deep part of the lung and not based on one EMP interacting with one lung cell" [10]. 
In our animal model we wanted to evaluate the myeloid lineage cellular composition and humoral component of the immune response in the mouse lungs upon exposure to the tested EMPs, in relation to the histopathological changes. All EMPs were still present in the mouse lungs after 1 year, even cleavage fragments. Asbestiform EMPs caused hyperplasia, mild alveolar septal fibrosis, inflammatory infiltrates, but no extensive lung fibrosis, which is probably a characteristic of $\mathrm{A} / \mathrm{J}$ mouse model. We had several reasonings for looking at the diverse immune cell population dynamic in the lungs: for instance, recruited mononuclear phagocytes actively participate in clearance mechanisms, proinflammatory and pro/antifibrotic signaling, contributing to the polarization of immune response. Asbestiform EMPs still caused more cytotoxicity in the in vitro model, and more drastic changes in the pulmonary immune cell populations in mice at the same mass doses compared to cleavage fragments. Consistent changes included alveolar macrophage depletion and eosinophilia. Increased apoptosis was observed in the asbestos-treated cells. There was clear depletion of resident AMs (expressing high Siglec-F, and negative for CD11b) observed in all treated groups at 3 months and persisting until 12 months in asbestos-treated animals. In all groups incoming monocytes (most likely) gave origin to new $A M s\left(C D 11 b^{+}\right.$, Siglec Flow). In cleavage fragments group AMs were "successfully" substituted by incoming CD11b positive cells and supplemented the population of resident AMs. This never happened in the asbestostreated groups, only partially alleviated by 12 months it was, and accompanied by the influx of eosinophils, increase of $\mathrm{TH}_{\mathrm{H}}$ type cytokines, and $\mathrm{T}_{\text {reg }}$ cells. Asbestos is a complete carcinogen, combining initiating and promoting properties [11]. In this study we wanted to assess the oncogenic potential of asbestiform and non-asbestiform EMPs in a lungcancer prone mouse model. Proneoplastic properties of asbestos were evident from the histopathology observations, while non-asbestiform cleavage fragments did not lead to significant increase in neoplastic lesions, when compared at equal mass doses. While the long-term neoplastic outcomes were still evidenced in the non-asbestiform group, most likely their carcinogenic potential in real exposure scenario is negligible. Based on the combined in vitro and in vivo results, one of the plausible explanations for rather benign effects of cleavage fragments exposure could be the preservation of resident "homeostatic" pool of AMs in the lungs. 
If approached from another metrics standpoint, such as surface area, we start seeing more similarities between asbestos and its non-asbestiform analogues in the in vitro settings. In animal model, however, due to the its complexity and numerous confounding factors, no such conclusions can be drawn from our study. Still, it seems that the chemical composition, unique for different minerals, also plays major role in the outcomes. In our mouse model we demonstrated that even one year after exposure nonasbestiform EMPs are still present in the mouse lungs. It supplements the notion that biodurability is another common parameter, that needs to be accounted for both habits. In in vivo settings, shorter EMPs can be cleared more easily, but it does not mean they are less potent in causing damage in the sustained exposure scenario. Importantly, responses to asbestiform tremolite and asbestiform riebeckite were discreet both in the cell model and animal model, confirming yet again that commercial term "asbestos" should probably be avoided in EMP toxicity research except for the narrative reasons. It is only possible to incorporate a finite amount of research in the dissertation; thus, I have included the future directions section to address several questions existing before and arising in the course of the study.

\section{2 - Future Directions and Questions}

Future toxicity studies can follow two paths: one is to focus on a comprehensive assessment of the EMP-induced changes in the pulmonary (and extrapulmonary) immune contexture following exposure to a panel of premade well-characterized reference materials; second is to investigate in more detail individual components of the general immune response using only a couple of pre-designed test articles at a time, in relevant in vitro and in vivo models. Experimental methods that do not involve animals include using established immortalized cell cultures, 3d organoids, organs-on-chip, and precision-cut lung tissues sections from donor lungs unsuitable for transplantation. For instance, a comprehensive assessment of the EMP-induced changes in the cultures of the major lung-derived cell lines can be performed, with an emphasis on immunological responses, such as production of cytokines and M1/M2 polarization, oxidative stress, genotoxic outcomes, modes/mediators of cell death. While we are as a biomedical research community try to minimize the use of animals, sometimes it is the only way to 
obtained reliable and relevant toxicological data. Specific endpoints for in vivo studies may include inflammation, changes in the immune cell compositions, functional activity of macrophages, immune activation/suppression, and autoantibodies titers in the blood. Induced carcinogenesis model (Lewis lung carcinoma cells) can be used to assess premetastatic niches in exposed animals. Animal research involving transgenic animals relevant for EMP-related pathology may focus on the KO/KD models, such as OGG1 -/[12, 13], HMOX1 -/- [14], and others. Studies that include inhibition of EMP recognition apparatus by macrophages (i.e. using SR-A inhibitor - fucoidan, or MARCO inhibitor polyguanylic acid).

Question 1: What could be the new prospective treatment approaches for asbestos-induced lung pathology?

There are several implications for treatment strategies in human asbestos exposures coming from the research on EMP immunotoxicity. Knowledge of macrophage polarization patterns allows for targeting or antagonizing a subset, known to have a role in pathology. For example, identification and selective blockade of inflammatory CD11 bos macrophages in the airways have been proposed for the treatment of acute lung exacerbations [15] therefore, one might also consider related. Treatment that deals with inflammasome pathways might be another viable strategy [16]. Inflammasome components and IL-1 $\beta$ have the potential to be biomarkers in malignancies, including lung cancer and mesothelioma [17]. There are also reports of successful use of IL-1R agonist for slowing down the progression of silicosis [18], making a possibility to use it for the treatment of asbestosis. Th17 targeting is another therapeutic opportunity in asbestosrelated pathology $[19,20]$. Targeting CD11b positive cells have been considered as one of the approaches to deal with chronic inflammation, including following asbestos exposures [15, 21]. Recently, a new approach has been suggested, aimed at modulating the CD11b expression, rather than depletion of CD11b positive cells [22]. Whether it can be successfully used for asbestos-related pathology can be evaluated in the successive studies. A good example of another approach are studies on MARCO receptor-based therapeutics against pulmonary fibrosis [23, 24].

\section{Question 2: How can we improve the particle characterization/harvesting approaches?}


Manual measurements of fiber lengths and widths is labor-intensive; thus, a faster and accurate measurement method is necessary to determine particle size distribution of the separated fibers. Cho et al. showed the capability of an automatic counting of asbestos fibers (High-Throughput Microscopy), although the study focused on fiber counting rather reporting fiber length or diameter information [25]. In addition, differential interference contrast microscopy might able to reduce fiber counting and detection time by increasing the contrast [26]. Cossio et al. reported an unattended scanning electron microscope (SEM)-energy dispersive spectroscopy (EDS) asbestos analysis method and it showed high precision and reproducibility, which can reduce analytical time (maximum 2 hours/sample)[27].

\section{Question 3: What methods can be used to track the EMP fate in the lungs?}

One of the novel approaches is the investigation of the mechanisms of EMP bioprocessing in the mouse lungs utilizing the high-resolution analytical scanning transmission electron microscopy (HRTEM/STEM), electron energy loss spectroscopy (EELS) and energy dispersive spectroscopy (EDS). This method has not been previously implemented in the largescale toxicological studies, particularly not for the nonasbestiform EMPs. Paraffin-embedded lung tissue sections can be analyzed to investigate the mechanisms of EMP bioprocessing and its role in the overall toxicity, fibrogenicity and carcinogenicity as described in an article [28]. In our study the use of imaging flow cytometer allowed capturing some of the macrophages with phagocytized EMPs, as well as free fibers during the run (Figures 5.1. and 5.2.).

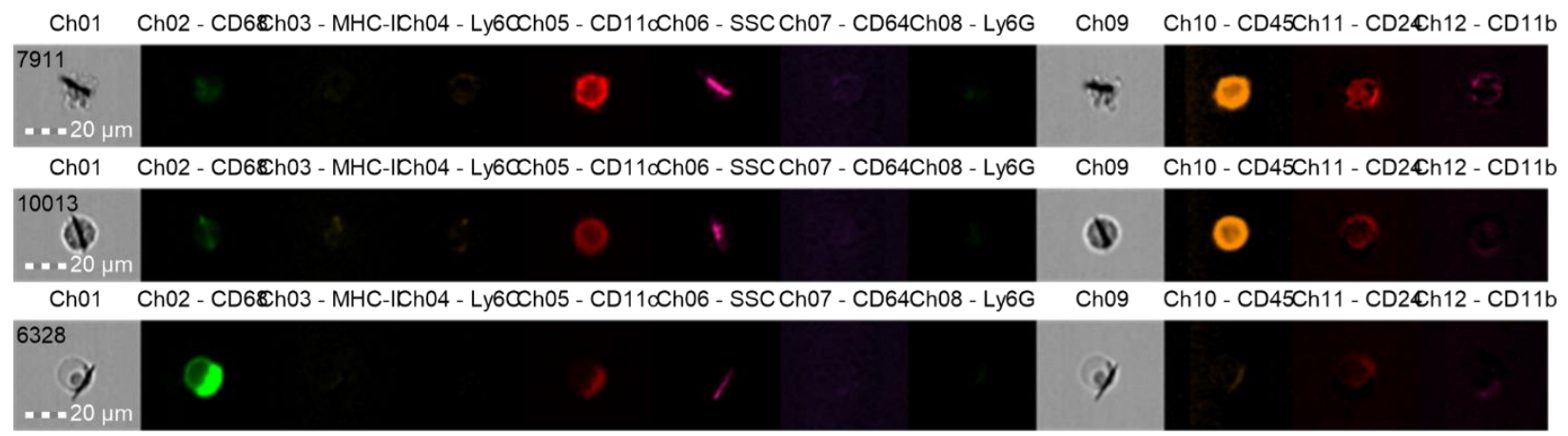

Figure 5.1. Images of the alveolar macrophages from exposed mice 1 year after exposure with phagocytized riebeckite asbestos fibers, obtained by imaging flow cytometry. 
Ch01 Ch02 - CD68h03 - MHC-ICh04 - Ly6CCh05 - CD11oCh06 - SSCCh07 - CD64Ch08 - Ly6G Ch09 Ch10 - CD45Ch11 - CD24h12 - CD11b

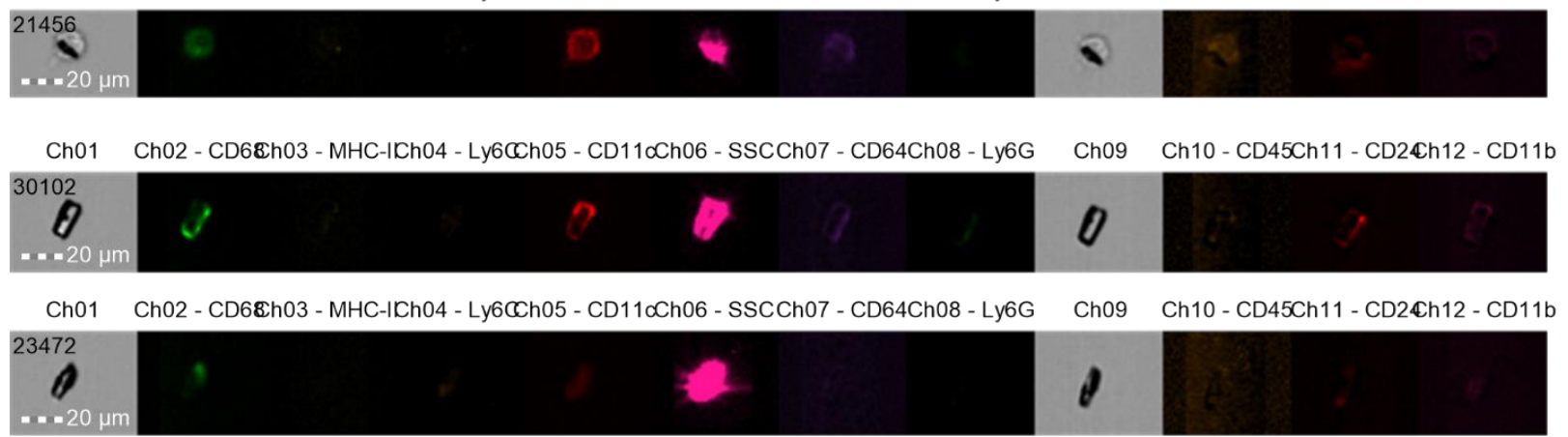

Figure 5.2. Images of the alveolar macrophage with tremolite cleavage fragment inside and free floating EMPs from exposed mouse 1 year after exposure, obtained by imaging flow cytometry.

Further experimentation with lung digestion procedure, cell sorting and EMP labeling techniques can yield a method for reliably quantifying the number and size distribution of the EMPs still present in the mouse lungs at different time points as well as the cell-fiber interaction peculiarities.

\section{Question 5: How can bioinformatic approaches aid in deciphering EMP toxicity profiles?}

Something that is currently missing in the field of EMP toxicology is an integrated bioinformatics approach. This approach, if implemented on a large scale, could help establishing correlations between the EMP characteristics and their immunological impact relevant to the progression into fibrosis and/or cancer. For example, utilizing RNA sequencing and epigenomic assessment of isolated (sorted) lung cells can give us a comprehensive picture of the 2-layered (transcriptome and epigenome) molecular responses. Add in global proteomics analysis using mass spectrometry, and one gets a plethora of data to mine for immunologically relevant parameters. Verification and validation of identified biomarkers in gene/protein expression/abundance profiles of patients with lung illnesses or in pulmonary human cells exposed to asbestos and other mineral fibers (such as found in Gene Expression Omnibus Datasets http://www.ncbi.nlm.nih.gov/geo/) can be used to select the biomarkers with highest predictive potency.

In the end, comparison and validation of the short- and long-term assessments using major lung-derived cell lines and in vivo animal models will permit developing the 
predictive models of EMP-induced immunotoxicity and immunity contribution to the disease progression, as well as tools that could facilitate prognostic risk assessments in humans. This together with the identified unique profiles of genes/proteins can aid in identification of disease-causing potential of EMPs based on their size, shape, growth habit and chemistry.

\subsection{References}

1. Lippmann, M., Toxicological and epidemiological studies on effects of airborne fibers: coherence and public [corrected] health implications. Crit Rev Toxicol, 2014. 44(8): p. 643-95.

2. Gamble, J.F. and G.W. Gibbs, An evaluation of the risks of lung cancer and mesothelioma from exposure to amphibole cleavage fragments. Regul Toxicol Pharmacol, 2008. 52(1 Suppl): p. S154-86.

3. Suzuki, Y., S.R. Yuen, and R. Ashley, Short, thin asbestos fibers contribute to the development of human malignant mesothelioma: pathological evidence. Int J Hyg Environ Health, 2005. 208(3): p. 201-10.

4. Dodson, R.F., M.A.L. Atkinson, and J.L. Levin, Asbestos fiber length as related to potential pathogenicity: A critical review. 2003. 44(3): p. 291-297.

5. Goodglick, L.A. and A.B. Kane, Cytotoxicity of long and short crocidolite asbestos fibers in vitro and in vivo. Cancer Res, 1990. 50(16): p. 5153-63.

6. Lippmann, M., Effects of fiber characteristics on lung deposition, retention, and disease. Environ Health Perspect, 1990. 88: p. 311-7.

7. Mossman, B.T., et al., Pulmonary endpoints (lung carcinomas and asbestosis) following inhalation exposure to asbestos. J Toxicol Environ Health B Crit Rev, 2011. 14(1-4): p. 76-121.

8. Duncan, K.E., et al., In vitro determinants of asbestos fiber toxicity: effect on the relative toxicity of Libby amphibole in primary human airway epithelial cells. Part Fibre Toxicol, 2014. 11: p. 2.

9. Lippmann, M., Asbestos exposure indices. Environ Res, 1988. 46(1): p. 86-106.

10. Weill, D., Proceedings of The Monticello Conference on Elongate Mineral Particles (EMP). Toxicology and Applied Pharmacology, 2018. 361: p. 1-2.

11. Barrett, J.C., P.W. Lamb, and R.W. Wiseman, Multiple mechanisms for the carcinogenic effects of asbestos and other mineral fibers. Environmental health perspectives, 1989. 81: p. 81-89.

12. Sakumi, K., et al., Ogg1 knockout-associated lung tumorigenesis and its suppression by Mth1 gene disruption. Cancer Res, 2003. 63(5): p. 902-5.

13. Cheresh, P., et al., Asbestos-induced pulmonary fibrosis is augmented in 8oxoguanine DNA glycosylase knockout mice. Am J Respir Cell Mol Biol, 2015. 52(1): p. 25-36.

14. Nagatomo, H., et al., Change of Heme Oxygenase-1 Expression in Lung Injury Induced by Chrysotile Asbestos In Vivo and In Vitro. Inhalation Toxicology, 2007. 19(4): p. 317-323.

15. Duan, M., et al., CD11b immunophenotyping identifies inflammatory profiles in the mouse and human lungs. Mucosal Immunol, 2016. 9(2): p. 550-63. 
16. Kanno, S., et al., The role of Rho-kinases in IL-1beta release through phagocytosis of fibrous particles in human monocytes. Arch Toxicol, 2015. 89(1): p. 73-85.

17. Lin, C. and J. Zhang, Inflammasomes in Inflammation-Induced Cancer. Frontiers in Immunology, 2017. 8(271).

18. Cavalli, G., et al., Treating pulmonary silicosis by blocking interleukin 1. Am J Respir Crit Care Med, 2015. 191(5): p. 596-8.

19. Fasching, P., et al., Therapeutic Potential of Targeting the Th17/Treg Axis in Autoimmune Disorders. Molecules, 2017. 22(1).

20. Ghosh, S., M. Lobera, and M.S. Sundrud, Chapter 10 - Targeting Th17 and Treg Signaling Pathways in Autoimmunity, in Annual Reports in Medicinal Chemistry, J.E. Macor, Editor. 2011, Academic Press. p. 155-170.

21. McCubbrey, A.L., et al., Deletion of c-FLIP from CD11b(hi) Macrophages Prevents Development of Bleomycin-induced Lung Fibrosis. Am J Respir Cell Mol Biol, 2018. 58(1): p. 66-78.

22. Geraghty, T., et al., Positive Allosteric Modulation of CD11b as a Novel Therapeutic Strategy Against Lung Cancer. Front Oncol, 2020. 10: p. 748.

23. Murthy, S., et al., Alternative activation of macrophages and pulmonary fibrosis are modulated by scavenger receptor, macrophage receptor with collagenous structure. FASEB journal : official publication of the Federation of American Societies for Experimental Biology, 2015. 29(8): p. 3527-3536.

24. Yang, M., et al., Inhibition of MARCO ameliorates silica-induced pulmonary fibrosis by regulating epithelial-mesenchymal transition. Toxicol Lett, 2019. 301: p. 64-72.

25. Cho, M.O., et al., Automated counting of airborne asbestos fibers by a highthroughput microscopy (HTM) method. Sensors (Basel), 2011. 11(7): p. 7231-42.

26. Zarubiieva, I., et al., Asbestos Imaging and Detection with Differential Interference Contrast Microscopy. Aerosol and Air Quality Research, 2013. 13(3): p. 1145-1150.

27. Cossio, R., et al., Innovative unattended SEM-EDS analysis for asbestos fiber quantification. Talanta, 2018. 190: p. 158-166.

28. Graham, U.M., et al., A case study of the translocation, bioprocessing and tissue interactions of EMP following inhalation exposure. Toxicol Appl Pharmacol, 2018. 361: p. 81-88. 